FREDERICO ABDO DE VILHENA

\title{
ANÁLISE DE PROCESSOS DE CENARIZAÇÃO NA GERAÇÃO HIDROENERGÉTICA
}

\author{
Dissertação apresentada à Escola \\ Politécnica da Universidade de São Paulo \\ para obtenção do título de Mestre em \\ Engenharia
}

São Paulo 
FREDERICO ABDO DE VILHENA

\title{
ANÁLISE DE PROCESSOS DE CENARIZAÇÃO NA GERAÇÃO HIDROENERGÉTICA
}

\author{
Dissertação apresentada à Escola \\ Politécnica da Universidade de São Paulo \\ para obtenção do título de Mestre em \\ Engenharia
}

Área de Concentração:

Recursos Hídricos

Orientador:

Prof. Dr. Mario Thadeu Leme de Barros

São Paulo 



\section{DEDICATÓRIA}

À minha mãe, in memoriam,

Vera Lucia Abdo 


\section{AGRADECIMENTOS}

A Deus.

Ao Prof. Dr. Mario Thadeu Leme de Barros, pela orientação, incentivo, apoio e confiança em todos os momentos.

Ao professor Ranato Zambon, cujas pesquisas e trabalhos orientaram a presente análise, e cujo modelo HIDROTERM subsidiou o desenvolvimento dessa dissertação.

Ao professor José Rodolfo Scarati Martins pelo incentivo e apoio.

Aos professores e funcionários do Departamento de Engenharia Hidráulica e Sanitária da Escola Politécnica da USP.

Aos meus pais, Reinaldo llha de Vilhena e Vera Lucia Abdo, que sempre me passaram o valor da educação, do conhecimento e do trabalho como meio para uma vida mais consciente e um futuro melhor.

A minha esposa e companheira, Maria do Carmo Bezerra de Lima, que me apoiou e motivou em todos os momentos, e que me inspira sempre a melhorar e a ser mais feliz.

A minha filha Maya, uma estrela brilhante em minha vida.

A todos que colaboraram direta ou indiretamente na execução deste trabalho. 


\section{RESUMO}

O planejamento de médio e longo prazo da operação hidrelétrica brasileira consiste em um problema de grande porte e que envolve muitas variáveis, onde, dentre estas, se destacam as vazões afluentes aos reservatórios. Estas vazões devem assim ser estimadas, com o objetivo de caracterizar a oferta futura de eletricidade em um horizonte de planejamento. Dentre as possíveis abordagens existentes para estimar estas vazões, se destaca a abordagem estocástica, que permite considerar variáveis em função de sua distribuição probabilística, e busca considerar o universo mais provável de manifestações. A abordagem estocástica pode se utilizar de modelos estocásticos, que costumam ser caracterizados através de árvores de cenários, que representam o universo de possibilidades de ocorrências. No entanto, devido à elevada dimensionalidade que o processo estocástico pode resultar ao se considerar árvores muito grandes, torna-se necessária a utilização de técnicas complementares, que visem a redução do número de cenários.

Com base nesta contextualização, esta dissertação aborda de modo geral o processo de otimização estocástica do planejamento da geração hidrelétrica, considerando árvores de cenários e técnicas de redução de cenários, e utilizando como meio a modelagem de otimização da geração desenvolvida no SSD HIDROTERM, em linguagem GAMS.

Como estudo de caso, foram desenvolvidos e adaptados algoritmos de otimização estocástica que consideram árvores com elevado número de cenários, gerados por meio de modelos estocásticos autorregressivos do tipo PAR e, sobre estas árvores, foi ainda aplicada a ferramenta de redução de cenários por agrupamento - SCENRED, desenvolvida em GAMS. As análises de sensibilidade realizadas visaram: validar o processo proposto de otimização estocástica; analisar os efeitos da utilização de diferentes árvores reduzidas de cenários de vazões, o impacto da consideração de diferentes horizontes de planejamento e a influência do regime hidrológico nos principais resultados do processo de otimização; além de estudar as vantagens e desvantagens deste processo para o planejamento da operação hidrelétrica. 
Os resultados indicam que o processo de otimização estocástica é eficaz ao considerar as aleatoriedades envolvidas na previsão de vazões afluentes. Estes também confirmaram tendências já esperadas no processo de otimização estocástica, como o fato de que quanto maior a árvore de cenários, mais precisos e estáveis tendem os resultados; assim como que quanto mais cenários envolvidos, maior o tempo de processamento requerido. Neste contexto, a utilização da ferramenta de redução SCENRED permitiu reduções significativas no tamanho da árvore de cenários, sem, contudo, ocasionar em perdas na qualidade e estabilidade da solução, além de viabilizar a aplicação do algoritmo de otimização estocástica proposto. 


\begin{abstract}
The medium and long-term planning of the Brazilian electric system consists of a complex problem with many uncertainties and variables, where, among these the inflows to the reservoirs highlight. These inflows need to be estimated in order to characterize the future availability of electricity in a planning horizon. Among the existing approaches to estimate these inflows, highlights the stochastic approach, which consider these variables according to their probability distribution, and aims to consider the most likely universe of manifestations. The stochastic approach can be developed through stochastic models, which are often characterized by scenarios trees that represent the possible universe. However, due to the high dimensionality that stochastic analyses can result when considering very large trees, it becomes necessary to use complementary tools, aimed at reducing the number of scenarios.
\end{abstract}

Based on this context, this dissertation discusses in general the process of stochastic optimization of the hydroelectric generation planning, considering scenarios trees and scenario reduction tools, through the optimization modeling developed in the DSS HIDROTERM, developed in GAMS language.

As a case study, it was generated and adapted stochastic optimization algorithms that consider trees with large number of scenarios, generated by autoregressive stochastic models PAR. Based on these trees it was applied the scenario reduction tool SCENRED, developed in GAMS language. The sensitivity analyzes developed intended to: validate the stochastic optimization process; analyze the effects of using different reduced scenarios trees of inflows; analyze the impacts of considering different planning horizons, analyze the hydrological influence on the main results of the optimization process, and the benefits and disadvantages of this process in the hydroelectric operation planning.

The results indicate that the stochastic optimization process is effective to consider the randomness involved in the prediction of inflow to the reservoirs. These results have also confirmed some well-known trends in the stochastic optimization process, such as the fact that the larger the tree scenarios, more accurate and stable tend the results but also greater the processing time 
required. In this context, the use of the reduction tool SCENRED allowed significant reductions in the size of scenarios tree, without causing losses in quality and solution stability, enabling the application of the stochastic optimization algorithm proposed. 


\section{LISTA DE FIGURAS}

Figura 1. Geração de Energia Elétrica no Brasil - 2013 (BEN - EPE, 2013)..... 9

Figura 2. Malha do Sistema de Transmissão de Energia Elétrica (EPE, 2013) 10

Figura 3. Sazonalidade da Energia Natural Afluente (EPE, 2011) .................. 12

Figura 4. Evolução da capacidade de armazenamento do SIN (Fonte: PDE EPE, 2013-2022)

Figura 5. Evolução da energia armazenável máxima em relação à carga de

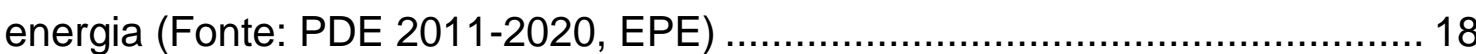

Figura 6. Evolução da proporção entre as capacidades de armazenamento e de geração de energia (Fonte: Falcetta et Zambon, 2013) ................................ 19

Figura 7. Possíveis realizações de afluências............................................ 20

Figura 8. Incertezas e detalhamento do sistema de acordo com o horizonte de

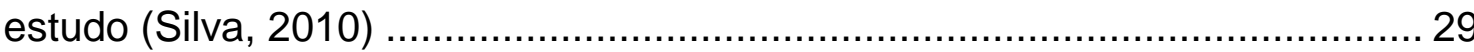

Figura 9. Exemplo de ramificação (Ramos, 2011) ......................................... 31

Figura 10. Árvore multiestágio (Domenica et al, 2007) .................................... 34

Figura 11. Cenários em formato árvore (Oliveira, 2007) ............................... 34

Figura 12. Procedimento para geração de cenários (Fonte: ONS, 2008) ........ 53

Figura 13. Árvore de cenários (Fonte: ONS, 2004) ......................................... 54

Figura 14. Geração para a simulação Forward (Fonte: ONS, 2004) ................ 55

Figura 15. Sequência de geração para a geração Backward (Fonte: ONS,

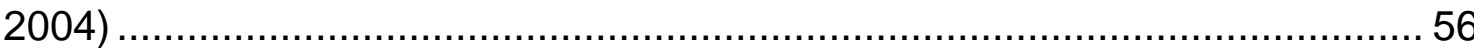

Figura 16. Geração em paralelo para a simulação backward (Fonte: ONS,

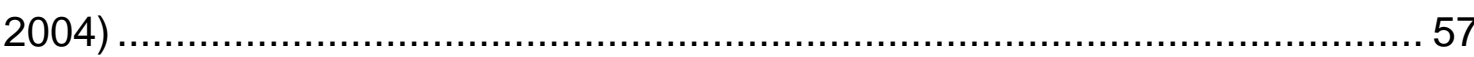

Figura 17. Exemplo de Sub Árvore de cenários por sorteio (Penna, 2009) ..... 61

Figura 18. Aplicação do Procedimento de Agregação (Penna, 2009) .............. 61

Figura 19. Representação das Incertezas e do Detalhamento dos Sistemas

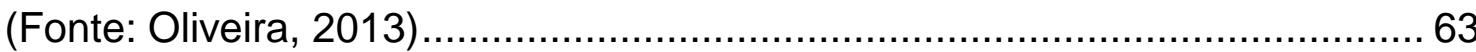

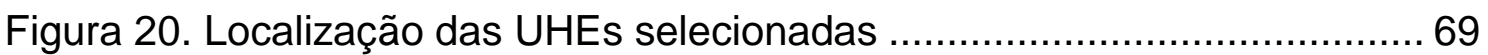

Figura 21. Etapas envolvidas no processo de otimização............................... 74

Figura 22. Vazões médias mensais no rio Iguaçú, na UHE Foz do Areia ........ 77

Figura 23. Vazões médias mensais no rio Araguari, na UHE Nova Ponte ....... 77

Figura 24. Vazões médias mensais no rio São Francisco, na UHE Três Marias 
Figura 25. Vazões médias mensais no rio Jequitinhonha, na UHE Irapé.

Figura 26. Vazões médias mensais no rio Tocantins, na UHE Serra da Mesa 78

Figura 27. Vazões médias mensais no rio Uatumã, na UHE Balbina. 78

Figura 28. Curvas de Permanência de Vazões normalizadas pela vazão média

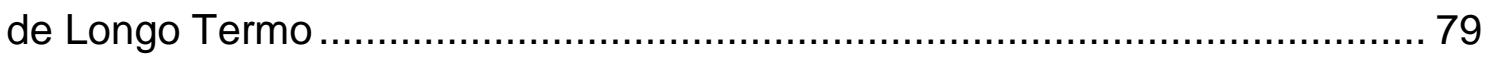

Figura 29. Vazões médias anuais - UHE Foz do Areia ……………............. 80

Figura 30. Vazões médias mensais - UHE Nova Ponte ............................... 81

Figura 31. Vazões médias mensais - UHE Três Marias ................................. 81

Figura 32. Vazões médias mensais - UHE Irapé ........................................ 81

Figura 33. Vazões médias mensais - UHE Serra da Mesa............................. 82

Figura 34. Vazões médias mensais - UHE Balbina ....................................... 82

Figura 35. Função de Autocorrelação das séries mensais............................... 84

Figura 36. Função de Autocorrelação das séries anuais ................................ 84

Figura 37. Representação da Cenarização hidrológica tipo "Garfo" a ser

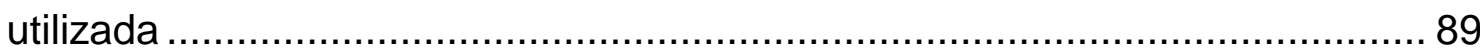

Figura 38. Arranjo de nós na geração de cenários de vazões ......................... 89

Figura 39. Exemplo esquemático de uma árvore reduzida de cenários do

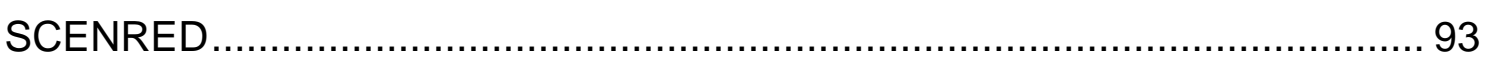

Figura 40. Demanda nacional do SIN. Fonte: ONS, 2014.............................. 98

Figura 41. Padrão de demanda utilizado nas otimizações ............................... 99

Figura 42. Esquema geral de procedimentos realizados no algoritmo de otimização estocástica 99

Figura 43. Função Objetivo - Resultados das otimizações - UHE Foz do Areia 103

Figura 44. Tempo de Processamento - Resultados das otimizações - UHE Foz do Areia. 104

Figura 45. Vazão Turbinada esperada em $T=1$ - Resultados das otimizações UHE Foz do Areia 105

Figura 46. Energia Gerada - Resultados das otimizações - UHE Foz do Areia 106

Figura 47. Função Objetivo - Resultados das otimizações - UHE Três Marias 
Figura 48. Tempo de Processamento - Resultados das otimizações - UHE Três Marias 108

Figura 49. Vazão Turbinada esperada em $\mathrm{T}=1$ - Resultados das otimizações UHE Três Marias 109

Figura 50. Energia Gerada - Resultados das otimizações - UHE Três Marias

Figura 51. Relações qualitativas em questão 114

Figura 52. Árvores de Vazões Afluentes - UHE Foz do Areia 116

Figura 53. Árvores de Vazões Afluentes - UHE Foz do Areia (continuação). 117

Figura 54. Porcentagem de Redução - UHE Foz do Areia ........................... 118

Figura 55. Tempo de Processamento - UHE Foz do Areia ......................... 118

Figura 56. Função Objetivo - UHE Foz do Areia ...................................... 119

Figura 57. Vazão turbinada esperada no instante $T=1$ - UHE Foz do Areia.. 119

Figura 58. Energia gerada ao longo dos 4 anos - UHE Foz do Areia ............. 119

Figura 59. Árvores de cenários - Volumes - UHE Foz do Areia.................... 120

Figura 60. Árvores de cenários - Volumes - UHE Foz do Areia (continuação)

Figura 61. Árvores de Vazões Afluentes - UHE Nova Ponte ....................... 122

Figura 62. Árvores de Vazões Afluentes - UHE Nova Ponte (continuação) .. 123

Figura 63. Porcentagem de Redução - UHE Nova Ponte ........................... 124

Figura 64. Tempo de Processamento - UHE Nova Ponte ............................ 124

Figura 65. Função Objetivo - UHE Nova Ponte .......................................... 125

Figura 66. Vazão turbinada esperada no instante $T=1$ - UHE Nova Ponte ... 125

Figura 67. Energia gerada ao longo dos 4 anos - UHE Nova Ponte ............. 125

Figura 68. Árvores de cenários - Volumes - UHE Nova Ponte .................... 126

Figura 69. Árvores de cenários - Volumes - UHE Nova Ponte (continuação)127

Figura 70. Árvores de Vazões Afluentes - UHE Três Marias......................... 128

Figura 71. Árvores de Vazões Afluentes - UHE Três Marias (continuação) .. 129

Figura 72. Porcentagem de Redução - UHE Três Marias ............................. 130

Figura 73. Porcentagem de Redução - UHE Três Marias ........................... 130

Figura 74. Função Objetivo - UHE Três Marias...................................... 131

Figura 75. Vazão turbinada esperada no instante $T=1$ - UHE Três Marias ... 131

Figura 76. Energia gerada ao longo dos 4 anos - UHE Três Marias ............. 131 
Figura 77. Árvores de cenários - Volumes - UHE Três Marias 132

Figura 78. Árvores de cenários - Volumes - UHE Três Marias (continuação) 133

Figura 79. Árvores de Vazões Afluentes - UHE Irapé ................................. 134

Figura 80. Árvores de Vazões Afluentes - UHE Irapé (continuação) .............. 135

Figura 81. Porcentagem de Redução - UHE Irapé ...................................... 136

Figura 82. Tempo de Processamento - UHE Irapé...................................... 136

Figura 83. Função Objetivo - UHE Irapé ................................................. 137

Figura 84. Vazão turbinada esperada no instante $T=1$ - UHE Irapé ............... 137

Figura 85. Energia gerada ao longo dos 4 anos - UHE Irapé....................... 137

Figura 86. Árvores de cenários - Volumes - UHE Irapé............................... 138

Figura 87. Árvores de cenários - Volumes - UHE Irapé (continuação) ......... 139

Figura 88. Árvores de Vazões Afluentes - UHE Serra da Mesa .................... 140

Figura 89. Árvores de Vazões Afluentes - UHE Serra da Mesa (continuação)

Figura 90. Porcentagem de Redução - UHE Serra da Mesa.......................... 142

Figura 91. Tempo de Processamento - UHE Serra da Mesa ........................ 142

Figura 92. Função Objetivo - UHE Serra da Mesa ..................................... 143

Figura 93. Vazão turbinada esperada no instante $T=1-$ UHE Serra da Mesa

Figura 94. Energia gerada ao longo dos 4 anos - UHE Serra da Mesa......... 143

Figura 95. Árvores de cenários - Volumes - UHE Serra da Mesa................. 144

Figura 96. Árvores de cenários - Volumes - UHE Serra da Mesa (continuação)

Figura 97. Árvores de Vazões Afluentes - UHE Balbina............................... 146

Figura 98. Árvores de Vazões Afluentes - UHE Balbina (continuação) .......... 147

Figura 99. Porcentagem de Redução - UHE Balbina .................................. 148

Figura 100. Tempo de Processamento - UHE Balbina .................................. 148

Figura 101. Função Objetivo - UHE Balbina.............................................. 149

Figura 102. Vazão turbinada ponderada no instante $T=1$ - UHE Balbina ...... 149

Figura 103. Energia gerada ao longo dos 4 anos - UHE Balbina .................. 149

Figura 104. Árvores de cenários - Volumes - UHE Balbina ......................... 150

Figura 105. Árvores de cenários - Volumes - UHE Balbina (continuação) ... 151 
Figura 106. Comparação dos resultados: Porcentagem de redução 154

Figura 107. Comparação dos resultados: Tempo de Processamento............. 154

Figura 108. Comparação dos resultados: Função Objetivo ........................... 155

Figura 109. Comparação dos resultados: Vazão turbinada esperada............. 155

Figura 110. Comparação dos resultados: Energia gerada ponderada ........... 155

Figura 111. Volume Inicial x Vazão Turbinada Esperada - UHE Foz do Areia

Figura 112. Volume Inicial x Energia Gerada Ponderada - UHE Foz do Areia

Figura 113. Volume Inicial x Vazão Turbinada Esperada - UHE Nova Ponte 160

Figura 114. Volume Inicial x Energia Gerada Ponderada - UHE Nova Ponte 160

Figura 115. Volume Inicial x Vazão Turbinada Esperada - UHE Três Marias 161

Figura 116. Volume Inicial x Energia Gerada Ponderada - UHE Três Marias 161

Figura 117. Volume Inicial x Vazão Turbinada Esperada - UHE Irapé ........... 162

Figura 118. Volume Inicial x Energia Gerada Ponderada - UHE Irapé .......... 162

Figura 119. Volume Inicial x Vazão Turbinada Esperada - UHE Serra da Mesa

Figura 120. Volume Inicial x Energia Gerada Ponderada - UHE Serra da Mesa 163

Figura 121. Volume Inicial x Vazão Turbinada Esperada - UHE Blbina ........ 164

Figura 122. Volume Inicial x Energia Gerada Ponderada - UHE Balbina ...... 164

Figura 123. Resumo dos resultados - Vazão Turbinada Esperada $\times$ Volume

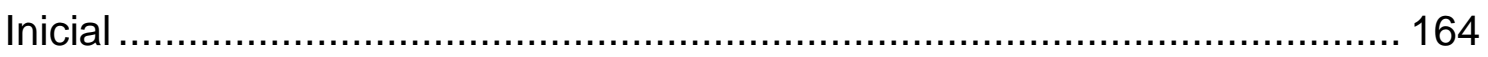

Figura 124. Resumo dos resultados - Energia Gerada x Volume Inicial ....... 165 Figura 125. Horizonte de Planejamento x Porcentagem de Redução - UHE Foz

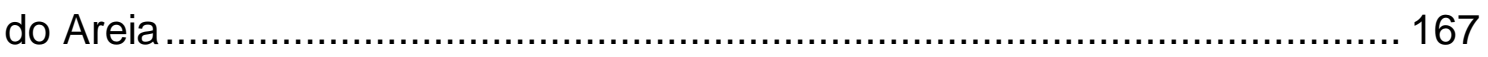

Figura 126. Horizonte de Planejamento x Tempo de Processamento - UHE Foz

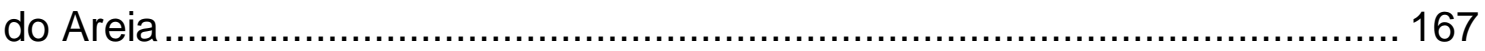

Figura 127. Horizonte de Planejamento x Vazão Turbinada Esperada - UHE Foz do Areia. 168

Figura 128. Horizonte de Planejamento x Energia Média Anual - UHE Foz do Areia. 168 
Figura 129. Horizonte de Planejamento x Porcentagem de Redução - UHE Nova Ponte.

Figura 130. Horizonte de Planejamento x Tempo de Processamento - UHE Nova Ponte.

Figura 131. Horizonte de Planejamento x Vazão Turbinada Esperada - UHE Nova Ponte. 169

Figura 132. Horizonte de Planejamento x Energia Média Anual - UHE Nova Ponte

Figura 133. Horizonte de Planejamento x Porcentagem de Redução - UHE Três Marias

Figura 134. Horizonte de Planejamento x Tempo de Processamento - UHE Três Marias

Figura 135. Horizonte de Planejamento x Vazão Turbinada Esperada - UHE Três Marias

Figura 136. Horizonte de Planejamento x Energia Média Anual - UHE Três Marias

Figura 137. Horizonte de Planejamento x Porcentagem de Redução - UHE Irapé

Figura 138. Horizonte de Planejamento x Tempo de Processamento - UHE Três Marias

Figura 139. Horizonte de Planejamento x Vazão Turbinada Esperada - UHE Irapé

Figura 140. Horizonte de Planejamento x Energia Média Anual - UHE Irapé 173

Figura 141. Horizonte de Planejamento x Porcentagem de Redução - UHE Serra da Mesa.

Figura 142. Horizonte de Planejamento x Tempo de Processamento - UHE Serra da Mesa.

Figura 143. Horizonte de Planejamento x Vazão Turbinada Esperada - UHE Serra da Mesa

Figura 144. Horizonte de Planejamento x Energia Média Anual - UHE Serra da Mesa 175

Figura 145. Horizonte de Planejamento x Porcentagem de redução - UHE Balbina 
Figura 146. Horizonte de Planejamento x Tempo de Processamento - UHE Balbina

Figura 147. Horizonte de Planejamento x Vazão Turbinada Esperada - UHE Balbina 176

Figura 148. Horizonte de Planejamento x Energia Média Anual - UHE Balbina 176

Figura 149. Séries de cenários históricos - UHE Foz do Areia...................... 179

Figura 150. Séries de cenários históricos - UHE Nova Ponte ...................... 179

Figura 151. Séries de cenários históricos - UHE Três Marias ....................... 180

Figura 152. Séries de cenários históricos - UHE Irapé................................. 181

Figura 153. Séries de cenários históricos - UHE Serra da Mesa................... 181

Figura 154. Séries de cenários históricos - UHE Balbina ............................. 182

Figura 155. Períodos críticos - UHE Foz do Areia...................................... 185

Figura 156. Períodos críticos - UHE Nova Ponte ........................................ 185

Figura 157. Períodos críticos - UHE Três Marias ........................................ 185

Figura 158. Períodos críticos - UHE Irapé.................................................. 186

Figura 159. Períodos críticos - UHE Serra da Mesa..................................... 186

Figura 160. Períodos críticos - UHE Balbina ........................................... 186 


\section{LISTA DE TABELAS}

Tabela 1. Expansão hidrotérmica contratada e em construção de 2013 a 2018

Tabela 2. Novos projetos hidrelétricos a serem viabilizados de 2018 a 2022 .. 14

Tabela 3. Novos projetos hidrelétricos a serem viabilizados de 2018 a 2022 .. 15

Tabela 4. Parâmetros Estatísticos das séries de vazões médias mensais

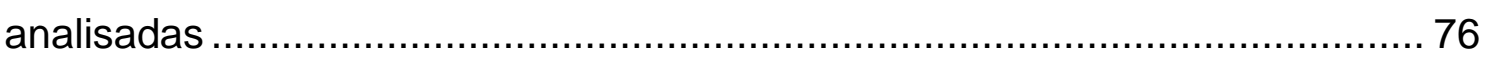

Tabela 5. Parâmetros ajustados dos modelos estocásticos autorregressivos

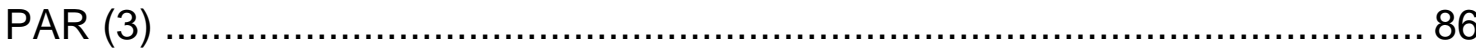

Tabela 6. Parâmetros estatísticos dos ruídos históricos ................................. 87

Tabela 7. Função Objetivo - Resultados das otimizações - UHE Foz do Areia 103

Tabela 8. Tempo de Processamento - Resultados das otimizações - UHE Foz

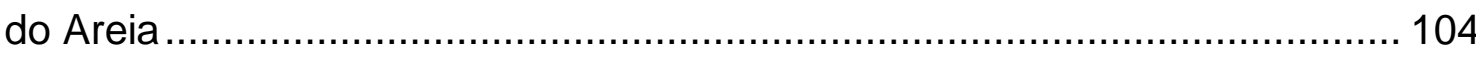

Tabela 9. Vazão Turbinada esperada em $\mathrm{T}=1$ - Resultados das otimizações -

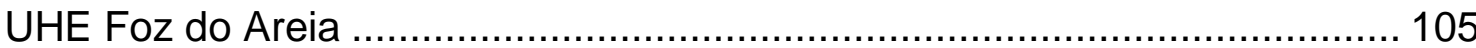

Tabela 10. Energia Gerada - Resultados das otimizações - UHE Foz do Areia 106

Tabela 11. Função Objetivo - Resultados das otimizações - UHE Três Marias 107

Tabela 12. Tempo de Processamento - Resultados das otimizações - UHE Três Marias 108

Tabela 13. Vazão Turbinada esperada em $T=1$ - Resultados das otimizações UHE Três Marias

Tabela 14. Energia Gerada - Resultados das otimizações - UHE Três Marias

Tabela 15. Comparação dos principais parâmetros estatísticos das séries de vazões - UHE Foz do Areia ................................................................ 117

Tabela 16. Parâmetros obtidos - UHE Foz do Areia.................................... 118

Tabela 17. Comparação dos principais parâmetros estatísticos das séries de vazões - UHE Nova Ponte................................................................ 123

Tabela 18. Parâmetros obtidos - UHE Nova Ponte ....................................... 124 
Tabela 19. Comparação dos principais parâmetros estatísticos das séries de vazões - UHE Três Marias

Tabela 20. Parâmetros obtidos - UHE Três Marias

Tabela 21. Comparação dos principais parâmetros estatísticos das séries de

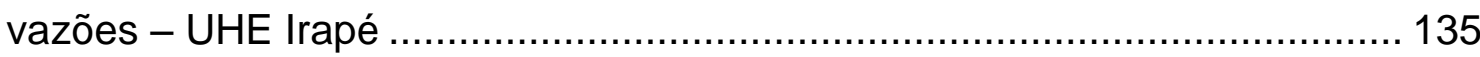

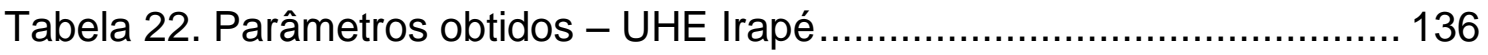

Tabela 23. Comparação dos principais parâmetros estatísticos das séries de

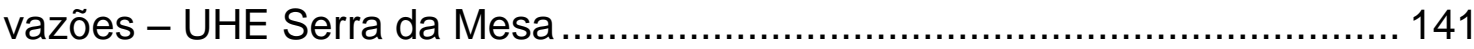

Tabela 24. Parâmetros obtidos - UHE Serra da Mesa ................................. 142

Tabela 25. Comparação dos principais parâmetros estatísticos das séries de

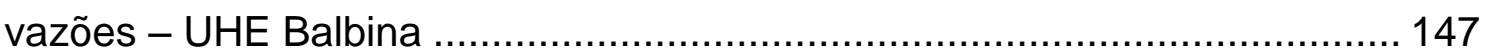

Tabela 26. Parâmetros obtidos - UHE Balbina ........................................... 148

Tabela 27. Valores de Volume Inicial considerados .................................... 158

Tabela 28. Resultados - UHE Foz do Areia.............................................. 158

Tabela 29. Resultados - UHE Nova Ponte …………................................ 159

Tabela 30. Resultados - UHE Três Marias ..................................................... 160

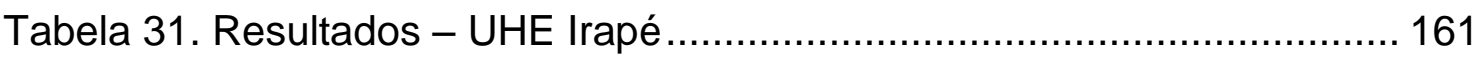

Tabela 32. Resultados - UHE Serra da Mesa........................................... 162

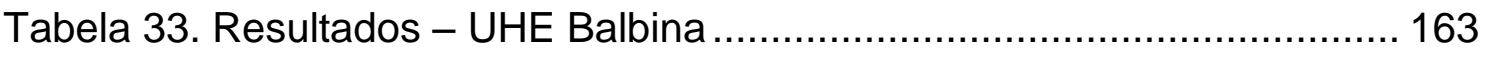

Tabela 34. Resultados - UHE Foz do Areia............................................. 167

Tabela 35. Resultados - UHE Nova Ponte …………............................... 168

Tabela 36. Resultados - UHE Três Marias ................................................ 170

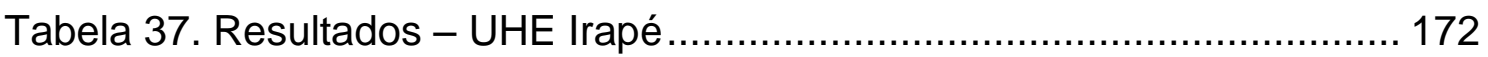

Tabela 38. Resultados - UHE Serra da Mesa........................................... 173

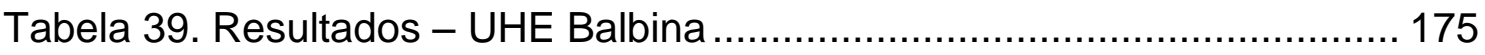

Tabela 40. Comparação dos resultados - UHE Foz do Areia ........................ 179

Tabela 41. Comparação dos resultados - UHE Nova Ponte.......................... 180

Tabela 42. Comparação dos resultados - UHE Três Marias ........................... 180

Tabela 43. Comparação dos resultados - UHE Irapé ................................... 181

Tabela 44. Comparação dos resultados - UHE Serra da Mesa...................... 182

Tabela 45. Comparação dos resultados - UHE Balbina ............................... 182

Tabela 46. Comparação dos resultados: Modelo Estocástico x Períodos

Críticos - UHE Foz do Areia .................................................................... 187 
Tabela 47. Comparação dos resultados: Modelo Estocástico x Períodos Críticos - UHE Nova Ponte.

Tabela 48. Comparação dos resultados: Modelo Estocástico x Períodos Críticos - UHE Três Marias.

Tabela 49. Comparação dos resultados: Modelo Estocástico x Períodos Críticos - UHE Irapé

Tabela 50. Comparação dos resultados: Modelo Estocástico x Períodos Críticos - UHE Serra da Mesa 188

Tabela 51. Comparação dos resultados: Modelo Estocástico x Períodos Críticos - UHE Balbina. 188 


\section{LISTA DE SIGLAS}

ACF Função de Autocorrelação

ANA Agência Nacional de Águas

ANEEL Agência Nacional de Energia Elétrica

AR Modelo Autorregressivo

CCEE Câmara de Comercialização de Energia Elétrica

CEMIG Centrais Elétricas de Minas Gerais

CEPEL Centro de Pesquisa de Energia Elétrica

CESP Companhia Energética de São Paulo

COPEL Companhia Paranaense de Energia

ENA Energia Natural Afluente

EPE Empresa de Pesquisas Energéticas

GAMS General Algebraic Modeling System

MLT Média de Longo Termo

MME Ministério de Minas e Energia

MRE Mecanismo de Realocação de Energia

ODIN Otimização do despacho Interligado Nacional

ONS Operador Nacional do Sistema Elétrico

PAR Modelo Autorregressivo Periódico

$\mathrm{PCH} \quad$ Pequena Central Hidrelétrica

PDE Programação Dinâmica Estocástica

PDE Plano Decenal de Expansão de Energia

PDDE Programação Dinâmica Dual Estocástica

PL Programação Linear

PLS Programação Linear Sequencial

PNL Programação Não Linear

PNLIM Programação Não Linear Inteira Mista

RNA Rede Neural Artificial

ROC Redução Ótima de Cenários

SAMS Stochastic Analisys Modeling and Simulation 
SIN Sistema Interligado Nacional

SSD Sistema de Suporte à Decisão

UHE Usina Hidrelétrica

UNICAMP Universidade Estadual de Campinas

USP Universidade de São Paulo 


\section{LISTA DE SÍMBOLOS}

$A=$ assimetria

a = série de ruídos independentes (ruído branco)

$a_{0}, a_{1}, a_{2}, a_{3}, a_{4}=$ coeficientes dos polinômios de ordem 4 para a equação do nível d'água de montante no reservatório em função do armazenamento

$A_{c, t}=$ área do reservatório $\left(\mathrm{km}^{2}\right)$, no cenário $\mathrm{c}$, para o instante $\mathrm{t}$

ACF = função de autocorrelação

At $=$ ruído branco

$a_{t}^{h}=$ ruído histórico ocorrido no mês t do ano histórico $\mathrm{h}$

$b_{0}, b_{1}, b_{2}, b_{3}, b_{4}=$ coeficientes dos polinômios de ordem 4 para a equação do nível d'água no canal de fuga de jusante do reservatório em função da vazão defluente

c = índice do cenário

$\mathrm{C}=$ número de cenários

COV = autocovariância

$\mathrm{CV}=$ coeficiente de Variação

$\mathrm{C}_{0}, \mathrm{C}_{1}, \mathrm{C}_{2}, \mathrm{C}_{3}, \mathrm{C}_{4}=$ coeficientes dos polinômios de ordem 4 para a equação da área no reservatório em função do nível d'água de montante

Dc,t = Demanda objetivo (MW), do cenários c, no instante t

Dt $=$ duração dos intervalos de tempo $\left(10^{6} \mathrm{~s}\right)$

$D T_{c, t}=$ desvios de vazão como bombeamento, transposição e outros a montante $\left(\mathrm{m}^{3} / \mathrm{s}\right)$, no cenário $\mathrm{c}$, para o instante $\mathrm{t}$

$d_{0}, d_{1}, d_{2}, d_{3}, d_{4}=$ coeficientes dos polinômios de ordem 4 para a equação da vazão máxima turbinada no reservatório em função da queda

$E=$ correlação serial 
$E_{c, t}=$ evaporação $\left(10^{6} \mathrm{~m}^{3}\right)$, no cenário $\mathrm{c}$, para o instante $\mathrm{t}$

$\mathrm{Hb}_{\mathrm{c}, \mathrm{t}}=$ queda bruta média $(\mathrm{m})$, no cenário $\mathrm{c}$, para o instante $\mathrm{t}$

$H_{c, t}=$ nível d'água a montante do reservatório $(m)$, no cenário $c$, para o instante $\mathrm{t}$

$H T c, t=$ nível d'água no canal de fuga a jusante do reservatório $(m)$, no cenário $c$, para o instante $t$

$\mathrm{lc}, \mathrm{t}=$ vazão afluente durante o intervalo t no reservatório $\left(\mathrm{m}^{3} / \mathrm{s}\right)$, no cenário $\mathrm{c}$, para o instante $t$

$\mathrm{IDc}, \mathrm{t}$ = índice de disponibilidade das máquinas, no cenário $\mathrm{c}$, durante o intervalo t, para efeitos de manutenção e expansão (adimensional entre 0 e 1).

$\mathrm{IE}, \mathrm{t}$ = índice de evaporação no período t $(\mathrm{m})$, no cenário c, para o instante t

$\mathrm{nt}=$ número de intervalos de tempo

$\mathrm{p}=$ ordem de cada operador autorregressivo

pct $=$ probabilidade do cenário $\mathrm{c}$, no instante $\mathrm{t}$

$\mathrm{Pc}, \mathrm{t}=$ produção de energia $(\mathrm{MW})$ da usina, em relação ao cenário $\mathrm{c}$, no instante $\mathrm{t}$

Pmax $=$ capacidade máxima total dos geradores $(\mathrm{MW})$

$\mathrm{Rc}, \mathrm{t}=$ vazão defluente média total $\left(\mathrm{m}^{3} / \mathrm{s}\right)$, no cenário $\mathrm{c}$, para $\mathrm{o}$ instante $\mathrm{t}$

$\mathrm{R}^{\prime} \mathrm{c}, \mathrm{t}=$ vazão turbinada $\left(\mathrm{m}^{3} / \mathrm{s}\right)$, no cenário $\mathrm{c}$, para o instante $\mathrm{t}$

$\mathrm{R} " \mathrm{c}, \mathrm{t}=$ vazão vertida $\left(\mathrm{m}^{3} / \mathrm{s}\right)$, no cenário $\mathrm{c}$, para o instante $\mathrm{t}$

$\mathrm{R}^{\prime \text { max }}=$ vazão máxima turbinada $\left(\mathrm{m}^{3} / \mathrm{s}\right)$

$\mathrm{R}^{\prime \text { min }}=$ vazão mínima turbinada $\left(\mathrm{m}^{3} / \mathrm{s}\right)$

$\mathrm{R}^{\mathrm{min}}=$ defluência mínima ambiental $\left(\mathrm{m}^{3} / \mathrm{s}\right)$

$S_{\mathrm{c}, \mathrm{t}}^{\max }=$ armazenamento máximo considerando volume de espera para controle de cheias $\left(106 \mathrm{~m}^{3}\right)$, no cenário $\mathrm{c}$, para o instante $\mathrm{t}$

$\mathrm{Sc}, \mathrm{t}=$ armazenamento no fim do intervalo $\mathrm{t}$ no reservatório $\left(106 \mathrm{~m}^{3}\right)$, no cenário $c$, para o instante $t$

$\mathrm{T}=$ índice dos intervalos de tempo 
UCc,t $=$ vazão retirada para usos consultivos $\left(\mathrm{m}^{3} / \mathrm{s}\right)$, no cenário $\mathrm{c}$, para 0 instante $\mathrm{t}$

$X_{n}=$ número aleatório de ordem $\mathrm{n}$

$\mathrm{Zt}=$ série temporal, contendo $\mathrm{t}$ intervalos de tempo

$\overline{\mathrm{Z}}=$ média Amostral

$\mathrm{ZH}=$ função objetivo do modelo $\left(10^{6} \mathrm{~s} . \mathrm{MW}^{2}\right)$

$\eta=$ rendimento médio considerando a operação dos conjuntos turbina-gerados e perda de carga dos circuitos hidráulicos $(0 \leq \eta \leq 1)$

$\varepsilon_{\text {red }}=$ distância absoluta da árvore de cenário inicial

$\varepsilon_{\text {red }}=$ distância probabilística absoluta entre a árvore reduzida

$\mu=$ média amostral

$\mu \mathrm{m}=$ média sazonal do período $\mathrm{m}$

$\sigma \mathrm{m}=$ desvio padrão sazonal de período $\mathrm{m}$

$\rho_{\mathrm{k}}=$ autocorrelação

$\widehat{\sigma}_{\mathrm{Z}}=$ desvio Padrão Amostral

$\widehat{\sigma}_{\mathrm{Z}}=$ desvio Padrão Amostral

$\Phi^{\mathrm{m}}=$ coeficiente autorregressivo de ordem $\mathrm{m}$ 


\section{SUMÁRIO}

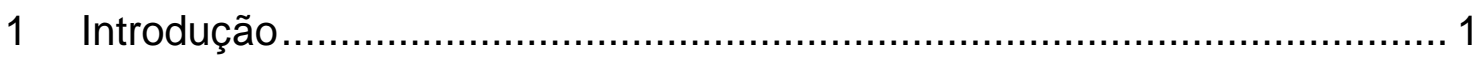

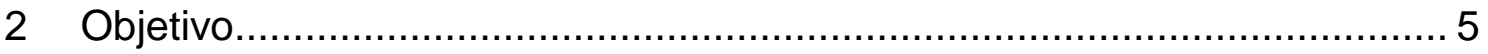

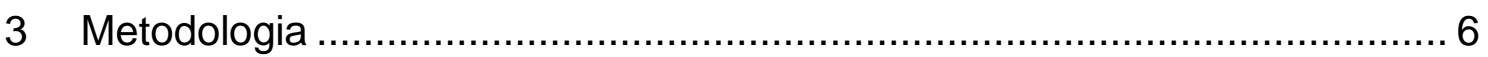

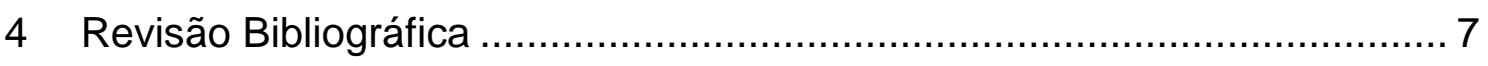

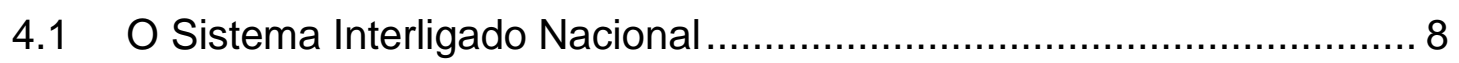

4.2 Planejamento da operação de sistemas hidrotérmicos ....................... 20

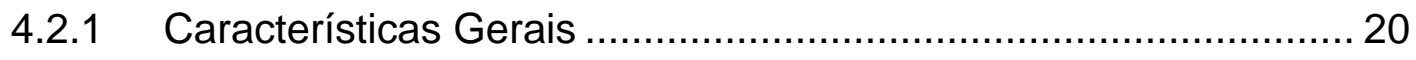

4.2.2 Abordagens utilizadas ...................................................... 26

4.2.3 Otimização Estocástica via Processos de Cenarização

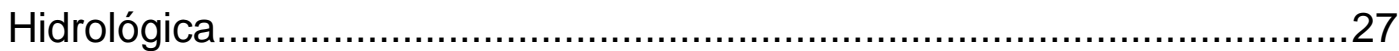

4.3 A Operação do Sistema Interligado Nacional...................................... 62

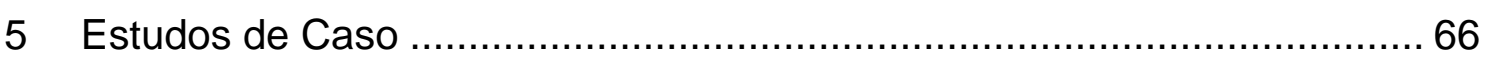

5.1 Justificativa do Estudo de Caso proposto e Critérios adotados para a

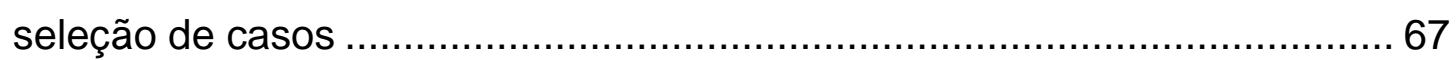

5.2 Descrição Geral das UHEs consideradas ........................................ 69

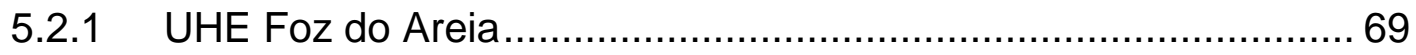

5.2.2 UHE Nova Ponte ................................................................ 70

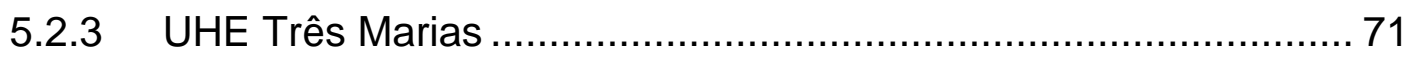

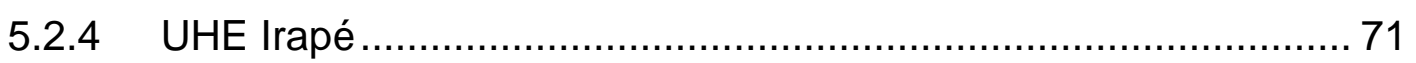

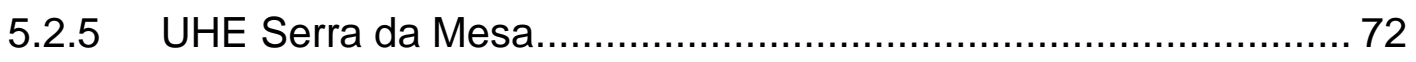

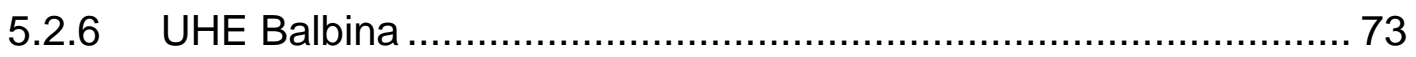

5.3 Detalhamento da metodologia adotada para as UHEs selecionadas . 73

5.4 Levantamento de dados das séries históricas de vazões naturais das

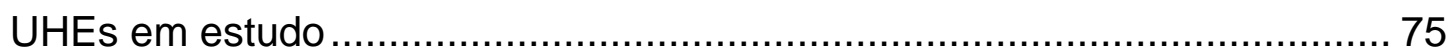

5.5 Análise dos parâmetros estatísticos das séries históricas ................. 75

5.6 Determinação do modelo estocástico adequado às séries históricas . 85

5.7 Construção de árvores de cenários de vazões afluentes .................... 88

5.8 Algoritmo de Redução de Cenários.................................................. 90

5.9 Algoritmo de Otimização Estocástica .................................................. 94

5.10 Aplicação do Algoritmo de Otimização estocástica ........................... 100 
5.10.1 Otimização estocástica considerando diferentes árvores de cenários e validação do modelo de otimização estocástica

5.10.2 Otimização estocástica frente a diferentes árvores reduzidas de cenários

5.10.3 Analise de sensibilidade do modelo de redução de cenários e de otimização estocástica frente a diferentes regimes hidrológicos 154

5.10.4 Otimização estocástica frente a diferentes volumes iniciais do reservatório

5.10.5 Otimização estocástica frente a diferentes horizontes de planejamento 166

5.10.6 Análise da Otimização Estocástica considerando árvores de cenários históricos

5.10.7 Comparação entre Otimização Estocástica e Otimização

Determinística do ponto de vista de eventos críticos

6 Conclusões 190

7 Pesquisas Futuras 193

8 Referências Bibliográficas 194 


\section{Introdução}

A Energia Elétrica é um dos principais constituintes da sociedade moderna e um dos pilares mais importantes e vitais para o crescimento da humanidade, possibilitando a sustentação do atual modo de vida e servindo de meio para o desenvolvimento tecnológico, econômico e social.

Desta forma, o desenvolvimento econômico e os atuais padrões de vida são dependentes de um mesmo componente: a disponibilidade de um abastecimento adequado e confiável de energia elétrica. Sendo assim, o suprimento de energia elétrica é fator limitante e primordial para o desenvolvimento econômico e social.

Cada vez mais a geração de energia elétrica se mostra um desafio sócio, econômico e ambiental para os países. As fontes de energia elétrica dependem basicamente dos recursos naturais disponíveis, resultando em conflitos e problemas ambientais, que a sociedade deve enfrentar buscando um equilíbrio entre: a utilização mais otimizada dos recursos; a minimização dos custos de expansão e a segurança de suprimento, do ponto de vista econômico; e o uso mais sustentável do ponto de vista sócio ambiental.

A matriz de energia elétrica brasileira é, atualmente, composta predominantemente por fontes hidráulicas. Segundo a ANEEL (Agência Nacional de Energia Elétrica), em fevereiro de 2014, o Brasil possuía no total 3.111 empreendimentos em operação, com 136.009,005 kW de potência instalada total, sendo $63,74 \%$ composta por fontes hidrelétricas. Esse total engloba não apenas as unidades geradoras do SIN, mas conta também com aquelas instaladas nos sistemas isolados e a autoprodução clássica, não contabilizando também a parcela de importação da UHE Itaipu não consumida pelo sistema elétrico paraguaio (EPE, 2013).

Do ponto de vista da geração, segundo a Empresa de Pesquisas Energéticas (EPE), durante o ano de 2012 aproximadamente 76,2\% da energia elétrica gerada no Sistema Interligado Nacional (SIN) teve proveniência de fontes hidráulicas. 
Até o final de 2022 é previsto ainda o aumento de 18GW no parque gerador devido a novas UHEs (EPE, 2014). Contudo, mesmo com um grande potencial de geração hidroelétrica ainda por ser explorado, sua capacidade tende a diminuir, em porcentagem, em relação às outras fontes.

O órgão responsável pela operação do Sistema Interligado Nacional (SIN) é o Operador Nacional do Sistema Elétrico (ONS). Esse coordena e controla a operação das instalações de geração e transmissão de energia elétrica no Sistema Interligado Nacional (SIN), sob a fiscalização e regulação da ANEEL. A ANEEL e o ONS são subordinados ao Ministério de Minas e Energia (MME), assim como à Câmara de Comercialização de Energia Elétrica (CCEE), que tem por finalidade viabilizar a comercialização de energia elétrica no SIN e nos Ambientes de Contratação Regulada e Contratação Livre, além de efetuar a contabilização e a liquidação financeira das operações realizadas no mercado de curto prazo (ANEEL, 2013).

O objetivo principal do ONS é operar o SIN de forma ótima, visando o pleno atendimento da demanda ao menor valor esperado do custo. Além disso, o ONS também é responsável pelos estudos indicativos de ampliação e reforço das linhas de transmissão e do parque gerador dentro do horizonte de cinco anos. Por sua vez, o órgão responsável pelos estudos de planejamento no horizonte acima de cinco anos é a EPE (ANEEL, 2013).

Decorrente da predominância hidroelétrica na matriz de geração brasileira, a estimativa do comportamento futuro das vazões que afluem aos aproveitamentos hidroelétricos se torna de grande importância para 0 planejamento de operações do sistema de geração e transmissão de energia elétrica (Braga, 2011).

Assim, no caso da geração hidroelétrica, a estocasticidade hidrológica se mostra como um dos grandes desafios para o planejamento e operação do sistema hidrotérmico, e, a adoção de metodologias que considerem de modo eficiente e robusto este fenômeno se torna imprescindível.

Uma das formas mais utilizadas para se representar a aleatoriedade dos parâmetros hidrológicos (vazões afluentes) durante a programação e 
otimização estocástica da geração hidroelétrica consiste na análise de processos de cenarização. Esta consiste na criação de árvores de cenários, uma ferramenta bastante comum na tomada de decisão sob incertezas ao longo do tempo, uma vez que os métodos computacionais geralmente representam as incertezas envolvidas via variáveis aleatórias discretas (ou discretizadas).

Dentro do contexto do planejamento da geração hidroelétrica, uma árvore de cenários pode consistir no conjunto de todas as possíveis realizações do processo estocástico de afluências, ao longo de todo horizonte de planejamento. Deste modo é considerada a hipótese de que esta árvore representa todo o universo probabilístico sobre o qual será efetuado o processo de otimização da operação energética.

No entanto, o processo de otimização estocástica considerando árvores sintéticas de cenários é considerada complexa por abranger um elevado número de variáveis, ocasionando em processos matemáticos que requeiram grande capacidade computacional para a solução dos processos de otimização.

Frente ao processo de modelagem estocástica considerando séries sintética existe uma gama de ferramentas de técnicas de geração e de redução de árvores de cenários, que combinadas podem impactar nos resultados da otimização da geração.

Além do mais, no contexto do planejamento e otimização da geração hidrelétrica, a definição da árvore de cenários é algo muitas vezes decidido sem critérios objetivos ou análises de sensibilidade frente ao processo como um todo. Assim, muitas vezes o processo de otimização estocástica é sujeito a simplificações e a falta de definições claras quanto ao processo de geração de árvores de cenários.

Nesta dissertação foi feita uma contextualização e análise da estocasticidade hidrológica no planejamento da geração hidrelétrica, com ênfase para o planejamento da operação de médio e longo prazo (discretização mensal e horizonte de planejamento entre 2 e 4 anos). 
Além do mais, esta dissertação visa o estudo e a aplicação de uma determinada técnica de otimização estocástica aplicada à geração de energia hidroelétrica, além da realização de análises de sensibilidade e de estudos de caso.

No capítulo 2 são apresentados os objetivos básicos desta dissertação e no capítulo 3 é apresentada a metodologia proposta para a elaboração dos estudos.

No capítulo 4 é elaborada a Revisão Bibliográfica dos temas relacionados às técnicas de cenarização aplicadas ao planejamento da operação de sistemas hidrotérmicos, com foco para o SIN.

No capítulo 5 são apresentados os Estudos de Caso e as Análises de sensibilidade realizadas.

O capítulo 6 apresenta as conclusões obtidas com base nos resultados alcançados.

O capítulo 7 contém indicações de pesquisas futuras com base nos resultados obtidos na presente dissertação.

Por fim, no capítulo 8 são apresentadas as referências bibliográficas consultadas para a elaboração desta dissertação. 


\section{Objetivo}

O objetivo deste estudo é analisar o impacto de diferentes condições de cenarizações de vazões afluentes no processo de otimização estocástica da geração hidroelétrica.

Esta dissertação visa fornecer informações a respeito de questionamentos envolvendo a utilização árvores de cenários estocásticos de vazões no processo de otimização da geração hidrelétrica, utilizando-se o algoritmo desenvolvido pelo Sistema de Suporte à Decisão HIDROTERM (Hidroterm, 2013). O presente estudo busca ainda analisar comportamentos e tendências inerentes ao processo de otimização estocástica e a existência de "pontos ótimos" entre a maneira mais representativa de considerar a estocasticidade de vazões e a sua viabilidade do ponto de vista técnico e computacional, dentro do processo de otimização estocástica do HIDROTERM.

As principais questões envolvidas foram:

- Até que ponto o número de cenários impacta nos resultados da otimização estocástica?

- Qual o acréscimo de tempo de processamento envolvido na otimização estocástica ao se utilizar diferentes números de cenários de vazões?

- Qual a vantagem da utilização de técnicas de redução de cenários? Quais os impactos da utilização destas técnicas no resultado da otimização estocástica?

- Quais as principais diferenças ao se considerar 2, 3 ou 4 anos de horizonte de previsão dentro da otimização estocástica?

- Existe alguma diferença na eficácia da aplicação de técnicas cenarização na otimização estocástica considerando séries de vazões provenientes de diferentes regimes hidrológicos brasileiros? Existe alguma correlação entre o regime hidrológico e os resultados obtidos?

- Qual o impacto nos resultados da otimização estocástica frente à variação no valor de armazenamento inicial no reservatório?

- Os resultados da otimização estocástica tendem a ser conservadores em relação à segurança energética? As árvores de cenários conseguem absorver cenários hidrológicos extremos? 


\section{Metodologia}

A metodologia adotada para a realização dos estudos foi definida em função dos conceitos envolvidos no processo de otimização estocástica da geração hidroelétrica, sendo definidas as seguintes etapas:

- Levantamento e análise das referências bibliográficas existentes sobre:

- Sistema Interligado Nacional;

- Planejamento da Geração hidroelétrica;

- Séries Sintéticas e Modelos Estocásticos;

- Processos de Geração e Redução de árvores de cenários de vazões;

- Otimização estocástica.

- Estudo de Caso:

- Levantamento de dados das séries históricas de vazões naturais dos rios em estudo;

- Análise dos parâmetros estatísticos das séries históricas;

- Determinação do modelo estocástico adequado às séries históricas;

- Construção de árvores de cenários de vazões afluentes;

- Modelagem da ferramenta de redução de cenários proposto;

- Desenvolvimento do algoritmo de otimização estocástica com base no algoritmo do Sistema de Suporte a Decisão HIDROTERM;

- Aplicação do algoritmo de otimização estocástica aos estudos de caso propostos;

- Análises de sensibilidade;

— Considerações e Conclusões Finais. 


\section{Revisão Bibliográfica}

Neste item é apresentada uma revisão bibliográfica sobre o Sistema Interligado Nacional; o modo de planejamento de sistemas hidrotérmicos e o planejamento da operação do SIN; o uso de ferramentas estocásticas para o planejamento da operação ótima de sistemas hidrotérmicos; além de modelos utilizados e disponíveis para a solução do processo de otimização. Foi dado enfoque à bibliografia envolvendo processos de otimização estocástica considerando técnicas de geração e redução de árvores de cenários. 


\subsection{O Sistema Interligado Nacional}

O Sistema Interligado Nacional (SIN) é o nome dado ao sistema de geração e transmissão de energia elétrica brasileira, sistema este que possui características únicas no âmbito mundial.

O SIN consiste em um sistema de geração hidrotérmico, com fonte primária predominantemente hidráulica, que abrange extensas regiões do território nacional, interligadas por linhas de transmissão. Conta com aproveitamentos hidráulicos dispostos em cascatas com reservatórios diversos num mesmo rio, e com reservatórios de regularização plurianual. O SIN está distribuído em diferentes bacias hidrográficas brasileiras com regimes hidrológicos e pluviométricos variados, e com grandes potenciais hidráulicos exploráveis disponíveis (Toscano, 2009).

Segundo o Banco de Informações de Geração da ANEEL, a capacidade instalada no Brasil em 2014 chegou a 136.009,005 Megawatts (MW), provenientes de 3111 usinas hidrelétricas, termelétricas, eólicas, nucleares, solares, pequenas centrais hidrelétricas e centrais geradoras hidrelétricas.

A porcentagem da Potência Total Instalada correspondente à geração hidroelétrica (UHE) corresponde por $63,74 \%$ da capacidade instalada do país, seguida das termelétricas, com $28,45 \%$, e das Pequenas Centrais Hidrelétricas (PCHs), com 3,87\%. Compõem ainda a matriz: $1,46 \%$ de potência proveniente de usinas nucleares, $1,80 \%$ de eólicas e $0,21 \%$ das centrais geradoras (ANEEL, 2014).

Segundo a ANEEL, existem 1105 usinas hidrelétricas implantadas no SIN, sendo 171 UHEs com potência superior a $30 \mathrm{MW}$. Da potência total instalada, cerca de $56 \%$ correspondem à UHEs com reservatórios de regularização e $44 \%$ à UHEs a fio d'água.

Tratando-se da geração efetiva de eletricidade é verificado que a predominância hidráulica vem sofrendo uma tendência de redução na sua participação, de modo que essa participação foi de 81,7\% em 2011 e correspondeu a 75,2\% da geração total de eletricidade em 2012 (EPE, 2013). A figura 1 a seguir ilustra o panorama de geração de eletricidade no Brasil em 
2012. Este percentual é variável ao longo dos anos em função das condições hidrológicas e das políticas de otimização hidrotérmica verificadas em cada ano.

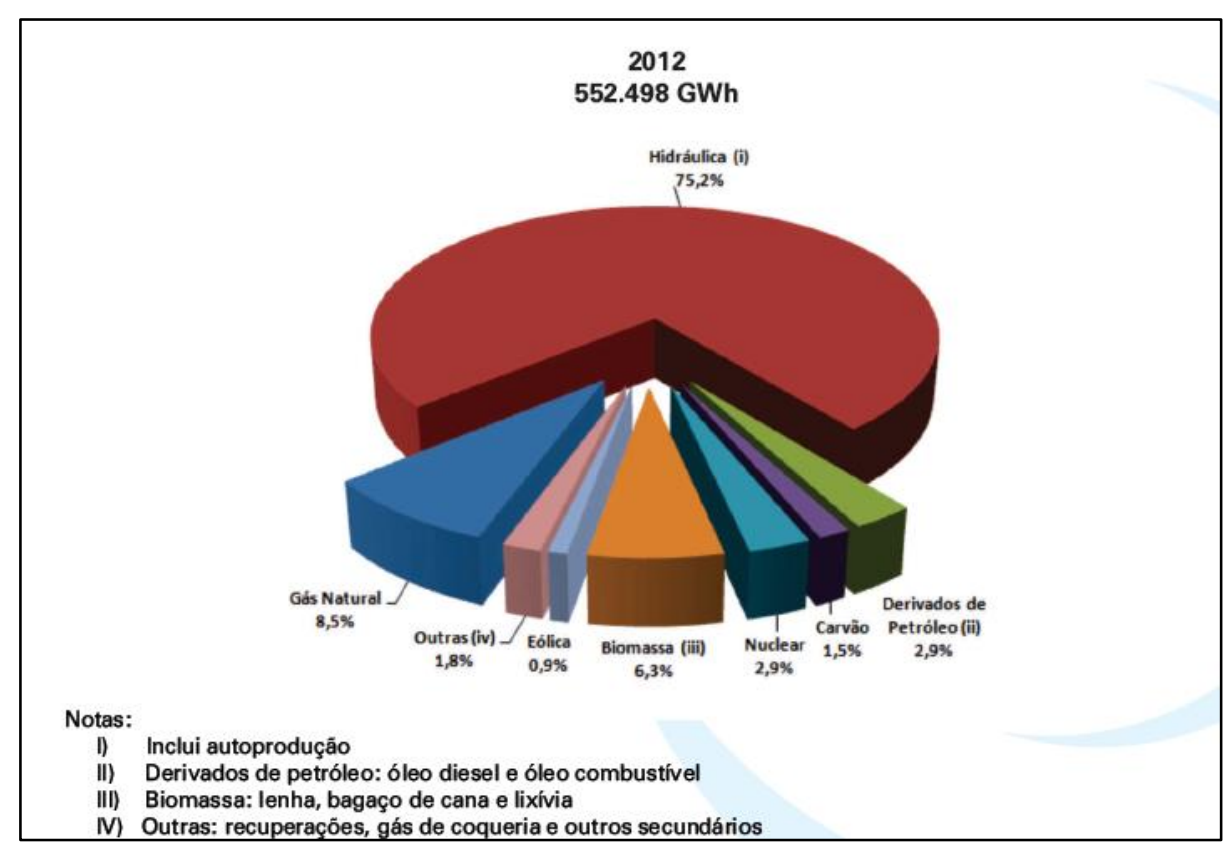

Figura 1. Geração de Energia Elétrica no Brasil - 2013 (BEN - EPE, 2013)

A coordenação e o controle do SIN são realizados dividindo-se o Brasil em quatro subsistemas: Sudeste/Centro-Oeste, Sul, Nordeste e Norte. A interligação destes subsistemas é realizada por uma extensa malha de linhas de transmissão, assim como pode ser visualizado na figura 2. As principais características destes sistemas frente ao contexto nacional são:

- Subsistema Sudeste/Centro-Oeste: Subsistema responsável pela maior parcela da geração e da demanda de energia dentre todos os quatro subsistemas. Os reservatórios das usinas contidas neste subsistema somam mais de 70\% da capacidade de acumulação total do SIN (EPE, 2013). Além do mais, devido à grande demanda, este é importador de eletricidade de outros Subsistemas durante a maior parte do ano.

- Subsistema Sul: Devido às incertezas hidrológica característica da região Sul do Brasil, este subsistema possui elevada variabilidade nos níveis de armazenamento de seus reservatórios, e, consequentemente, do sentido de intercâmbio (importação/exportação) com os outros Subsistemas. 
- Subsistema Nordeste: Subsistema que pode ser importador ou exportador de energia, conforme as condições hidrológicas na Região Nordeste do Brasil.

- Subsistema Norte: Subsistema com montante de geração superior ao de consumo, sendo eminentemente exportador de energia para os outros Subsistemas. Fornece energia para o período de ponta por pelo menos nove meses do ano (EPE, 2013).

A figura 2 a seguir apresenta a malha do Sistema de Transmissão de Energia Elétrica (EPE, 2013) referente ao ano de 2012, com indicação de futuras instalações a serem implantadas até 2015.

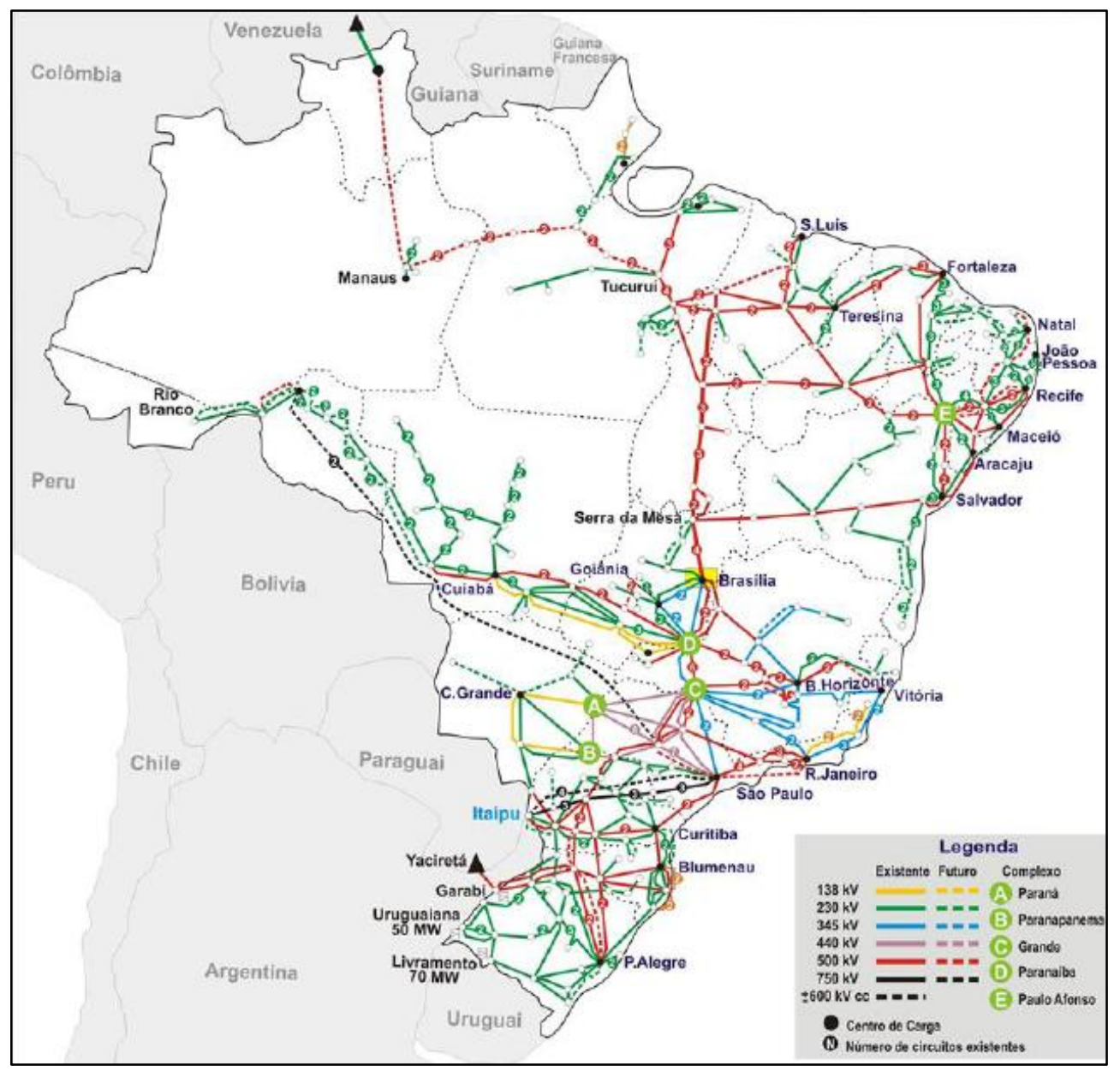

Figura 2. Malha do Sistema de Transmissão de Energia Elétrica (EPE, 2013)

Dadas as grandes dimensões territoriais do Brasil, existem diferenças hidrológicas significativas entre as regiões, ou seja, os períodos secos e úmidos não são coincidentes e, portanto, demandam um fluxo permanente de 
energia elétrica entre essas regiões. Uma região em período seco deve armazenar água e, dessa forma, produzir energia em níveis abaixo da média, enquanto uma região úmida produz acima da média (CCEE, 2013).

Assim, a malha de transmissão de energia interliga os quatro subsistemas/submercados e possibilita a transferência dos excedentes energéticos de uma região para a outra, fazendo com que haja uma complementariedade energética entre os subsistemas e aumentando a garantia do atendimento ao mercado. Quando um subsistema se encontra em situação desfavorável, os demais podem atendê-lo fornecendo energia através das interligações. Para isso a Rede Básica de transmissão do SIN compreende linhas com tensões entre $230 \mathrm{kV}$ e $750 \mathrm{kV}$.

Além desta vantagem a interligação dos submercados de energia elétrica permite a equalização dos preços da energia por meio da minimização dos estrangulamentos entre os submercados, resultando na adoção de um despacho ótimo do parque gerador (EPE, 2013).

Deste modo, as diferentes sazonalidades hidrológicas entre as regiões podem ser aproveitadas através das interligações. Quando os subsistemas do Sudeste/Centro-Oeste, do Nordeste e do Norte encontram-se no período úmido, período este de maiores vazões afluentes, o Subsistema Sul encontrase no período seco. E quando o Sul encontra-se no seu período úmido, os demais se encontram no período seco, possibilitando assim aproveitar a complementariedade sazonal entre os subsistemas.

A figura 3 a seguir ilustra a sazonalidade de energia natural afluente, correspondente ao potencial de energia hidráulica, em cada subsistema. Notase, nesta figura, a necessidade de um sistema interligado eficiente. Contudo, demonstra que o potencial de geração de eletricidade do Subsistema Sul não é suficiente para abastecer, sozinho, os outros Subsistemas durante o período de inverno no Brasil. 


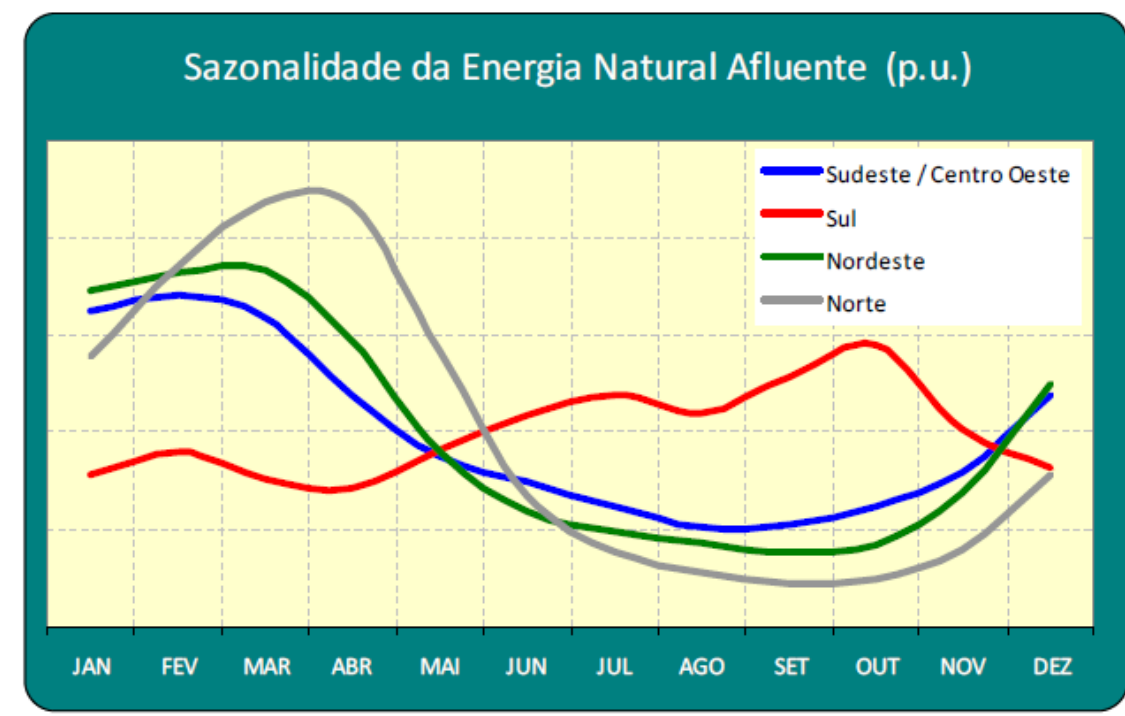

Figura 3. Sazonalidade da Energia Natural Afluente (EPE, 2011)

Além do mais, a existência física da rede de transmissão viabiliza o Mecanismo de Realocação de Energia (MRE), concebido como um processo contábil para compartilhar entre seus integrantes (usinas hidrelétricas) os riscos financeiros associados à comercialização de energia pelas usinas hidráulicas despachadas de modo centralizado e otimizado pelo ONS.

Como o despacho é centralizado, ou seja, como a água é compartilhada por todos e o seu uso não é gerido pelo proprietário da usina, o MRE minimiza e compartilha entre os agentes integrantes o risco de venda de energia em longo prazo. O MRE não corresponde à transmissão física de eletricidade entre as usinas, mas assegura que todas as usinas participantes recebam seus níveis de garantia física independentemente da produção real de energia, desde que a geração total do MRE não esteja abaixo do total da garantia física do SIN. Em outras palavras, o MRE realoca a energia entre os integrantes do "mecanismo", transferindo o excedente daqueles que geraram além de suas garantias físicas para aqueles que geraram abaixo (CCEE, 2013).

Deve ser destacado também o grande potencial de implantação de novos empreendimentos hidrelétricos.

Segundo o Plano Decenal de Energia (PDE) 2013-2022, elaborado pela Empresa de Pesquisas Energética (EPE), as usinas hidrelétrica já contratadas com previsão de entrada em operação entre os anos de 2013 e 2018 somam 
uma potência de cerca de 19,5 GW. A tabela 1 a seguir apresenta a expansão hidrotérmica contratada até 2018.

Tabela 1. Expansão hidrotérmica contratada e em construção de 2013 a 2018

\begin{tabular}{|c|c|c|c|c|c|c|c|c|}
\hline \multirow{2}{*}{$\mathrm{Ano}^{(\mathrm{b})}$} & \multicolumn{2}{|c|}{ Sudeste/Centro-Oeste } & \multicolumn{2}{|l|}{ Sul } & \multicolumn{2}{|c|}{ Nordeste } & \multicolumn{2}{|l|}{ Norte } \\
\hline & Projeto & Pot $^{(a)}$ & Projeto & Pot $^{(a)}$ & Projeto & Pot $^{(a)}$ & Projeto & Pot $^{(a)}$ \\
\hline \multirow{6}{*}{2013} & UHE São Domingos & 48 & & & UTE Porto Pecém 2 & 360 & UHE Jirau & 3.750 \\
\hline & UHE Simplicio $^{(\mathrm{d})}$ & 334 & & & UTE Suape II & 381 & UTE Porto do Itaqui & 360 \\
\hline & UHE Batalha & 53 & & & & & UTE Maranhão III (e) & 499 \\
\hline & & & & & & & UTE Maranhão IV ${ }^{(e)}$ & 338 \\
\hline & & & & & & & UTE Maranhão V ${ }^{(e)}$ & 338 \\
\hline & & & & & & & UTE MC2 $\mathrm{N}$ Venécia $2^{(\mathrm{e})}$ & 176 \\
\hline 2014 & $\begin{array}{l}\text { UTE Baixada } \\
\text { Fluminense }\end{array}$ & 530 & UHE Garibaldi( ${ }^{(d)}$ & 175 & & & UTE Mauá 3 & 583 \\
\hline \multirow{5}{*}{2015} & & & & & UTE Pernambuco 3 & 201 & UHE Sto. Ant. do Jari(d) & 370 \\
\hline & & & & & & & UHE Colider & 300 \\
\hline & & & & & & & UHE Ferreira Gomes & 252 \\
\hline & & & & & & & UHE Belo Monte & 11.233 \\
\hline & & & & & & & UHE Teles Pires & 1.820 \\
\hline \multirow{2}{*}{2016} & & & UHE São Roque & 135 & & & UHE Salto Apiacás & 45 \\
\hline & & & UHE Baixo Iguaçu & 350 & & & & \\
\hline 2017 & & & & & & & $\begin{array}{l}\text { UHE Cachoeira } \\
\text { Caldeirão }\end{array}$ & 219 \\
\hline 2018 & UNE Angra $3^{(c)}$ & 1.405 & & & & & UHE Sinop & 400 \\
\hline Total & & 2.370 & & 660 & & 942 & & 20.683 \\
\hline Notas: & \multicolumn{8}{|c|}{$\begin{array}{l}\text { (a) Potência total do empreendimento, em MW. No caso de usinas cuja motorização total não ocorre dentro do ano indicado, esta } \\
\text { potência não corresponde à potência incorporada no ano. } \\
\text { (b) Ano esperado de inicio da operação do empreendimento segundo acompanhamento do DMSE - reunião de dezembro de } 2012 \text {, } \\
\text { salvo a inclusão das usinas vencedoras do } 16^{\circ} \text { Leilão de Energia Nova (A-5/2013) e a alteração do cronograma da UTE Angra } 3 \\
\text { (DMSE - reunião de maio de } 2013 \text { ). } \\
\text { (c) A Portaria MME no } 980 / 2010 \text { autorizou a contratação da UNE Angra } 3 \text { na modalidade de energia de reserva. } \\
\text { (d) Usinas com casa de força complementar modelada como PCH. } \\
\text { (e) Usinas localizadas geograficamente no Maranhão, porém representadas eletricamente no subsistema Norte. }\end{array}$} \\
\hline Fonte: & EPE. & & & & & & & \\
\hline
\end{tabular}

Fonte: EPE - PDE 2013 - 2022

Quanto aos novos projetos a serem viabilizados de 2018 a 2022, é previsto a implantação de mais de $19,9 \mathrm{GW}$. A tabela 2 a seguir apresenta os projetos em questão. 
Tabela 2. Novos projetos hidrelétricos a serem viabilizados de 2018 a 2022

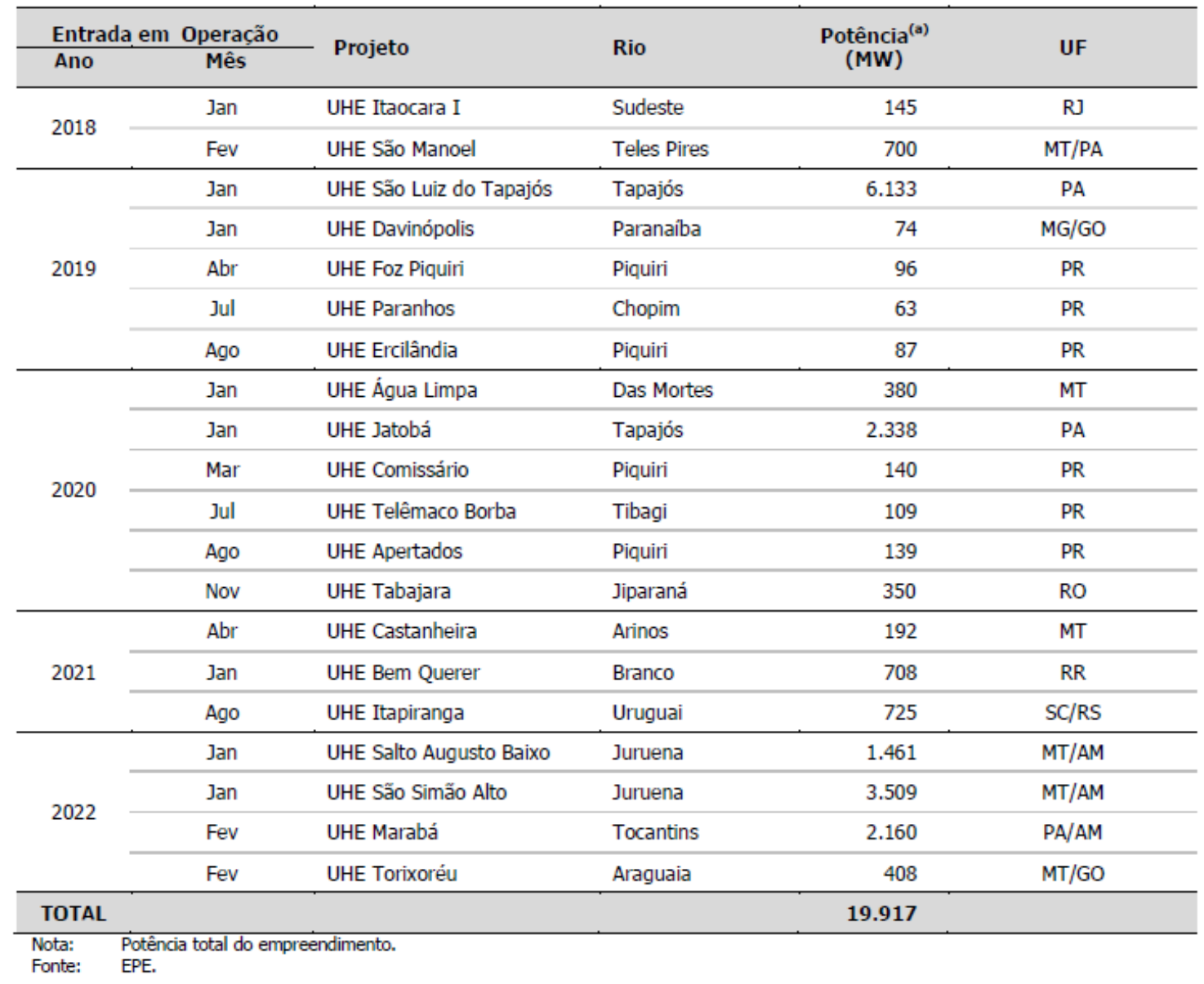

Fonte: PDE 2013 - 2022

Além desses projetos, há outros em estágios de desenvolvimento avançados mas ainda não confirmados. A tabela 3 a seguir apresenta as usinas hidrelétricas (com potência instalada superior a $50 \mathrm{MW}$ ) que possuem Estudos de Viabilidade na ANEEL, aprovados ou com aceite, cujo montante soma cerca de $6.900 \mathrm{MW}$. 
Tabela 3. Novos projetos hidrelétricos a serem viabilizados de 2018 a 2022

\begin{tabular}{|c|c|c|c|c|c|c|}
\hline Usina & Rio & UF & $\begin{array}{l}\text { Potência } \\
\text { (MW) }\end{array}$ & Desenvolvedor do Projeto & Situação & $\begin{array}{l}\text { Ato } \\
\text { ANEEL }\end{array}$ \\
\hline Água Limpa & Mortes & MT & 380,00 & $\begin{array}{l}\text { PCE/Enercamp/Energética- } \\
\text { Tech/Furnas/Alstom/Andrade } \\
\text { Gutierrez/Eletronorte }\end{array}$ & $\begin{array}{l}\text { EV em } \\
\text { andamento }\end{array}$ & Desp. 592/09 \\
\hline \multirow{2}{*}{ Apertados } & \multirow{2}{*}{ Piquiri } & \multirow{2}{*}{ PR } & 135,50 & $\mathrm{BE} /$ Desenvix & \multirow{2}{*}{$\begin{array}{l}\text { EV em } \\
\text { andamento }\end{array}$} & Desp. $211 / 12$ \\
\hline & & & $139,00^{(1)}$ & COPEL Geração e Transmissão S.A. & & Desp. $1138 / 12$ \\
\hline Barra do Pomba & Paraiba do Sul & RJ & 80,00 & Empreendimentos Patrimoniais Santa Gisele Ltda. & EV & Desp. 2161/06 \\
\hline Cachoeira & Parnaiba & $\mathrm{PI} / \mathrm{MA}$ & 63,00 & Chesf/CNEC/Queiroz Galvão/ENERGIMP & EV & Desp. 3809/10 \\
\hline Cambuci & Paraiba do Sul & $R J$ & 50,00 & Empreendimentos Patrimoniais Santa Gisele Ltda. & EV & Desp. 2162/06 \\
\hline Castelhano & Pamaiba & $\mathrm{PI} / \mathrm{MA}$ & 64,00 & Chesf/CNEC/Queiroz Galvão/ENERGIMP & EV & Desp. 4771/11 \\
\hline \multirow{2}{*}{ Comissário } & \multirow{2}{*}{ Piquiri } & \multirow{2}{*}{ PR } & $140^{(1)}$ & COPEL Geração e Transmissão S.A. & \multirow{2}{*}{$\begin{array}{l}\text { EV em } \\
\text { andamento }\end{array}$} & Desp. $1140 / 12$ \\
\hline & & & 105,3 & $\mathrm{BE} /$ Desenvix & & Desp. $2587 / 12$ \\
\hline Davinópolis & Paranaiba & MG/GO & 74,00 & CEMIG/Neoenergia & $\begin{array}{l}\text { EV em } \\
\text { andamento }\end{array}$ & Desp. 4462/09 \\
\hline \multirow{2}{*}{ Ercilândia } & \multirow{2}{*}{ Piquiri } & \multirow{2}{*}{ PR } & 96,6 & $\mathrm{BE} /$ Desenvix & \multirow{2}{*}{$\begin{array}{l}\text { EV em } \\
\text { andamento }\end{array}$} & Desp. $257 / 12$ \\
\hline & & & $87,1^{(1)}$ & COPEL Geração e Transmissão S.A. & & Desp. 1137/12 \\
\hline $\begin{array}{l}\text { Estreito } \\
\text { (Parnaiba) }\end{array}$ & Pamaíba & $\mathrm{PI} / \mathrm{MA}$ & 56,00 & Chesf/CNEC/Queiroz Galvão/ENERGIMP & EV & Desp. $3808 / 10$ \\
\hline Foz do Apiacás & Apiacás & MT & 230,00 & Empresa de Pesquisa Energética - EPE & $\begin{array}{l}\text { EV em } \\
\text { andamento }\end{array}$ & Desp. $1242 / 10$ \\
\hline \multirow{2}{*}{ Foz do Piquiri } & \multirow{2}{*}{ Piquiri } & \multirow{2}{*}{ PR } & $96,08^{(1)}$ & COPEL Geração e Transmissão S.A. & \multirow{2}{*}{$\begin{array}{l}\mathrm{EV} \text { em } \\
\text { andamento }\end{array}$} & Desp. 1139/12 \\
\hline & & & 101,2 & BE - Empresa de Estudos Energéticos S.A. & & Desp. 2596/12 \\
\hline Iraí & Uruguai & SC/RS & 330,00 & Companhia Energética do Uruguai - CEU & $\begin{array}{l}\mathrm{EV} \text { em } \\
\text { andamento }\end{array}$ & Desp. 2302/11 \\
\hline Marabá & Tocantins & $\mathrm{PA} / \mathrm{MA}$ & $2.160,00$ & Eletronorte/Camargo Corrêa & $\begin{array}{l}\mathrm{EV} \text { em } \\
\text { andamento }\end{array}$ & Desp. 1141/12 \\
\hline Paranhos & Chopim & PR & 62,50 & Foz do Chopim Energética Ltda. & $\begin{array}{l}\text { EV em } \\
\text { andamento }\end{array}$ & Desp. 2934/11 \\
\hline Pompéu & São Francisco & MG & 209,10 & Concremat/Andrade Gutierrez/CEMIG/EDP & $\begin{array}{l}\text { EV em } \\
\text { andamento }\end{array}$ & Desp. 009/12 \\
\hline Riacho Seco & São Francisco & $\mathrm{BA} / \mathrm{PE}$ & 276,00 & Desenvix/Chesf/CNO/Engevix & $\begin{array}{l}\text { EV em } \\
\text { andamento }\end{array}$ & Desp. $2100 / 08$ \\
\hline $\begin{array}{l}\text { Ribeiro } \\
\text { Gonçalves }\end{array}$ & Pamaiba & $\mathrm{PI} / \mathrm{MA}$ & 113,00 & Chesf/CNEC/Queiroz Galvão/ENERGIMP & EV & Desp. 3344/12 \\
\hline São Manoel & Teles Pires & MT/PA & 700,00 & Empresa de Pesquisa Energética - EPE & $\begin{array}{l}\text { EV em } \\
\text { andamento }\end{array}$ & Desp. 441/10 \\
\hline Serra Quebrada & Tocantins & $\mathrm{TO} / \mathrm{MA}$ & $1.328,00$ & $\begin{array}{l}\text { Consórcio Alcoa/Billinton/Camargo } \\
\text { Corrêa/Eletronorte }\end{array}$ & $\begin{array}{l}\text { EV em } \\
\text { andamento }\end{array}$ & Desp. 3367/07 \\
\hline Telêmaco Borba & Tibagi & PR & 109,00 & Promon Engenharia Ltda. & $\begin{array}{l}\text { EV em } \\
\text { andamento }\end{array}$ & $\begin{array}{l}\text { Oficio } \\
339 / 03 / \mathrm{SPH}\end{array}$ \\
\hline Uruçui & Parnaiba & $\mathrm{PI} / \mathrm{MA}$ & 134,00 & Chesf/CNEC/Queiroz Galvão/ENERGIMP & $\begin{array}{l}\text { EV em } \\
\text { andamento }\end{array}$ & Desp. $239 / 07$ \\
\hline $\begin{array}{l}\text { Volta Grande } \\
\text { Baixa }\end{array}$ & Chopim & PR & 54,70 & Foz do Chopim Energética Ltda. & $\begin{array}{l}\text { EV em } \\
\text { andamento }\end{array}$ & Desp. 3166/11 \\
\hline Total 27 & 27 projetos & \multicolumn{3}{|c|}{$6.935,48$} & & \\
\hline
\end{tabular}

Notas: (1) Para efeitos da simulação eletroenergética, foram consideradas as características técnicas cadastradas para o último Leilão.

(2) EV - EVTE aprovado pela ANEEL.

(3) EV em andamento - EVTE com aceite ou em análise pela ANEEL.

Fonte: Despachos ANEEL (30/08/2013).

Fonte: PDE- EPE, 2013-2022

Caracterizada a matriz elétrica nacional e suas principais características, destaca-se a grande importância das fontes hidráulicas para a segurança energética nacional, o que resulta em um processo de planejamento da operação energética de alta complexidade, devido às incertezas envolvidas no processo de geração hidráulica.

Verifica-se que na maior parte do tempo do histórico da operação energética as energias (ou vazões) afluentes ao parque hidroelétrico permitem atender à demanda nacional a um custo operacional muito inferior ao custo da geração 
térmica, reduzindo-se o acionamento das fontes de geração térmica. Deste modo o processo de operação ocorre, simplificadamente, seguindo a lógica de que a geração térmica funciona como um seguro, sendo acionada em períodos hidrológicos desfavoráveis. Contudo, em muitas situações as usinas térmicas são acionadas por ordem de mérito, sem critérios exclusivamente técnicos. No entanto, a geração térmica tem se tornado uma solução utilizada em grande escala em períodos de extensa seca hidrológica, como a verificada entre 2013 e 2014.

Devido à capacidade de complementariedade entre a geração hidrelétrica e térmica, pode-se apontar que sistemas hidrotérmicos apresentam racionamentos menos profundos que sistemas 100\% hidráulicos de igual nível de garantia, ou seja, os sistemas hidrelétrico e térmico se complementam de modo significativo. Atualmente o Setor Elétrico considera um risco de déficit energético de $5 \%$, valor este que já foi ultrapassado em determinados momentos do histórico nacional, mesmo com o atual parque gerador instalado.

Por um lado se associa a segurança energética à capacidade de regularização dos reservatórios do SIN em suportar períodos hidrológicos desfavoráveis. Todavia, ao longo do tempo, tem-se observado uma redução continuada na capacidade de regularização (em porcentagem) do SIN, dado que houve uma significativa redução na implantação de novas usinas com capacidade de regularização de vazões. Este fato conduz a uma perda significativa na capacidade de regularização do SIN, o que se traduz em uma crescente dependência de períodos hidrológicos favoráveis e no despacho de usinas térmicas.

Segundo a EPE, em relação à capacidade de regularização dos reservatórios, pode-se destacar a importância dos grandes reservatórios instalados na região Sudeste/Centro-Oeste, que representam $71 \%$ do total do SIN, seguida pela região Nordeste, com $18 \%$ da capacidade de energia armazenável máxima do Brasil. As regiões Sul e Norte possuem, respectivamente, $7 \%$ e $4 \%$ da capacidade de armazenamento total prevista em 2012.

Cabe observar, também, que as hidroelétricas licitadas nos últimos anos são praticamente todas a fio d'água ou com capacidade ínfima de acumulação. 
Esta configuração do sistema gera consequências diversas, dentre as quais: a impossibilidade de controle de cheias; maior exigência das atuais usinas do sistema com capacidade de regularização, gerando grandes alterações de nível dos reservatórios ao longo de curtos ciclos hidrológicos; e maior despacho térmico para atender às exigências sazonais da carga, que não poderão ser atendidas pelo armazenamento hidráulico.

O ONS, por diversas vezes, tem alertado sobre a redução da capacidade de regularização plurianual do sistema: a razão entre toda a energia armazenável (em MWmédios) em forma de água nos reservatórios e a demanda nacional (também em MWmédios) apresentou, em números aproximados, queda de 6,7 meses, em 2000, para 4,5 meses, em 2012. A consultoria PSR estimou, por sua vez, que haverá uma perda na capacidade de regularização do sistema hidroelétrico da ordem de 10\%, entre 2010 e 2020 (CBIE, 2011).

Analisando a previsão de capacidade de armazenamento dos reservatórios ao final do ano de 2022 (EPE, 2013), percebe-se, em termos percentuais, que a elevação de $2 \%$ da capacidade de armazenamento do SIN até 2022 é bem inferior ao aumento da capacidade instalada de usinas hidrelétricas, de $40 \%$.

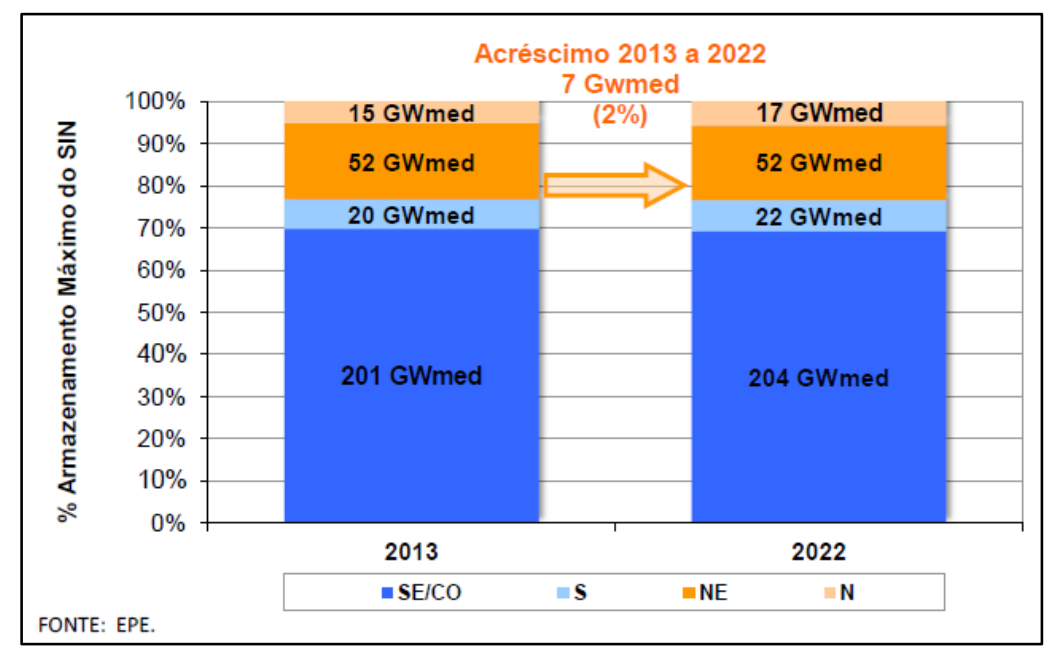

Figura 4. Evolução da capacidade de armazenamento do SIN (Fonte: PDE EPE, 2013-2022)

A relação entre a energia armazenável máxima e a carga de energia é apresentada na figura 5 a seguir, onde se destacam a região Sul, por manter a baixa capacidade de regularização ao longo de todo o período (2020-2020), e as regiões Sudeste/Centro-Oeste e Nordeste, pela trajetória decrescente dessa 
relação, com forte redução da energia armazenável em relação à carga ao longo do período deste Plano.

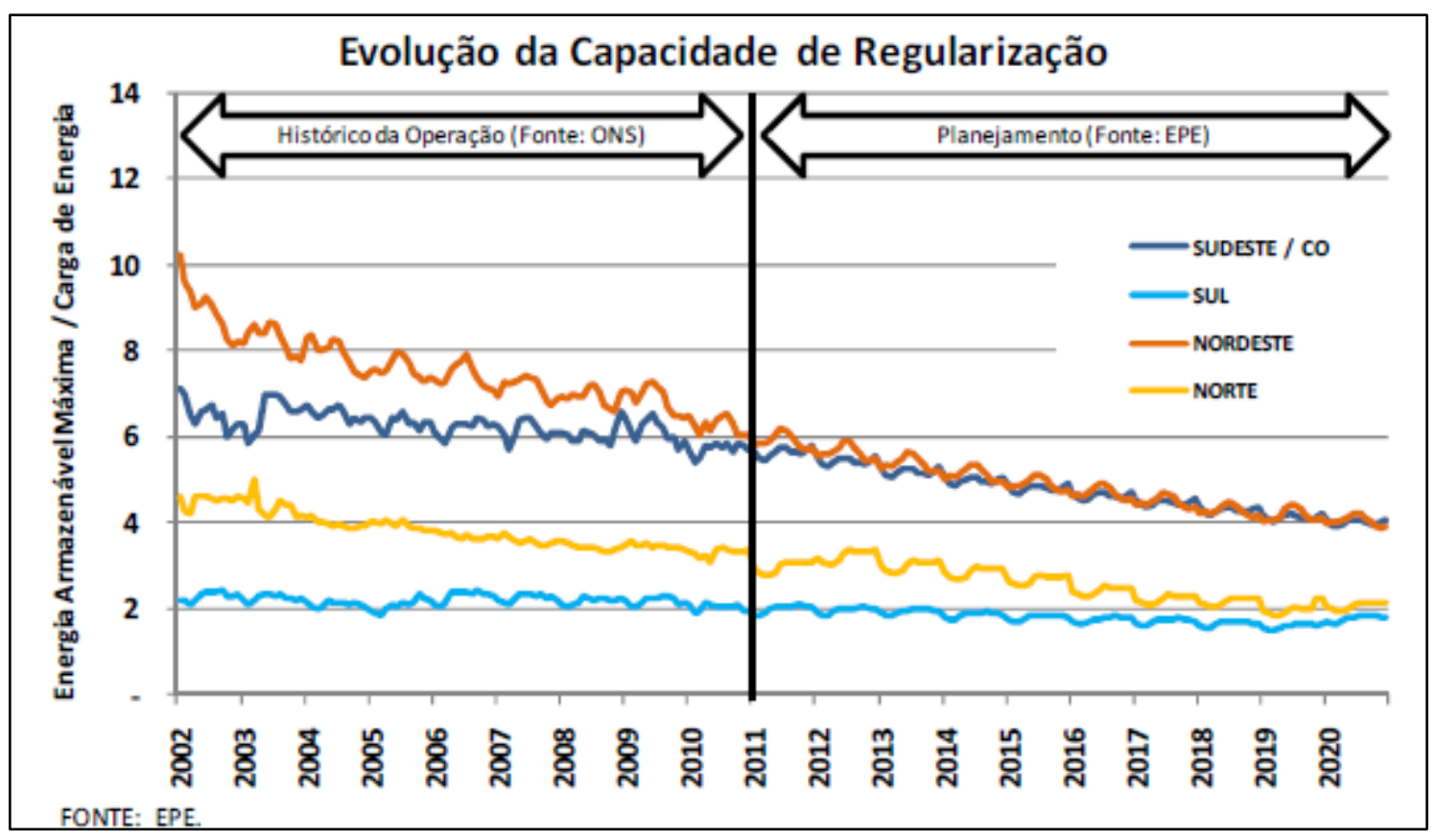

Figura 5. Evolução da energia armazenável máxima em relação à carga de energia (Fonte: PDE 2011-2020, EPE)

A figura 6, extraída de Falcetta et Zambon (2013), ilustra a proporção entre a energia armazenada máxima e a capacidade instalada do SIN para o período entre 1908 (com base no histórico da evolução anual da capacidade instalada e de regularização do sistema a partir desse ano) até 2017 (com base na expansão prevista até essa data). Segundo os autores a redução dos valores verificada no trecho final do gráfico implica em maiores variabilidades sazonais e incertezas na geração hidrelétrica, além da necessidade crescente de ampliar a capacidade instalada e o despacho térmico complementar em proporção bem maior que ao crescimento da demanda. 


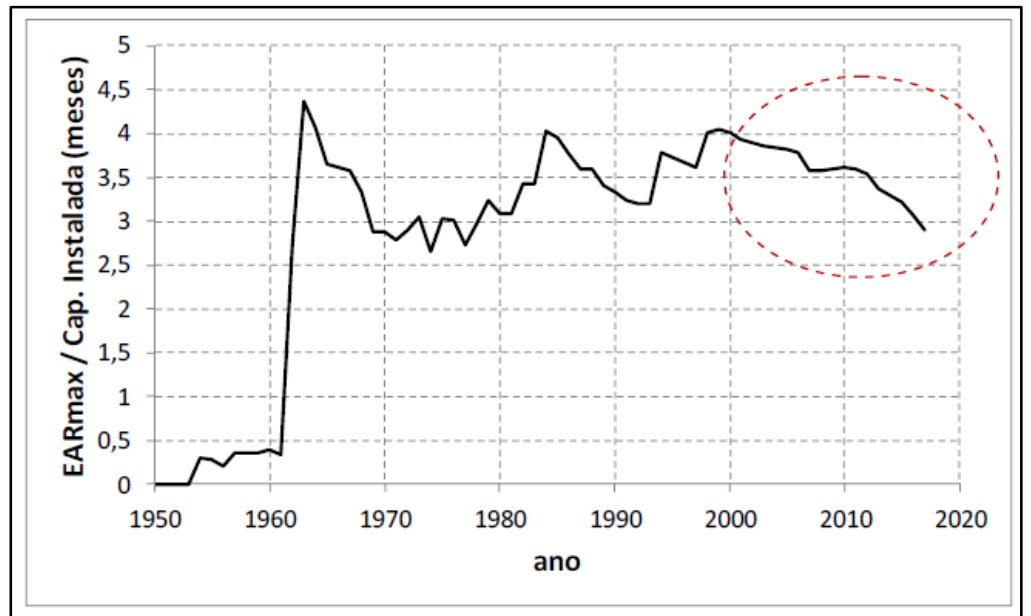

Figura 6. Evolução da proporção entre as capacidades de armazenamento e de geração de energia (Fonte: Falcetta et Zambon, 2013)

Dentre as principais explicações para esta tendência destacam-se duas vertentes: a primeira, em função da significativa necessidade de capital para a implantação de usinas de grande porte com reservatórios de regularização. A segunda, em função dos requisitos crescentes associados ao Meio Ambiente e ao Uso Múltiplo da Água, que podem tem inviabilizado a construção de usinas hidroelétricas com grandes reservatórios.

Nos próximos anos, a tendência é de que novas fontes de geração de eletricidade aumentem sua participação na matriz elétrica, tornando a operação do sistema interligado ainda mais complexa.

Segundo CBIE (2011), os principais exemplos dessas novas fontes são a energia eólica e a biomassa, cuja geração de energia não é regular: no primeiro caso, pelo caráter intermitente; no segundo, pela sazonalidade da safra de cana de-açúcar. Portanto, os atuais procedimentos operacionais, concebidos para um modelo majoritariamente hidroelétrico com usinas de grandes reservatórios, estarão comprometidos e enfrentarão dificuldades em relação à operação ótima do sistema.

Neste contexto, a diminuição da capacidade de regularização do sistema acentua a importância de previsões confiáveis de afluências e de cenários hidrológicos para a composição das Estratégias e Políticas de Operação. Além do mais, demonstram que a necessidade de usinas térmicas para fornecer energia elétrica nos períodos críticos e de ponta irá crescer. 


\subsection{Planejamento da operação de sistemas hidrotérmicos}

\subsubsection{Características Gerais}

O planejamento da operação do SIN se mostra como um problema de grande complexidade, devido principalmente aos seguintes aspectos:

- Longo horizonte de planejamento a ser analisado. Atualmente considera-se horizontes de planejamento de até 5 anos, ocasionando na necessidade de sistemas robustos de previsão de vazões;

- Dependência temporal das decisões. Decisões operativas tomadas hoje afetam as decisões operativas no futuro. Isto pode ser visualizado pela figura 7 a seguir, onde dois cenários distintos de afluências futuras são mostrados (úmida e seca), com a consequência de cada um no estado do sistema e no custo operativo decorrente;

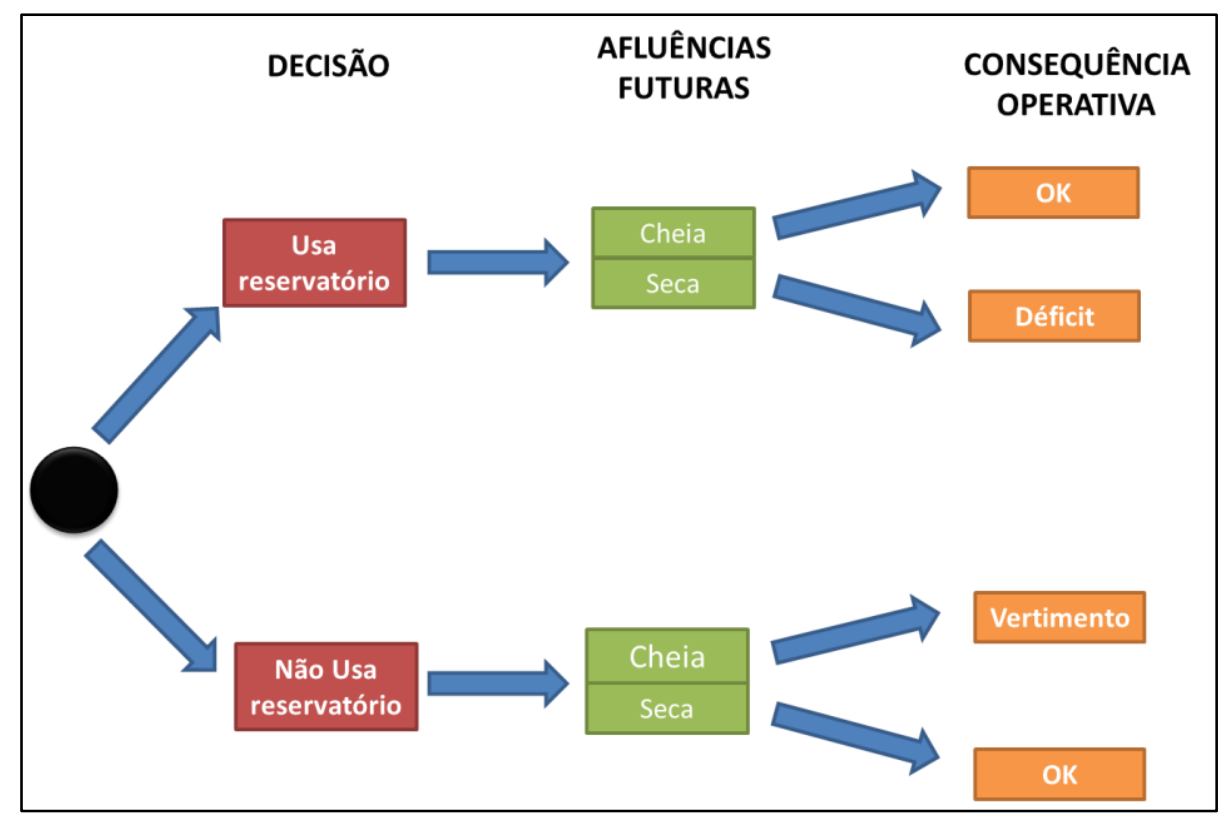

Figura 7. Possíveis realizações de afluências

- Acoplado no espaço. O parque hidrelétrico está disposto ao longo de diversas bacias hidrográficas, muitas delas dispostas em uma mesma cascata, onde a operação de usinas a montante afeta a operação das usinas a jusante;

- Estocástico. Há grande incerteza em relação às futuras afluências, que variam sazonal e regionalmente e podem possuir períodos secos de 
longa duração. Além disso, existem ainda incertezas com relação à geração térmica e à demanda de energia elétrica;

- Relações não lineares presentes nas funções de geração das usinas hidrelétricas e de custo da complementação termelétrica;

- Elevado número de aproveitamentos e reservatórios de acumulação com regularização plurianual, e

- Vasta rede de transmissão interligando as usinas aos centros de carga.

O planejamento da operação de um sistema hidrotérmico deve ainda ser realizado tendo por objetivo atender os requisitos de consumo de forma econômica e confiável. Isto significa utilizar os recursos hidrelétricos disponíveis da melhor forma possível, reduzindo os custos da operação, sem, entretanto, comprometer a confiabilidade do sistema quanto ao atendimento da demanda de energia elétrica (Toscano, 2009).

Deste modo, o problema do planejamento da operação energética de um sistema de geração de energia hidrotérmico consiste em determinar metas de geração para as usinas hidrelétricas e termelétricas para cada estágio de tempo ao longo do horizonte de estudo, atendendo à demanda de energia elétrica, às restrições operativas das usinas e às restrições elétricas do sistema. A determinação da alocação ótima dos recursos hídricos e térmicos é norteada segundo um determinado critério, como por exemplo, o critério de minimização dos custos globais de produção da energia elétrica, com vistas à modicidade tarifaria (Toscano, 2009).

O problema de planejamento da operação energética deve ainda considerar as restrições operativas associadas às usinas hidrelétricas, termelétricas e às restrições elétricas do sistema.

Diversas ferramentas e abordagens têm sido desenvolvidas buscando-se o planejamento de sistemas hidrelétricos ou hidrotémicos, tal como do SIN. As distintas abordagens se utilizam de diferentes técnicas de otimização, modos de gerenciamento de reservatórios e abordagens quanto à consideração das incertezas nos processos envolvidos. 
A consideração das incertezas envolvidas no processo de planejamento da operação resulta na necessidade de abordagens complexas do ponto de vista técnico e computacional e que envolvam conceitos de probabilidade e de analise de risco.

Em Yeh (1985), Simonovic (1992), Wurbs (1993), Momoh et al.(1999a,b) Labadie (2004), Zambon (2008) e Oliveira (2013), há uma extensa revisão bibliográfica das diferentes técnicas de otimização adotada para 0 planejamento de sistemas hidrotérmicos.

Diversos modelos tem sido desenvolvidos, tanto no Brasil quanto no contexto internacional. Internacionalmente destacam-se trabalhos de Rosenthal (1981) e Oliveira (1992), como métodos baseados em algoritmos de fluxos de rede, Yeh et al. (1992), que desenvolveu um modelo de otimização em tempo real para a operação do sistema hidrotérmico na China, considerando variações sazonais de vazões afluentes aos reservatórios, perdas na transmissão com diferentes regras de despacho e cargas nas usinas hidrelétricas e termelétricas (Zambon, 2008); Castro e González (2004), que apresentaram o modelo HTCOOR (Hydro Thermal Coordination package) para sistemas hidrotérmicos com predominância da geração hidrelétrica e aplicando a técnica da rede de fluxo "multicommodity" não linear através dos "solvers" MINOS e SNOPT para minimizar os custos com combustíveis e com energia emergencial. As aplicações foram apenas para casos hipotéticos simplificados, distantes de problemas reais de maior porte.

Destaca-se também o trabalho de Escudero et al. (1996), que utilizou cenários para representar as incertezas em sistemas hidrelétricos, compostos por conjuntos com 10 a 35 usinas, e também por técnicas de processamento paralelo através da definição de uma função objetivos não lineares.

No trabalho de Labadie (2004), foi discutido as diversas técnicas baseadas na otimização estocástica implícita (programação linear, fluxo em rede, programação não linear, programação dinâmica discreta, programação dinâmica diferencial e teoria de controle ótimo a tempo discreto), otimização estocástica explícita (programação com restrições probabilísticas, programação linear estocástica, programação não linear estocástica, programação dinâmica 
estocástica, teoria de controle ótimo estocástico, otimização multiobjetivo), controle em tempo real com previsão e métodos de programação heurística (algoritmos genéticos, redes neurais e conjuntos nebulosos). Labadie destaca o fato de que alguns problemas de otimização de reservatórios, particularmente a geração hidrelétrica, devem ser tratados diretamente como problemas de programação linear sucessiva, programação quadrática sucessiva, método dos multiplicadores e o método do gradiente reduzido generalizado (Zambon, 2008).

Labadie conclui que as chaves do sucesso na implementação de modelos de otimização na operação de sistemas de reservatórios são: aumentar o nível de confiança através de maior interação com os tomadores de decisão no desenvolvimento, melhor "empacotamento" dos modelos e também uma melhor articulação com modelos de simulação que os operadores possam aceitar mais prontamente (Zambon, 2008). Esta conclusão se mostra muito pertinente se aplicado ao contexto atual do planejamento da operação do SIN.

No contexto nacional destacam-se o modelo ACQUANET desenvolvido por Porto et al. (2005) com PL, o modelo SISAGUA por Barros et al. (2005a,b) com PNL e PNLIM e o modelo SISOPT por Barros et al. (2003,2005), aplicados á otimização de sistemas complexos e de grande porte de recursos hídricos incluindo conjuntos de reservatórios. O SISOPT se aplica a sistemas de usinas hidrelétricas e utiliza técnicas de PL, PLS e PNL, a última baseada no MINOS (MURTAGH e SAUNDERS, 1987) e aplicadas para diferentes funções objetivo e aplicações concentradas em subsistemas do SIN (Zambon, 2008).

O modelo SDDP comercializado pela PSR Inc. utiliza, com metodologia semelhante ao NEWAVE/DECOMP, a técnica da PDDE e é utilizado em vários países. A metodologia desse modelo é apresentada por Pereira et al. (1998), juntamente com a aplicação a um sistema de 40 reservatórios na Colômbia (Zambon, 2008).

Lopes (2007) desenvolveu o modelo SolverSIN para o planejamento da operação de sistemas hidrotérmicos utilizando a PNL e a agregação das hidrelétricas em subsistemas e aplicado ao sistema brasileiro. As imprecisões resultantes da agregação dos reservatórios são minimizadas através de 
funções de perdas por vertimento e por variação de queda associadas às afluências e ao armazenamento e calibradas com dados históricos do SIN. Lopes conclui ainda que a consideração das usinas hidrelétricas de forma individualizada pode acarretar em uma grande melhoria na solução do problema em substituição ao reservatório equivalente (Zambon, 2008).

Segundo Lopes (2007) os principais dados indicados e discutidos que interferem significativamente nos resultados dos modelos são: rendimento dos conjuntos turbina/gerador, curva nível jusante $x$ vazão defluente, nível montante em usinas a fio d'agua, período do histórico de vazões naturais e o ajuste de valores médios dos dados físicos para longo período.

Marcato (2002) da PUC-RJ propõe um modelo híbrido com usinas individualizadas nos primeiros estágios, porém com produtividades e níveis no canal de fuga constantes, e agregação em subsistemas equivalentes posteriormente. Na UNICAMP, Oliveira e Soares (1990) desenvolveram o modelo POSH (Planejamento da Operação de Sistemas Hidrotérmicos) com a técnica de fluxos em rede não linear com arcos capacitados e que foi posteriormente incorporado ao SSD SAPE (Vinhal, 1998) e mais tarde evoluiu para o SSD HIDROLAB (Cicogna, 2003). Martinez (2001) comparou a técnica da PDDE (malha fechada) com a otimização determinística com o modelo POSH acoplada a modelos de previsão de vazões (malha aberta), aplicadas para um único reservatório e para um sistema em cascata, e destacou resultados favoráveis com a opção pela malha aberta (Zambon, 2008).

Leite (2003) na EESC-USP utilizou a técnica da inteligência artificial com os princípios da evolução genética para planejamento da operação de sistemas hidrotérmicos, com aplicações para sistemas de até 35 usinas hidrelétricas, onde foram obtidos resultados satisfatórios. Sacchi (2004) aplicou a previsão por redes neurais para reservatórios do sistema Sudeste. Seus testes mostraram que o previsor neural possui uma forte tendência em seguir os resultados da otimização determinística realizada com a PNL utilizada no treinamento. Nazareno (2005) apresentou um algoritmo de fluxo em rede não linear para solução de um sistema hidrotérmico com usinas individualizadas aplicado a subsistemas da região Sudeste (Zambon, 2008). 
Zambon (2008) desenvolveu o sistema de suporte à decisão HIDROTERM, que consiste em um modelo de otimização com base na linguagem GAMS, com rotina de Programação não linear (PNL). Dividido em dois módulos interligados, inicia-se o modelo HIDRO, que otimiza o sistema considerando as usinas individualizadas e aproveitando ao máximo a capacidade hidrelétrica instalada para então processar o modelo TERM, que otimiza o despacho térmico e os intercâmbios entre os subsistemas. Os dois modelos podem ser utilizados separadamente ou de modo integrado, no chamado HIDROTERM. As usinas são consideradas individualizadas no modelo, enquanto as demandas, as usinas termelétricas e os intercâmbios são agregados em subsistemas, podendo ainda ser representadas outras fontes de geração de energia.

O GAMS (General Algebraic Modeling System) é uma linguagem de modelação composta por recursos algébricos e suporte de recursos comuns a linguagem de programação, que permitem uma representação direta dos modelos matemáticos de otimização (função objetivo, restrições, etc).

Mendes (2012) avaliou os impactos que os múltiplos usos da água causam à operação dos reservatórios de uma bacia hidrográfica para a geração de energia elétrica, através da utilização da interface do SSD HIDRO, A aplicação do modelo foi feita para a bacia do rio São Francisco, localizada entre as regiões Sudeste e Nordeste do Brasil.

Assim como exposto, existem diversas técnicas de otimização aplicadas a sistemas hidrelétricos ou hidrotérmicos. Contudo, a complexidade envolvida no processo de geração e transmissão e o grande porte do problema induzem a maioria dos modelos desenvolvidos à simplificações e a aceitação de limitações, tais como a utilização de reservatórios equivalentes e a simplificação nas linearidades do problema.

As abordagens mais utilizadas para considerar/estimar as previsões de vazões afluentes aos reservatórios são apresentadas no item 4.2.2. a seguir. 


\subsubsection{Abordagens utilizadas}

De modo geral, os modelos utilizados de otimização do planejamento de sistemas hidrotérmicos são: determinísticos, ou hidrológicos de chuva-vazão, (consideram características geográficas da região de interesse); estocásticos, com extração de informações com base em modelagens matemáticas e estatísticas dos dados disponíveis ao longo do tempo; e, por fim, os modelos baseados em inteligência artificial, sobretudo pela utilização de Redes Neurais e Lógica Nebulosa.

Dentre estes, a presente dissertação deu maior ênfase às abordagens estocásticas de previsão de vazões afluentes aos reservatórios.

\subsubsection{Abordagem determinística}

A abordagem determinística resulta da atribuição de valores previstos às variáveis aleatórias (vazões afluentes) do problema, possibilitando a obtenção da solução ótima com um modelo de otimização determinística. Essa categoria de modelos costuma representar o processo físico de transformação chuva vazão, com base em parâmetros simplificados relacionados às condições de escoamento na bacia em estudo. Além do mais, usualmente se utilizam dados históricos para fazer a calibração e validação do modelo. A programação deste modelo pode ser linear, não linear, quadrático, entre outros.

Um exemplo bastante representativo desta abordagem consiste no modelo ODIN (Otimização do Despacho Interligado Nacional), elaborado pela Universidade Estadual de Campinas (UNICAMP), mais especificamente no Laboratório de Coordenação da Operação de Sistemas Elétroenergéticos COSE, pertencente ao Departamento de Engenharia de Sistemas - DENSIS da Faculdade de Engenharia Elétrica e de Computação FEEC) e pela Companhia Energética de São Paulo (CESP).

O modelo ODIN é um modelo determinístico de otimização não linear a usinas individualizadas. Utiliza a técnica de controle em malha aberta utilizando realimentação para assegurar o desempenho do sistema. Estudos de sua aplicação para o planejamento da operação de usinas isoladas e de pequenas cascatas do sistema brasileiro demonstraram que essa técnica é bastante 
promissora, por ser capaz de aliar uma abordagem eficiente do problema aos benefícios da representação detalhada do sistema hidráulico, considerando cada usina individualmente, com suas próprias restrições operacionais e características de produção (Martinez, 2001).

\subsubsection{Abordagem baseada em inteligência computacional}

Nesta classe de problemas destacam-se as Redes Neurais Artificiais (RNA), os sistemas nebulosos (fuzzy) e modelos neurais-nebulosos (neurofuzzy).

Estes consistem em sistemas constituídos por elementos de processamento interconectados, chamados de neurônios, os quais estão dispostos em camadas e são responsáveis pela não-linearidade e pela memória da rede. As redes com aprendizagem supervisionada utilizam o conhecimento prévio do resultado desejado para poder calcular os pesos desejados (Ballini, 2000).

Os modelos baseados em inteligência computacional tornaram-se alternativas atraentes para o estudo das séries temporais, devido a sua capacidade de tratar as incertezas que podem estar presentes nos dados, a capacidade de realizar mapeamentos não lineares, assim como a adaptação a possíveis mudanças na dinâmica da série quando se trata de modelos adaptativos (Zambelli, 2009).

\subsubsection{Abordagem estocástica}

A abordagem estocástica é característica dos tipos de problemas onde se é necessário considerar incertezas ou fenômenos probabilísticos para se tomar decisões. Esta abordagem tem a vantagem de se considerar, assim, o possível universo de manifestações da variável, e será melhor descrita no item 4.2.3 a seguir, com ênfase nas técnicas de geração de cenários.

Os modelos estocásticos podem proporcionar um planejamento da operação de modo mais robusto e até levar a maiores benefícios se comparado com modelos determinísticos (Follestade et al, 2011).

\subsubsection{Otimização Estocástica via Processos de Cenarização Hidrológica}

Dentre os fenômenos envolvidos no processo de geração hidroelétrica, destacam-se aqueles cujas incertezas de previsão são mais relevantes: 
- Vazões Naturais Afluentes;

- Demanda de Energia;

- Indisponibilidades na geração e transmissão de energia;

- Disponibilidade de combustíveis;

- Evaporatranspiração.

Dentre os fenômenos enumerados acima se destaca a incerteza inerente ao processo de previsões de vazões naturais afluentes aos reservatórios (por representar a energia hidráulica disponível) e, consequentemente, a importância na previsão destas vazões.

As abordagens estocásticas atualmente consideram a aleatoriedade das vazões afluentes através de funções de distribuição de probabilidades e aplicam técnicas de otimização clássicas, tal como a programação dinâmica estocástica (PDE). Essas abordagens são amplamente utilizadas em problemas de planejamento hidrotérmico por serem capazes de considerar, além das incertezas das vazões, as não linearidades do problema (Zambelli, Toscano \& al, 2008).

A técnica estocástica no planejamento da geração hidrelétrica tem sido adotada pela metodologia em vigor no Brasil desde a década de 70 , que evoluiu na década de 90 para o modelo NEWAVE cuja modelagem de solução se baseia em programação dinâmica dual estocástica (PDDE), melhor abordado no item 4.2.4 desta dissertação.

O extenso horizonte do planejamento da operação e a estocasticidade das afluências tornam o problemas de planejamento da operação energética de um sistema hidrotérmico um problema de grande porte e de difícil solução, sendo necessária sua divisão em diversas etapas, de tal forma que cada etapa considere diferentes graus de detalhamento do sistema, horizonte de estudo e representatividade da incerteza hidrológica. Assim, a modelagem costuma ser dividida em diversos subproblemas, onde em cada uma deles é adotado um horizonte de planejamento diferente, e também, uma representação da 
estocasticidade das afluências e das não linearidades do problema com diferentes graus de detalhamento. A figura 8 a seguir ilustra esta divisão:

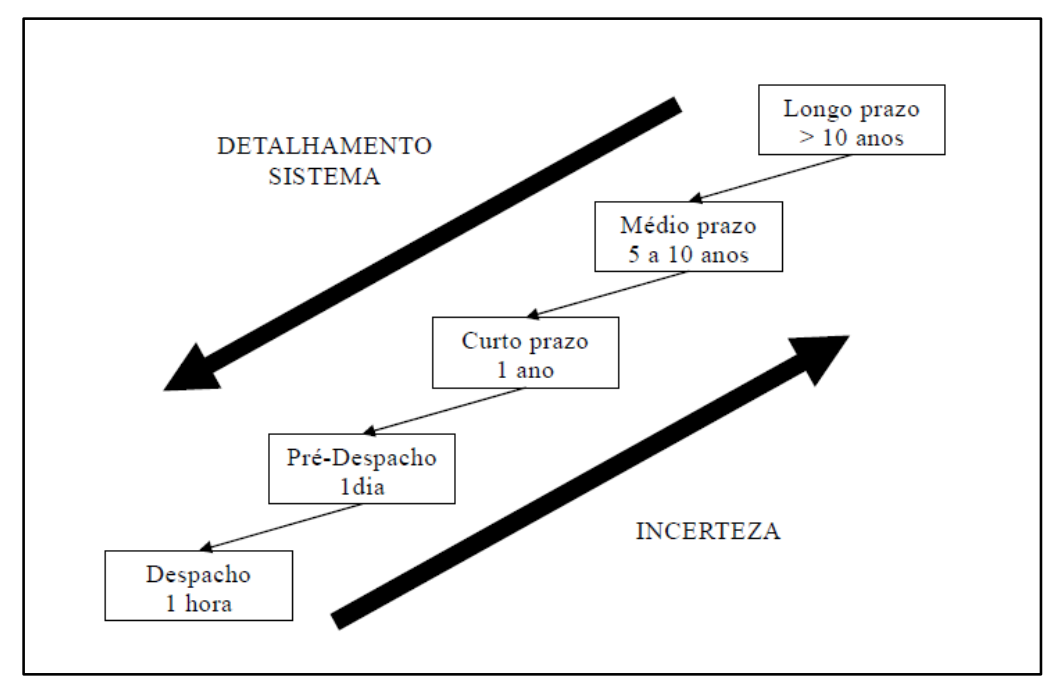

Figura 8. Incertezas e detalhamento do sistema de acordo com o horizonte de estudo (Silva, 2010)

Uma vez definido o núcleo central do problema a ser otimizado (com as funções objetivo, restrições e parâmetros iniciais), define-se o modelo estocástico através da adoção de uma distribuição probabilística que represente a aleatoriedade do processo. Deste modo, pode-se então gerar diferentes cenários que seguem a mesma distribuição e representam a incerteza envolvida. Além do mais, ao se executar o processo de geração de cenários, os parâmetros randômicos do modelo de decisão podem ser justificados. Dependendo do contexto do problema de decisão, um tipo diferente de Geração de Cenários pode ser mais apropriado.

Assim, as incertas dos parâmetros das vazões afluentes aos aproveitamentos hidroelétricos são representadas por meio de uma árvore de cenários com probabilidades associadas. Porém, quando se utilizam árvores com muitos estágios, a complexidade do problema de otimização resultante para sistemas hidrotérmicos torna difícil a resolução em tempos computacionais razoáveis.

Segundo Dupačová (2003), o conceito de cenários é usualmente aplicado para a modelagem da aleatoriedade em modelos de programação estocástica, onde os dados evoluem no tempo e as decisões devem ser realizadas 
independentes do conhecimento dos possíveis caminhos/possibilidades de ocorrência.

Uma vez que os métodos computacionais geralmente representam as incertezas envolvidas via variáveis aleatórias discretas (ou discretizadas), o tema de árvore de cenários é uma das principais áreas da otimização estocástica envolvendo problemas de tomada de decisão sob incertezas (ONS, 2004).

Segundo Domenica et al (2007), de modo geral, o procedimento de geração de cenários envolve os seguintes ou todos os procedimentos (para problemas multi estágio):

- Coleção de observações históricas dos parâmetros estocásticos considerados e adoção de um modelo que explique o comportamento desses parâmetros aleatórios;

- Estimativa/calibração dos parâmetros para o modelo escolhido com base nos dados históricos;

- Geração de possíveis trajetórias (caminhos/cenários) de acordo com 0 modelo escolhido ou com a distribuição adotada, utilizando-se de propriedade estatísticas; e

- Escolha de amostras das trajetórias de modo que a árvore de cenários com as propriedades desejadas possam ser construídas.

Os diferentes modelos estocásticos, de modo geral, possuem diferentes parâmetros como input e output, contudo, todos os modelos possuem em comum a necessidade das observações de dados históricos para a construção do mesmo. Os dados históricos se mostram fundamentais para que sejam previstos e determinados os modelos estocásticos pertinentes para então, se gerar diferentes cenários.

A evolução dos cenários no tempo é representada via uma árvore onde a cada etapa os nós representam possíveis realizações das variáveis aleatórias naquela etapa, havendo um arco ligando um nó de uma etapa com outro da etapa seguinte, ambos relativos ao mesmo cenário. O nó raiz se refere à condição inicial conhecida, e os nós folhas se referem à etapa final. O número 
de cenários é, portanto, igual ao número de nós folhas. Se a abertura de cada nó de uma etapa é a mesma, diz-se que a árvore é balanceada, hipótese bastante usual que introduz uma uniformidade na cenarização, mas ao mesmo tempo permite que a abertura varie de um estágio para outro (ONS, 2004).

A cada nó (exceto as folhas) saem arcos para nós sucessores de algum cenário da etapa seguinte, cada um com sua probabilidade condicional de transição, de modo que estas somam a unidade. A probabilidade de um cenário é dada pelo produtório das probabilidades condicionais dos nós que o compõem, e consequentemente, a soma das probabilidades dos cenários também é unitária.

Dentro da cenarização estocástica, cada processo de divisão pode acontecer de diferentes maneiras, assim pode como visualizado na figura 9 , proveniente de Ramos (2011).

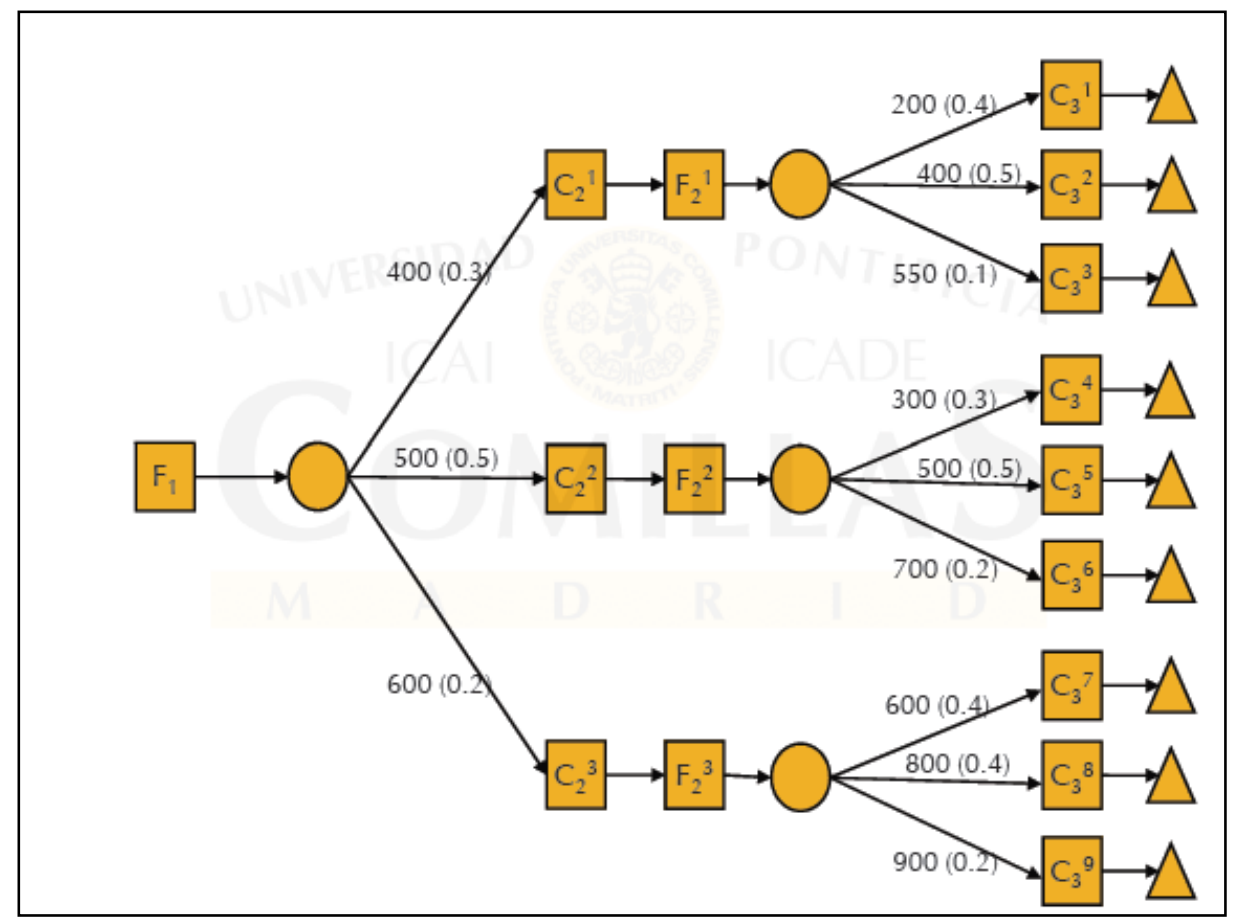

Figura 9. Exemplo de ramificação (Ramos, 2011)

Esta forma construtiva de descrição da estrutura de dependência temporal entre cada nó e seus nós sucessores permite caracterizar a evolução temporal das incertezas envolvidas via um processo estocástico a estados discretos. $\mathrm{O}$ custo computacional deste método cresce significativamente com o número de etapas, de cenários e com a dimensão da configuração do sistema. Assim, a 
dimensão do problema de otimização estocástica, com incertezas modeladas via árvore de cenários, é potencialmente muito grande.

Supondo, por exemplo, que se use uma árvore balanceada (aberturas iguais ao longo das etapas) com $\mathrm{T}$ etapas e abertura binária constante, teríamos 2T-1 cenários distintos, de modo que o porte do problema de otimização linear resultante desta modelagem cresce exponencialmente com o número de etapas, na base dada pela abertura. É, portanto, essencial que a árvore seja de baixa cardinalidade, e ao mesmo tempo ser representativa em termos do universo de cenários de vazões das usinas do parque gerador ao longo do horizonte de estudo.

$\mathrm{Na}$ literatura especializada ainda não há um paradigma para o que seria uma estrutura desejável para uma árvore de cenários. Para cada problema, propõese uma estrutura topológica e probabilística básica da árvore de cenários, que é aferida e reavaliada via testes experimentais, envolvendo escolher qual a abertura requerida a cada estágio, como produzir realizações associadas a cada nó da árvore condicionados aos valores ocorridos nos seus antecessores, etc (ONS, 2004).

Não há limitação prática quanto ao número de usinas hidráulicas ou de etapas a serem considerados, havendo apenas uma necessidade de estabelecer uma precisão desejada para os resultados.

\section{Programação Estocástica em Dois e Multiestágios}

Segundo Oliveira (2007), a resolução de problemas de otimização estocástica em mais de um estágio se baseia na ideia de trabalhar o problema em uma forma decomposta, fixando valores das variáveis de decisão sequencialmente, segundo as incertezas vão sendo reveladas com o decorrer do tempo, por estágios.

O planejamento da operação energética é modelado como um problema de otimização estocástica multiestágio. Isto significa que o processo de decisão deve ser tomado para as $\mathrm{n}$ futuras etapas/estágios do horizonte de planejamento. Com base nos parâmetros definidos para os $\mathrm{n}$ futuros estágios 
de tempo, decide-se a operação nos intervalos próximos. Ainda segundo Oliveira (2007) os modelos estocásticos podem ser divididos em dois modos:

\section{- Modelos estocásticos em Dois Estágios}

$\mathrm{Na}$ formulação estocástica em dois estágios os dados estão reorganizados em dois níveis diferentes. Os dados correspondentes às variáveis de primeiro estágio são determinísticos. Já as variáveis de segundo estágio dependem de dados incertos, variando com cada cenário, suposto $\mathrm{w}$.

A variável (supostamente $x_{1}$ ) representa 0 vetor de decisões anteriores à realização do evento incerto correspondente a algum cenário $(w)$. Este primeiro período, em que não há incertezas, é denominado de "primeiro estágio" e todas as variáveis relacionadas a este período são denominadas variáveis de primeiro estágio, bem como as restrições pertinentes. Já o segundo estágio é determinado pelo conjunto de períodos em que há incertezas em uma ou mais variáveis.

As variáveis de segundo estágio são dadas pelos vetores $x_{2}(w)$, sendo $w$ um cenário, ou seja, uma possível realização dos dados incertos para os quais se deseja otimizar a variável $\mathrm{x}_{2}(\mathrm{w})$.

\section{○ Modelos estocásticos Multiestágios}

Nos modelos multiestágios, todas as incertezas ocorrem após passado 0 primeiro estágio de decisão, de modo que o primeiro estágio possui um caráter determinístico, enquanto que as variáveis aleatórias são reveladas sequencialmente com o desenrolar dos estágios, e as decisões devem ser analisadas em muitos períodos, sendo necessário um outro tipo de enfoque no tratamento das incertezas.

Assim, os modelos multiestágios evitam a necessidade de uma escolha demasiadamente incerta no início do período de análise. Um aspecto importante consiste na evolução do fenômeno aleatório ao longo do tempo, pois na formulação multiestágio o problema pode ter variável de primeiro estágio aleatória, neste sentido não há então distinção entre primeiro estágio e subsequentes estágios. 
Um problema de decisão num estágio t pode variar drasticamente dependendo das incertezas realizadas nos períodos anteriores. Para o problema de planejamento da operação hidroenergética, extremamente dependente das afluências aos reservatórios, pode-se utilizar um programa estocástico multiestágios. Além do mais, toda decisão a ser tomada, referente ao estágio t, leva em consideração o nível de água nos reservatórios até o final do estágio $t$ -1 , deste modo, as decisões são acopladas no tempo.

Uma maneira de representar os possíveis estados das variáveis aleatórias nos modelos de multiestágios é colocando os cenários em formato de árvore, conforme as Figuras 10 e 11 a seguir.

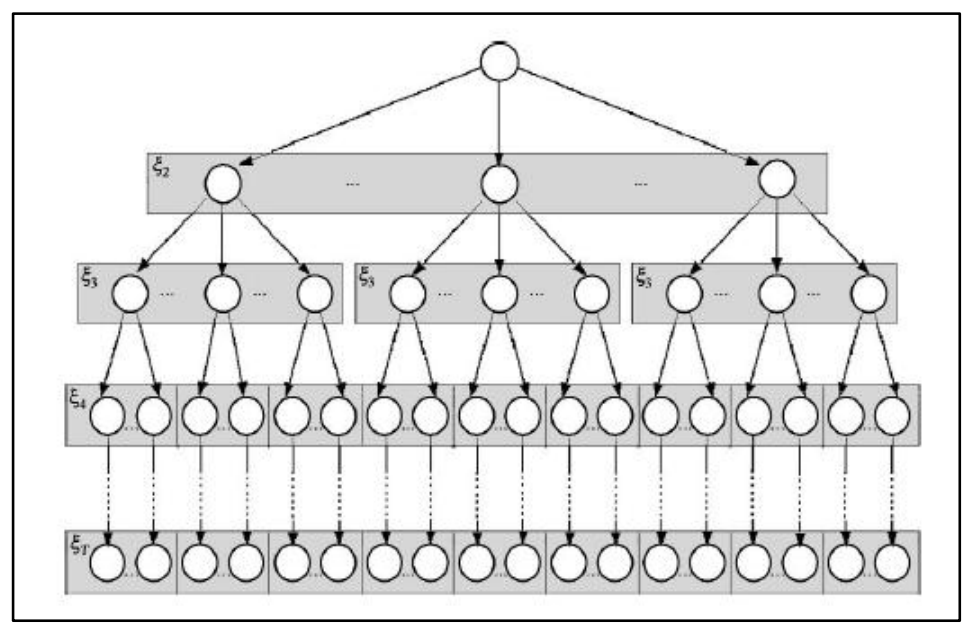

Figura 10. Árvore multiestágio (Domenica et al, 2007)

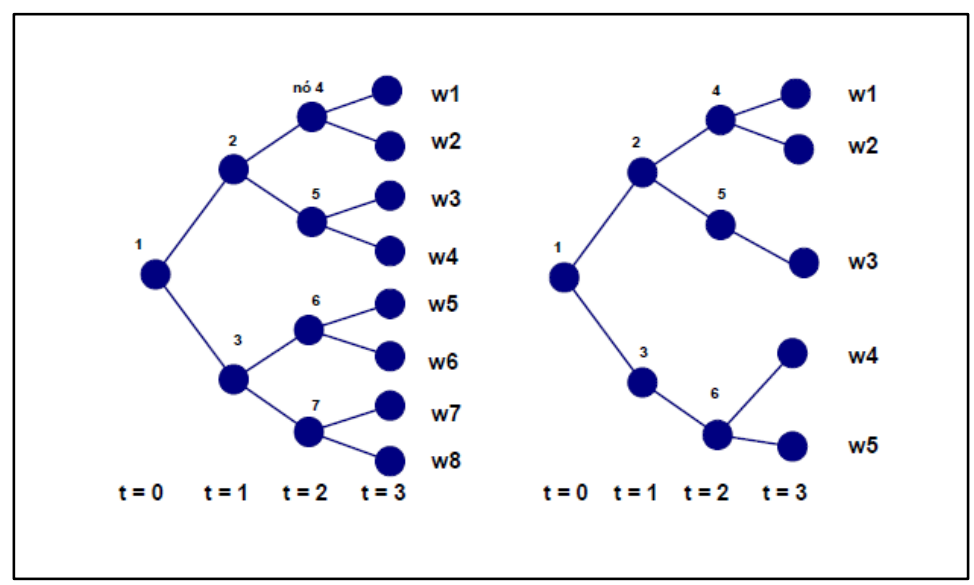

Figura 11. Cenários em formato árvore (Oliveira, 2007) 
Cada cenário wi tem $T$ componentes (cada componente pode ser vetorial). É assumido que todos os cenários coincidem no instante de tempo $t=0$, isto é, $\mathrm{w}_{01}=\mathrm{w}_{02}=\mathrm{w}_{03}=\cdots=\mathrm{w}_{0 \mathrm{~N}}$. Isto significa que $\mathrm{t}=0$ pode ser considerado como a raiz da árvore que contém $\mathrm{N}$ cenários.

Cada nó da árvore corresponde à realização da variável aleatória para um estágio $t$, ressaltando-se que um mesmo valor pode corresponder a diferentes cenários. Na Figura 11, por exemplo, o nó 4 pertence tanto ao cenário w1 como ao cenário $\mathrm{w}_{2}$ (ou seja, $\mathrm{w}_{21}=\mathrm{w}_{22}$ ).

Quando usado o formato árvore, a denominada multiplicidade indica quantos "ramos" da árvore são abertas em cada nó. Por exemplo, a árvore à direita na Figura 11, possui multiplicidade constante e igual a dois (árvore binária), enquanto que a árvore à esquerda possui multiplicidade variável entre 1 e 2.

Devido ao acoplamento no tempo das variáveis decisão, tem-se a definição de implementabilidade, muito importante para modelos multo-estágios, também chamada de "nonanticipativity" em inglês. Em geral, se dois cenários têm a mesma sequência de nós entre o primeiro e o k-ésimo estágios, eles têm a mesma parcela de informações durante estes períodos. Consequentemente, decisões associadas a tais cenários devem ser idênticas até o k-ésimo período. Este requerimento é conhecido como condição de implementabilidade.

Uma vez que as árvores de cenários representam o universo das possíveis realizações das variáveis estocásticas (vazões afluentes), a criação de tais árvores é realizada através da geração de diferentes séries sintéticas de vazões, com base em um modelo estocástico pré-definido.

Assim, os cenários são constituídos de diferentes séries sintéticas de vazões, e, essas são baseados em séries temporais associadas às séries históricas. Deste modo, torna-se necessário, neste estudo, que antes de se aprofundar nas técnicas de construção de cenários em si, sejam introduzidos os conceitos de Séries Sintéticas, Séries Temporais e Modelo Estocásticos de Geração de Séries Sintéticas. 


\section{Séries Sintéticas}

Denomina-se série sintética todo possível evento gerado por um modelo de uma variável aleatória, seja este físico, heurístico ou estocástico.

Na maior parte dos casos, na impossibilidade de se conhecer as ocorrências futuras de fenômenos incertos, adota-se a hipótese de que ocorrências passadas, chamadas de "séries históricas", proporcionam uma descrição razoável do que pode acontecer no futuro. No entanto, apesar de fornecer subsídios bastante úteis para algumas aplicações, os estudos com séries históricas podem apresentar limitações sérias, já que não é possível contemplar situações mais severas das registradas no histórico.

A série histórica é apenas uma das possíveis realizações de um processo estocástico. Isto é, pode-se imaginar que a Natureza "sorteou" a série histórica, segundo algum conjunto de leis probabilísticas. Um novo sorteio redundaria numa outra série, diferente da histórica, mas igualmente provável. Um modelo estocástico aproxima este comportamento estocástico, de modo a permitir que se façam tantos sorteios artificiais quantos forem necessários para o estudo em foco (Kelman, 1987).

Cada sorteio estará associado a uma série de vazões, chamada de série sintética. Como estas séries serão todas distintas entre si, pode-se obter diversos resultados provenientes de simulações, ao invés de um único resultado que seria obtido caso apenas a série histórica estivesse disponível, Desta forma, a informação contida na série histórica pode ser mais completamente extraída, permitindo assim que se avalie riscos e incertezas pertinentes a um sistema hidroelétrico. Por exemplo, pode-se calcular para cada uma das séries sintéticas uma "energia firme sintética", á semelhança do que se faz com a série histórica. A probabilidade de não atendimento de uma demanda energética, dentro do horizonte de planejamento, pode ser estimada pela frequência com que as "energias firmes sintéticas" forem inferiores á esta demanda. (Kelman, 1987)

Por este motivo, as séries históricas podem resultar insuficientes para compor uma amostra que estime acuradamente alguns índices de risco (como o não 
suprimento da demanda), associados com situações severas ou extremas. Já os modelos de geração de séries sintéticas de afluências a partir da série histórica resolvem a dificuldade mencionada, por serem capazes de capturar características básicas das ocorrências passadas, permitindo ao mesmo tempo a avaliação de riscos e incertezas extremos pertinentes a um sistema hidroelétrico (Oliveira, 2007).

Ressalta-se, no entanto, que a disponibilidade de muitas séries sintéticas pode dar a impressão de que é possível ter confiança absoluta nos resultados encontrados com o seu emprego. É importante ressaltar, no entanto, que a geração de séries sintéticas não apresenta informações adicionais. Existem até casos em que é preferível utilizar apenas a série histórica (Kelman, 1987).

\section{Séries Temporais}

Os mencionados processos estocásticos descrevem medidas disponíveis ao longo do tempo, sob a forma de séries temporais, e muitas vezes os dados descritos apresentam uma dependência entre si. O corpo de técnicas disponíveis para a análise de séries de observações dependentes é chamado de Análise de Séries Temporais.

Uma série temporal é um conjunto de dados observados e coletados cronologicamente. $\mathrm{Na}$ análise de séries temporais a ordem de ocorrência dos fatos é crucial.

Segundo Deus (2010), existem séries temporais contínuas que são provenientes de dados coletados em todo instante de tempo ou séries temporais discretas que provêm de dados discretos. As séries temporais, em sua maioria são espaçadas em intervalos constantes de tempo, sejam eles horário, diário, semanal, mensal, anual, etc. As séries discretas são as mais utilizadas e simplificam muito a matemática que suporta os modelos. Além disso, séries contínuas no tempo podem ser discretizadas em intervalos iguais, como a de temperatura por exemplo. 
Existem séries que podem ser modeladas por uma função polinomial, e com isso a observação futura pode ser prevista com exatidão. Este tipo de série segue uma função determinística. Quando não se pode prever com exatidão as observações futuras e elas podem ser descritas somente em termos de distribuição de probabilidade, esta série segue um modelo não determinístico o que geralmente é um modelo estatístico ou estocástico (Deus, 2010).

Outra importante classificação das séries temporais é quanto a sua estacionaridade. Segundo Hipel et Mcleod (1994), a estacionaridade de um processo estocástico pode ser qualitativamente interpretada como uma forma de equilíbrio estatístico. As distribuições de probabilidade das séries temporais estacionárias não se alteram ao longo do tempo, ou seja, seus parâmetros estatísticos como média e variância se repetem a cada período. Já as séries temporais não estacionárias apresentam parâmetros estatísticos variantes ao longo do tempo. A não estacionariedade das séries temporais pode ser atribuída a três fatores: tendência, sazonalidade e ciclos.

A tendência de uma série indica seu comportamento de longo prazo, isto é, se o seu parâmetro descritor, como a média, aumenta, diminui, ou permanece constante, e qual a velocidade dessas mudanças. As tendências mais utilizadas são as constantes, lineares ou não lineares. Já a sazonalidade indica a repetição de um padrão na série dentro do período de um ano. Os ciclos indicam padrões que se repetem na série em períodos superiores a um ano.

Diversos fenômenos naturais podem ser classificados como séries temporais não estacionárias, devido às variações naturais e interferências humanas que ocorrem ao longo do tempo. No entanto, para modelar uma série temporal não estacionária, um procedimento comum é primeiramente remover a não estacionariedade através da aplicação de uma transformação e depois ajustar um modelo estocástico estacionário a sequência transformada. Esta transformação, também conhecida como derivação, pode ser realizada mais de uma vez, até que se obtenha a série estacionária (Hipel et Mcleod, 1994). 


\section{Propriedades Estatísticas das Séries Temporais}

Dada uma série temporal observada $\left[z_{1}, z_{2}, \ldots, z N\right]$, os seguintes parâmetros estatísticos podem ser definidos:

- Média Amostral

A média amostral do processo é definida como a soma de todos os valores da amostra dividida pelo número de observações da amostra.

$$
\bar{Z}=\frac{1}{N} \sum_{t=1}^{N} Z_{t}
$$

A média teórica do processo pode ser estimada a partir da amostra realizada.

- Desvio Padrão Amostral

A dispersão de dados do processo espalhados em torno da média é medida pelo desvio padrão amostral que pode ser estimado a partir da série através do seguinte equacionamento:

$$
\hat{\sigma}_{Z}=\sqrt{\frac{\sum_{t=1}^{N}\left(Z_{t}-\bar{Z}\right)^{2}}{N}}
$$

- Coeficiente de Variação

O coeficiente de variação $(\mathrm{CV})$ é obtido pela razão entre o desvio-padrão e a média, também considerado como uma medida de dispersão por medir a variabilidade dos valores em torno da média.

$$
C V=\frac{\bar{Z}}{\hat{\sigma}_{Z}}
$$

- Assimetria

A assimetria é um parâmetro que avalia a forma como os dados estão distribuídos em relação à média. Para que os dados apresentem distribuição normal, a assimetria deve ser próxima ou igual a zero. Em termos de dados hidrológicos, por apresentarem um padrão com limitação inferior (normalmente, valor mínimo é zero) e sem limitação superior (os eventos hidrológicos podem 
ser superados), a assimetria é positiva. A assimetria pode ser calculada da seguinte forma:

$$
A=\frac{\sum_{t=1}^{N}\left(Z_{t}-\bar{Z}\right)^{3}}{n}
$$

\section{- Autocovariância}

A covariância mede o grau de dependência linear entre duas variáveis aleatórias espaçadas de um intervalo de tempo. A covariância de ordem um é calculada pela seguinte equação:

$$
\gamma_{1}(1)=\operatorname{COV}\left[Z_{t}, Z_{t+1}\right]=\frac{1}{N} \sum_{t=2}^{N}\left(Z_{t}-\bar{Z}\right)\left(Z_{t+1}-\bar{Z}\right)
$$

De forma generalizada, a autocovariância de ordem $k$ é representada pela equação abaixo:

$$
\gamma_{k}(1)=\operatorname{COV}\left[Z_{t}, Z_{t+k}\right]=\frac{1}{N} \sum_{t=2}^{N}\left(Z_{t}-\bar{Z}\right)\left(Z_{t+k}-\bar{Z}\right)
$$

Onde:

$\mathrm{k}$ representa o lag temporal entre $\mathrm{Z}_{\mathrm{t}} \mathrm{e} \mathrm{Z}_{\mathrm{t}+\mathrm{k}}$.

○ Autocorrelação

A autocorrelação pode ser entendida como a normalização da autocovariância. A autocovariância de ordem k é normalizada pela autocovariância de ordem zero, ou seja, pela variância da série.

$$
\rho_{k}=\frac{\gamma_{k}}{\gamma_{0}}=\frac{\gamma_{k}}{\widehat{\sigma}^{2}}
$$

Esta normalização é feita de modo a facilitar os cálculos, uma vez que este coeficiente passa a não possuir dimensão e dependência de escala e passa a variar de menos uma unidade a uma unidade.

- Matriz de autocaviância e Autocorrelação

A Função de Autocorrelação (ACF) mede o grau de dependência linear entre a variável no instante $\mathrm{t} e$ no instante $\mathrm{t}+\mathrm{k}$. Ela permite que se analise o grau de 
irregularidade de um sinal. Pode ser definida como a razão entre a autocovariância e a variância de um conjunto de uma série temporal. Para uma série histórica $\mathrm{N}$, a matriz de autocovariância pode ser definida como:

$$
\left[\begin{array}{cccc}
\gamma_{0} & \gamma_{1} & \gamma_{2} & \gamma_{N-1} \\
\gamma_{1} & \gamma_{0} & \gamma_{1} & \gamma_{N-2} \\
\vdots & \vdots & \vdots & \vdots \\
\gamma_{N-1} & \gamma_{N-2} & \gamma_{N-3} & \gamma_{0}
\end{array}\right]
$$

\section{Modelos estocásticos e métodos de geração de séries sintéticas}

A definição do modelo estocástico é precursora da construção dos cenários sintéticos de vazões, uma vez que os cenários correspondem a diferentes conjuntos de séries sintéticas.

No contexto do planejamento da operação hidroenergética os modelos estocásticos tem como principal objetivo a geração de séries sintéticas para a construção da árvore de cenários.

Um método de previsão de séries temporais pode ser definido como o conjunto de procedimentos usados no desenvolvimento de uma determinada previsão. Os métodos de previsão de séries temporais baseiam suas previsões na extrapolação de características de observações passadas e no interrelacionamento entre essas observações, fornecendo previsões acuradas se 0 futuro apresentar comportamento similar ao passado (Deus, 2008).

Segundo Deus (2008), a maioria dos métodos de previsão de séries temporais se baseia na suposição de que observações passadas contêm todas as informações sobre o padrão de comportamento da série temporal e esse padrão é recorrente no tempo. O objetivo dos métodos de previsão é distinguir o padrão de qualquer ruído que possa estar contido nas observações e então usar esse padrão para prever os valores futuros da série temporal. Assim, pela identificação desse componente, a previsão para períodos de tempo subsequentes ao observado pode ser desenvolvida. 
O processo de seleção de um modelo e de estimação de seus parâmetros é feito a partir de inferência com a série histórica. Portanto, a utilização do modelo estocástico de vazões deve ser encarada simplesmente como uma das maneiras de se manipular a informação existente. Nenhuma nova informação é criada, a não ser pela adoção de hipóteses subjacentes ao modelo estocástico. Estas hipóteses devem ser exaustivamente testadas antes que se aceite qualquer modelo. Infelizmente nunca se pode ter certeza quanto a identidade do verdadeiro modelo utilizado pela Natureza (Kelman, 1987).

Não existe uma classificação fechada das técnicas de geração de cenários a partir de séries sintéticas, mas varia conforme a abordagem do autor.

Pires, 2008 apresentou classificações elaboradas por diferentes autores, nos quais destacam-se Kaunt e Wallace (2003) e Heitsch et Romisch (2005).

Os primeiros focaram o seu trabalho no processo de construção das árvores de cenários, dividindo-os em duas categorias principais, que são os processos de simulações propriamente ditos, e métodos de geração de cenários a partir de séries existentes, denominados por eles, respectivamente, como: i)métodos puros de geração de cenários; ii) métodos relacionados.

Os métodos puros de geração incluem: ia) amostragem condicional; ib) amostragem a partir das distribuições marginais e correlações; ic) moment matching; id) path-based method; ie) discretização ótima. Os métodos relacionados são: iia) redução de cenários; iib) métodos de amostragem internos.

Já em Heitsch et Romisch (2005), as técnicas para geração de árvores de cenários estão divididas em i) bound-based approximations methods; ii) Monte Carlo based sampling schemes; iii) moment-matching principle; iv) aproximação baseada em métricas de probabilidade; v) uso de integração de quadraturas.

Ainda em Pires (2008), depois de levantada as referências bibliográficas quanto ao modo de discretização, adotou-se a seguinte classificação para seus trabalhos: 
Quanto ao momento de geração dos cenários, estes podem ser realizada em a) antecipada - que ocorre na maioria dos casos e caracteriza-se pela construção total da árvore antes da otimização; b) tempo real - constrói-se a árvore de cenários no momento em que se está realizando a otimização, ou seja, é realizada a geração dos cenários imediatamente após a otimização do período anterior.

Quanto ao processo de construção da árvore, subdividido em: i) direta, onde a geração de cada conjunto de cenários de cada estágio é feita diretamente a partir do nó gerado e, ii) por agrupamento, onde se geram todas as simulações a partir do estágio inicial e, posteriormente, realizam-se os agrupamentos de forma a se gerar as ramificações da árvore.

Quanto ao processo de discretização, podem ser subdivididos em:

- Estatístico: Subdividido em baseados na distribuição (conhece-se, ou julga-se conhecer, a distribuição de probabilidade da variável aleatória simulada na construção do cenário); baseados no momento (não se conhece antecipadamente a distribuição e, portanto, tenta-se emulá-la a partir de seus momentos ou percentis); baseado no técnica de redução de variância (identificação de estruturas determinísticas ou relações com outras variáveis, de modo a se acelerar o processo de convergência do erro de aproximação, tais como os métodos das variâncias de controle, variáveis antitéticas, amostragem estratificada, hipercubo latino e moment matching).

- Determinístico: Podendo ser: baseados no espaço das variáveis (discretização desconsiderando as probabilidades de cada cenário, tais como os métodos de baixa discrepância ou como o método de QuaseMonte Carlo); baseados no espaço de probabilidade, onde se consideram as probabilidades relacionadas a cada cenários no momento da discretização, tais como os métodos de integração de quadraturas e métodos baseados em métricas de probabilidades.

- Auxiliar, que incluem as técnicas para reduzir a dimensão do espaço de probabilidades de ocorrência, como o método dos componentes principais. 
Os métodos de previsão também podem ser classificados quanto ao número de séries temporais envolvidas na modelagem: univariados, funções de transferência e multivariado.

Os métodos univariados, que compreendem a maior parte dos métodos de previsão de séries temporais, consideram somente uma única série para a realização dos prognósticos. As previsões decorrentes da aplicação de métodos univariados podem estar relacionadas apenas com as informações contidas na série histórica de interesse (métodos baseados na estatística clássica) ou também, além de incorporarem essas informações, consideram outras supostamente relevantes e que não estão contidas na série analisada (métodos baseados na estatística bayesiana) (Deus, 2008).

Aquelas metodologias nas quais a série de interesse é explicada não só pelo seu passado histórico, como também por outras séries temporais não correlatas entre si, são conhecidas como funções de transferência. Esta classe de métodos de previsão, chamado de multivariado, envolve, portanto, mais de uma série temporal, com a ressalva de que a relação de causalidade entre estas séries é perfeitamente conhecida.

Os métodos multivariados abrangem os procedimentos de previsão que associam mais de uma série temporal na efetivação de prognósticos sem, no entanto, qualquer imposição com relação à causalidade entre essas séries.

Focando no processo de previsão de vazões médias mensais, costuma-se concluir que as series de vazões naturais médias mensais se caracterizam por um comportamento periódico, ou seja, a média, a variância, a assimetria e a estrutura de autocorrelação apresentam caraterísticas periódicas. Para analisar estes tipos de séries, cujos parâmetros apresentam um comportamento periódico, costuma-se usar modelos univariados auto-regressivos periódicos.

Dentre os diversos métodos estocásticos de previsão e geração de séries temporais, o Setor de Energia Elétrica optou pela utilização da metodologia auto-regressiva periódica na geração dos cenários de vazão e energia natural afluente, através do modelo Auto-regressivo Periódico PAR(p). Este modelo foi melhor apresentado e utilizado na presente dissertação. 


\section{Modelo Estocástico Auto-Regressivos AR (p)}

Modelos Auto-Regressivos descrevem como uma observação depende diretamente de uma ou mais observações feitas em períodos anteriores, e do termo de ruído branco. Estes estimam a variável dependente a partir de valores assumidos por ela em tempos anteriores, ou seja, a própria variável é capaz de explicar a sua ocorrência partindo dos dados registrados na série temporal. Este tipo de modelo é utilizado em vários campos do conhecimento.

Quando uma observação $\mathrm{Zt}$, medida num instante de tempo $\mathrm{t}$, depende de valores da série temporal medidos no instante $\mathrm{t}-1$ com o ruído branco at, este processo é chamado de Auto-Regressivo de ordem 1, ou AR(1). O processo AR(1) é comumente conhecido como Processo de Markov e pode ser escrito sob a forma da seguinte equação.

$$
Z_{t}-\mu=\varphi_{1}\left(Z_{t-1}-\mu\right)+a_{t}
$$

Onde:

$\mu$ = média do processo;

$\varphi_{1}=$ parâmetro auto-regressivo;

at $=$ ruído branco independemente e identicamente distribuído $\left(0, \sigma_{a}^{2}\right)$.

A sequência da variável at é a parte randômica da série, o ruído branco ou 0 distúrbio adicionado à série. A premissa mais importante para o ruído branco é que ele é independente e identicamente distribuídas (i.i.d), o que infere que os at's são descorrelatados e devem satisfazer a equação 10 a segui.

Além do mais, é assumido que os ruídos brancos sigam a distribuição normal.

$$
E\left[a_{t} a_{t-k}\right]=\left\{\begin{array}{c}
\sigma_{a}^{2}, k=0 \\
0, k \neq 0
\end{array}\right.
$$

Onde:

E corresponde à correlação serial. 


\section{Modelo Estocástico Auto-Regressivos PAR ( $p$ )}

O modelo PAR (p) consiste em um modelo não estacionário da família dos modelos Autor-regressivos. Estes foram extensivamente estudados por Box \& Jenkings (1994).

O modelo $\operatorname{PAR}(\mathrm{p})$ é uma adequação do modelo $A R(p)$ adaptado para séries sazonais que apresentam uma estrutura de autocorrelação que depende não apenas do intervalo de tempo entre as observações, mas também das estações sazonais ao longo do ano. Estes processos, quando analisados em escala semanal ou mensal, têm como característica o comportamento periódico, refletindo o ciclo das estações do ano. Cada período apresenta um conjunto de suas propriedades probabilísticas, definidas pela média, desviopadrão e função de autocorrelação.

A essência do modelo PAR ( $p$ ) é definir um modelo AR para cada mês do ano, fazendo assim com que a periodicidade considerada seja mensal.

Uma vez que as séries mensais de vazões afluentes possuem comportamento periódico e dependência temporal, o modelo PAR $(p)$ costuma se adequar à metodologia descrita acima, cujas principais características são a representação da periodicidade e da correlação temporal.

A metodologia do $\operatorname{PAR}(\mathrm{p})$ ajusta um modelo de séries temporais e, por simulação, gerar cenários através da utilização dos parâmetros obtidos na consulta ao histórico, que contém os acontecimentos passados; através da correlação de ordem $\mathrm{p}$ com o passado recente; e através de uma parte aleatória que confere a estocasticidade aos cenários. Sua formulação é representada da seguinte maneira (Hipel et Mcleod, 1994):

Os modelos periódicos consideram para o ajuste de parâmetros somente determinadas semanas de um mês, trimestre ou semestre, agrupando determinados períodos do ano, enquanto que modelos estacionários consideram a série como um todo com todos os meses do ano, no qual meses e trimestres diferentes são tratados do mesmo modo. 
O número de termos autorregressivos do modelo PAR ( $p$ ) indica a ordem do modelo para modelos mensais, onde cada elemento fornece a ordem de cada período/mês.

$$
\left(\frac{Z_{t}-\mu_{m}}{\sigma_{m}}\right)=\varphi_{1}^{m}\left(\frac{Z_{t-1}-\mu_{m-1}}{\sigma_{m-1}}\right)+\cdots+\varphi_{p}^{m}\left(\frac{Z_{t-p}-\mu_{m-p}}{\sigma_{m-p}}\right)+a_{t}
$$

$\mathrm{Ou}$

$$
\Phi^{\mathrm{m}}(B)\left(\frac{Z_{t}-\mu_{m}}{\sigma_{m}}\right)
$$

Onde:

Zt é uma série sazonal de períodos s;

T é o índice do tempo, $t=1,2, \ldots, \mathrm{sN}$, função do ano $\mathrm{T}(\mathrm{T}=1,2, \ldots, \mathrm{N})$ e do período $\mathrm{m}(\mathrm{m}=1,2, \ldots, \mathrm{s})$;

S é o número de períodos ( $\mathrm{s=12}$ para séries mensais);

$\mathrm{N}$ é o número de anos que se deseja gerar as séries;

$\mu \mathrm{m}$ é a média sazonal do período $\mathrm{m}$;

om é o desvio padrão sazonal de período m;

pi é o coeficiente autorregressivo para a estação m;

$\Phi^{\mathrm{m}}(\mathrm{B})$ é o operador autorregressivo de ordem pm;

$$
\begin{gathered}
\Phi^{\mathrm{m}}(B)=\left(1-\Phi^{\mathrm{m}} B-\Phi_{2}^{m} B^{2}-\cdots-\Phi_{p}^{m} B^{p m}\right) \\
B^{i} \text { aplicando a Zt resulta em } Z_{t-i}\left(B^{i} Z_{t}=Z_{t-i}\right)
\end{gathered}
$$

p é a ordem de cada operador autorregressivo;

at é a série de ruídos independentes com média zero e variância $2(m)$.

De modo a exemplificar a aplicação, supondo que se deseje gerar cenários de afluência para o mês de julho de um ano, e que a ordem deste mês (também 
conhecida como grau de dependência) seja 2. Sendo assim, a equação anterior assumiria a seguinte forma:

$$
\left(\frac{Z_{7}-\mu_{7}}{\sigma_{7}}\right)=\varphi_{1}^{m}\left(\frac{Z_{6}-\mu_{6}}{\sigma_{6}}\right)+\varphi_{2}^{m}\left(\frac{Z_{5}-\mu_{5}}{\sigma_{5}}\right)+a_{7}
$$

Onde:

$Z_{7}$ representa a vazão natural afluente a ser calculada para o mês de julho; o termo $Z_{6}$ representa a vazão afluente de junho e $Z_{5}$ a vazão afluente de maio; o termo i representa a média histórica das vazões afluentes de cada mês, ou seja, a Média de Longo Termo (MLT) de cada mês; $\varphi_{1}$ representa o parâmetro autorregressivo entre as vazões afluentes de julho e junho e o termo $\varphi_{2}$ representa o parâmetro autorregressivo entre as vazões afluentes de julho e maio; já o termo $a_{7}$ a representa um vetor de ruído que irá conferir a aleatoriedade à série.

A sequência da variável $a_{t}$ é a parte randômica da série. Este termo também é conhecido como ruído branco, ou o distúrbio adicionado à série. A premissa mais importante para os ruídos brancos é que eles sejam independentes e identicamente distribuídos (i.i.d.), não podendo, desta maneira, existir correlação serial entre os $a_{t}$ 's

Assume-se também, que os ruídos brancos sejam distribuídos segundo uma distribuição normal.

O processo de geração dos ruídos aleatórios consiste em uma importante etapa do processo de modelagem estocástica. Resumidamente, alguns dos principais geradores numéricos utilizados são:

- Geradores de números pseudo-aleatórios uniformes;

- Geradores lineares;

- Geradores portáveis;

- Lineares multivariáveis;

- Lineares multivariáveis com incremento pseudo-aleatório;

- Geradores não-lineares;

- Combinação de geradores. 
Na prática, costuma-se gerar números aleatórios uniformamente distribuídos e sobre estes, aplicar a distribuição normal desejada. Esta transformação pode ser realizada pela transformação de Box-Muller (Box-Muller, 1958), descrita a seguir.

\section{Distribuição normal a partir de uma distribuição uniforme}

Dispondo de um gerador com distribuição uniforme (assim como enumerado anteriormente), uma distribuição normal de média $\mu$ e variância $\sigma_{2}$, com $\mathrm{x} \sim N$ $\left(\mu, \sigma_{2}\right)$, pode ser obtida na forma:

$$
x=\mu+\sigma \sqrt{-2 \ln \left(u_{1}\right)} \cos \left(2 \pi u_{2}\right)
$$

Ou então:

$$
x=\mu+\sigma \sqrt{-2 \ln \left(u_{1}\right)} \operatorname{sen}\left(2 \pi u_{2}\right)
$$

Onde: $\mathrm{u}_{1}$ e $\mathrm{u}_{2}$ correspondem a dois valores independentes provenientes do intervalo $(0,1)$.

\section{Geração de Séries Sintéticas}

A geração de séries sintéticas ocorre através dos modelos apresentados, contudo, ao se aplicar de modo direto os ruídos históricos à série gerada poderia resultar em um grande número de valores de energia/vazões negativos significativamente elevados.

Com relação à geração dos cenários sintéticos de afluências, podem ser adotadas diferentes abordagens quanto à geração dos cenários para se evitar tal ocorrência, destacando-se duas alternativas: via ajuste de uma distribuição Log Normal aos resíduos históricos e via simulação utilizando Bootstrap (Oliveira, 2010). 


\section{○ Bootstrap}

O Bootstrap, introduzido por Efron (1993), é uma técnica estatística não paramétrica computacionalmente intensiva que permite a avaliação da variabilidade de estimadores com base nos dados de uma única amostra existente, como por exemplo, a de uma série histórica.

A técnica Bootstrap é indicada para problemas nos quais os procedimentos estatísticos convencionais sejam de difícil aplicação. Em geral, apresenta vantagens se usado em situações de amostras pequenas ou grandes, desde que forneça resultados próximos aos obtidos por meios assintóticos usuais em grandes amostras ou superior a amostras reduzidas.

Operacionalmente, a técnica consiste de um sorteio com reposição dos elementos de uma amostra aleatória, gerando uma "amostra Bootstrap", de tamanho igual à original. Extrai-se um número suficiente de amostras a fim de se obter a "distribuição Bootstrap" de qualquer estatística de interesse do pesquisados. Desta forma, o conjunto de observações Bootstrap corresponde a uma estimativa da verdadeira distribuição amostral da estatística em questão. Como mostrado em Efron (1993), à medida que o tamanho da amostra tende ao infinito, a distribuição Bootstrap converge para a distribuição verdadeira da estatística.

Oliveira (2010) estudou duas alternativas de melhorias no modelo PAR (p): a utilização da técnica de Bootstrap na fase de identificação da ordem dos modelos autorregressivos periódicos e durante a geração de cenários sintéticos de afluência para input na fase de programação estocástica. Nesse estudo, o emprego do Bootstrap para estimar os coeficientes das funções de autocorrelação parcial levou à identificação de ordens inferiores na maioria (92\% dos casos) dos períodos de todos os subsistemas, tornando os modelos substancialmente mais parcimoniosos um dos principais fundamentos da metodologia proposta por Box \& Jenkings (1994).

No contexto de séries temporais, há basicamente duas maneiras para aplicação: Bootstrap nos resíduos e os chamado "moving blocks" (Souza, 2004). 


\section{○ Distribuição Log Normal}

A distribuição estatística da componente estocástica (ruído) do modelo PAR(p) adotado para a geração de cenários é assimétrica. Assim, a distribuição Log Normal de três parâmetros ajustada aos ruídos busca reproduzir a média e o desvio padrão da amostra e apresenta um parâmetro $t{ }_{t} \psi \mathrm{t}$, de forma a evitar a geração de afluências negativas, que é responsável por acentuar a assimetria à medida em que o valor médio esperado das afluências apresente valores baixos ou se aproxime de zero.

Deste modo, as distribuições ajustadas devem ser transferidas para a série gerada de acordo com a sua própria assimetria. Os itens a seguir detalham tal procedimento.

\section{Cálculo dos ruídos históricos}

O ruído histórico $a_{t}^{h}$ ocorrido no mês t do ano histórico h é calculado por:

$$
a_{t}^{h}=\frac{z_{t}-\hat{z}_{t}}{\widehat{\sigma}_{t}}
$$

Onde:

Zt é o valor histórico observado da afluência ou vazão;

$\hat{Z}_{t}$ é o valor esperado da previsão para o estágio $\mathrm{t}$ calculado pelo modelo $\operatorname{PAR}(\mathrm{p})$, como abaixo:

$$
\hat{Z}_{t}=\hat{\mu}_{t}+\sum_{i=1}^{p_{m}}\left(\frac{\widehat{\sigma}_{t} \varphi_{i}^{(t)}}{\hat{\sigma}_{t-i}} \cdot\left(Z_{t-i}-\hat{\mu}_{t-i}\right)\right)
$$

\section{Ajuste da distribuição log-normal}

Em geral, na formulação paramétrica, adota-se a distribuição log-normal de três parâmetros, para cada mês t, para os ruídos mensais at. Os parâmetros desta distribuição são estimados a partir da média a e da variância dos ruídos históricos $a_{t}^{h}$. O parâmetro de deslocamento t é estimado de forma que o valor resultante para a vazão $Z_{t}$ seja maior do que um limite inferior pré-estabelecido $\mathrm{k}_{\mathrm{t}}$. 


$$
Z_{t}=\hat{Z}_{t}+a_{t} \hat{\sigma}_{t}>k_{t}
$$

Consequentemente, os ruídos aleatórios $a_{t}$ utilizados para gerar os cenários, possuem um valor mínimo $\psi_{t}$, para cada t, apresentado a seguir.

$$
a_{t}>\frac{k_{t}-\widehat{z}_{t}}{\widehat{\sigma}_{t}}=\psi_{t}
$$

Os parâmetros: média e variância da distribuição log-normal podem ser estimados por:

Onde:

$$
\begin{gathered}
\mu_{l n}=\frac{1}{2} \ln \left(\frac{\theta}{\Delta(\Delta-1)}\right) \\
\sigma_{l n}^{2}=\ln (\Delta)
\end{gathered}
$$

$\Delta=1+\frac{\theta}{\left(\mu_{a}-\psi\right)^{2}}$

e

$$
\theta=\sigma_{a}^{2}
$$

Sendo: $\mu \mathrm{a}$ e $\sigma^{2}$ correspondem à média e à variância dos resíduos históricos, respectivamente.

\section{Geração de cenários a partir da distribuição log-normal}

Segundo ONS (2008), a sequência adotada para a geração de cenários a partir da distribuição Log Normal pode ser resumida em:

1 - Cálculo do valor esperado da previsão $\hat{Z}_{t}^{h}$ de cada posto usando o modelo $\operatorname{PAR}(\mathrm{p})$, a partir do conhecimento dos $\mathrm{p}$ valores anteriores, $Z_{t-i}, i=1, \ldots, p$ utilizando a expressão (19);

2 - Cálculo dos ruídos históricos, conforme a expressão $a_{t}^{h}=\frac{z_{t}^{h}-\hat{z}_{t}^{h}}{\widehat{\sigma}_{t}}$;

3 - Cálculo dos parâmetros da distribuição log-normal $\mu_{l n} e \sigma_{l n}^{2}$ dados pelas expressões (22) e (23); 
4 - Determinação de ruídos normais $\mathrm{N}(0,1)$ independentes para cada posto e para cada estágio t;

5 - Multiplicação do vetor de ruídos normais independentes sorteados por uma matriz de carga, resultando em ruídos normais espacialmente correlacionados

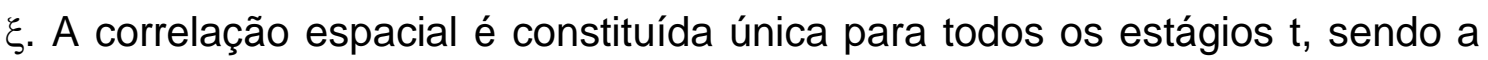
matriz de carga estimada a partir da matriz de correlações espaciais das vazões.

6 - Transformação log-normal de três parâmetros, para cada mês t, nos ruídos correlacionados $\xi_{\mathrm{t}}$, para cada posto, visando garantir que o cenário resultante $\hat{Z}_{t}+a_{t} \hat{\sigma}_{t}$ seja maior que zero. Para tanto, os ruídos log-normais at de cada posto, para cada t, a serem utilizados para gerar os cenários possuem um valor mínimo $\psi t$, obtidos de (21) com kr = 0 (vazão não negativa), de forma que:

$$
a_{t}>\frac{-\hat{z}_{t}}{\widehat{\sigma}_{t}}=\psi_{t}
$$

A transformação log-normal realizada é dada pela equação abaixo:

$$
a_{t}=\psi_{t}+e^{\mu_{l n}+\xi \sigma_{l n}}
$$

7 - Cálculo dos cenários resultantes de cada posto a partir de condições antecedentes definidas para as quais se tem $\hat{Z}_{t} \neq \hat{Z}_{t}^{h}$ :

$$
\mathrm{Z}_{\mathrm{t}}=\hat{\mathrm{Z}}_{\mathrm{t}}+\mathrm{a}_{\mathrm{t}} \widehat{\sigma}_{\mathrm{t}}
$$

A aplicação dos passos 1 a 7 permite gerar um conjunto de cenários de afluências. Estes passos são ilustrados na Figura 12 a seguir:

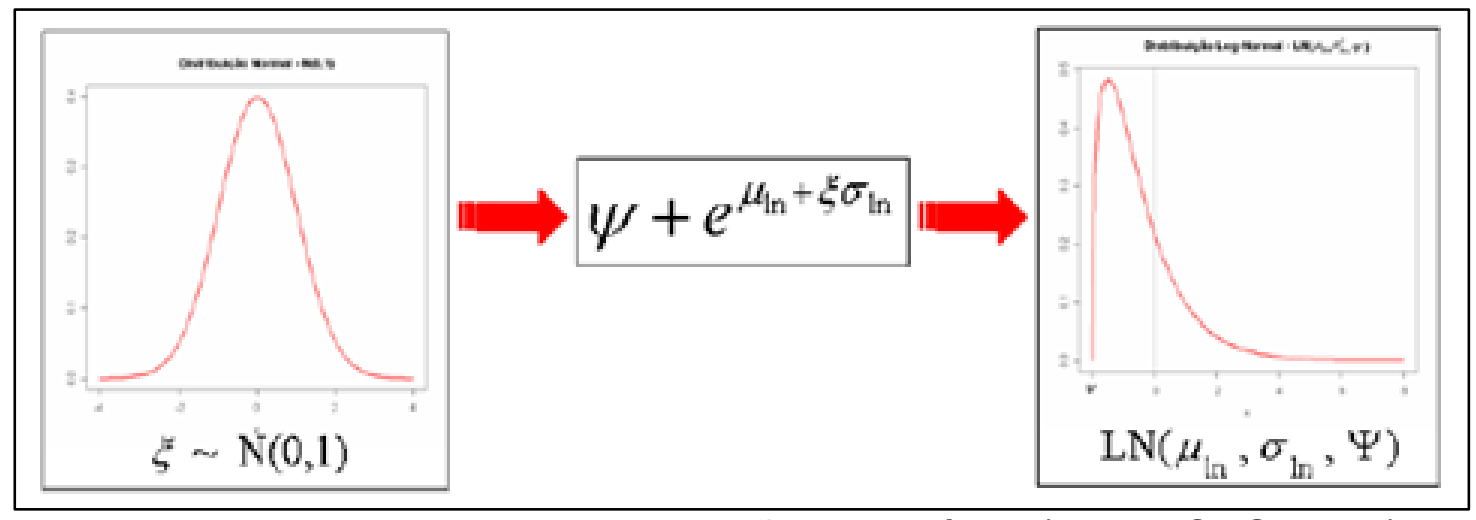

Figura 12. Procedimento para geração de cenários (Fonte: ONS, 2008) 


\section{Processo de Geração de Cenários}

Conforme descrito anteriormente, os cenários hidrológicos de vazões são gerados com base no seu histórico de realizações, em um modelo estocástico e com base em ruídos aleatórios distribuídos normalmente e independentes.

Além do mais, os cenários podem ser vinculados e representados através de uma árvore, onde cada caminho representa um possível cenário de afluência e cada nó representa uma possível realização da variável aleatória (afluência) correspondente.

O processo de geração dos cenários consiste em gerar $n$ cenários para cada cenário do estágio anterior, ou seja, para $n^{\circ}$ aberturas $=3$, são gerados três cenários a partir do único cenário do estágio $t=0$, no estágio $t+1$. No estágio $\mathrm{t}+2$, são gerados mais três cenários para cada um dos três cenários de estágio $t+1$. No estágio $t+3$ são gerados mais três cenários para cada um dos nove cenários anteriores, e assim por diante. A Figura 13 ilustra este exemplo de árvore de discretização mensal, ressaltando-se que os primeiros quatro pontos, anteriores a $\mathrm{t}=0$, possui discretização semanal.

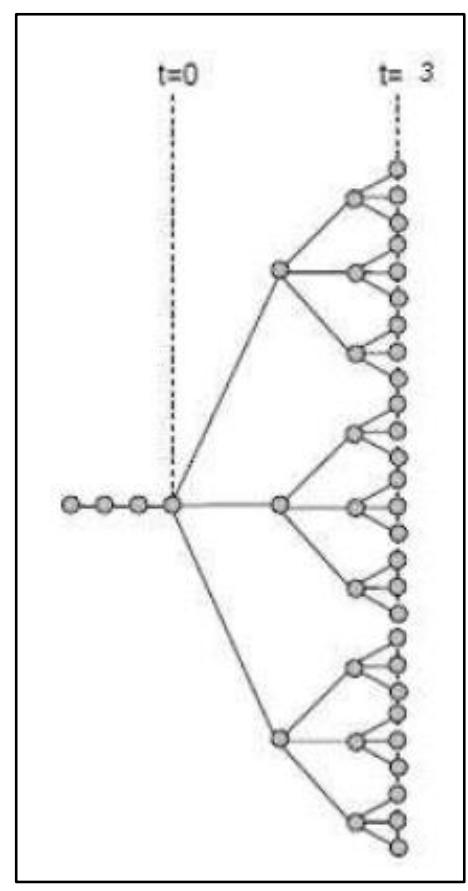

Figura 13. Árvore de cenários (Fonte: ONS, 2004) 
Desta forma, percebe-se que a dimensão da árvore cresce exponencialmente ao longo do período de estudo. Para o exemplo ilustrado na figura 13, considerando um período de planejamento de $\mathrm{T}=60$ meses (5 anos), a dimensão da árvore seria de $3^{59}$. Assim, considerando que a resolução do problema estocástico deve percorrer toda a árvore, a solução pode se tornar inviável do ponto de vista computacional, tornando-se necessária a utilização de uma subárvore, proveniente da árvore inicial.

A seleção de uma subárvore pode ser obtida por diferentes metodologias, tais como por sorteio ou por métodos de agrupamento, que são melhores abordados no item Redução de Cenários, mais a diante.

A construção das aberturas dos cenários costuma ser dividido em duas categorias: geração de cenários Forward, e geração de cenários Backward, apresentadas a seguir.

\section{Geração de Cenários Forward}

Para a simulação forward, a geração das séries é feita de forma sequencial, onde $Z_{t}$ é obtido a cada instante $t$ como uma função dos valores passados e da atribuição do ruído branco. A partir de cada nó é gerado apenas um valor de afluência. A geração é feita de forma direta até o final do horizonte, sendo que apenas um afluência para cada "folha" da árvore é utilizado a cada período e série. A Figura 14 ilustra o processo de geração das séries forward, ao se considerar o ponto de início da geração.

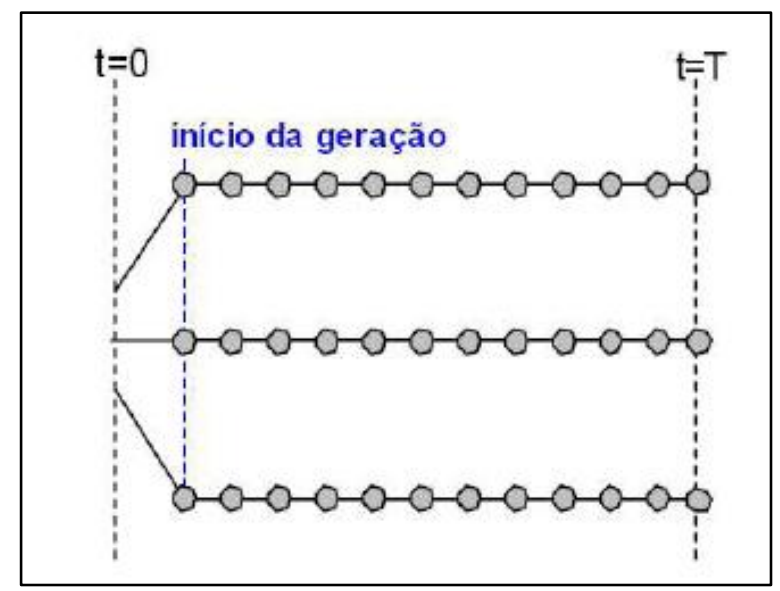

Figura 14. Geração para a simulação Forward (Fonte: ONS, 2004) 
No caso de se partir de um nó inicial, e se realizar uma única abertura, e a partir desse ponto se gerar cenários de modo forward é também conhecido como geração pente ou garfo, pois se usa apenas uma afluência em cada série para gerar o cenário do estágio seguinte. (Exemplo, ver figura 14, entre $t=0$ e $t=T)$.

\section{Geração de Cenários Backward}

$\mathrm{Na}$ simulação backward, a geração dos cenários também é feita de forma sequencial, no entanto, é utilizado, para cada nó, um número maior de valores de afluência a cada período e série. Esses valores determinam as aberturas. Essas aberturas são geradas de modo semelhante à geração forward para aquela série e estágio. A Figura 15 apresenta a sequência de geração de aberturas da simulação backward. Assim como na geração dos cenários da forward, na geração backward também são gerados sequencialmente até 0 final do período de estudo, fazendo um sorteio de ruído para cada estágio e utilizando os valores passados.

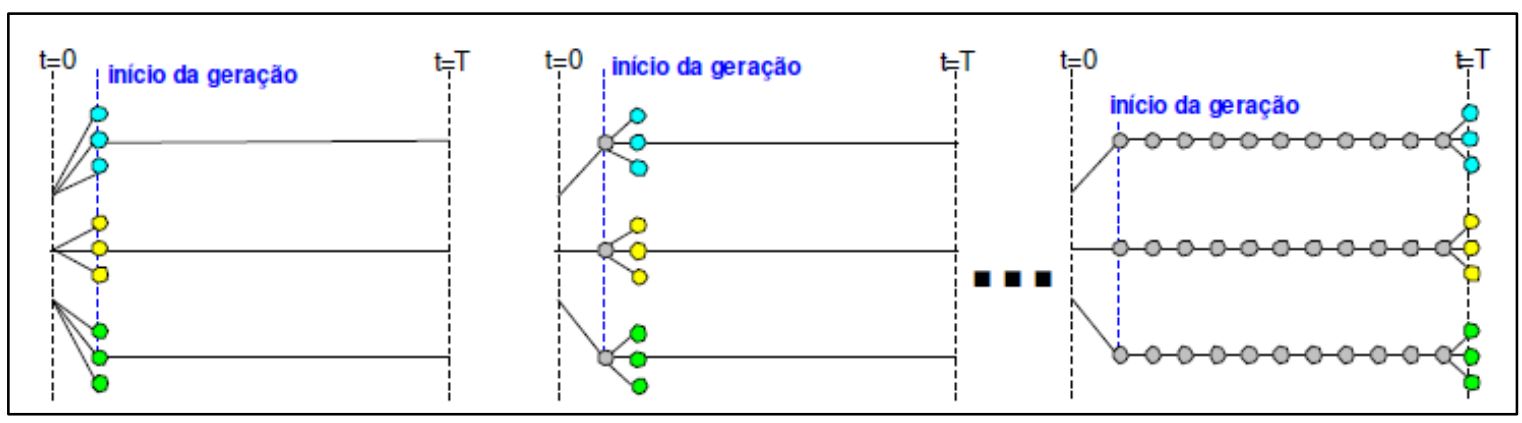

Figura 15. Sequência de geração para a geração Backward (Fonte: ONS, 2004)

Sendo assim, para cada uma das i séries forward de cada estágio t são geradas $n$ aberturas, conforme ilustrado na Figura 16, onde no aberturas $=3$. 


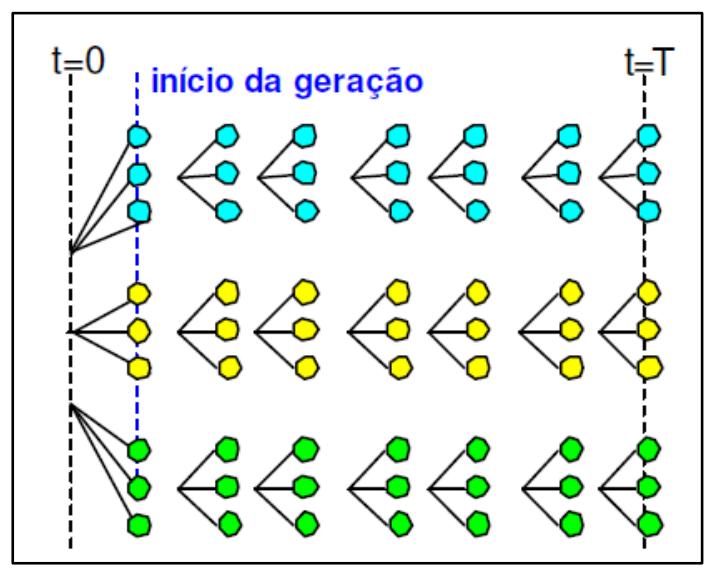

Figura 16. Geração em paralelo para a simulação backward (Fonte: ONS, 2004)

Em resumo, é realizado uma seleção de ruídos para cada etapa do passo forward e uma seleção de ruídos para cada etapa do passo backward, sendo que a mesma seleção é utilizada para gerar as aberturas de todas as séries forwards. Os vetores de ruídos resultantes do processo de seleção não são mais tratados como equiprováveis.

A probabilidade do cenário de vazão afluente é, então, igual à probabilidade do vetor de ruídos resultante a partir do qual ele foi gerado.

Resumidamente, a construção da árvore de cenários, para o caso da aplicação da distribuição Log Normal aos ruídos, consiste nas seguintes etapas:

- Seleção dos vetores de ruídos normais independentes da backward para todos os estágios;

- Aplicação da matriz de carga para correlacioná-los espacialmente;

- Aplicação da distribuição log-normal para evitar a geração de cenários negativos;

- Calculo da previsão, a partir do histórico, para todos os cenários forward;

- Calcula a previsão, a partir das forward, para todas as aberturas backward;

- Geração dos cenários backward adicionando os ruídos à previsão backward;

- Geração dos cenários forward adicionando todos os ruídos da backward à previsão forward. 
Os cenários sintéticos são gerados de forma multivariada e deve ser tomado 0 cuidado para que não sejam gerados valores negativos para as afluências. Para tanto, é ajustada uma distribuição log-normal três parâmetros à parcela aleatória do modelo PAR (p).

Os modelos estocásticos podem gerar, assim, tantas séries sintéticas (e consequentemente cenários) quanto se queira, uma vez conhecidos: os valores dos parâmetros do modelo, as variáveis de estudo, além de se inserir a semente aleatória, também conhecida como ruído.

\section{Redução de Cenários}

Assim como mencionado, a consideração de um número elevado de cenários acarreta em um número muito grande de variáveis envolvidas e ocasiona em dificuldades na resolução do problema da otimização. Uma possível solução consiste na aplicação de técnicas específicas para reduzir a complexidade do problema.

Uma destas técnicas se baseia em decompor o problema tratado em problemas menores e mais simples, que são chamados de problemas locais, seja através da decomposição por preços ou por recursos. No entanto, há situações em que tais decomposições não são suficientemente eficazes, já que não conseguem contornar a inviabilidade computacional do problema decomposto. Neste caso, uma alternativa é a redução dos dados incertos, isto é, reformular o problema desconsiderando alguns possíveis eventos e descartando cenários $\mathbf{w} \in \Theta$ (Oliveira, 2011).

Geralmente, o número de cenários em árvores de cenarização cresce exponencialmente com o número de etapas consideradas, originando, assim, problemas no processamento de um número tão grande de dados e na perda da eficiência dos programas de otimização. Isto remete aos métodos de redução do número de cenários ou na discretização do processo estocástico, de modo que o problema possa ser resolvido com um número adequado de cenários sem alterar significativamente a solução (Sigurbjörnsson, 2008). 
Existem diversos métodos que propõem construir uma árvore de cenários de tamanho controlado. Penna (2009) fez uma extensa e completa revisão das técnicas de redução de cenários. Deste, podem-se destacar os trabalhos mencionados abaixo.

Latorre et al (2007) apresentam métodos para construção da árvore de cenários a ser utilizada em problemas de otimização estocástica. Após a construção da árvore são aplicadas técnicas para agrupar cenários com o intuito de reduzir cardinalidade do problema. Em todos os métodos sugeridos há problemas para preservação da correlação temporal do processo.

Em Heitsh et Romish (2001) é sugerida a utilização de métricas probabilísticas, tal como a métrica de Fourtet-Mourier, para a determinação da redução ótima de cenários a ser aplicada em algoritmos de programação estocástica.

Segundo Oliveira (2007), as métricas probabilísticas são muito utilizadas no ambiente estocástico para avaliar a proximidade entre os cenários de realização aleatória, cujo desenvolvimento teórico parte do caso contínuo.

Outros trabalhos que também seguem esta linha são Dupacová et al. (2000) e Growe-Kuska et al (2003). O processo modelado nestes trabalhos não apresenta correlação temporal, portanto o método proposto não garante que essas correlações sejam preservadas na árvore reduzida.

Segundo Penna (2009), técnicas de agregação de cenários são utilizadas com o intuito de gerar uma árvore de cenários hidrológicos multivariados com boa representatividade do processo estocástico das afluências e baixa cardinalidade.

Oliveira (2007) apresentou a formulação da Redução Ótima de Cenários $(R O C)$, fundamentada na minimização da diferença entre os valores funcionais ótimos, correlacionando com o problema de transporte de Monge-Kantorovich, considerando como custo de transporte as probabilidades de ocorrência de cada cenário, e como distâncias entre as localidades de carga e descarga, as distâncias entre cenários. Segundo este autor, a técnica de redução ótima de cenários é uma ferramenta eficiente para selecionar cenários suficientemente representativos, proporcionando boa aderência estatística entre o grupo e o 
subgrupo de cenários de vazões afluentes. Além do mais, o uso da métrica de Fortet-Mourier para definir o problema de ROC e selecionar um subgrupo de cenários, a partir de uma árvore original com muitos cenários, permite eliminar redundâncias de informações, e reduzir significativamente o tempo de processamento computacional.

Costa (2007) apresenta uma proposta para tratamento das incertezas em modelos de programação estocástica baseada em árvore de cenários de tamanho limitado, porém representativa. Para reduzir a dimensionalidade do espaço de estados é utilizado o método dos componentes principais antes de empregar técnicas para definir uma amostra representativa. São avaliados diversos métodos para a geração da árvore de cenários, entre eles o método do reticulado. $O$ trabalho concentra-se na geração de árvores para 0 planejamento de curto-prazo, que tem um horizonte bem menor do que o planejamento de médio prazo.

Segundo Penna (2009), resumidamente, as técnicas de redução podem ser divididas em:

1. Técnicas de Seleção de Cenários

a) Métodos de Agrupamento

i. Métodos Hierárquicos

ii. Métodos Não Hierárquicos

b) Método K-MEANS

2. Técnicas de Amostragem
a) Amostragem por Hipercubo Latino
b) Amostragem Descritiva
c) Quase-Monte Carlo 


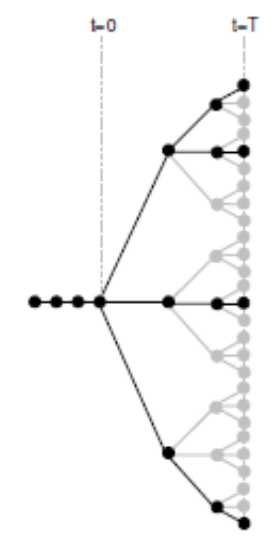

Figura 17. Exemplo de Sub Árvore de cenários por sorteio (Penna, 2009)

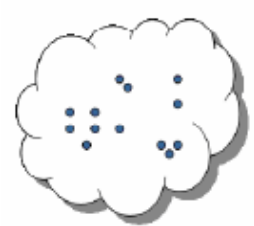

Equiprovável

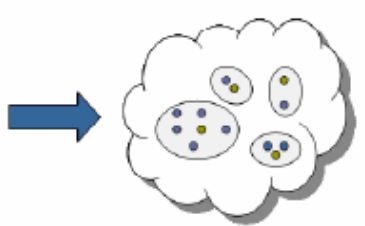

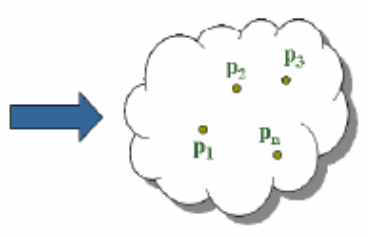

Năo equiprovável

Figura 18. Aplicação do Procedimento de Agregação (Penna, 2009)

O enfoque do processo de redução de cenários consiste em se determinar técnicas para reduzir a dimensionalidade dos cenários definindo o problema de otimização. O objetivo é tentar eliminar redundâncias e semelhanças de informações, reduzindo assim a dimensionalidade da árvore de cenários, de modo que a árvore reduzida obtida represente acuradamente o processo estocástico, e que seja viável em termos de tempo computacional. Assume-se aqui, "redundância" como sendo a ocorrência de eventos próximos, ou seja, eventos considerados "parecidos" segundo alguma métrica probabilística. Deseja-se ainda que os cenários resultantes respeitem propriedades estatísticas relevantes da distribuição multivariada das vazões de cada etapa de sua condição inicial, em particular as médias e covariâncias condicionadas.

Para a análise da eficiência do processo, segundo Kaut et Wallace (2007), deve-se julgar uma árvore de cenários pela qualidade da decisão que esta nos fornece. Assim, não se deve preocupar apenas sobre o quão boa a distribuição se aproxima, contudo que a arborização de cenários forneça uma boa decisão. Deste modo, quando comparados diferentes técnicas, o foco está no desempenho prática, e não apenas nas propriedades teóricas. 


\subsection{A Operação do Sistema Interligado Nacional}

A cadeia de modelos adotada para o planejamento da operação do SIN pode ser subdividida em dois tipos: modelos hidrológicos, que realizam as previsões das vazões e geram os cenários de vazões e energia natural afluente (Previvazh, Previvazm, Previvaz, Gevazp) e os modelos de otimização energética (Newave, Decomp, Dessem-PAT), sendo o Newave e o Decomp os modelos estocásticos de programação utilizados para formulação da política operativa no médio (intervalos mensais) e no curto prazo (semanais), respectivamente, e o Dessem-PAT um modelo determinístico de programação não linear e de curtíssimo prazo. Esta cadeia de modelos de otimização foi desenvolvida pelo Centro de Pesquisas de Energia Elétrica (CEPEL).

Além do mais, com a retomada dos estudos de planejamento da expansão pelo Ministério de Minas e Energia (MME) e pela Empresa de Pesquisa Energética (EPE), o modelo NEWAVE vem sendo utilizado para auxiliar na elaboração dos Planos Decenais de Energia (PDE).

No âmbito do planejamento da operação energética a modelagem é por sua vez subdividida em diversos problemas, e, em cada um destes é considerado um horizonte de planejamento específico, assim como acontece com a representação da estocasticidade das afluências e das não linearidades do problema, que apresentam diferentes graus de detalhamento (Oliveira, 2013). Desta forma, o problema é desagregado em horizontes temporais, de acordo com as principais decisões a serem tomadas e o nível de representação do sistema. A figura 19 a seguir ilustra a discretização das análises e dos horizontes de planejamento correspondentes. De modo geral, quanto mais distante o horizonte de tomada de decisão, maior é a necessidade de consideração das incertezas associadas ao problema e menor o grau de detalhamento na representação do sistema. 


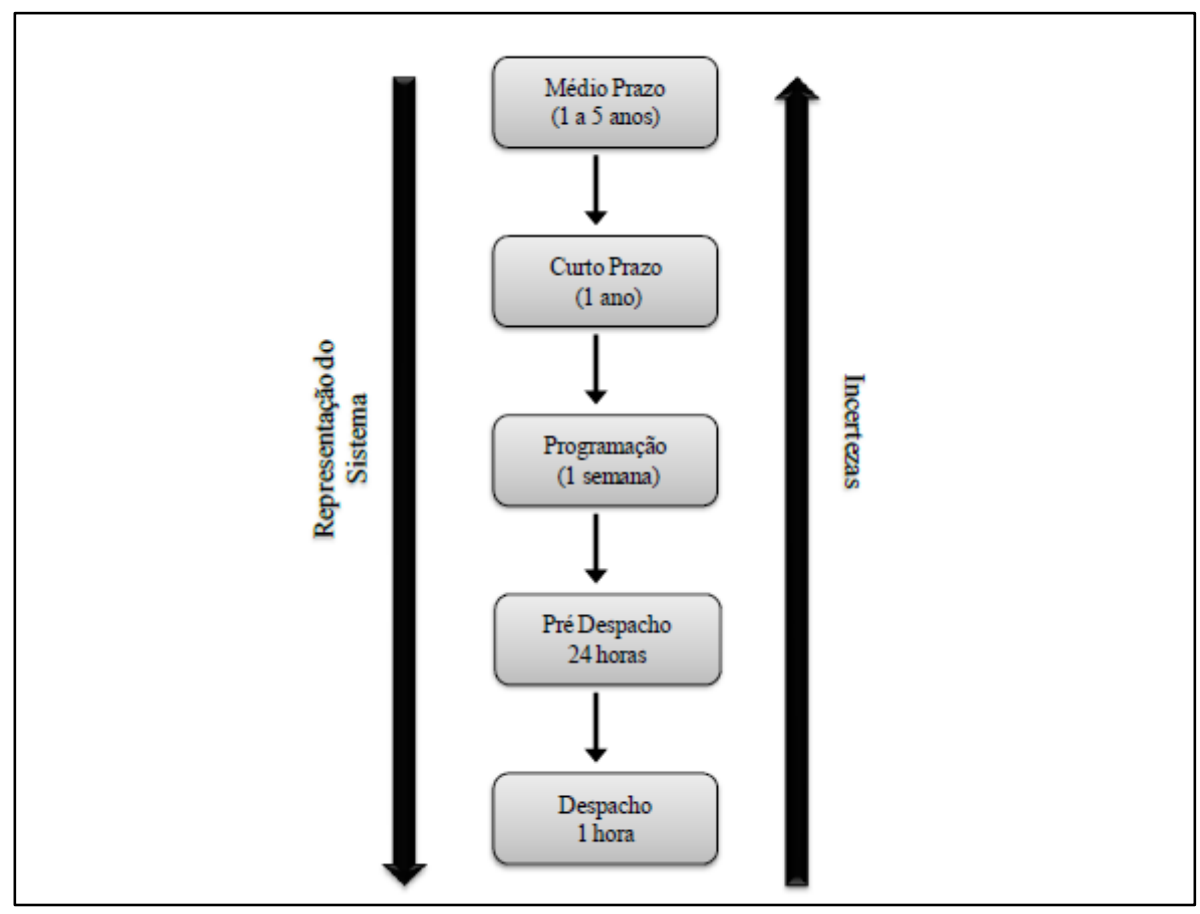

Figura 19. Representação das Incertezas e do Detalhamento dos Sistemas (Fonte: Oliveira, 2013)

Mais especificamente ao planejamento da operação de médio prazo, cujo programa base é o NEWAVE, o horizonte de estudo é de cinco anos, discretizado em etapas mensais.

O Programa NEWAVE resolve o problema de planejamento da operação interligada de sistemas hidroelétrico empregando a técnica de programação dinâmica dual estocástica - PDDE (Maceira et al, 2002).

O NEWAVE busca minimizar o valor esperado do custo da operação, considerando o custo presente do combustível e o chamado custo futuro da água, e considera a estocasticidade de modo implícito. Como resultados ele decide mensalmente, para um horizonte de cinco anos, o quanto de energia deve ser produzida pelo sistema hidrelétrico e o quanto deve ser produzido pelo sistema térmico para atender á demanda prevista no período. As variáveis de decisão são a geração hidrelétrica, a geração térmica e o intercâmbio de energia entre os subsistemas (Zambon, 2008).

O NEWAVE considera a aleatoriedade das vazões afluentes através de funções de distribuição de probabilidades e aplica técnicas de otimização clássicas baseadas em programação dinâmica estocástica. Essas abordagens 
são amplamente utilizadas em problemas de planejamento hidrotérmico por serem capazes de considerar, além das incertezas das vazões, as não linearidades do problema (CEPEL, 2012). Entretanto, devido ao crescimento exponencial do tempo computacional com a dimensão do sistema, o NEWAVE faz uma simplificação da representação do sistema, agregando múltiplos reservatórios em um equivalente energético, e/ou no procedimento de resolução, através de linearizações, como por exemplo, na utilização da decomposição de Benders.

Segundo Zambon (2008), a simplificação mencionada quanto aos subsistemas consiste em dividir o sistema brasileiro em quatro grandes subsistemas equivalentes: Norte, Nordeste, Sudeste/Centro-Oeste e Sul. Cada subsistema é formado por um grande reservatório de energia, com volume equivalente á somatória da "energia armazenada" em cada região. O método dos subsistemas equivalentes é adotado para viabilizar o emprego da técnica PDDE, evitando a chamada "praga da dimensionalidade". Os resultados do modelo NEWAVE servem como dados de entrada para o modelo DECOMP, que é processado para um horizonte de tempo menor e desagrega os subsistemas equivalentes em usinas individualizadas. Isto é, o DECOMP decide o quanto será produzido por cada usina de geração do sistema brasileiro a partir das variáveis de decisão produzidas pelo NEWAVE.

Em relação à estocasticidade hidrológica, a árvore completa de cenários do NEWAVE possui cardinalidade bastante elevada (2000 cenários). Por isso, de forma a viabilizar computacionalmente o processo de otimização do NEWAVE, somente uma parte dessa árvore (sub-árvore) é utilizada, construída de forma que se consiga uma boa representação do processo estocástico de afluências. Na versão atual do NEWAVE essa sub-árvore é "extraída" da árvore original utilizando Amostragem Aleatória Simples (AAS) (Silva, 2010). Ou seja, a árvore de cenários escolhida ocorre de forma aleatória e representa uma pequena porção da árvore completa de cenários. Segundo (Penna, 2009) esse método se mostrou pouco robusto com relação à estabilidade de resultados quando são alterados parâmetros utilizados na construção da árvore. Adicionalmente, este método de geração apresenta grande instabilidade na reprodução das médias, desvios-padrão e correlações cruzadas históricas de vazões naturais 
afluentes. Mesmo considerando um maior número de cenários forward, mostrou-se que o ganho é pequeno, analisando-se a representatividade da série de ruídos. Uma alternativa para melhorar a instabilidade referida acima, segundo Penna (2009), seria aumentar o tamanho da amostra backward, o que acarretaria em um aumento significativo no tempo computacional necessário para solução do problema.

O gerador de números aleatórios utilizado no NEWAVE é o gerador congruolinear (LCG) do tipo multiplicativo. Este gerador parte de um único valor inicial para gerar todos os números aleatórios, porém a geração de cada etapa depende do valor gerado na etapa anterior, por isso ele é denominado de congruo-linear (Penna, 2009). Este gerador é regido pela seguinte equação:

$$
X_{n}=\left(a x_{n-1}+c\right) \bmod N
$$

Onde a e c são números inteiros positivos e a notação mod $\mathrm{N}$ representa $\mathrm{O}$ resto da divisão por $\mathrm{N}$.

Sendo assim, a geração de todos os números só depende de um valor inicial $\left(x_{0}\right)$, também conhecido como semente.

No NEWAVE, os parâmetros da equação (29) já foram pré-estabelecidos. O parâmetro c é nulo, o parâmetro $\mathrm{N}$ equivale a 231 , e o parâmetro a equivale a $2^{16}+3$.

Estes ruídos são gerados de maneira uniforme e após a geração eles são normalizados, partindo-se da premissa de que na geração dos cenários através da modelagem autorregressiva, o ruído deve possuir uma distribuição normal com média zero e uma certa determinada variância. 


\section{Estudos de Caso}

Os presentes estudos de caso visam à aplicação e análise de técnicas de cenarização de vazões no planejamento estocástico da operação hidroenergética.

Para isso utilizou-se como base a modelagem de otimização hidroenergética determinística aplicada no Sistema de Suporte à Decisão (SSD) HIDROTERM, elaborado por Zambon (2008), descrito no item 4.2. A partir do algoritmo presente nesse SSD, foi feita sua adequado à otimização estocástica, ou seja, considerando deferentes cenários prováveis de vazões. Além do mais, foi aplicada uma técnica de redução de árvores de cenários (apresentada em maiores detalhes no item 5.8) ao algoritmo de otimização estocástica desenvolvido.

O SSD HIDROTERM se encontra atualmente em fase de adequação à modelagem estocástica (Zambon, 2013), não considerando, no entanto análises estocásticas complexas. A escolha deste SSD como base para a aplicação das técnicas estocásticas se baseou no fato de se tratar de um modelo com formulações teóricas explícitas e completas. Este modelo não agrega os sistemas de reservatórios e trabalha com Programação Não Linear (PNL). Além do mais a linguagem de modelação do software GAMS, utilizado como plataforma para o HIDROTERM, permite a aplicação da técnica de redução de cenários proposta, explicada mais detalhadamente no item 5.8.

Assim, os objetivos dos estudos de caso propostos consistem em verificar a aplicabilidade do modelo HIDROTERM frente à abordagem estocástica de cenários de vazões, de analisar a sensibilidade e o impacto de diferentes condições de árvores de cenários nos resultados esperados da operação hidrelétrica.

Ressalta-se que o foco destes estudos consiste na aplicação de técnicas de otimização estocástica dentro do horizonte de planejamento de médio e longo prazo, mais especificamente entre 2 a 4 anos, com intervalos de discretização mensal. 


\subsection{Justificativa dos Estudos de Caso propostos e Critérios adotados para a seleção de casos}

O processo de otimização estocástica da geração hidroelétrica possui por si mesmo uma série de incertezas, inerentes às variáveis e processos envolvidos.

Primeiramente, destacam-se as incertezas envolvidas nas séries históricas de vazões provenientes do ONS, que, mesmo se tratando de séries consistidas, possuem implícitas uma série de procedimentos matemáticos teóricos de transferência de vazões entre diferentes bacias e de preenchimentos de falhas.

Em segundo lugar, o processo de calibração de um modelo estocástico PAR (p) e a geração de séries sintéticas de vazões médias mensais também é um tema de intensas discussões e, como qualquer modelo, possui suas limitações.

Existem ainda simplificações envolvendo o processo de otimização da geração hidrelétrica, principalmente em relação à: utilização de valores médios de evapotranspiração, quantificação das paradas nas turbinas, tanto para manutenção quanto reparo dos equipamentos eletromecânicos (que podem limitar ou interromper a geração), e previsão da demanda por eletricidade.

A etapa de redução de cenários acrescenta uma nova incerteza ao processo, principalmente em relação à manutenção das propriedades estatísticas do universo total/original de cenários de vazões afluentes pelo modelo de redução utilizado.

Visando não incorporar novas variáveis além daquelas propostas na presente dissertação, decidiu-se, nas análises realizadas, não incorporar as incertezas inerentes à outras variáveis do processo, tal como a dependência espacial entre as séries de vazões de diferentes usinas. Contudo, no caso de estudos que considerem usinas em cascata, e até mesmo no caso do SIN, estas variáveis devem ser consideradas.

Além do mais, cada estudo de caso se baseou na otimização estocástica da geração hidrelétrica em usinas individualizadas, de modo independente e isoladas. 
A escolha das usinas hidrelétricas contempladas nos estudos de caso teve como principais critérios:

- Ausência de UHEs / reservatórios de relevância a montante do aproveitamento hidrelétrico selecionado, ou seja, cuja previsão de vazões não dependa do regime de operação de outras UHEs / reservatórios. Assim, evita-se recair na análise da dependência espacial entre diferentes séries sintéticas de vazões;

- Usinas com capacidade de reservação / acumulação de água, ou seja, que não sejam a fio d'água;

- Preferencialmente UHEs com Potência Instalada superior a 100 MW;

- UHEs que estejam em diferentes bacias hidrográficas brasileiras;

- UHEs cujas séries históricas sejam estacionárias.

Deste modo, foram selecionadas seis UHEs, distribuídas ao longo de diferentes bacias hidrográficas, que seguem.

1. UHE G.B. Munhoz (Foz do Areia)

2. UHE Nova Ponte

3. UHE Três Marias

4. UHE Irapé

5. UHE Serra da Mesa

6. UHE Balbina

A figura 20 ilustra as UHEs selecionadas dentro do território nacional. 


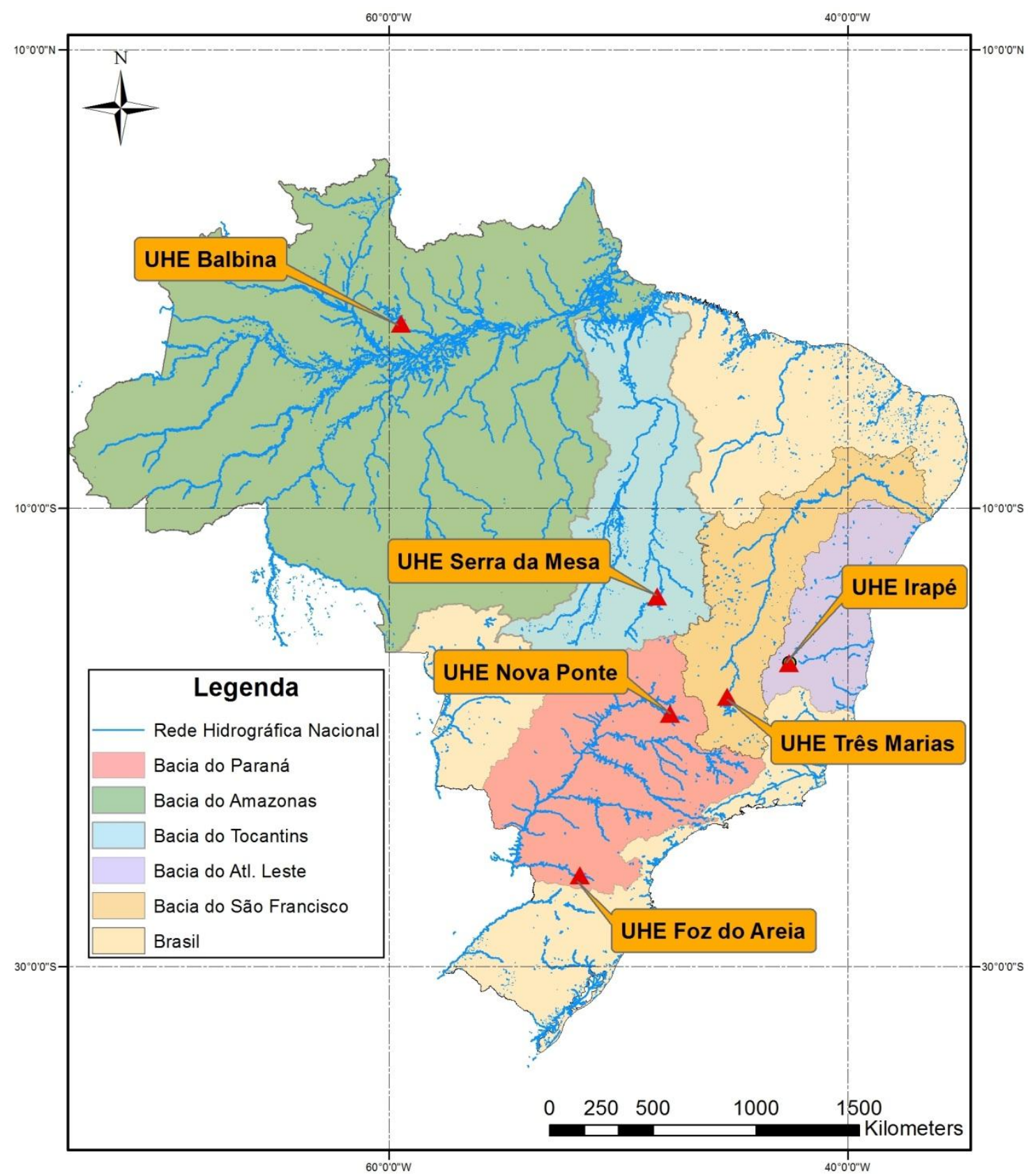

Figura 20. Localização das UHEs selecionadas

\subsection{Descrição Geral das UHEs consideradas}

\subsubsection{UHE Foz do Areia}

A Usina Governador Bento Munhoz da Rocha Netto, anteriormente denominada Usina Foz do Areia, é a maior usina da Copel (concessionária dessa usina) e está localizada no rio Iguaçu, Estado do Paraná, município de Pinhão, distante $5 \mathrm{~km}$ a jusante da foz do rio Areia a $240 \mathrm{~km}$ de Curitiba. 
O rio Iguaçu é um afluente do rio Paraná consiste no maior rio do estado do Paraná. Seu curso segue o sentido geral leste a oeste, com algumas partes servindo de divisa natural entre o Paraná e Santa Catarina, bem como em certo trecho do seu baixo curso, que faz fronteira entre o Brasil e Argentina.

A UHE Foz do Areia possui 1.676 MW de potência instalada e garantia física de $576 \mathrm{MW}$ (Aneel, 2014). Atualmente, essa UHE opera com quatro unidades geradoras de 419 MWméd de potência cada (Copel, 2013).

A bacia hidrográfica do rio Iguaçú, no eixo deste aproveitamento, é de cerca de $29.800 \mathrm{~km}^{2}$ e sua vazão média natural é de $544 \mathrm{~m}^{3} / \mathrm{s}$ (Copel, 2013). A barragem, construída de enrocamento compactado com face de concreto, possui $160 \mathrm{~m}$ de altura e $828 \mathrm{~m}$ de comprimento, e consistiu na primeira barragem construída com esta tecnologia no Brasil e uma das maiores do mundo deste gênero. O vertedouro, tipo calha escavada a céu aberto, foi projetado para uma descarga máxima de $11.000 \mathrm{~m}^{3} / \mathrm{s}$ (Copel, 2013).

A usina Foz do Areia possui dois objetivos principais: o da criação de um reservatório (área de $139 \mathrm{~km}^{2}$ e volume útil de $3.805 \mathrm{Hm}^{3}$ ) regulador de vazões a montante das demais usinas hidrelétricas localizadas no rio Iguaçu; além da geração de energia elétrica em si.

\subsubsection{UHE Nova Ponte}

A Usina Hidrelétrica de Nova Ponte está localizada na Bacia Hidrográfica do Rio Araguari, no município de Nova Ponte (MG). Sua capacidade instalada é de 510 MW e garantia física de 276 MWméd (Aneel, 2014), com geração realizada através de 3 unidades geradoras.

Tendo entrado em operação em 1994, sua barragem tem $142 \mathrm{~m}$ de altura máxima e $1620 \mathrm{~m}$ de comprimento, sendo considerada a maior usina hidrelétrica presente no rio Araguari. O reservatório possuí uma área de cerca de $443 \mathrm{~km}^{2}$ e o volume útil é de cerca de $10.380 \mathrm{Hm}^{3}$ (Cemig, 2013).

O Rio Araguari nasce no Parque Nacional da Serra da Canastra, no município de São Roque de Minas e percorre $475 \mathrm{Km}$ até a sua foz no Rio Paranaíba, sendo, integrante a Bacia do Rio Paraná (CBAraguari, 2014). 
Assim como no caso da UHE Foz do Areia em relação ao rio Iguaçú, a UHE Nova Ponte possui um importante papel de regularizar as vazões do rio Araguari através de seu reservatório e, assim, otimizar a geração hidrelétrica nesse rio.

\subsubsection{UHE Três Marias}

A Usina Bernardo Mascarenhas, ou UHE Três Marias, está localizada no rio São Francisco, estado de Minas Gerais. É administrada pela Cemig - Centrais Elétricas de Minas Gerais, sendo a primeira usina construída por essa empresa.

A Usina Hidrelétrica Três Marias foi inaugurada em 1962, sendo um dos primeiros grandes empreendimentos hidráulicos do país. Além da geração hidrelétrica esta usina possui outras finalidades, tais como controle da vazão do rio São Francisco, irrigação, turismo e lazer. Sua barragem usina possui 75 metros de altura e seu reservatório possui uma área de $1.040 \mathrm{Km}^{2}$ e um volume útil de cerca de $15.278 \mathrm{Hm}^{3}$. A UHE Três Marias possui 6 turbinas geradoras, totalizando uma potência instalada de 396 MW (Cemig, 2013).

O rio São Francisco consiste em um dos principais rios brasileiros, tanto do ponto social, econômico quanto cultural. Ao longo desse percurso, este banha cinco Estados, e é dividido conceitualmente em quatro trechos, estando o trecho entre sua nascente e a barragem de Três Marias localizado no Alto São Francisco.

A montante da UHE Três Marias se encontra a UHE Retiro Baixo (83,7MW), no rio Paraopeba, afluente do rio São Francisco. O reservatório da UHE Retiro Baixo possui uma capacidade de regularização de $41 \mathrm{Hm}^{3}$, com capacidade de regularização principalmente horária ou diária. Este volume foi considerado desprezível em relação ao volume da UHE Três Marias, validando a utilização da UHE Três Marias para o presente estudo de caso.

\subsubsection{UHE Irapé}

A UHE Irapé, ou Usina Hidrelétrica Presidente Juscelino Kubitschek, se situa no rio Jequitinhonha, bacia do Atlântico Leste, na região nordeste do estado de Minas Gerais. 
O Jequitinhonha é um rio federal que percorre uma extensão de $1.082 \mathrm{~km}$, da nascente no Pico do Itambé, na Serra do Espinhaço, nos arredores da localidade de Capivari, sopé do Morro Redondo, até o Oceano Atlântico, onde deságua em Belmonte, no estado da Bahia (Cemig, 2013).

A usina Irapé possui 360 MW de potência instalada e 206 MWméd de garantia física (ANEEL, 2014), foi inaugurada em 2006 e é operada pela Companhia Energética de Minas Gerais (CEMIG). Seu reservatório possui uma área de $137 \mathrm{~km}^{2}$ e volume útil de $3.696 \mathrm{Hm}^{3}$.

Segundo a Cemig, sua barragem, com 208 metros de altura e $540 \mathrm{~m}$ de comprimento, é a mais alta do país e a segunda maior da América do Sul. A casa de força é equipada com 3 unidades geradoras.

\subsubsection{UHE Serra da Mesa}

A Usina Hidrelétrica de Serra da Mesa, localizada na Bacia do Alto Tocantins, em Goiás, possui elevada importância no panorama energético brasileiro. Com a entrada em operação das suas três unidades geradoras, que totalizam 1.275 MW de potência instalada, a usina torna-se indispensável ao atendimento do mercado de energia elétrica do Sistema Interligado Sul/Sudeste/Centro-Oeste. Além disto, ela é responsável pela ligação entre esse sistema e o sistema Norte / Nordeste, sendo o elo da Interligação Norte-Sul (Furnas, 2012).

A usina de Serra da Mesa iniciou suas operações em 1998 e sua concessão para operação é detida por Furnas, que também a opera. Sua garantia física é de 671 MWméd (Aneel, 2014).

O reservatório dessa usina consiste em um dos maiores do Brasil em volume de água $\left(43.250 \mathrm{Hm}^{3}\right.$ ) e possui uma área de cerca de $1.784 \mathrm{~km}^{2}$. A regularização do rio Tocantins, promovida por seu reservatório, proporciona ganhos energéticos sobre as usinas localizadas a jusante (UHEs Tucuruí e Estreito).

Sua barragem, de enrocamento com núcleo de argila, possui $154 \mathrm{~m}$ de altura e é responsável pelo represamento do rio Tocantins. Durante sua operação o nível d'água do reservatório pode deplecionar até $43 \mathrm{~m}$. Sua casa de força, subterrânea, é equipada com 3 unidades geradoras. 


\subsubsection{UHE Balbina}

A UHE Balbina possui $250 \mathrm{MW}$ de potência instalada e foi inaugurada em 1989. É operada pela Eletrobrás Eletronorte, sendo a responsável pelo fornecimento de energia elétrica para maior parte de Manaus (AM), principalmente durante o período em que Manaus não pertencia ao SIN.

A Usina Hidrelétrica de Balbina está localizada no rio Uatumã, afluente do rio Amazonas pela sua margem esquerda, no município de Presidente Figueiredo (AM), precisamente no distrito de Balbina.

Em julho de 2013 a UHE Balbina, e a cidade de Manaus, se conectaram ao SIN, o que garantiu uma oferta de energia bem acima da demanda, com aumento de confiabilidade e robustez do atendimento à região (D24, 2013).

Cada uma das 5 unidades geradoras tem capacidade de geração de até 50 MW de energia elétrica, totalizando $250 \mathrm{MW}$.

A usina é criticada por seu elevado custo ambiental em relação à baixa potência instalada, uma vez que seu Volume Útil é de cerca de $10.224 \mathrm{Hm}^{3}$. Segundo a Folha de São Paulo (2007), a contribuição de gases de efeito estufa em Balbina é de cerca de dez vezes superior à emissão de uma termelétrica movida a carvão de potência igual à da hidrelétrica.

\subsection{Detalhamento da metodologia adotada para as UHEs selecionadas}

A metodologia adotada para os Estudos de Caso foi:

- Levantamento de dados das séries históricas de vazões naturais dos rios em estudo;

- Análise dos parâmetros estatísticos das séries históricas;

- Determinação do modelo estocástico adequado às séries históricas;

- Construção de árvores de cenários de vazões afluentes;

- Modelagem do algoritmo de redução de cenários e de otimização estocástica na linguagem do software GAMS;

- Aplicação do algoritmo de otimização estocástica aos parâmetros das UHEs em estudo;

- Análises de sensibilidade;

- Conclusões e Considerações Finais 
A figura 21 a seguir ilustra as etapas envolvidas em todo o processo estudado, desde a coleta de dados até a análise dos resultados da otimização estocástica. É descrito também a Interface utilizada para cada etapa (Internet / Excel / SAMS / GAMS).

O algoritmo de otimização estocástica, elaborado na linguagem do software GAMS é composto por um processo que envolve as seguintes ações: importar as séries de vazões geradas pelo modelo estocástico (SAMS), realizar a etapa de redução de cenários, exportar os resultados para uma planilha de excel (que adequa os dados para o formato adequado para a etapa de otimização), importar os dados da mesma planilha excel, realizar a etapa de otimização estocástica, e, por fim, exportar os resultados para uma outra planilha que organiza os resultados. Este processo é melhor detalhado no item 5.9 a seguir.

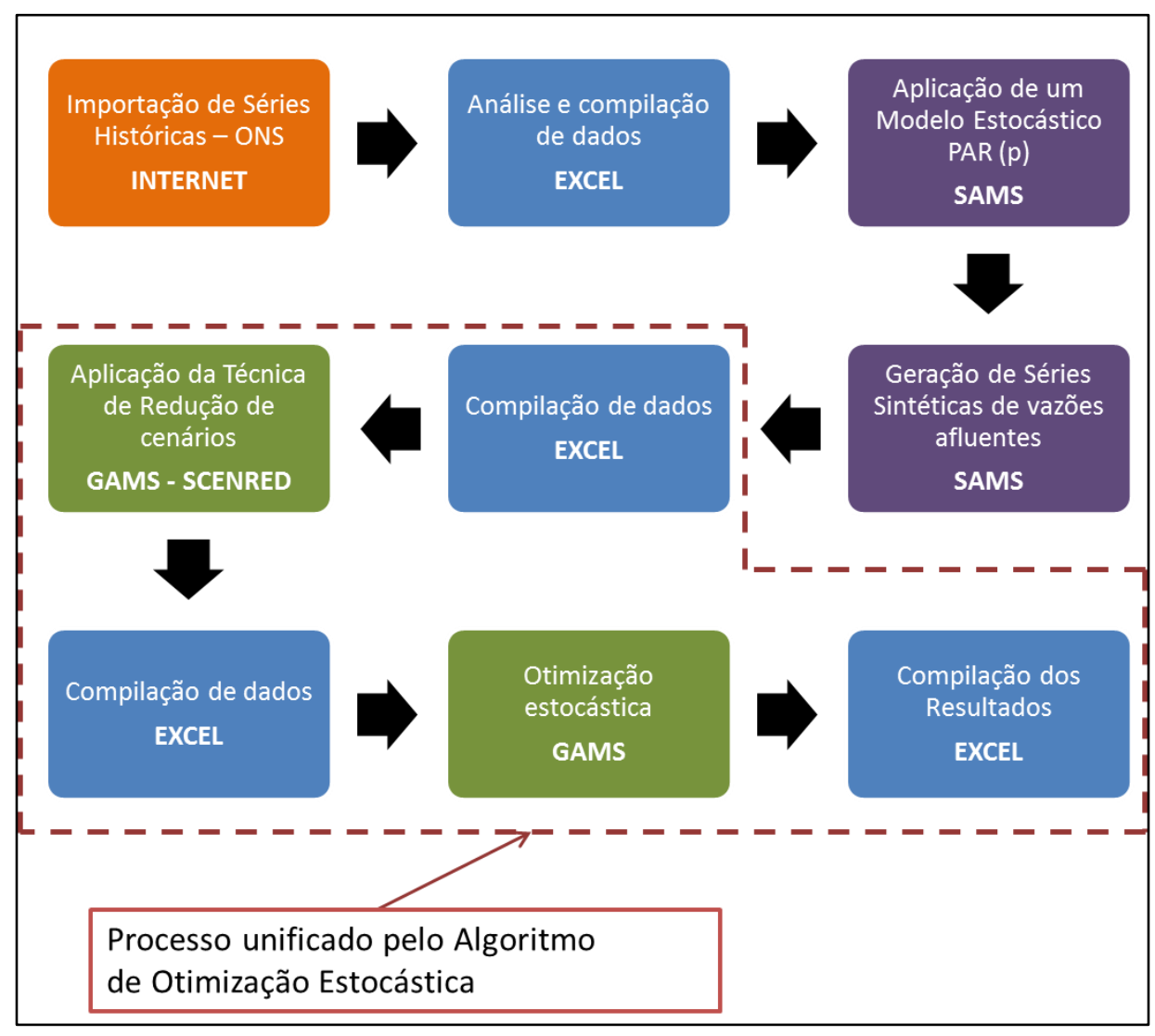

Figura 21. Etapas envolvidas no processo de otimização

A descrição de cada etapa é apresentada nos itens a seguir: 


\subsection{Levantamento de dados das séries históricas de vazões naturais das UHEs em estudo}

Para o estudo do comportamento hidrológico e a determinação dos parâmetros estatísticos que caracterizem as vazões nos locais das UHEs em estudo foram utilizadas as séries históricas de vazões naturais mensais, no período de Janeiro de 1931 a Dezembro de 2012, disponibilizadas pelo ONS.

Segundo o ONS, o termo vazão natural é utilizado por este órgão para identificar a vazão que ocorreria em uma seção do rio, se não houvesse as ações antrópicas na sua bacia contribuinte - tais como regularizações de vazões realizadas por reservatórios, desvios de água, evaporações em reservatórios e usos consuntivos (irrigação, criação animal e abastecimentos urbano, rural e industrial). A vazão natural é obtida por meio de um processo de reconstituição, que considera a vazão observada no local e as informações relativas às ações antrópicas na bacia.

\subsection{Análise dos parâmetros estatísticos das séries históricas}

As séries de vazões naturais disponibilizadas pelo ONS são consideradas consistidas, de modo que no presente estudo não foram realizadas análises complementares de consistência nessas séries.

No entanto, a análise das propriedades estatísticas das séries se mostra de vital importância para que se verifique a aplicabilidade dos modelos propostos. $\mathrm{Na}$ tabela 4 e nas figuras 22 a 28 a seguir são ilustrados os principais parâmetros estatísticos das séries analisadas. 
Tabela 4. Parâmetros Estatísticos das séries de vazões médias mensais analisadas

\begin{tabular}{|c|c|c|c|c|c|c|}
\hline UHE & Foz do Areia & Nova Ponte & Três Marias & Irapé & Serra da Mesa & Balbina \\
\hline Período de amostragem & \multicolumn{6}{|c|}{ De 1931 a 2012} \\
\hline Área de Drenagem $\left(\mathbf{k m}^{2}\right)$ & 29800 & 15480 & 50732 & 16200 & 50975 & 18450 \\
\hline Vazão específica (L/s.km²) & 22.0 & 19.3 & 13.6 & 9.3 & 15.2 & 32.4 \\
\hline \multicolumn{7}{|l|}{$\operatorname{Vazão~}\left(\mathrm{m}^{3} / \mathrm{s}\right)$} \\
\hline Média & 656 & 299 & 691 & 150 & 774 & 598 \\
\hline Máxima & 5150 & 1243 & 4435 & 1572 & 6163 & 2690 \\
\hline Mínima & 80 & 53 & 58 & 8 & 97 & 19 \\
\hline Desv. Pad & 495 & 199 & 605 & 174 & 690 & 410 \\
\hline Mediana & 513 & 231 & 453 & 80 & 527 & 487 \\
\hline Assimetria & 2.29 & 1.41 & 1.84 & 2.59 & 2.12 & 1.20 \\
\hline Coef. de Variação (\%) & 76 & 61 & 88 & 116 & 89 & 69 \\
\hline Permanência (\%) & \multicolumn{6}{|c|}{ Vazão (m³/s) } \\
\hline 1 & 2220 & 928 & 2730 & 851 & 3251 & 1849 \\
\hline 2 & 2056 & 862 & 2403 & 688 & 2775 & 1677 \\
\hline 3 & 1868 & 793 & 2223 & 622 & 2541 & 1535 \\
\hline 5 & 1636 & 704 & 1932 & 529 & 2132 & 1341 \\
\hline 10 & 1288 & 593 & 1493 & 367 & 1635 & 1163 \\
\hline 15 & 1084 & 509 & 1319 & 286 & 1386 & 1068 \\
\hline 20 & 942 & 434 & 1132 & 229 & 1217 & 944 \\
\hline 25 & 833 & 386 & 940 & 192 & 1050 & 829 \\
\hline 30 & 759 & 353 & 789 & 161 & 920 & 753 \\
\hline 35 & 681 & 311 & 673 & 135 & 810 & 670 \\
\hline 40 & 628 & 284 & 593 & 113 & 691 & 596 \\
\hline 45 & 562 & 253 & 530 & 96 & 619 & 542 \\
\hline 50 & 513 & 231 & 453 & 80 & 527 & 487 \\
\hline 55 & 481 & 214 & 403 & 70 & 481 & 444 \\
\hline 60 & 437 & 193 & 361 & 60 & 419 & 386 \\
\hline 65 & 396 & 179 & 327 & 52 & 366 & 341 \\
\hline 70 & 351 & 165 & 297 & 47 & 325 & 303 \\
\hline 75 & 312 & 154 & 272 & 41 & 288 & 274 \\
\hline 80 & 280 & 141 & 244 & 37 & 252 & 247 \\
\hline 85 & 252 & 130 & 213 & 31 & 224 & 213 \\
\hline 90 & 207 & 114 & 187 & 27 & 192 & 183 \\
\hline 95 & 170 & 95 & 154 & 22 & 153 & 150 \\
\hline 98 & 132 & 82 & 119 & 18 & 129 & 118 \\
\hline 100 & 80 & 53 & 58 & 8 & 97 & 19 \\
\hline
\end{tabular}




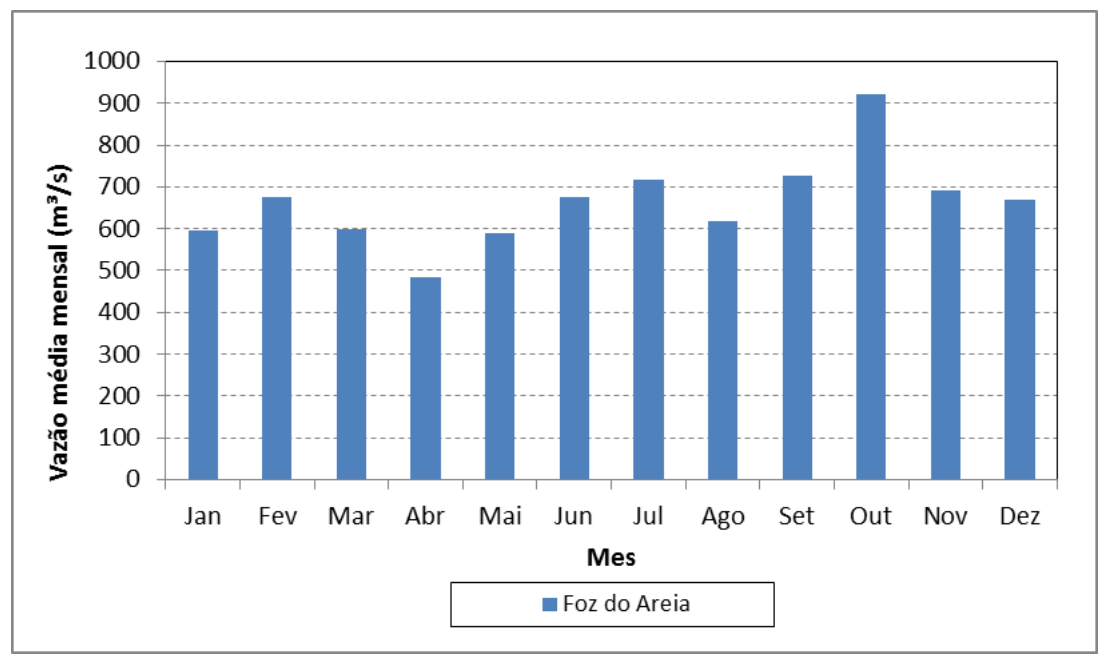

Figura 22. Vazões médias mensais no rio Iguaçú, na UHE Foz do Areia

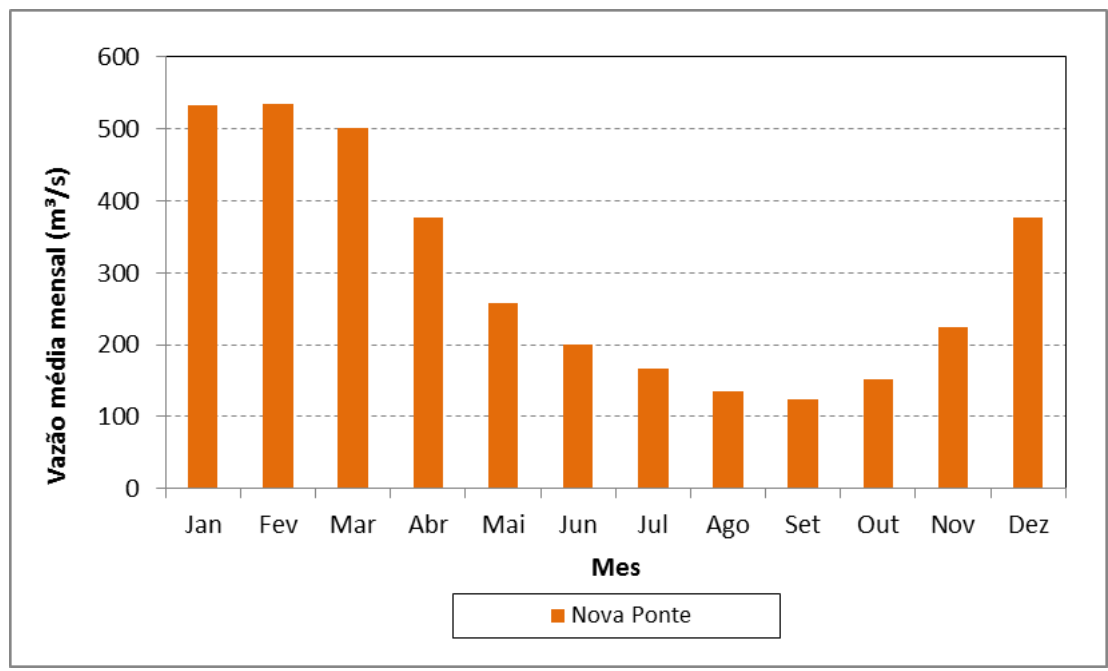

Figura 23. Vazões médias mensais no rio Araguari, na UHE Nova Ponte

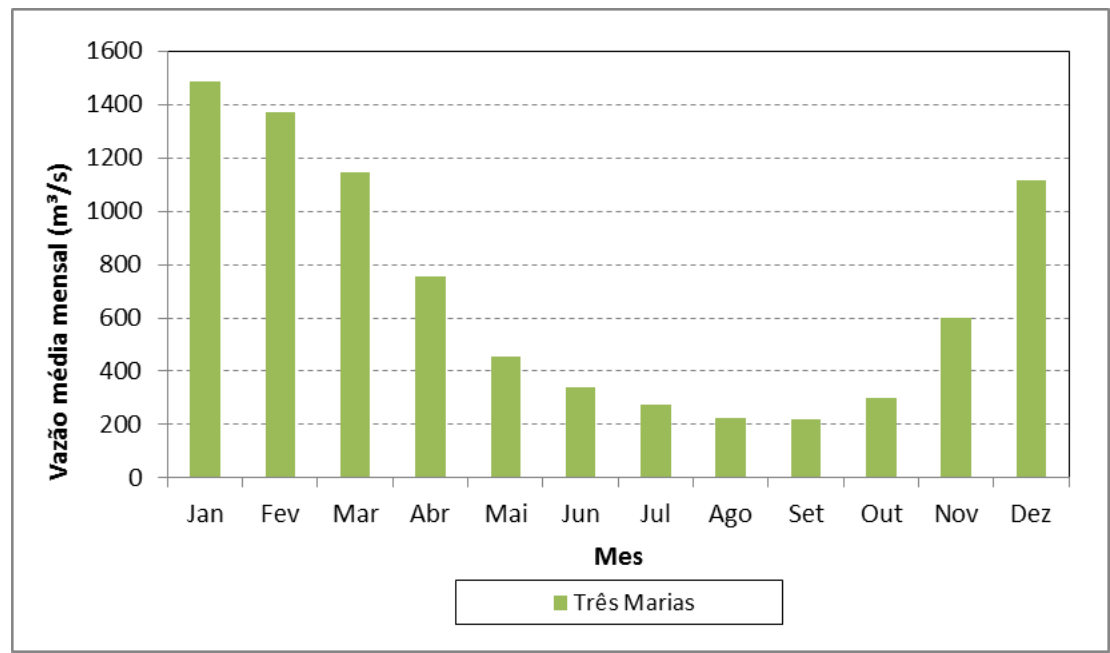

Figura 24. Vazões médias mensais no rio São Francisco, na UHE Três Marias 


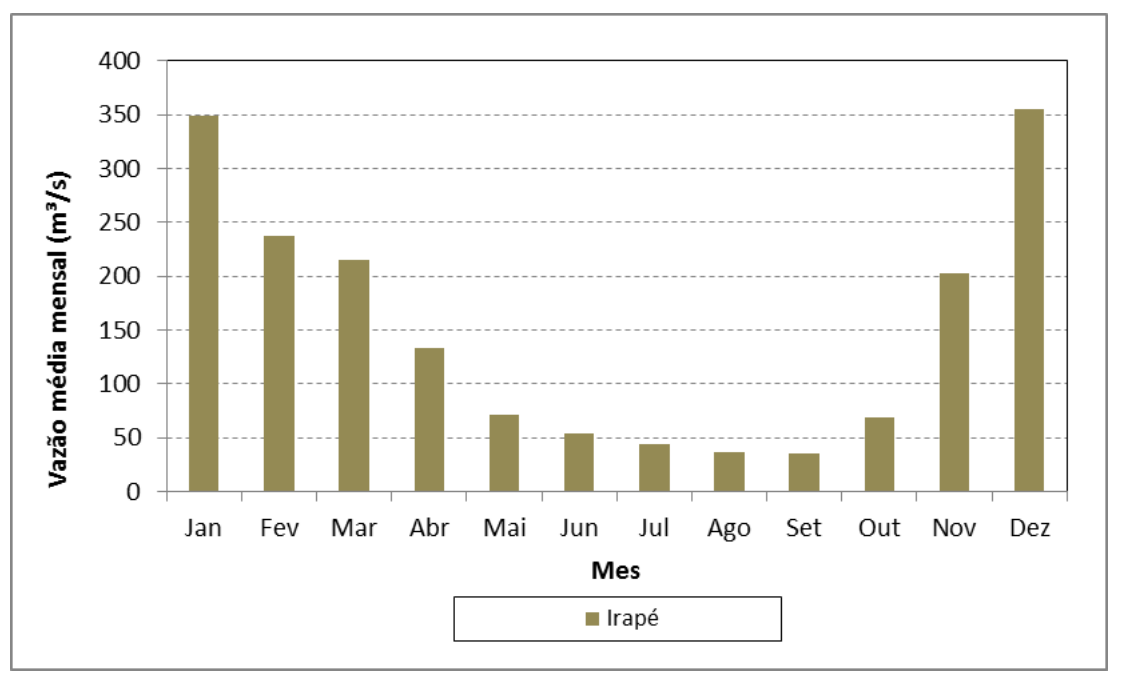

Figura 25. Vazões médias mensais no rio Jequitinhonha, na UHE Irapé

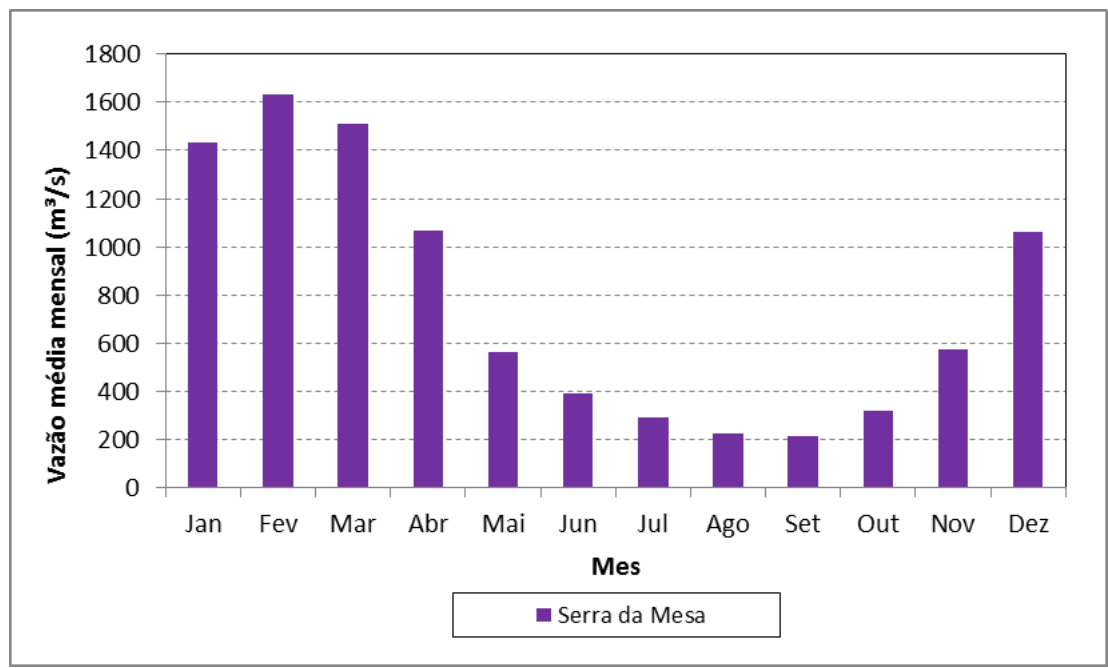

Figura 26. Vazões médias mensais no rio Tocantins, na UHE Serra da Mesa

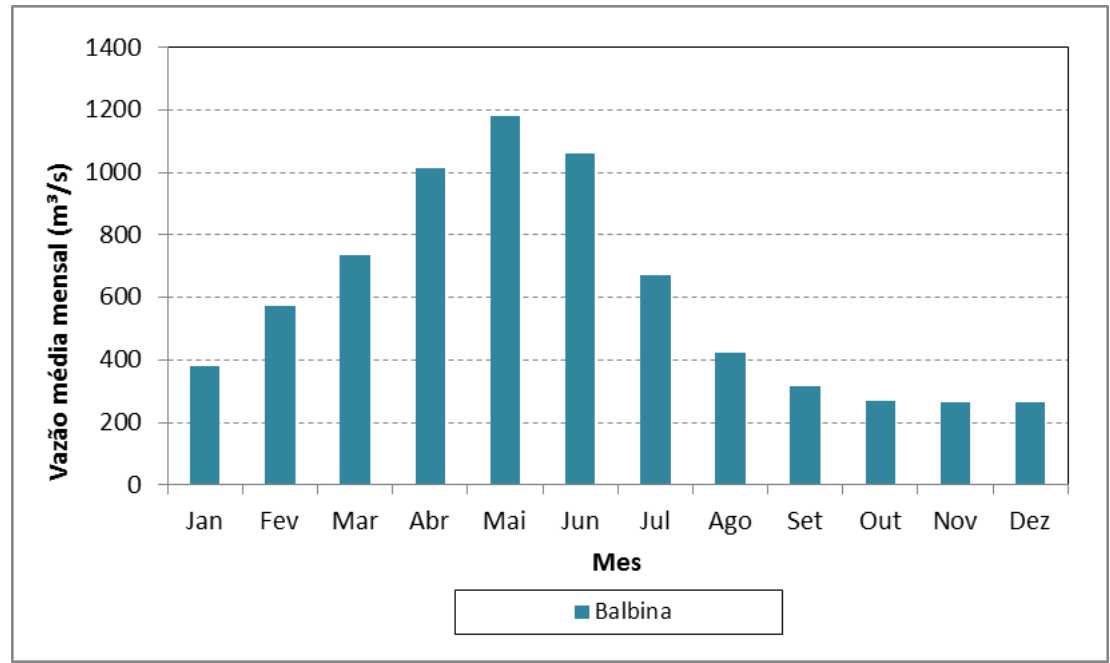

Figura 27. Vazões médias mensais no rio Uatumã, na UHE Balbina 


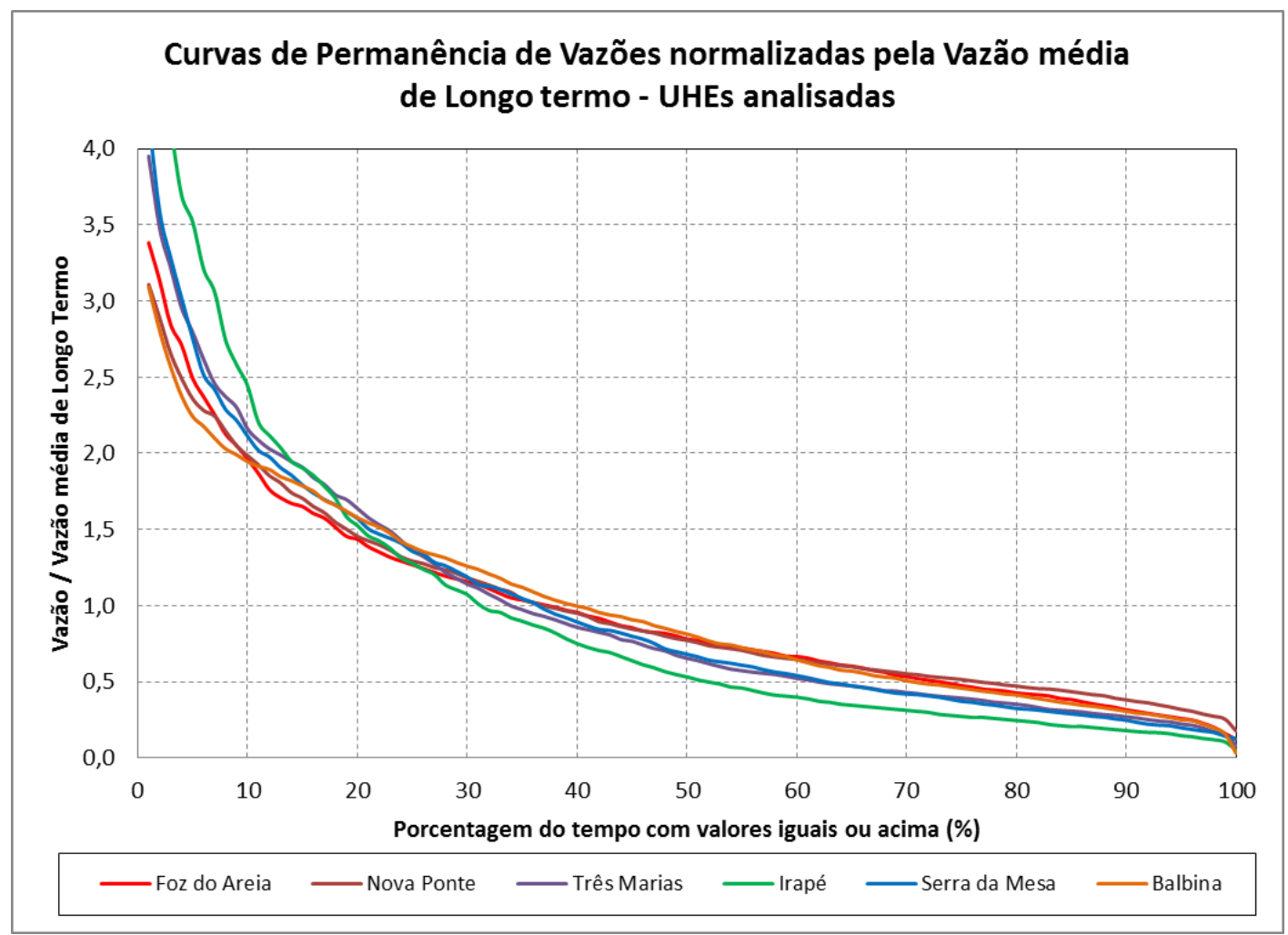

Figura 28. Curvas de Permanência de Vazões normalizadas pela vazão média de Longo Termo

Com base na análise da tabela 4 e das figuras 22 a 28 pode-se verificar que os regimes hidrológicos das bacias selecionadas apresentam diferenças significativas quanto à sazonalidade, vazões médias, coeficiente de variação e assimetria de suas séries históricas.

A UHE Foz do Areia se encontra na bacia do Paraná, porém sob a influência de um regime hidrometeorológico típico da região Sul do Brasil. O rio Iguaçu, até o eixo desta UHE, não apresenta um regime hidrológico bem definido, verificando-se cheias ao longo de todo o ano. Esta bacia apresenta uma vazão específica $\left(22 \mathrm{~L} / \mathrm{s} . \mathrm{km}^{2}\right)$ superior dentre as bacias analisadas nas regiões Sudeste, Centro Oeste e Nordeste.

A UHE Nova Ponte, também pertencente à bacia do Paraná, no entanto, apresenta um comportamento hidrológico (sazonalidade) mais bem definido em relação ao caso anterior, com maiores vazões entre os meses de Dezembro e Março. 
As UHE Três Marias e Irapé se encontram nas bacias do São Francisco e Atlântico Leste, respectivamente, possuem regimes hidrológicos bem definidos, com períodos de cheia entre Novembro e Março e períodos de seca acentuados. A variabilidade hidrológica do rio Jequitinhonha, onde se situa a UHE Irapé, é mais acentuada que o rio São Francisco, até a UHE Três Marias, devido às características climatológicas da região Nordeste de Minas Gerais. A bacia da UHE Irapé possui a menor contribuição específica $\left(9,3 \mathrm{~L} / \mathrm{s} . \mathrm{km}^{2}\right)$, o maior coeficiente de variação $(116 \%)$ e a maior assimetria $(2,59)$ dentre as séries das bacias analisadas.

A bacia do rio Tocantins, até o eixo da UHE Serra da Mesa, apresenta um período de cheias bem definido, que se estende de outubro a abril, com pico em fevereiro, característico do curso superior do rio.

A UHE Balbina está contida no regime hidrometeorológico da região amazônica, significativamente divergente do restante dos outros rios analisados. A bacia se encontra no hemisfério norte, de modo que o período de cheias se estende entre os meses de Março e Agosto.

Nas figuras 29 a 34 a seguir são apresentadas as séries de vazões médias anuais dos rios analisados.

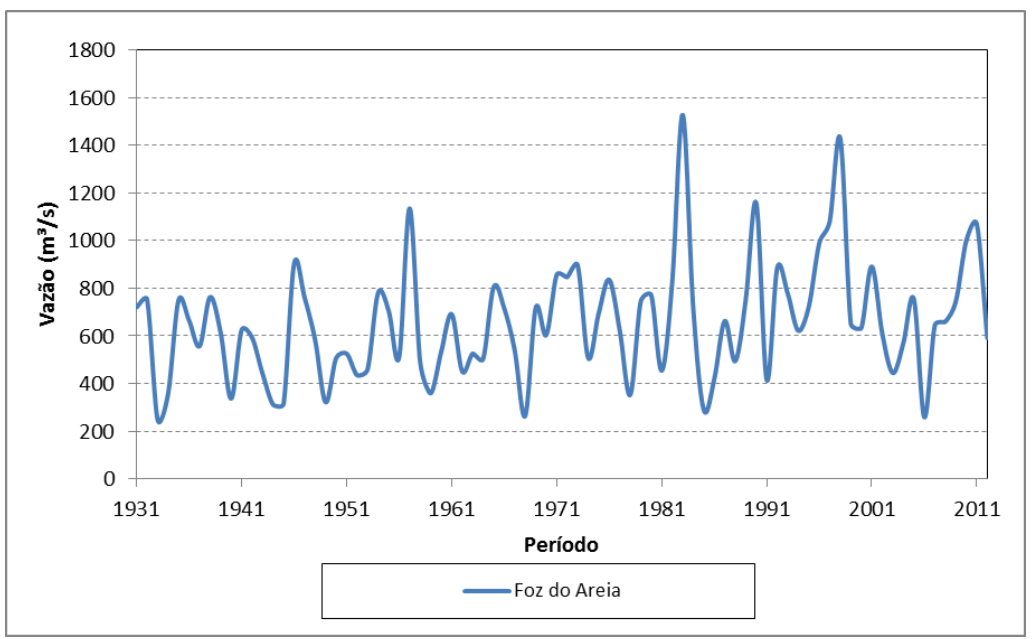

Figura 29. Vazões médias anuais - UHE Foz do Areia 


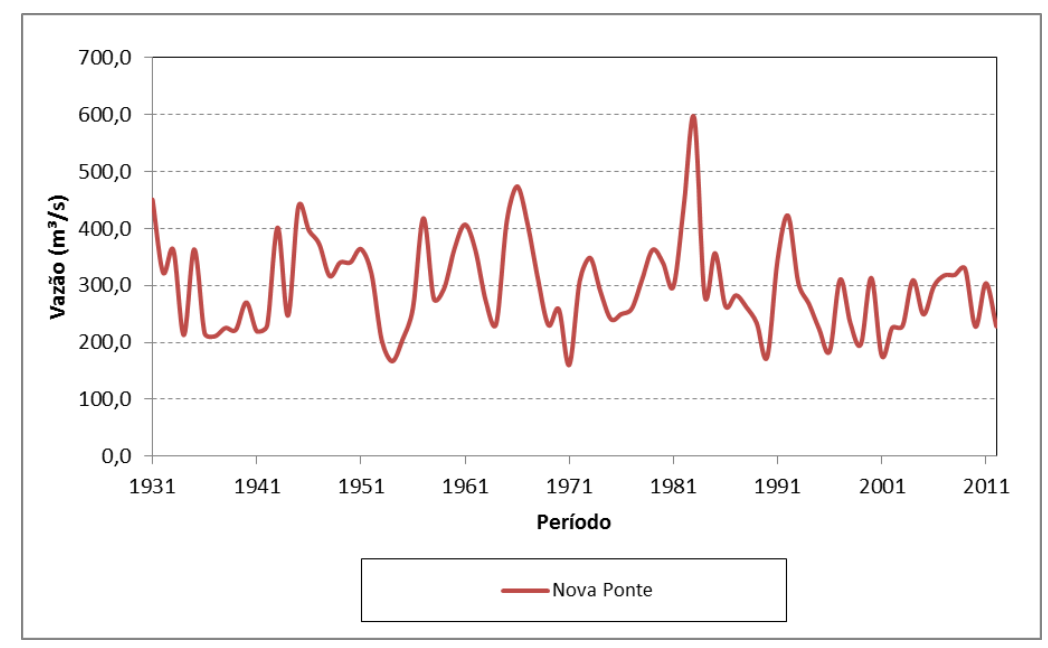

Figura 30. Vazões médias mensais - UHE Nova Ponte

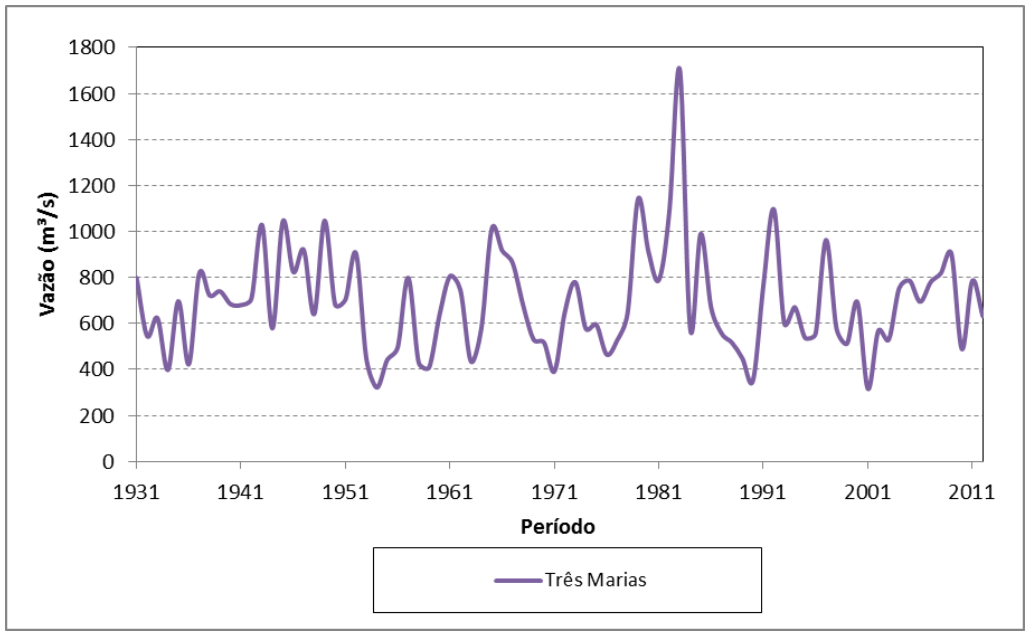

Figura 31. Vazões médias mensais - UHE Três Marias

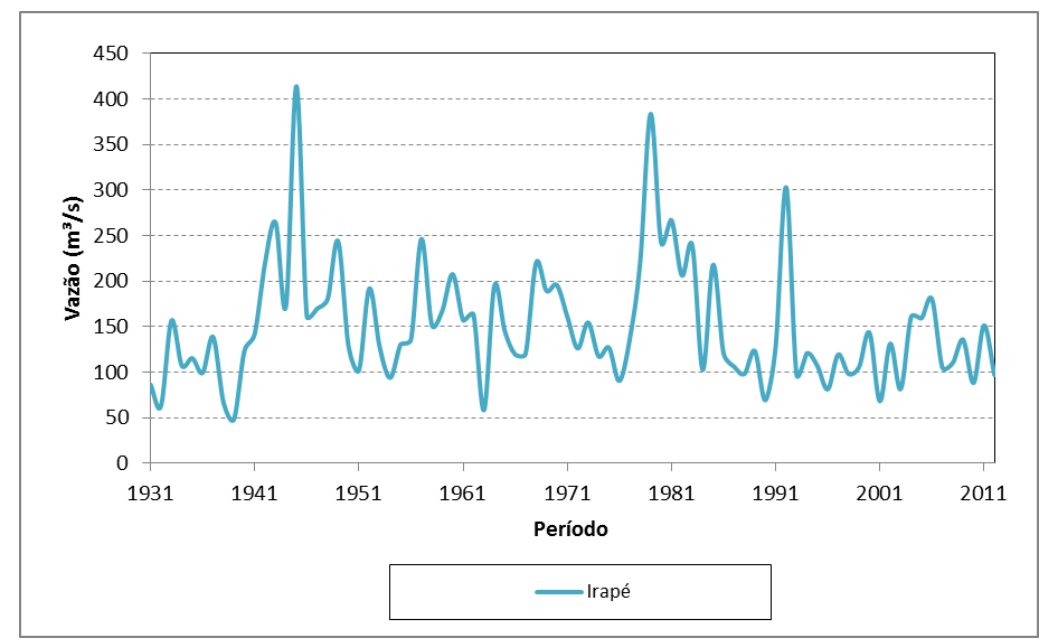

Figura 32. Vazões médias mensais - UHE Irapé 


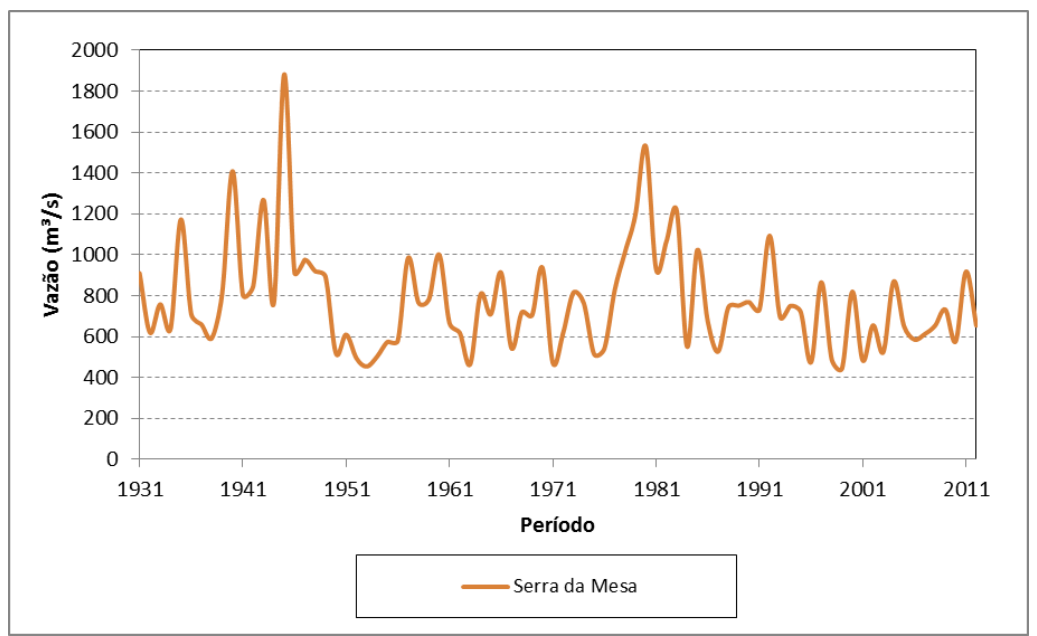

Figura 33. Vazões médias mensais - UHE Serra da Mesa

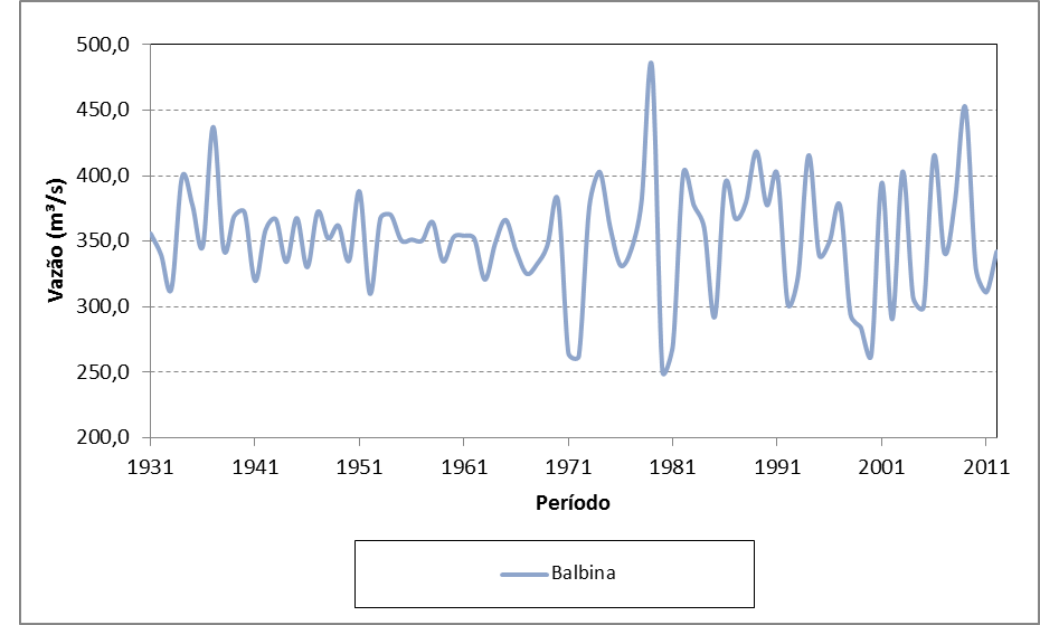

Figura 34. Vazões médias mensais - UHE Balbina

A análise da Estacionariedade das Afluências às Usinas Hidrelétricas Brasileiras foi analisada de modo detalhado por Detzel et al (2011), onde foi feita uma investigação das condições de estacionariedade das séries hidrológicas de todas as usinas hidrelétricas que compunham o Sistema Interligado Nacional entre 1931 a 2007. Para tanto foram empregados os seguintes testes estatísticos às séries de vazões médias anuais: Teste tStudent, Teste de Cox-Stuart, Teste de Wilcoxon, Teste do Coeficiente de Correlação de Spearman, Teste de Mann-Kendall e Teste F-Snedecor.

Os resultados do mencionado estudo indicaram que as séries históricas das UHEs Nova Ponte, Serra da Mesa, Três Marias e Irapé são estacionárias. No entanto a série da UHE Foz do Areia indicou possuir indício significativo de não estacionariedade na média. A UHE Balbina não foi contemplada neste estudo 
por não fazer parte do SIN até a data do referido estudo (2011), no entanto, análises expeditas indicaram estacionariedade nesta série.

A UHE Foz do Areia se encontra sob um regime hidrológico não bem definido, apresentando cheias e secas nos diferentes períodos do ano, o que dificulta a adequação dessa série a um regime estacionário. A análise da figura 29 não indica que a série possui uma variação significativa das vazões médias ao longo do histórico, contudo, aponta para a maior ocorrência de eventos extremos, ou seja, maior frequência e intensidade nos eventos de cheias e de secas, sem intervalos regulares. Mesmo com este indício, a UHE Foz do Areia foi considerada adequada ao estudo.

Ainda no mencionado artigo é sugerido o método de correção utilizado primeiramente por Mine et al. (2009) e depois em Batista et al. (2009). Este método parte do princípio que, em uma série estacionária, é esperado que o traçado gráfico da curva acumulativa de vazões em uma estação fluviométrica possa ser ajustado por uma linha de tendência contínua ao longo de todo o período. Uma mudança na declividade da curva faria com que duas retas de tendência possam ser ajustadas, uma para cada período. Essa condição, por sua vez, caracterizaria uma série não estacionária. A correção da não estacionariedade é feita através do cálculo dos coeficientes angulares das duas retas ajustadas.

Em seguida foi analisada a dependência linear entre os valores do processo no instante $t$ e no instante $t+j$ e as funções de autocorrelação das séries. Os resultados podem ser visualizados nas figuras 35 e 36 , que apresentam a função de autocorrelação das séries de vazões médias mensais e anuais, respectivamente. 


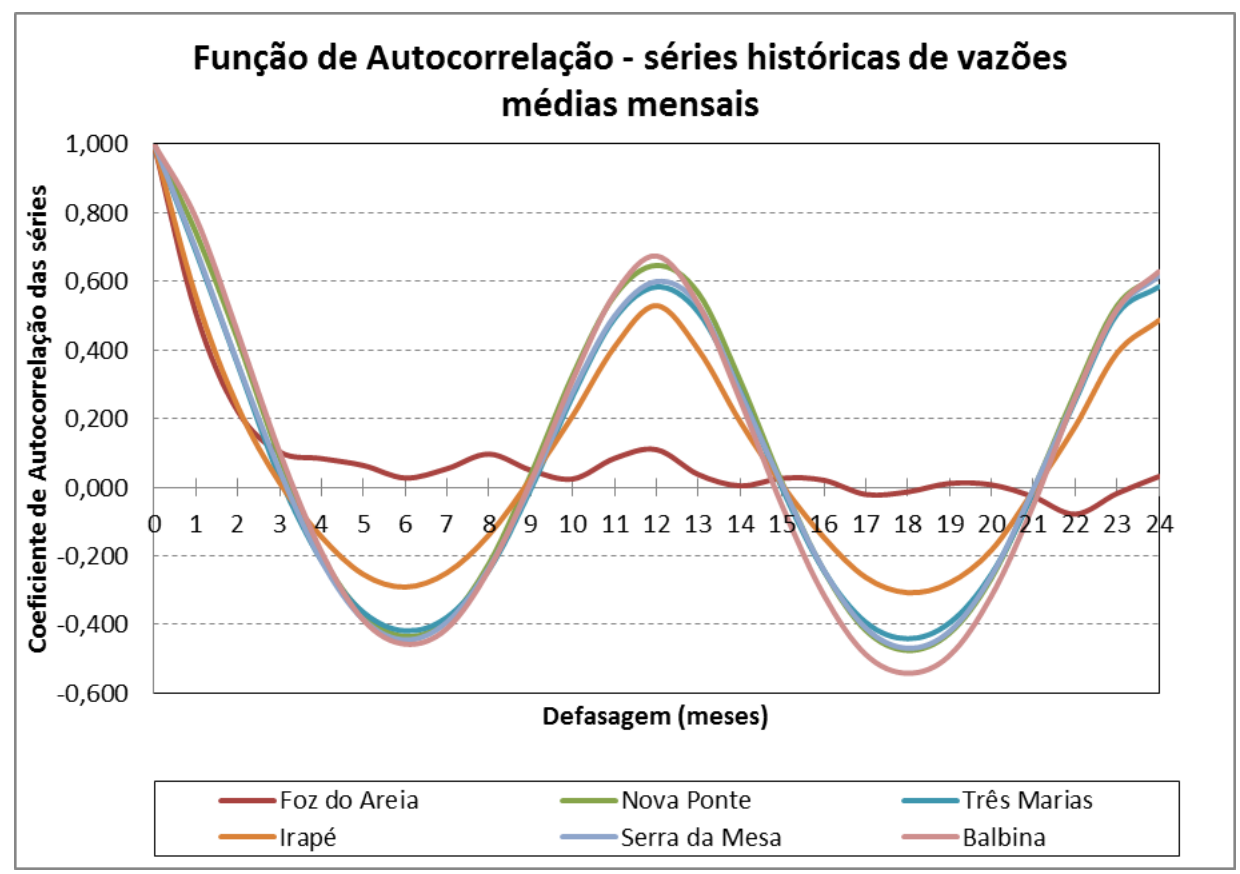

Figura 35. Função de Autocorrelação das séries mensais

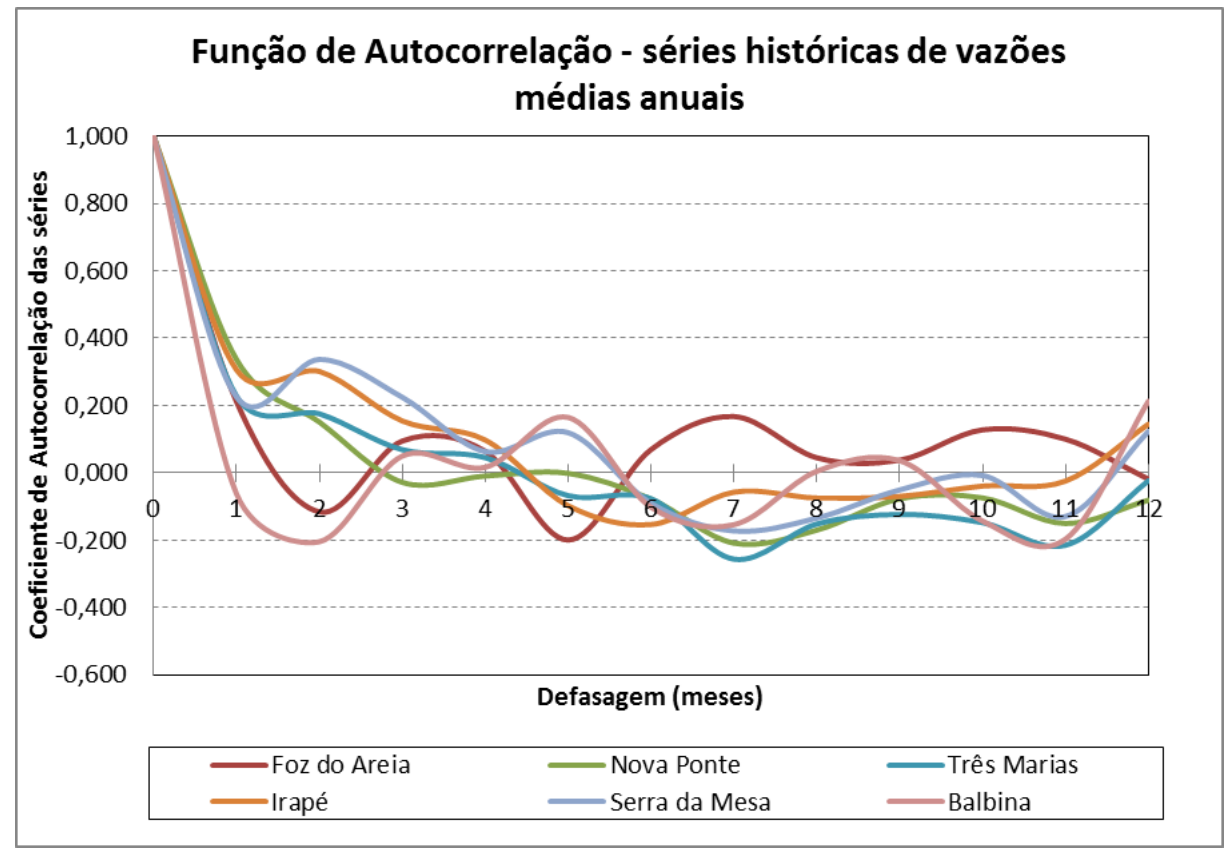

Figura 36. Função de Autocorrelação das séries anuais 


\subsection{Determinação do modelo estocástico adequado às séries históricas}

Foi adotado o modelo estocástico PAR (p) como representativo para a previsão e geração de séries sintéticas de vazões nas bacias dos rios analisados. $O$ ajuste deste modelo foi realizado com base nas séries históricas de vazões, definidas no item 5.1, e através do software SAMS.

O SAMS (Stochastic Analisys Modeling and Simulation), versão 2007, é um software gratuito desenvolvido pela Colorado State University e o U.S. Bureau of Reclamation. Este consiste em um software que lida com análises estocásticas, modelagens e simulações de séries hidrológicas, sendo escrito em C, Fortran e $\mathrm{C}++$. Este software tem como principal dado de entrada séries históricas, com as quais são feitas as análises estatísticas e modelagens estocásticas desejadas.

O software SAMS possui três opções básicas de ferramentas: análise estatística de dados, ajuste de modelos estocásticos (inclui estimativa e testes de parâmetros) e geração de séries sintéticas, sendo todas as ferramentas utilizadas no presente estudo.

Buscou-se ajustar os parâmetros de modelo PAR ( $p$ ) de modo que a escolha fosse o mais parcimoniosa possível, e optou-se pelo Método dos Momentos para o ajuste dos modelos estocásticos.

A tabela 5 ilustra os parâmetros ajustados para cada série e para os 12 meses do ano. 
Tabela 5. Parâmetros ajustados dos modelos estocásticos autorregressivos PAR (3)

\begin{tabular}{|c|c|c|c|c|c|c|c|c|c|c|c|}
\hline \multicolumn{12}{|c|}{ Parâmetros dos modelos estocásticos autorregressivos PAR (3) } \\
\hline \multicolumn{4}{|c|}{ UHE Foz do Areia } & \multicolumn{4}{|c|}{ UHE Nova Ponte } & \multicolumn{4}{|c|}{ UHE Três Marias } \\
\hline & $\phi 1$ & $\phi 2$ & $\phi 3$ & & $\phi 1$ & $\phi 2$ & $\phi 3$ & & $\phi 1$ & $\phi 2$ & $\phi 3$ \\
\hline Jan & 0.5377 & -0.1625 & 0.2141 & Jan & 1.3699 & -0.0175 & 0.2514 & Jan & 0.1031 & -0.0031 & -0.0119 \\
\hline Fev & 0.6059 & 0.0377 & -0.1858 & Fev & 0.1323 & 0.0510 & -0.0024 & Fev & 1.0653 & -0.0256 & -0.1072 \\
\hline Mar & 0.6376 & 0.0458 & -0.0652 & Mar & 0.9186 & 0.0891 & -0.1654 & Mar & 0.4160 & 0.2120 & -0.0287 \\
\hline Abr & 0.5336 & 0.1146 & 0.1460 & Abr & 0.7805 & 0.0952 & 0.0393 & Abr & 0.5996 & 0.2092 & 0.1718 \\
\hline Mai & 0.7353 & -0.3639 & 0.0207 & Mai & 0.5104 & 0.0390 & 0.3157 & Mai & 0.5454 & 0.1694 & 0.1928 \\
\hline Jun & 0.6045 & -0.0723 & 0.0297 & Jun & 2.6603 & 0.2678 & 0.1106 & Jun & 0.7344 & 0.0358 & -0.0411 \\
\hline Jul & 0.8101 & -0.0826 & 0.0466 & Jul & 0.1359 & 0.2156 & 0.0037 & Jul & 0.5655 & 0.1890 & 0.0256 \\
\hline Ago & 0.5433 & 0.1057 & 0.0266 & Ago & 3.7435 & 0.1760 & 0.0605 & Ago & 3.1033 & 0.9459 & -0.2846 \\
\hline Set & 0.6951 & 0.0839 & -0.2316 & Set & 0.3422 & 0.5176 & -0.1594 & Set & 0.2809 & 0.0063 & -0.0688 \\
\hline Out & 0.4344 & -0.0438 & 0.0404 & Out & 0.3482 & 0.1693 & -0.1007 & Out & 0.4328 & 0.1945 & -0.3209 \\
\hline Nov & 0.6699 & -0.1667 & 0.0741 & Nov & 1.3180 & -0.1182 & -0.0863 & Nov & 0.8945 & 0.2398 & -0.2139 \\
\hline Dez & 0.4736 & 0.0449 & -0.0258 & Dez & 0.1642 & 0.1644 & 0.0009 & Dez & 0.8437 & 0.3477 & -0.0742 \\
\hline \multicolumn{4}{|c|}{ UHE Irapé } & \multicolumn{4}{|c|}{ UHE Serra da Mesa } & \multicolumn{4}{|c|}{ UHE Balbina } \\
\hline & $\phi 1$ & $\phi 2$ & $\phi 3$ & & $\phi 1$ & $\phi 2$ & $\phi 3$ & & $\phi 1$ & $\phi 2$ & $\phi 3$ \\
\hline Jan & 0.1413 & -0.0878 & 0.1347 & Jan & 0.1550 & 0.0769 & 0.0836 & Jan & 0.5337 & 0.2174 & 0.1766 \\
\hline Fev & 0.8821 & 0.0432 & -0.2197 & Fev & 0.7662 & -0.2606 & 0.1967 & Fev & 0.3202 & 0.0708 & -0.0368 \\
\hline Mar & 0.1388 & 0.2494 & -0.1318 & Mar & 0.3302 & 0.1984 & -0.0617 & Mar & 0.4362 & 0.0690 & -0.0088 \\
\hline Abr & 0.7158 & 0.0930 & 0.1789 & Abr & 0.5277 & 0.1102 & 0.0450 & Abr & 3954.19 & -2895.22 & 188.0959 \\
\hline Mai & 0.5096 & 0.0818 & 0.1851 & Mai & 0.7538 & 0.1654 & 0.1156 & Mai & 0.0002 & 0.0782 & 0.0578 \\
\hline Jun & 0.9439 & -0.0069 & 0.0249 & Jun & 0.6144 & 0.0986 & 0.0362 & Jun & 3.9672 & -0.0004 & 0.5561 \\
\hline Jul & 0.5966 & 0.1547 & -0.0123 & Jul & 1.1066 & 0.0197 & -0.0295 & Jul & 0.8891 & -0.0529 & 0.0001 \\
\hline Ago & 0.8466 & 0.2520 & -0.1732 & Ago & 1.0435 & 0.2526 & -0.0859 & Ago & 0.2172 & 0.0384 & -0.0087 \\
\hline Set & 1.0717 & 0.0648 & -0.3260 & Set & 0.4059 & 0.7491 & -0.2580 & Set & 0.5309 & 0.0145 & 0.0104 \\
\hline Out & 0.6381 & 0.6736 & -0.3272 & Out & 0.9457 & 0.1060 & 0.5058 & Out & 1.9595 & -0.4429 & 0.0084 \\
\hline Nov & 0.4841 & -0.0212 & -0.1901 & Nov & 0.3389 & -0.0732 & -0.2008 & Nov & 0.7490 & 0.0690 & -0.1254 \\
\hline Dez & 0.4435 & -0.0785 & 0.2221 & Dez & 1.0254 & -0.0839 & -0.0345 & Dez & 0.7282 & 0.2213 & 0.0389 \\
\hline
\end{tabular}

De posse dos parâmetros do modelo estocástico, foi possível o cálculo dos ruídos históricos das séries, cuja metodologia foi exposta no item 4.2. Os resultados obtidos são apresentados na tabela 6 a seguir: 
Tabela 6. Parâmetros estatísticos dos ruídos históricos

\begin{tabular}{|c|c|c|c|c|c|c|}
\hline \multicolumn{7}{|c|}{ Parâmetros estatísticos dos ruídos históricos } \\
\hline Desvio padrão & Foz do Areia & Nova Ponte & Três Marias & Irapé & Serra da Mesa & Balbina \\
\hline Janeiro & 0,55 & 0,81 & 0,24 & 0,64 & 0,46 & 0,37 \\
\hline Fevereiro & 0,48 & 0,04 & 0,40 & 0,72 & 0,37 & 0,18 \\
\hline Março & 0,47 & 0,08 & 0,31 & 0,63 & 0,39 & 0,10 \\
\hline Abril & 0,61 & 0,05 & 0,26 & 0,49 & 0,27 & 0,62 \\
\hline Maio & 0,72 & 0,01 & 0,13 & 0,27 & 0,23 & 0,16 \\
\hline Junho & 0,56 & 0,14 & 0,09 & 0,19 & 0,10 & 0,66 \\
\hline Julho & 0,57 & 0,00 & 0,06 & 0,16 & 0,06 & 0,44 \\
\hline Agosto & 0,61 & 0,08 & 0,35 & 0,09 & 0,12 & 0,14 \\
\hline Setembro & 0,54 & 0,03 & 0,21 & 0,20 & 0,29 & 0,15 \\
\hline Outubro & 0,48 & 0,06 & 0,37 & 0,56 & 0,76 & 0,24 \\
\hline Novembro & 0,47 & 0,26 & 0,44 & 0,50 & 0,28 & 0,23 \\
\hline Dezembro & 0,39 & 0,05 & 0,81 & 0,45 & 0,46 & 0,34 \\
\hline
\end{tabular}

Os ruídos históricos correspondem aos ruídos brancos inerentes ao processo estocástico tendo como base os registros históricos, ou seja, os ruídos verificados nos registros históricos.

A análise dos ruídos históricos não permite tirar afirmações conclusivas ou correlações com outras variáveis/parâmetros, contudo, verifica-se uma tendência de ruídos com menor desvio padrão para os meses de seca hidrológica, e maiores desvio padrão nos períodos de cheias. 


\subsection{Construção de árvores de cenários de vazões afluentes}

A construção das árvores de cenários foi realizada através do software SAMS, por meio dos modelos estocásticos autorregressivos PAR (3) definidos para cada usina.

O objetivo consiste na geração de séries sintéticas de vazões médias mensais aos aproveitamentos. Cada série sintética corresponde a um cenário possível de ocorrência.

Durante a programação de geração foi utilizada a opção de evitar a geração de valores negativos de vazões, similar às metodologias expostas no item 4.2.

Adotou-se a geração de cenários no formato garfo (ver figura 37), de modo que todos os cenários gerados partem da mesma vazão média mensal inicial, chamado de "nó raiz". Esse nó corresponde ao último mês de medição da série histórica de vazões fornecida pelo ONS, Dezembro/2012.

Os cenários de vazões gerados são equiprováveis, ou seja, possuem a mesma probabilidade de ocorrência, igual a $1 / \mathrm{N} N{ }^{\circ}$ total de cenários.

Dentro do universo estocástico de geração de séries sintéticas, busca-se o maior número possível de cenários, de modo a abranger um número maior de possibilidades de ocorrência de vazões, no entanto, o modelo estocástico deve ser viável do ponto de vista computacional, de modo que se faz necessário aproximar a previsão por um número limitado de cenários e nós.

Assim, nesta dissertação foi adotado um universo de até 1000 cenários iniciais de vazões, buscando definir números menores de cenários, não equiprováveis, após a etapa de redução de cenários.

Para o caso de 1000 cenários iniciais, o número de nós da árvore inicial é de 48000 para 4 anos de análise, 36000 para 3 anos de análise e 24000 para 2 anos de análise. A compilação dos dados envolve, assim, a necessidade de tratar com matrizes $48000 \times 48000$. Para o caso de 10000 cenários iniciais, este número subiria para $480000 \times 480000$. 
Além do mais, algumas etapas do processo de otimização estocástica ocorrem em planilhas EXCEL (.xls), que não comportam a compilação de um número tão grande de dados (versão 2013, máximo 16384 colunas).

A figura 37 a seguir ilustra um arranjo esquemático de cenários equiprováveis.

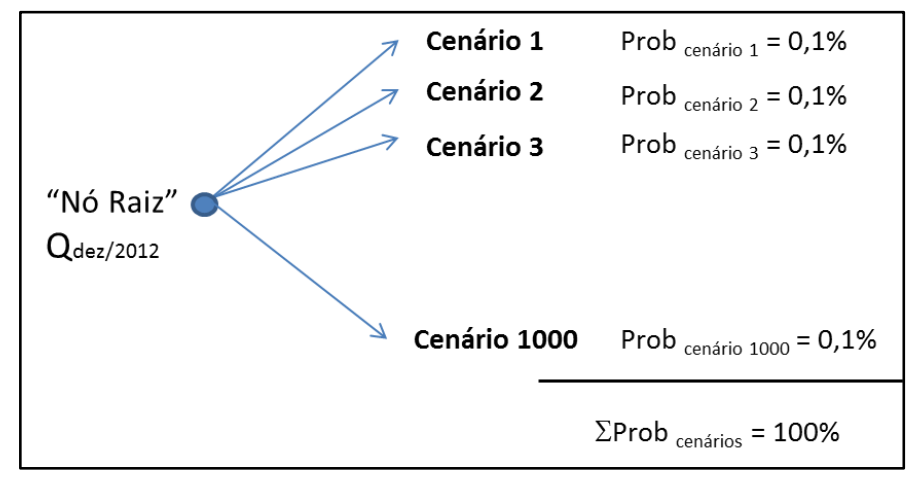

Figura 37. Representação da Cenarização hidrológica tipo "Garfo" a ser utilizada

A metodologia utilizada pelo SAMS corresponde ao processo de geração de cenários Forward, descrita anteriormente.

O estudo dos diferentes modos de representar a árvores de cenários, com cenários não equiprováveis, será realizado na etapa de redução de cenários item 5.8 .

Após a geração de cenários, os dados foram ordenados de modo a serem compatíveis com o formato de leitura de dados do algoritmo de redução de cenários adotado (SCENRED), assim como apresentado na figura 38 a seguir.

\begin{tabular}{|c|c|c|c|c|c|}
\hline \multirow[t]{7}{*}{$\begin{array}{l}\mathrm{T}=0 \\
\text { Dez } / 2012\end{array}$} & $\begin{array}{l}T=1 \\
\text { Jan/2013 }\end{array}$ & $\begin{array}{l}T=2 \\
\text { Fev/2013 }\end{array}$ & & $\begin{array}{l}T=48 \\
\text { Dez/16 }\end{array}$ & \\
\hline & Nó 1 & Nó 1001 & . & Nó 47001 & Cenário 1 \\
\hline & Nó 2 & Nó 1002 & ......... & Nó 47002 & Cenário 2 \\
\hline & Nó 3 & Nó 1003 & ......... & Nó 47003 & Cenário 3 \\
\hline & . & . & & . & \\
\hline & . & . & & . & \\
\hline & Nó 1000 & $\rightarrow$ Nó 2000 & ......... & Nó 48000 & Cenário 1000 \\
\hline
\end{tabular}

Figura 38. Arranjo de nós na geração de cenários de vazões 


\subsection{Algoritmo de Redução de Cenários}

No presente estudo a etapa de redução de cenários se destaca por dois objetivos principais: primeiramente 0 de reduzir a dimensão do problema através da redução do número de cenários e, em segundo, mas não menos importante, o de preservar aqueles cenários cujas principais características estatísticas sejam próximas da árvore de cenários inicial, ou seja, os cenários mais representativos. Assim, cenários muito próximos são agrupados em um cenário representante, e cenários que apresentam baixa probabilidade de ocorrência tendem a serem eliminados.

A ferramenta selecionada para tais funções é o SCENRED, que consiste em uma coleção de ferramentas de redução de árvores de cenários, desenvolvidos por H. Heitsch \& W. Romisch (2001), elaborado e atualmente vinculado à linguagem do software GAMS.

Os algoritmos de redução de cenários presentes no SCENRED utilizam a rotina de programação $\mathrm{C}++_{+}$, determinando sub-árvores ótimas de cenários, de acordo com o cardinalidade ou precisão necessária. O SCENRED utiliza métricas probabilísticas, tal como a métrica de Fourtet-Mourier, para a determinação da redução ótima de cenários. Segundo a gama de classificação de técnicas de redução expostas no capítulo 4 - Redução de Cenários, o SCENRED se enquadra no grupo de técnicas de redução de cenários por agrupamento hierárquico.

Os algoritmos existentes determinam uma seleção de cenários dentro do universo de cenários iniciais e calculam novas probabilidades aos cenários preservados. A todos os cenários descartados é atribuído probabilidade zero. Estes algoritmos consistem em um processo iterativo que se inicia com uma árvore de cenário reduzida vazia. Em cada iteração, o algoritmo seleciona o conjunto de cenários que minimiza a distância de Kantorovich entre as árvores de cenários reduzidas e originais. $O$ algoritmo para o processo caso se tenha alcançado o número determinado/desejado de cenários ou caso a determinada distância Kantorovich tenha sido atingida. Finalmente, as probabilidades dos cenários selecionados são atualizadas. O objetivo da redução de cenário 
consiste em encontrar uma nova distribuição discreta que minimize a distância Kantorovich da distribuição de probabilidade da árvore inicial (Carrión et al, 2004).

Resumidamente, o SCENRED contém três algoritmos de redução: O método Fast Backward, uma mistura dos métodos Fast Backward/Forward, e uma combinação dos métodos Fast Backward/Backward. O desempenho computacional (precisão, tempo de processamento) dos métodos difere de método para método: O método Fast/Backward tende a ter 0 melhor desempenho no tempo de processamento para a redução de grandes árvores de cenários. Por sua vez os métodos Forward e Backward possuem resultados mais precisos, mas à custa de um maior tempo de processamento. O método Forward consiste no melhor algoritmo ao se comparar o quesito precisão, mas é recomendado quando o número de cenários reduzidos é pequena. Caso nenhum método de redução seja selecionado, o programa automaticamente busca aquele com a melhor performace em respeito ao tempo de processamento (GAMS, 2006).

O procedimento aplicado por este conjunto de algoritmos tem como principais dados de entrada:

1) Parâmetros escalares que definem a árvore inicial e reduzida de cenários, além de parâmetros que influenciam no desempenho do processo:

- Num_leaves: Número de cenários iniciais, antes da etapa de redução;

- Num_nodes: número de nós da árvore inicial (cada nó corresponde a uma vazão média mensal de um determinado cenário);

- Num_random: Número de variáveis randômicas vinculado aos nós, isto é, a dimensão do processo aleatório.

- Num_time_steps: Comprimento do "caminho" entre o nó raiz e o nó "folha" da árvore de cenários, isto é, o número de discretizações de tempo envolvidos;

- Red_num_leaves: número desejado de cenários reduzidos 
- Red_percentage: porcentagem de redução desejado, em termos de distância relativa entre os cenários originais e reduzidos (número entre 0 e 1).

- Num_stages: número de estágios do modelo -1. (Caso num_stages=1 não ocorre processo de formação de cenários)

- Reduction_method: Seleção do método/algoritmo de redução:

- 0: Automático (seleção do melhor método do ponto de vista do tempo de processamento)

- 1: método Fast Backward

- 2: Misto de métodos Fast Backward / Forward

- 3: Misto de métodos Fast Backward/Backward

- Run_time_limit: Definição do limite no tempo de processamento, em segundos

2) Matrizes:

- Nós (vazões médias mensais) que formam a árvore inicial de cenários;

- Matriz ancestral entre os nós da árvore inicial. Esta matriz determina a árvore de cenários, vinculando cada nó ao seu antecessor (ou sucessores);

- Probabilidade de cada nó da árvore inicial.

Uma melhor descrição dos elementos que compõe o SCENRED pode ser visualizado no tutorial do GAMS (anexo ao próprio software) e o detalhamento dos procedimentos matemáticos aplicados pode ser visualizado em Heitsch et Romisch (2001).

A figura 39 ilustra um exemplo esquemático de árvore de cenários reduzida (hipoteticamente oriunda da árvore da figura 38), destacando que as probabilidades dos cenários preservados somam 100\%. 


\begin{tabular}{|c|c|c|c|c|c|c|}
\hline \multirow{8}{*}{$\begin{array}{l}\text { "Nó Raiz" } \\
Q_{\text {dez/2012 }}\end{array}$} & $\begin{array}{l}\mathrm{T}=1 \\
\text { Jan/2013 }\end{array}$ & $\begin{array}{l}\mathrm{T}=\mathbf{2} \\
\mathrm{Fev} / 2013\end{array}$ & & $\begin{array}{l}T=48 \\
\text { Dez/16 }\end{array}$ & & \\
\hline & Nó 20 & Nó 1020 & ( & Nó 47020 & Cenário 2 & Probcen $2=12 \%$ \\
\hline & Nó 170 & Nó 1170 & ......... & Nó 47170 & Cenário 170 & Probcen170= 7\% \\
\hline & Nó $290^{-}$ & Nó 1290 & ........ & Nó 47290 & Cenário 290 & Probcen $290=21 \%$ \\
\hline & Nó 560 & Nó 1560 & ......... & Nó 47560 & Cenário 560 & Probcen560= 33\% \\
\hline & Nó 830 & Nó 1830 & .......... & Nó 47830 & Cenário 830 & Probcen $830=8 \%$ \\
\hline & Nó 970 & Nó 1970 & ........ & Nó 47970 & Cenário 970 & Probcen970=19\% \\
\hline & & & & & & $\sum$ Probcen $=100 \%$ \\
\hline
\end{tabular}

Figura 39. Exemplo esquemático de uma árvore reduzida de cenários do SCENRED

Segundo Follestad (2012) O grau (ou porcentagem) de redução obtido para uma árvore de cenários reduzidos pode ser quantificada em termos de distância relativa Erel, definido como:

$$
\varepsilon_{r e l}=\frac{\varepsilon_{r e d}}{\varepsilon_{l}}
$$

A distância $\varepsilon_{\text {red }}$ corresponde à distância probabilística absoluta entre a árvore de cenários reduzida e a árvore de cenários original (ou distância de Kantorovich), e $\varepsilon_{1}$ corresponde à distância de probabilidade entre o primeiro cenário selecionado (considerado o cenário mais representativo) e o restante da árvore original. 


\subsection{Algoritmo de Otimização Estocástica}

O raciocínio utilizado para a formulação do algoritmo de otimização estocástica teve como ponto de partida a formulação de otimização determinística desenvolvida por Zambon (2008). A partir dessa formulação o algoritmo foi ajustado para a abrangência de apenas uma usina hidrelétrica e foram adicionados os parâmetros correspondentes aos cenários de vazões.

A formulação utilizada para a otimização estocástica de uma usina individualizada é apresentada a seguir:

$$
\min Z H=\sum_{c=1}^{c} p_{c, t} \times \sum_{t=1}^{n t} d t \times\left[D_{c, t}-P_{c, t}\right]^{2}
$$

Onde:

$Z H$ = função objetivo do modelo $\left(10^{6}\right.$ s.MW'2);

c = índice do cenário;

$\mathrm{C}$ = número de cenários;

$\mathrm{t}$ = índice dos intervalos de tempo;

$\mathrm{nt}=$ número de intervalos de tempo;

pci $=$ probabilidade do cenário $\mathrm{c}$, no instante $\mathrm{t}$;

$P_{c, t}=$ Produção de energia $(M W)$ da usina, em relação ao cenário $c$, no instante $\mathrm{t}$;

$\mathrm{Dc}_{\mathrm{c}, \mathrm{t}}=$ Demanda objetivo $(\mathrm{MW})$, do cenários $\mathrm{c}$, no instante $\mathrm{t}$;

$\mathrm{dt}=$ duração dos intervalos de tempo $\left(10^{6} \mathrm{~s}\right)$.

De modo geral, a definição da função objetivo envolve aspectos subjetivos, função dos interesses e expectativas dos stakeholders envolvidos. Em Barros et al (2005). Foi analisada a utilização de diferentes funções objetivo no processo de otimização. Mesmo sem a conclusão de uma função mais adequada, ficou mostrado que o equacionamento tal como a função (31) é a que melhor se adapta à produção hidroenergética e à minimização da complementação energética por outras fontes. Além do mais, esse tipo de 
função tem sido utilizada para operar o sistema elétrico brasileiro devido aos altos custos da complementação da geração térmica.

O modelo de otimização é constituído por equações não lineares, de modo que este deve ser resolvido por programação não linear (PNL), ficando sujeito às seguintes equações:

$$
R_{c, t}=R_{c, t}^{\prime}+R^{\prime \prime}{ }_{c, t}
$$

Equação da continuidade para uma usina com reservatório de acumulação:

$$
S_{c, t}=S_{c, t-1}+d t_{t}\left[\sum_{t=1}^{n t} I_{c, t}-R_{c, t}-U C_{c, t}-D E_{c, t}\right]-E_{c, t}
$$

Perda por evaporação para uma usina com reservatório de acumulação:

$$
E_{c, t}=\frac{A_{c, t}-A_{c, t-1}}{2} \cdot I E_{c, t}
$$

Capacidade da unidade geradora:

$$
P_{c, t} \leq P i^{\max } \cdot I D_{c, t}
$$

Armazenamento mínimo e máximo do reservatório:

$$
S_{t}^{\min } \leq S_{c, t} \leq S_{t}^{\max }
$$

Armazenamento final:

$$
S_{t=n t} \geq S_{\text {final }}
$$

Limites de vazão ambiental e outros usos, turbinada e vertida:

$$
\begin{gathered}
R_{c, t} \geq R^{\min } \\
R^{\prime m i n} \cdot I D_{c, t} \leq R_{c, t}^{\prime} \leq R_{c, t}^{\prime \max } \cdot I D_{c, t} \\
R_{c, t}>0
\end{gathered}
$$

Queda bruta média para uma usina com reservatório de acumulação:

$$
H b_{c, t}=\frac{H_{c, t}+H_{c, t-1}}{2}-H T_{c, t}
$$

Produção de Energia:

$$
P_{c, t}=\eta \cdot H b_{c, t} R_{c, t}^{\prime}
$$

Nível d'água a montante do reservatório 


$$
H_{c, t}=a_{0}+a_{1} S_{c, t}+a_{2} S_{c, t}^{2}+a_{3} S_{c, t}^{3}+a_{4} S_{c, t}^{4}
$$

Nível d'água no canal de fuga a jusante do reservatório:

$$
H T_{c, t}=b_{0}+b_{1} R_{c, t}+b_{2} R_{c, t}^{2}+b_{3} R_{c, t}^{3}+b_{4} R_{c, t}^{4}
$$

Limite de turbinamento em função da queda:

$$
R_{c, t}^{\prime \max }=d_{0}+d_{1} H b_{c, t}+d_{2} H b_{c, t}^{2}+d_{3} H b_{c, t}^{3}+d_{4} H b_{c, t}^{4}
$$

Onde:

$\mathrm{A}_{\mathrm{c}, \mathrm{t}}=$ Área do reservatório $\left(\mathrm{km}^{2}\right)$, no cenário $\mathrm{c}$, para o instante $\mathrm{t}$;

$\mathrm{DT}_{\mathrm{c}, \mathrm{t}}=$ desvios de vazão como bombeamento, transposição e outros a montante $\left(\mathrm{m}^{3} / \mathrm{s}\right)$, no cenário $\mathrm{c}$, para o instante $\mathrm{t}$;

$E_{c, t}=$ evaporação $\left(10^{6} \mathrm{~m}^{3}\right)$, no cenário $c$, para o instante $t$;

$\mathrm{Hb}_{\mathrm{c}, \mathrm{t}}=$ queda bruta média $(\mathrm{m})$, no cenário $\mathrm{c}$, para o instante $\mathrm{t}$;

$\eta=$ rendimento médio considerando a operação dos conjuntos turbina-gerador e perda de carga do circuito hidráulico $(0 \leq \eta \leq 1)$;

$\mathrm{H}_{\mathrm{c}, \mathrm{t}}=$ nível d'água a montante do reservatório $(\mathrm{m})$, no cenário $\mathrm{c}$, para o instante $\mathrm{t}$;

$H T_{c, t}=$ nível d'água no canal de fuga a jusante do reservatório $(m)$, no cenário c, para o instante $t$;

$I D_{c, t}=$ índice de disponibilidade das máquinas, no cenário $\mathrm{c}$, durante o intervalo $t$, para efeitos de manutenção e expansão (adimensional entre 0 e 1);

$\mathrm{IE}_{\mathrm{c}, \mathrm{t}}$ = Índice de evaporação no período $\mathrm{t}(\mathrm{m})$, no cenário $\mathrm{c}$, para o instante $\mathrm{t}$; $\mathrm{I}_{\mathrm{c}, \mathrm{t}}=$ Vazão afluente durante $\mathrm{o}$ intervalo $\mathrm{t}$ no reservatório $\left(\mathrm{m}^{3} / \mathrm{s}\right)$, no cenário $\mathrm{c}$, para o instante $\mathrm{t}$;

$\mathrm{P}_{\max }=$ capacidade máxima total dos geradores $(\mathrm{MW})$;

$\mathrm{R}_{\mathrm{c}, \mathrm{t}}^{\prime}=$ vazão turbinada $\left(\mathrm{m}^{3} / \mathrm{s}\right)$, no cenário $\mathrm{c}$, para o instante $\mathrm{t}$; 
$\mathrm{R}_{\mathrm{c}, \mathrm{t}}=$ vazão vertida $\left(\mathrm{m}^{3} / \mathrm{s}\right)$, no cenário $\mathrm{c}$, para o instante $\mathrm{t}$;

$R_{c, t}=$ Vazão defluente média total $\left(m^{3} / s\right)$, no cenário $c$, para o instante $t$;

$R^{\prime m a x}=$ vazão máxima turbinada $\left(\mathrm{m}^{3} / \mathrm{s}\right) ;$

$R^{\prime m a x}=$ vazão mínima turbinada $\left(\mathrm{m}^{3} / \mathrm{s}\right) ;$

$R^{\min }=$ defluência mínima ambiental $\left(\mathrm{m}^{3} / \mathrm{s}\right)$;

$\mathrm{S}_{\mathrm{c}, \mathrm{t}}=$ armazenamento no fim do intervalo $\mathrm{t}$ no reservatório $\left(10^{6} \mathrm{~m}^{3}\right)$, no cenário $c$, para o instante $\mathrm{t}$;

$S_{c, t}^{\max }=$ armazenamento máximo considerando volume de espera para controle de cheias $\left(10^{6} \mathrm{~m}^{3}\right)$, no cenário $\mathrm{c}$, para o instante $\mathrm{t}$;

$\mathrm{UC}_{\mathrm{c}, \mathrm{t}}=$ Vazão retirada para usos consultivos $\left(\mathrm{m}^{3} / \mathrm{s}\right)$, no cenário $\mathrm{c}$, para 0 instante t;

$a_{0}, a_{1}, a_{2}, a_{3}, a_{4}=$ coeficientes dos polinômios de ordem 4 para a equação do nível d'água de montante no reservatório em função do armazenamento;

$b_{0}, b_{1}, b_{2}, b_{3}, b_{4}=$ coeficientes dos polinômios de ordem 4 para a equação do nível d'água no canal de fuga de jusante do reservatório em função da vazão defluente;

$\mathrm{c}_{0}, \mathrm{C}_{1}, \mathrm{C}_{2}, \mathrm{C}_{3}, \mathrm{C}_{4}=$ coeficientes dos polinômios de ordem 4 para a equação da área no reservatório em função do nível d’água de montante;

$d_{0}, d_{1}, d_{2}, d_{3}, d_{4}=$ coeficientes dos polinômios de ordem 4 para a equação da vazão máxima turbinada no reservatório em função da queda.

Tanto a função objetivo como parte das restrições são não lineares. A produtividade depende da diferença entre os níveis no reservatório e no canal de fuga. Estes por sua vez dependem do armazenamento e da vazão defluente. A evaporação é função da área e o turbinamento máximo, sendo funções não lineares.

A determinação da demanda de eletricidade foi realizada com base nos dados de demanda nacional de energia elétrica, disponíveis pelo ONS. A figura 40 a 
seguir ilustra a evolução da demanda nacional de energia elétrica para o ano de 2013. Nessa figura os valores foram obtidos a partir da geração de energia de todas as usinas programadas e despachadas centralizadamente pelo ONS, somada à de usinas não monitoradas pelo ONS revisada em fevereiro/14, conforme informações dos agentes.

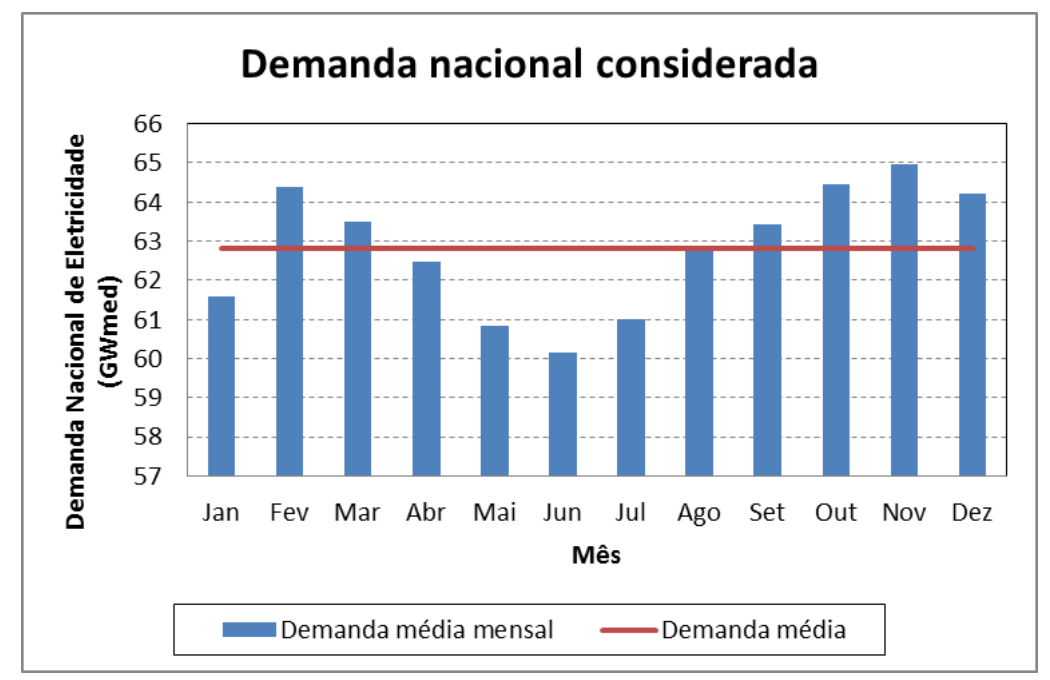

Figura 40. Demanda nacional do SIN. Fonte: ONS, 2014.

Além do mais, segundo os dados de demanda analisados verificou-se que o crescimento médio anual entre os anos de 2012 e 2013 foi de 3,6\%.

Assim, com base no padrão de demanda verificado para o contexto nacional (adimensioalizado pela demanda média anual), no crescimento anual médio verificado entre 2012 e 2013 (aplicado para a estimativa da demanda de energia elétrica a partir do $13^{\circ}$ mês de otimização), e no valor da potência instalada de cada usina em estudo, foram fixadas as demandas de energia elétrica de cada usina analisada.

A figura 41 a seguir ilustra o padrão de demanda adimensionalisado utilizado para o cálculo das demandas individuais em cada usina em estudo. 


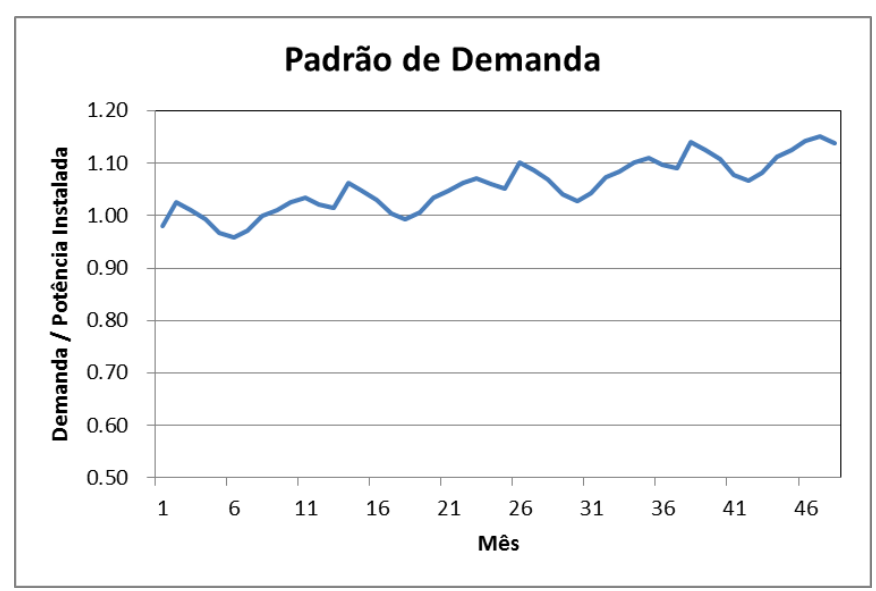

Figura 41. Padrão de demanda utilizado nas otimizações

Uma vez detalhados os dados de entrada e desenvolvido o algoritmo de otimização, foi consolidado o procedimento completo do algoritmo, assim como ilustrado na figura 42.

Ressalta-se que o algoritmo de redução de cenários está incorporado ao algoritmo de otimização. A exportação de dados do SCENRED para o excel (.xls) e a importação destes de volta para o GAMS acontece de modo automático, realizado através de arquivos .gdx (GAMS Data Exchange).

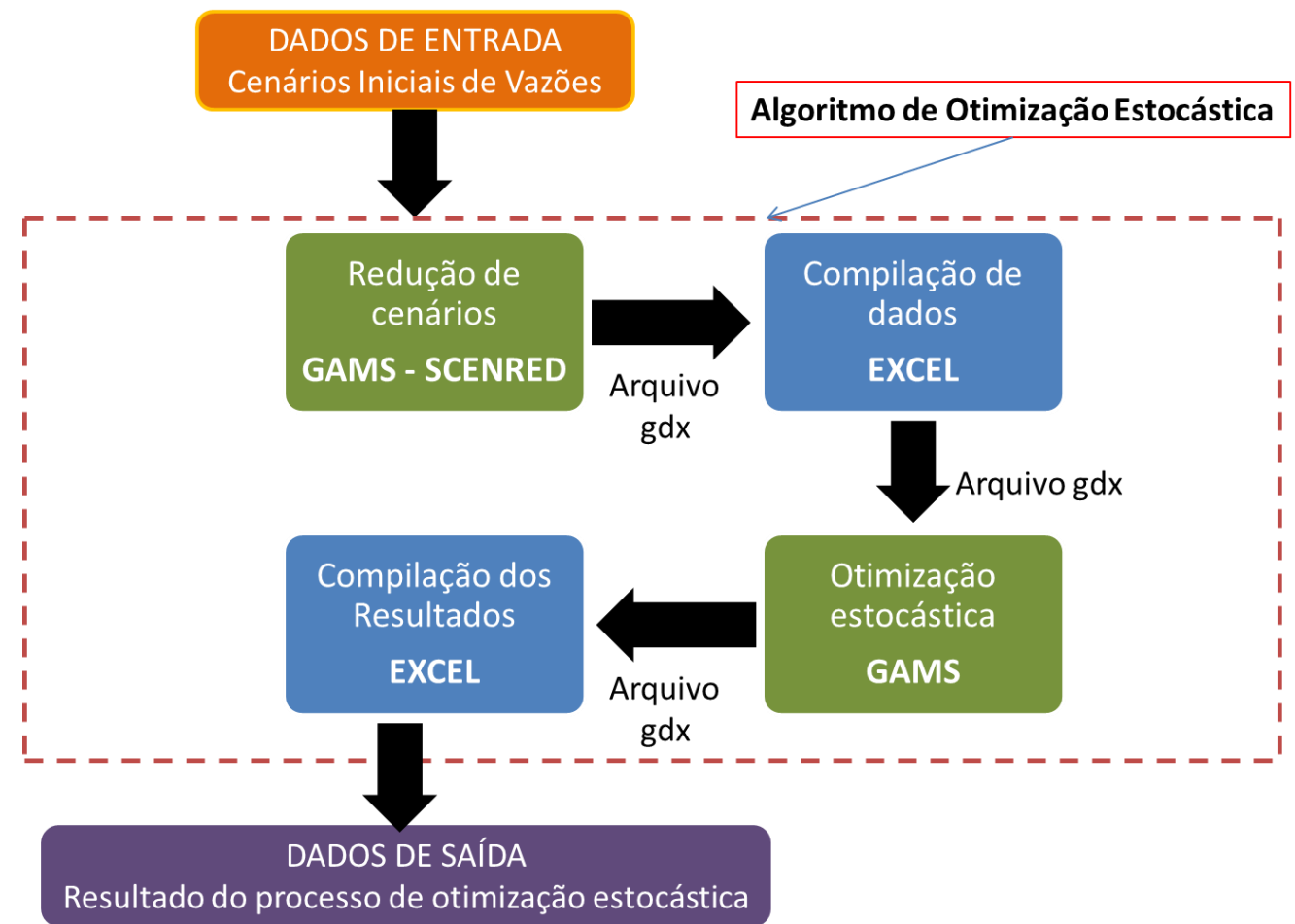

Figura 42. Esquema geral de procedimentos realizados no algoritmo de otimização estocástica 


\subsection{Aplicação do Algoritmo de Otimização estocástica}

A Aplicação do algoritmo de otimização estocástica consiste no núcleo do presente estudo e subsidiou as análises de sensibilidade propostas.

Estas análises buscaram primeiramente validar o modelo de otimização para, assim, analisar os efeitos da estocasticidade de vazões afluentes no processo de otimização hidroenergética do algoritmo do HIDROTERM.

As análises de sensibilidade propostas são:

I. Otimização estocástica considerando diferentes árvores de cenários e validação do modelo de otimização estocástica;

II. Otimização estocástica frente a diferentes árvores reduzidas de cenários;

III. Análise dos resultados frente a diferentes regimes hidrológicos;

IV. Otimização estocástica frente a diferentes volumes iniciais do reservatório;

V. Otimização estocástica frente a diferentes horizontes de planejamento;

VI. Análise da Otimização Estocástica considerando árvores de cenários históricos;

VII. Comparação entre a Otimização estocástica e a Otimização determinística considerando períodos hidrológicos críticos.

Os resultados destas análises e as considerações obtidas são apresentados nos itens 5.10.1 a 5.10.7.

O algoritmo de otimização foi elaborado e aplicado no software GAMS versão 22.3, em um computador com processador Intel Core 2 Duo 2.22 GHz, 4 MB de memória RAM. Para tal foi utilizado o otimizador MINOS, já incorporado ao GAMS, e especialmente adaptado para resolver problemas de otimização não linear no ambiente desse software. 


\subsubsection{Otimização estocástica considerando diferentes árvores de cenários e validação do modelo de otimização estocástica}

Ao se buscar um universo de cenários que abranja o máximo de possibilidades de vazões, recai-se sobre um tamanho da árvore de cenário demasiadamente grande (entre 100 e 10.000 cenários), de modo que o processo de otimização estocástica se torna de difícil manipulação e solução.

Segundo Follestad et al (2012), a qualidade do processo estocástico deve ser associada em termos da estabilidade da solução (ou função objetivo). Alguns métodos de avaliação do processo de cenarização na otimização estocástica são analisados em Kaut et Wallace (2007).

Ainda segundo Follestad et al (2012), no caso dos métodos de otimização estocástica, a estabilidade do processo se refere ao requisito de que diferentes árvores geradas a partir do mesmo modelo estocástico e mesmos dados de entrada devam produzir resultados similares.

Dois tipos de estabilidade foram considerados: estabilidade "In-sample" (dentro da amostra) e estabilidade "out-of-sample" (fora da amostra).

O primeiro caso significa que os valores dos resultados obtidos nas resoluções das otimizações estocásticas através de diferentes árvores de cenários, com a mesma configuração (número de cenários) e distribuição de probabilidades, são similares. Esta estabilidade foi testada em Fleten et al (2011), onde foi exemplificado que um dos objetivos do teste de estabilidade consiste em se analisar qual o número mínimo de cenários que ainda forneça um resultado estável, ou seja, quantos cenários podem ser eliminados da árvore inicial sem perda significativa na solução.

Por sua vez, a estabilidade "out-of-sample" significa que a diferença entre os valores da função objetivo obtidos na solução do problema considerando uma árvore de cenários reduzida, mas com a distribuição da árvore original de cenários, é pequena.

Um tipo de estabilidade não implica necessariamente na existência da outra, de modo que ambas os testes devem ser testados. Enquanto que, dadas as 
soluções das otimizações, o teste "in-sample" é feito de modo direto, o teste "out-of-sample" não o é, uma vez que a árvore reduzida não possui todos os nós da árvore inicial (Follestad et al, 2012).

O objetivo deste item consiste em se verificar a validade do modelo proposto, através da análise do comportamento da otimização estocástica frente a diferentes árvores de cenários, que consiste na análise de estabilidade nomeada "in sample". Esta análise se baseou na simulação de 10 diferentes árvores de cenários para cada tipo de arborização $(5,10,25,50$ e 100 cenários finais), ou seja, para cada número de aberturas foram simuladas 10 diferentes árvores de cenários. Através desta análise podem-se verificar dois comportamentos: a variabilidade dos resultados ao se considerar diferentes árvores com o mesmo número de aberturas, e a diferença entre os resultados para números diferentes de cenários.

Ressalta-se que as árvores consideradas são do tipo "garfo". Além do mais, não foram aplicadas técnicas de redução de cenários nesta análise.

Como estudo de caso foi realizada a otimização estocástica em respeito à operação das UHEs Foz do Areia e Três Marias. Foram analisados os parâmetros: Função Objetivo, Tempo de Processamento envolvido, Vazão esperada a ser turbinada no mês 1 (primeiro mês de planejamento) e a Energia gerada esperada no horizonte de planejamento (4 anos).

Os resultados seguem nos itens 5.10.1.1 e 5.10.1.2 a seguir. 


\subsubsection{Foz do Areia}

Tabela 7. Resultados das otimizações - Função Objetivo - UHE Foz do Areia

\begin{tabular}{|c|c|c|c|c|c|c|}
\hline No de Cenários & 5 & 10 & 25 & 50 & 100 \\
\hline Árvore & \multicolumn{5}{|c|}{ Função Objetivo } \\
\hline A1 & 98272650 & 108895000 & 119458700 & 122300000 & 121063900 \\
\hline A2 & 109621200 & 128163500 & 125501500 & 125253200 & 120399800 \\
\hline A3 & 137909200 & 118422900 & 115933500 & 125331300 & 120279800 \\
\hline A4 & 125095500 & 110314600 & 119440900 & 129398300 & 128265100 \\
\hline A5 & 120668400 & 127547900 & 115233900 & 124666900 & 124507900 \\
\hline A6 & 123020200 & 119591400 & 116813700 & 112918600 & 122984400 \\
\hline A7 & 87592740 & 132872200 & 109098900 & 125598900 & 125361400 \\
\hline A8 & 123871800 & 117202000 & 131814400 & 134079200 & 127817100 \\
\hline A9 & 128554000 & 129603800 & 122304900 & 125639300 & 128345100 \\
\hline A10 & 110288900 & 120169300 & 126380900 & 126362300 & 128594200 \\
\hline Média & 116489459 & 121278260 & 120198130 & 125154800 & 124761870 \\
\hline Desvio Padrão & 15075838 & 8116103 & 6534750 & 5350967 & 3423907 \\
\hline $\begin{array}{l}\text { Coef. de } \\
\text { Variação }\end{array}$ & $13 \%$ & $7 \%$ & $5 \%$ & $4 \%$ & $3 \%$ \\
\hline
\end{tabular}

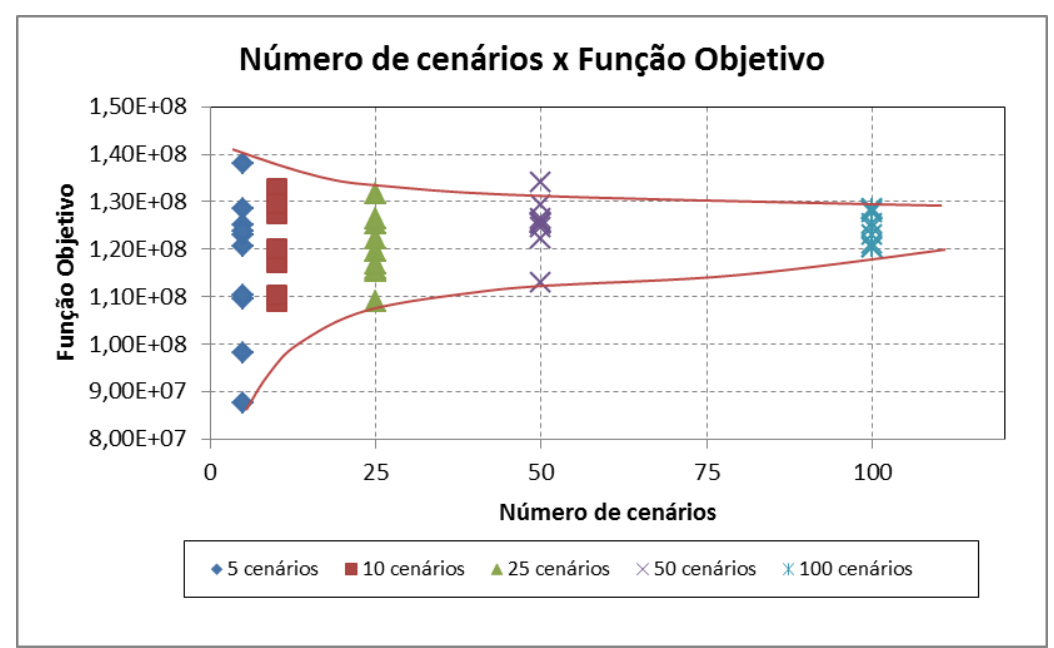

Figura 43. Resultados das otimizações - Função Objetivo - UHE Foz do Areia 
Tabela 8. Resultados das otimizações - Tempo de Processamento - UHE Foz do Areia

\begin{tabular}{|c|c|c|c|c|c|c|}
\hline No de Cenários & 5 & 10 & 25 & 50 & 100 \\
\hline Árvore & \multicolumn{4}{|c|}{ Tempo de Processamento (MM:SS) } \\
\hline A1 & $00: 26$ & $00: 30$ & $00: 39$ & $01: 54$ & $09: 30$ \\
\hline A2 & $00: 26$ & $00: 28$ & $00: 39$ & $01: 51$ & $09: 30$ \\
\hline A3 & $00: 25$ & $00: 25$ & $00: 39$ & $01: 54$ & $09: 31$ \\
\hline A4 & $00: 25$ & $00: 25$ & $00: 39$ & $01: 51$ & $10: 06$ \\
\hline A5 & $00: 28$ & $00: 26$ & $00: 39$ & $01: 55$ & $09: 49$ \\
\hline A6 & $00: 28$ & $00: 26$ & $00: 39$ & $01: 48$ & $09: 41$ \\
\hline A7 & $00: 26$ & $00: 30$ & $00: 38$ & $01: 47$ & $10: 03$ \\
\hline A8 & $00: 24$ & $00: 26$ & $00: 39$ & $01: 58$ & $09: 57$ \\
\hline A9 & $00: 24$ & $00: 25$ & $00: 37$ & $01: 48$ & $10: 12$ \\
\hline A10 & $00: 23$ & $00: 25$ & $00: 38$ & $01: 55$ & $10: 01$ \\
\hline Média & $00: 26$ & $00: 27$ & $00: 39$ & $01: 52$ & $09: 50$ \\
\hline Desvio Padrão & $00: 02$ & $00: 02$ & $00: 01$ & $00: 04$ & $00: 16$ \\
\hline $\begin{array}{l}\text { Coef. de } \\
\text { Variação (\%) }\end{array}$ & $6 \%$ & $8 \%$ & $2 \%$ & $3 \%$ & $3 \%$ \\
\hline
\end{tabular}

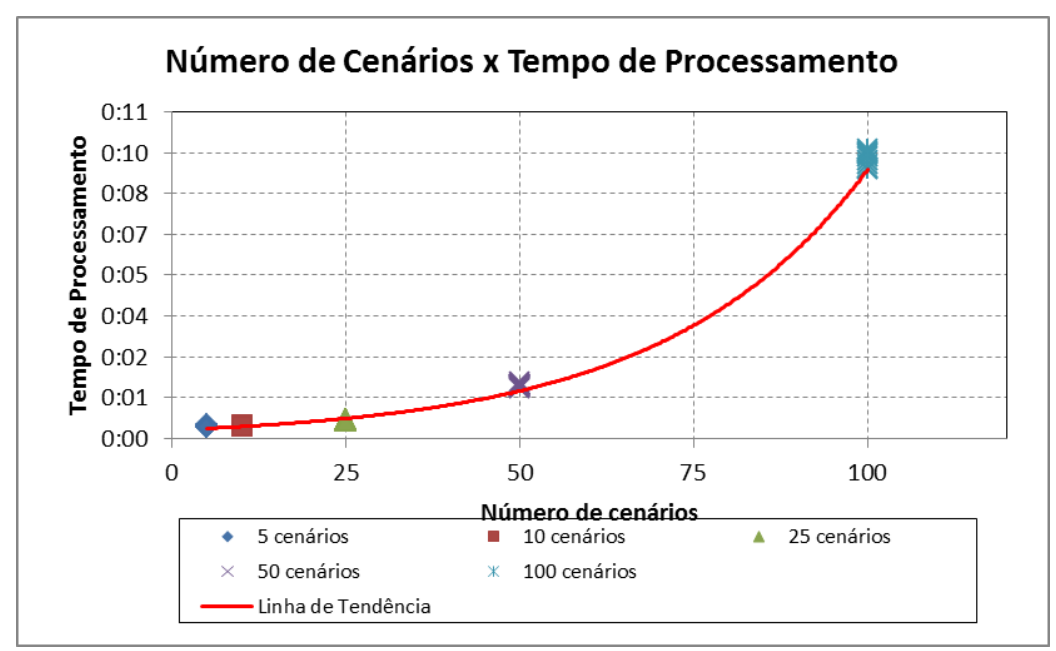

Figura 44. Resultados das otimizações - Tempo de Processamento - UHE Foz do Areia 
Tabela 9. Resultados das otimizações - Vazão Turbinada esperada em $T=1-$ UHE Foz do Areia

\begin{tabular}{|c|c|c|c|c|c||}
\hline No de Cenários & 5 & 10 & 25 & 50 & 100 \\
\hline Árvore & \multicolumn{5}{|c|}{ Vazão Turbinada (m $\mathbf{3}$ /s) } \\
\hline A1 & 511,6 & 499,0 & 431,6 & 362,1 & 366,1 \\
\hline A2 & 642,0 & 342,1 & 447,1 & 387,2 & 365,8 \\
\hline A3 & 460,8 & 341,5 & 340,0 & 366,9 & 378,6 \\
\hline A4 & 302,0 & 356,8 & 436,4 & 312,2 & 346,5 \\
\hline A5 & 542,6 & 396,2 & 482,5 & 359,1 & 362,4 \\
\hline A6 & 403,6 & 371,1 & 515,6 & 401,3 & 372,6 \\
\hline A7 & 654,3 & 448,0 & 432,2 & 350,1 & 367,0 \\
\hline A8 & 433,8 & 484,3 & 373,7 & 375,8 & 356,9 \\
\hline A9 & 500,8 & 336,7 & 510,6 & 364,9 & 348,9 \\
\hline A10 & 380,9 & 544,8 & 435,5 & 369,7 & 370,6 \\
\hline Média & 483,2 & 412,1 & 440,5 & 364,9 & 363,5 \\
\hline Desvio Padrão & 111 & 76 & 55 & 24 & 10 \\
\hline $\begin{array}{l}\text { Coef. de } \\
\text { Variação (\%) }\end{array}$ & $23 \%$ & $18 \%$ & $12 \%$ & $6 \%$ & $3 \%$ \\
\hline
\end{tabular}

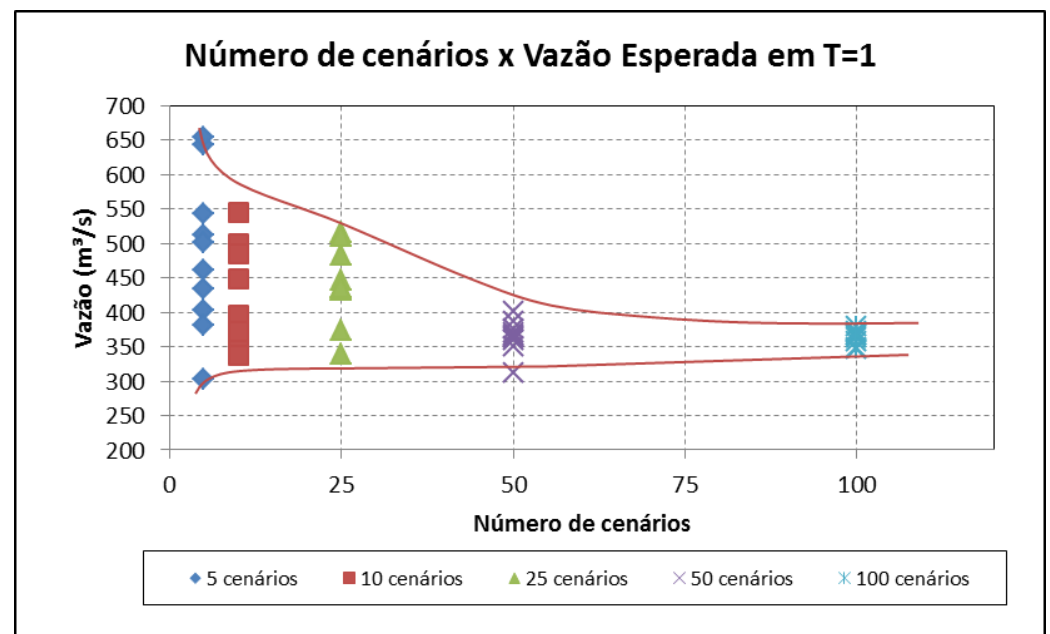

Figura 45. Resultados das otimizações - Vazão Turbinada esperada em T=1 UHE Foz do Areia 
Tabela 10. Resultados das otimizações - Energia Gerada - UHE Foz do Areia

\begin{tabular}{|c|c|c|c|c|c|}
\hline No de Cenários & 5 & 10 & 25 & 50 & 100 \\
\hline Árvore & & \multicolumn{4}{|c|}{ Energia Gerada (MW) } \\
\hline A1 & 44449 & 42358 & 40087 & 38684 & 39900 \\
\hline A2 & 42274 & 38015 & 38499 & 38892 & 39371 \\
\hline A3 & 36639 & 40062 & 40845 & 38793 & 39926 \\
\hline A4 & 38858 & 41923 & 40194 & 38077 & 38294 \\
\hline A5 & 39562 & 38171 & 40790 & 39156 & 39120 \\
\hline A6 & 39628 & 39680 & 40462 & 41424 & 39414 \\
\hline A7 & 46802 & 37145 & 42400 & 39049 & 38849 \\
\hline A8 & 39617 & 40616 & 37481 & 37011 & 38272 \\
\hline A9 & 38787 & 37776 & 39536 & 38884 & 38327 \\
\hline A10 & 42385 & 40082 & 38871 & 38684 & 38781 \\
\hline Média & 40900 & 39583 & 39916 & 38865 & 39025 \\
\hline Desvio Padrão & 3043 & 1776 & 1389 & 1095 & 627 \\
\hline $\begin{array}{l}\text { Coef. de } \\
\text { Variação (\%) }\end{array}$ & $7 \%$ & $4 \%$ & $3 \%$ & $3 \%$ & $2 \%$ \\
\hline
\end{tabular}

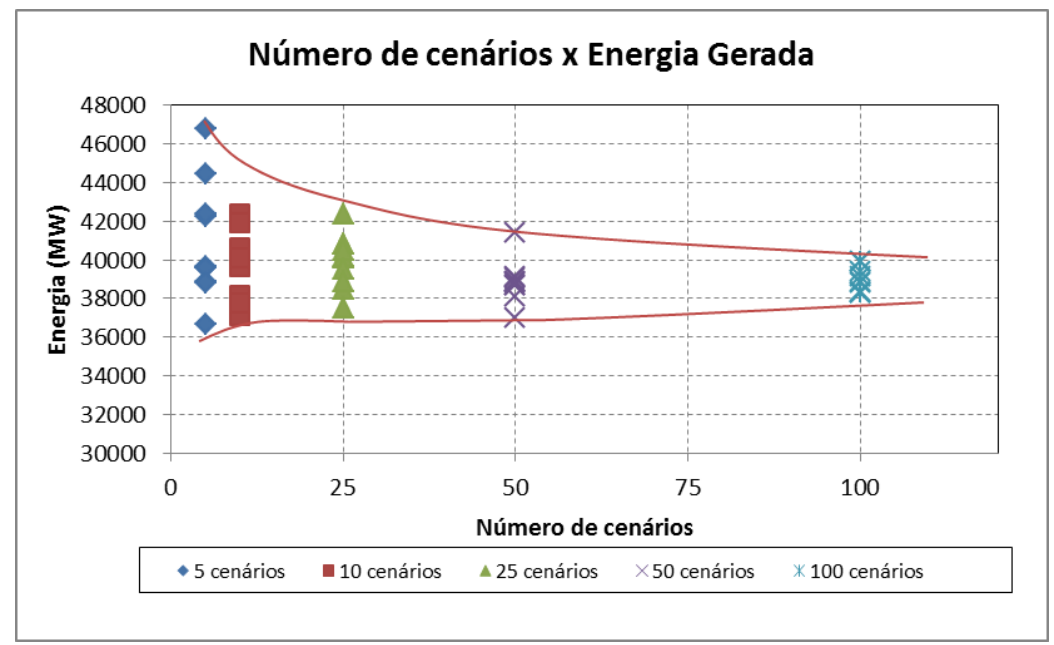

Figura 46. Resultados das otimizações - Energia Gerada - UHE Foz do Areia 


\subsubsection{Três Marias}

Tabela 11. Resultados das otimizações - Função Objetivo - UHE Três Marias

\begin{tabular}{|c|c|c|c|c|c|c|}
\hline No de Cenários & 5 & 10 & 25 & 50 & 100 \\
\hline Árvore & \multicolumn{5}{|c|}{ Função Objetivo } \\
\hline A1 & 2212498 & 2143639 & 2513005 & 2397943 & 2240402 \\
\hline A2 & 2104070 & 2756024 & 2313954 & 2284265 & 2348161 \\
\hline A3 & 2488315 & 2416448 & 2217948 & 2239486 & 2204975 \\
\hline A4 & 2233713 & 2201302 & 2344262 & 2367578 & 2409798 \\
\hline A5 & 2640762 & 2256401 & 2266351 & 2325699 & 2219812 \\
\hline A6 & 3317827 & 2498988 & 2388363 & 2213205 & 2283665 \\
\hline A7 & 2475064 & 2105801 & 2611236 & 2222823 & 2265442 \\
\hline A8 & 2626897 & 2456466 & 2243928 & 2138922 & 2265442 \\
\hline A9 & 2531660 & 2326647 & 2451516 & 2249834 & 2272745 \\
\hline A10 & 2168987 & 2242238 & 2115439 & 2302615 & 2379145 \\
\hline Média & 2479979,3 & 2340395,4 & 2346600,2 & 2274237 & 2288958,7 \\
\hline Desvio Padrão & 353146 & 196392 & 148516 & 77497 & 68175 \\
\hline $\begin{array}{l}\text { Coef. de } \\
\text { Variação }\end{array}$ & $14 \%$ & $8 \%$ & $6 \%$ & $3 \%$ & $3 \%$ \\
\hline
\end{tabular}

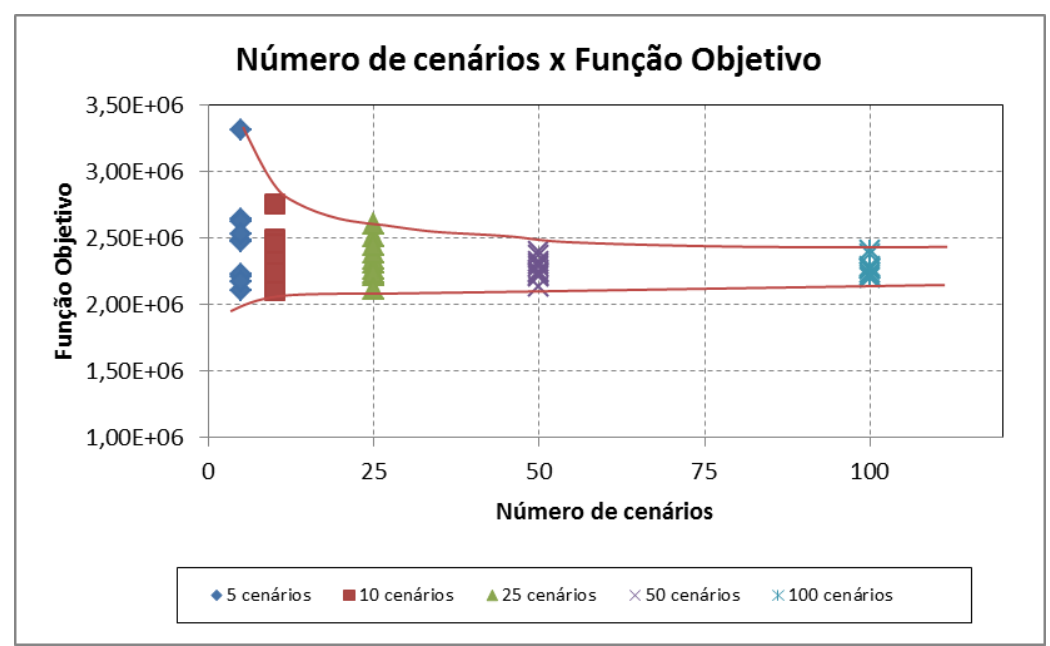

Figura 47. Resultados das otimizações - Função Objetivo - UHE Três Marias 
Tabela 12. Resultados das otimizações - Tempo de Processamento - UHE Três Marias

\begin{tabular}{|c|c|c|c|c|c|}
\hline No de Cenários & 5 & 10 & 25 & 50 & 100 \\
\hline Árvore & \multicolumn{5}{|c|}{ Tempo de Processamento (MM:SS) } \\
\hline A1 & $00: 30$ & $00: 30$ & $00: 50$ & $02: 19$ & $09: 22$ \\
\hline A2 & $00: 30$ & $00: 29$ & $00: 47$ & $01: 59$ & $09: 35$ \\
\hline A3 & $00: 29$ & $00: 30$ & $00: 49$ & $01: 57$ & $08: 23$ \\
\hline A4 & $00: 28$ & $00: 29$ & $00: 49$ & $01: 58$ & $09: 34$ \\
\hline A5 & $00: 28$ & $00: 29$ & $00: 48$ & $02: 09$ & $09: 40$ \\
\hline A6 & $00: 30$ & $00: 29$ & $00: 45$ & $01: 56$ & $09: 08$ \\
\hline A7 & $00: 29$ & $00: 28$ & $00: 49$ & $01: 54$ & $08: 22$ \\
\hline A8 & $00: 28$ & $00: 29$ & $00: 48$ & $01: 51$ & $08: 22$ \\
\hline A9 & $00: 29$ & $00: 29$ & $00: 45$ & $01: 58$ & $08: 47$ \\
\hline A10 & $00: 30$ & $00: 29$ & $00: 45$ & $01: 58$ & $09: 07$ \\
\hline Média & $00: 29$ & $00: 29$ & $00: 47$ & $02: 00$ & $09: 02$ \\
\hline Desvio Padrão & $00: 01$ & $00: 01$ & $00: 02$ & $00: 08$ & $00: 32$ \\
\hline $\begin{array}{l}\text { Coef. de } \\
\text { Variação }\end{array}$ & $3 \%$ & $2 \%$ & $4 \%$ & $7 \%$ & $6 \%$ \\
\hline
\end{tabular}

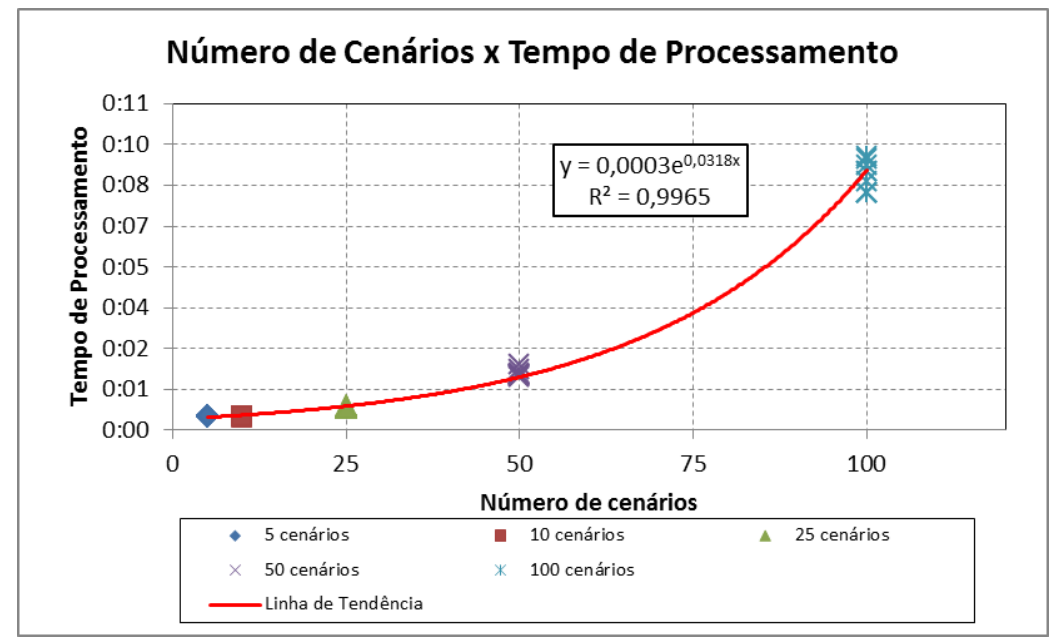

Figura 48. Resultados das otimizações - Tempo de Processamento - UHE Três Marias 
Tabela 13. Resultados das otimizações - Vazão Turbinada esperada em $T=1$ UHE Três Marias

\begin{tabular}{|c|c|c|c|c|c|}
\hline No de Cenários & 5 & 10 & 25 & 50 & 100 \\
\hline Árvore & \multicolumn{5}{|c|}{ Vazão Turbinada (m³ $\mathbf{s}$ ) } \\
\hline A1 & 511,6 & 499,0 & 431,6 & 362,1 & 366,1 \\
\hline A2 & 642,0 & 342,1 & 447,1 & 387,2 & 369,0 \\
\hline A3 & 460,8 & 341,5 & 497,7 & 366,9 & 378,6 \\
\hline A4 & 307,0 & 356,8 & 320,0 & 312,2 & 346,5 \\
\hline A5 & 542,6 & 396,2 & 482,5 & 359,1 & 362,4 \\
\hline A6 & 403,6 & 371,1 & 515,6 & 401,3 & 372,6 \\
\hline A7 & 654,3 & 448,0 & 432,2 & 350,1 & 367,0 \\
\hline A8 & 433,8 & 484,3 & 373,7 & 375,8 & 356,9 \\
\hline A9 & 500,8 & 336,7 & 510,6 & 364,9 & 348,9 \\
\hline A10 & 380,9 & 544,8 & 435,5 & 369,7 & 370,6 \\
\hline Média & 483,7 & 412,1 & 444,6 & 364,9 & 363,9 \\
\hline Desvio Padrão & 111 & 76 & 62 & 24 & 10 \\
\hline $\begin{array}{l}\text { Coef. de } \\
\text { Variação }\end{array}$ & $23 \%$ & $18 \%$ & $14 \%$ & $6 \%$ & $3 \%$ \\
\hline
\end{tabular}

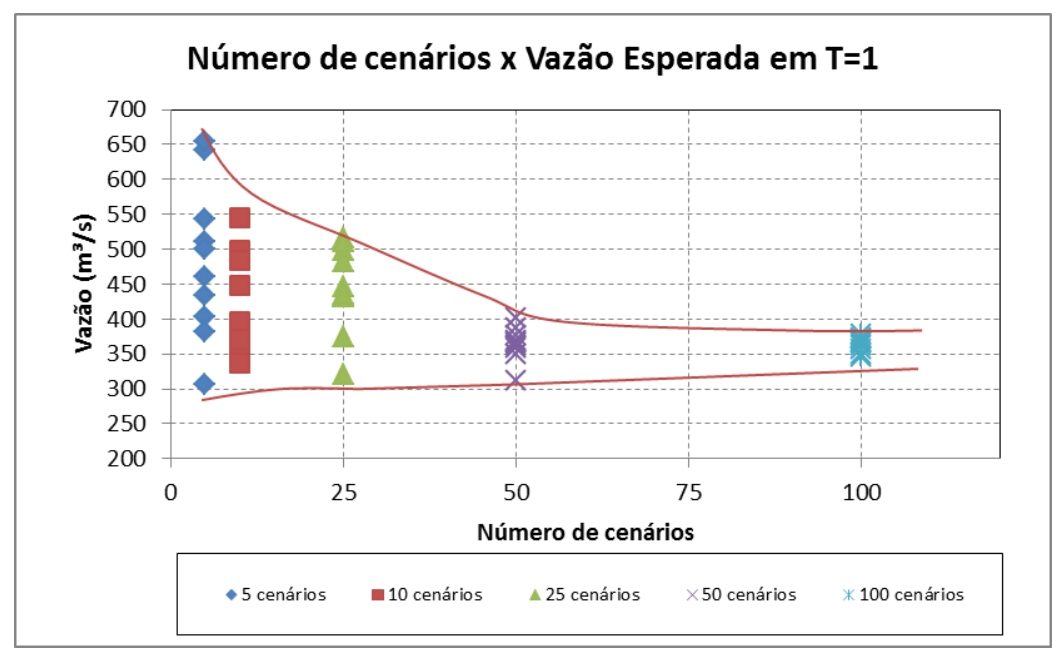

Figura 49. Resultados das otimizações - Vazão Turbinada esperada em T=1 UHE Três Marias 
Tabela 14. Resultados das otimizações - Energia Gerada - UHE Três Marias

\begin{tabular}{|c|c|c|c|c|c|c|}
\hline No de Cenários & 5 & 10 & 25 & 50 & 100 \\
\hline Árvore & & \multicolumn{4}{|c|}{ Energia Gerada (MW) } \\
\hline A1 & 44449 & 42358 & 40087 & 38684 & 39900 \\
\hline A2 & 42274 & 38015 & 38499 & 38892 & 39371 \\
\hline A3 & 36639 & 40062 & 40845 & 38793 & 39926 \\
\hline A4 & 38858 & 41923 & 40194 & 38077 & 38294 \\
\hline A5 & 39562 & 38171 & 40790 & 39156 & 39120 \\
\hline A6 & 39628 & 39680 & 40462 & 41424 & 39414 \\
\hline A7 & 46802 & 37145 & 42400 & 39049 & 38849 \\
\hline A8 & 39617 & 40616 & 37481 & 37011 & 38272 \\
\hline A9 & 38787 & 37776 & 39536 & 38884 & 38327 \\
\hline A10 & 42385 & 40082 & 38871 & 38684 & 38781 \\
\hline Média & 40900 & 39583 & 39916 & 38865 & 39025 \\
\hline Desvio Padrão & 3043 & 1776 & 1389 & 1095 & 627 \\
\hline $\begin{array}{l}\text { Coef. de } \\
\text { Variação }\end{array}$ & $7 \%$ & $4 \%$ & $3 \%$ & $3 \%$ & $2 \%$ \\
\hline
\end{tabular}

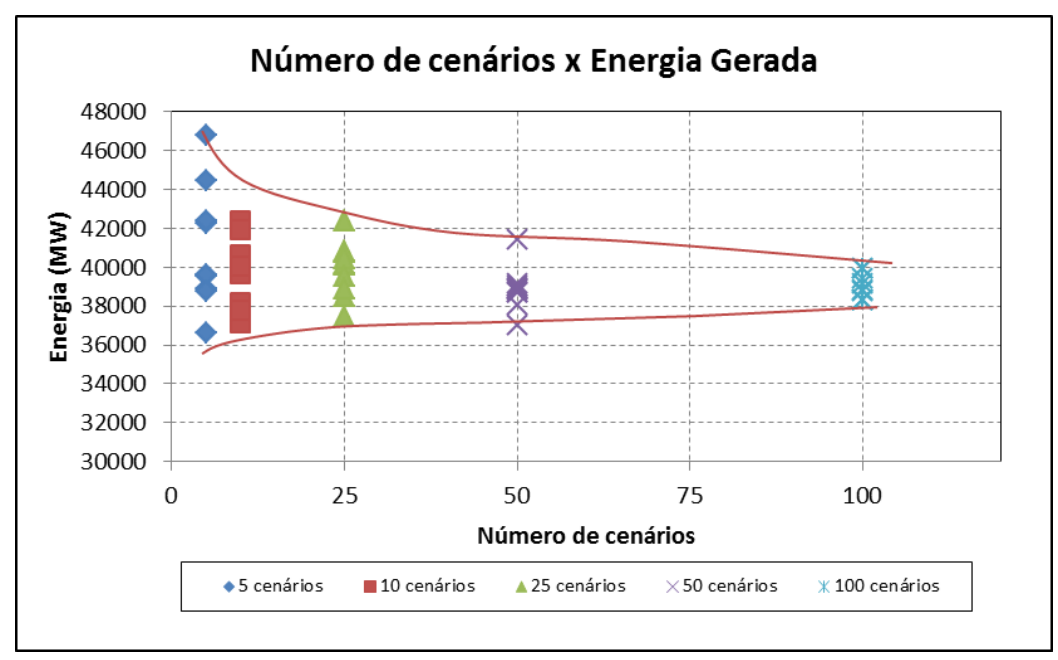

Figura 50. Resultados das otimizações - Energia Gerada - UHE Três Marias 


\subsubsection{Considerações a respeito dos resultados}

Os resultados indicam algumas tendências que merecem atenção, sendo elas:

Verifica-se que há maior estabilidade na solução da otimização estocástica ao se utilizar árvores com mais cenários de vazões. Pode-se considerar, de modo geral, que o modelo de otimização estocástico proposto pode ser considerado válido para o caso da utilização de árvores com ao 50 cenários, quando se verificam menores desvios padrão do valor da solução média (da ordem de $5 \%)$.

Para os dois casos em análise (UHE Foz do Areia e UHE Três Marias), ao se considerar uma árvore com apenas 5 cenários de vazões afluentes, o valor da vazão turbinada esperada em $T=1$ pode variar significativamente (coef. e variação de $23 \%$ ). Este valor pode ser ainda maior caso sejam analisados mais de 10 árvores de 5 cenários.

Por outro lado, a utilização de 100 cenários de vazões afluentes implica em resultados mais estáveis, ou seja, não se esperam grandes divergências nos resultados ao se considerar diferentes árvores contendo esse número de cenários.

O parâmetro tempo de processamento apresenta uma menor tendência de redução do desvio padrão ao se aumentar o número de cenários, chegando a casos de aumento desse valor.

Assim, pode-se concluir que a utilização de uma árvore com um número elevado de cenários de vazões tende à resultados mais precisos e estáveis na otimização da geração. De maneira oposta, a utilização de uma árvore com poucos cenários não se mostra confiável no planejamento da geração hidrelétrica. Estes resultados são, de modo geral, concordantes com os resultados esperados para processos de otimização estocástica.

Sabendo-se que o regime de vazões afluentes da UHE Foz do Areia e Três Marias são diferentes, sendo o primeiro menos bem definido que o segundo (ver figuras 22 e 24), não se verifica uma influência clara do regime hidrológico 
no comportamento médio e na variação dos resultados da otimização estocástica frente à árvores com diferentes cenários.

Ressalta-se que as árvores utilizadas possuem cenários equiprováveis de vazões, ou seja, possuem a mesma probabilidade de ocorrência, Assim, cenários com poucas aberturas de cenários se mostram ainda menos adequados para o processo de otimização estocástica da geração hidrelétrica.

\subsubsection{Otimização estocástica frente a diferentes árvores reduzidas de cenários}

Uma vez verificado o comportamento médio dos resultados frente à utilização de diferentes cenários de vazões, cabe, neste item, analisar a sensibilidade do processo de otimização frente à aplicação de técnicas de redução de cenários.

Se por um lado as técnicas de redução de cenários visam reduzir a dimensão do problema, e assim, viabilizar o problema, por outro as principais características da árvore inicial devem ser mantidas e a solução do problema com a árvore reduzida deve ser próxima daquela com a árvore inicial. Este tema tem sido alvo de muitos estudos, tanto no contexto nacional quanto internacional.

A metodologia aplicada no SCENRED, apresentada no item 5.8, possui esta preocupação inerente ao próprio processo. O conceito de distância de probabilidade (ou métrica probabilística), apresentada no item 4 - Redução de Cenários, consiste em um parâmetro que mede a "distância" entre os cenários de uma árvore, de modo que a técnica de redução de cenários aplicada busca minimizar a diferença entre as métricas probabilísticas da árvore inicial e reduzida.

Segundo Follestad et al (2012) no processo estocástico de dois estágios pode ser mostrado que o valor ótimo do problema resolvido com a árvore reduzida é próximo ao valor da solução com a árvore original caso as distâncias sejam próximas. Esta estabilidade não é mais válida para problemas de programação estocástica multi-estágio, e requer a introdução da "distância de filtragem", que mede o quão próximo estão as estruturas de duas árvores de cenários. 
No caso de modelos multi-estágio (caso estudado na presente dissertação), a experiência indica que a técnica de redução deve ser otimizada não só em relação as distâncias de probabilidades, mas também em respeito à distância de filtragem, medida através da distância entre as estruturas de cada cenário como um todo (Heitsch et Romisch, 2009).

Assumindo que a modelagem do SCENRED (elaborado por Heitsch et Romisch, 2003) já otimiza o processo de redução de cenários no que concerne à manutenção das distâncias de probabilidade, e que, assim como verificado no item 5.10.1, há estabilidade na solução ao se utilizar árvores com um número de cenários superior a cerca de 50 cenários, este item busca analisar o modelo frente a estabilidade "out of sample".

Assim como mencionado no item 5.10.1.3 a utilização de mais cenários levam a resultados mais estáveis. Os programas atuais de planejamento da operação, como o caso do NEWAVE, utilizam elevado número de cenários de vazões afluentes tais como 1.000 ou 10.000 cenários. Contudo, assim como já esperado pela bibliografia, e confirmado através das figuras 44 e 48 , verifica-se um crescimento exponencial do tempo de processamento computacional ao se aumentar o número de cenários (levando ao chamado "Mal da Dimensionalidade"), chegando-se à necessidade de se obter um ponto intermediário entre os dois seguintes extremos: árvores com elevados número de cenários (que necessitam de elevados tempos de processamento) e árvores reduzidas (que podem levar a resultados instáveis e pouco confiáveis). A figura 51 a seguir resume esta questão. 


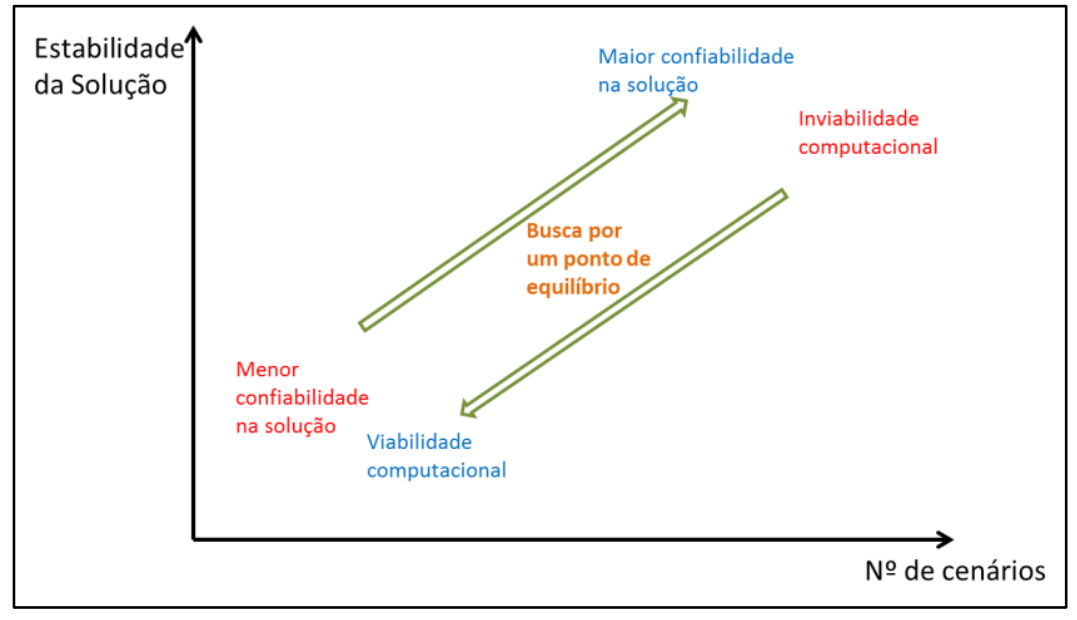

Figura 51. Relações qualitativas em questão

Deste modo, um artifício consiste em se utilizar inicialmente um número elevados de cenários (buscando uma maior representatividade estatística), e, antes da etapa de otimização, aplicar uma técnica de redução de cenários, de modo a conservar as principais estatísticas da árvore reduzida em relação à árvore inicial. A partir da árvore reduzida é então aplicado o algoritmo de otimização estocástica. Este raciocínio consistiu no foco das análises de sensibilidade deste item.

As principais premissas consideradas foram:

- Foi utilizado sempre o mesmo computador (hardware) em todas as otimizações;

- Partiu-se de uma árvore de cenários inicial do tipo "garfo", com 1.000 cenários equiprováveis (todos os cenários possuem a mesma probabilidade de ocorrência) de vazões médias mensais para cada UHE, com abertura, geradas a partir do modelo estocástico descrito no item 5.8;

- Para cada UHE, a partir da respectiva árvore inicial gerada, foram realizadas 14 otimizações, considerando, em cada otimização, uma árvore reduzida com um número diferente de cenários $(5,10,15,20,25$, $30,40,50,60,70,80,90,100$ e 150 cenários);

- Não foram analisadas árvores reduzidas com mais de 150 cenários devido ao excessivo tempo computacional demandado para a solução do problema considerando árvores com esse número de cenários; 
- Foram realizadas análises para as seis UHEs em estudo (Foz do Areia, Nova Ponte, Três Marias, Irapé, Serra da Mesa e Balbina);

- Foram definidos os seguintes parâmetros de análise:

- Porcentagem de Redução (equação 30);

- Tempo de Processamento;

○ Função Objetivo (ZH), (equação 31);

- Vazão turbinada esperada no instante $T=1$ (correspondente ao primeiro mês após a abertura da árvore e ao primeiro mês abrangido na otimização estocástica), valor ponderado pelas probabilidades de cada cenário; e

- Energia gerada ao longo do horizonte de planejamento; ponderada pelas probabilidades de cada cenário.

- Foi considerado um horizonte de 4 anos (48 meses) de planejamento $O$ processo de otimização foi realizado entre os meses $T=1$ e $T=48$, de modo que o mês $T=0$, correspondente ao nó de origem da árvore de cenários, não foi considerado na análise;

- Os parâmetros operativos das usinas, tais como: evapotranspiração média mensal, usos consuntivos, curvas Cota $x$ Área $x$ Volume, curva chave no Canal de Fuga, produtividade específica $\left(\mathrm{MW} /\left(\mathrm{m}^{3} / \mathrm{s}\right)\right.$ e vazões mínima e máxima turbináveis, são os mesmos fornecidos no software HIDROTEM (Hidroterm, 2013), com início das simulações no mês de Janeiro de 2013;

- Foi adotado que os volumes dos reservatórios no início da otimizações sejam de $70 \%$ do Volume Útil;

- Foi adotado que os volumes dos reservatórios no final da otimizações sejam de $30 \%$ do Volume Útil;

- Foi considerado que a ferramenta de redução de cenários utilizado SCENRED - Heitsch e Romisch (2005), é válido quanto à manutenção das principais estatísticas em relação à árvore inicial, cabendo à presente dissertação apenas o levantamento destas estatísticas.

Nos itens 5.10.2.1 a 5.10.2.6 a seguir são apresentados os resultados obtidos. As considerações e conclusões a respeito dos resultados obtidos são concentrados no item 5.10.2.7. 


\subsubsection{UHE Foz do Areia}
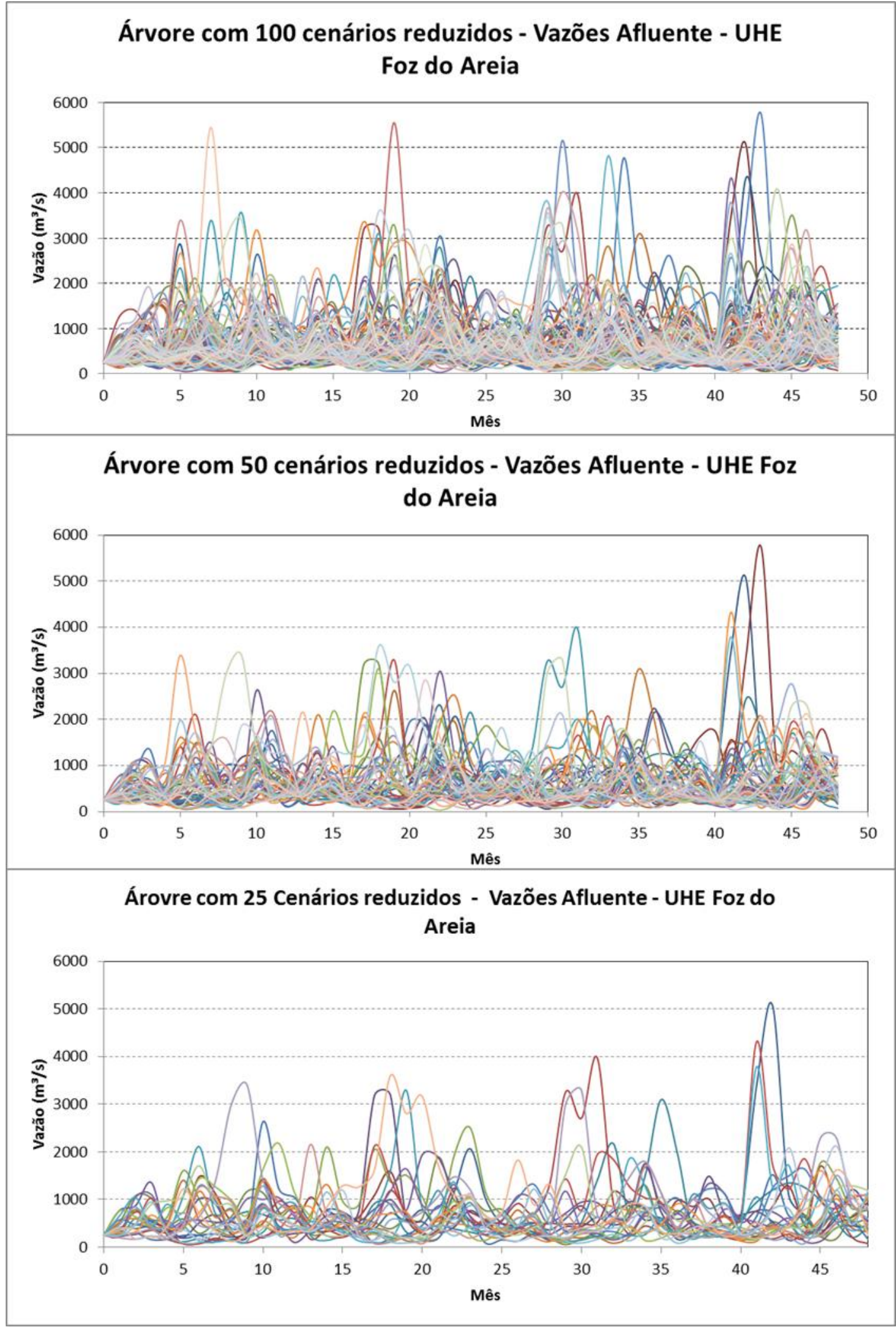

Figura 52. Árvores de Vazões Afluentes - UHE Foz do Areia 


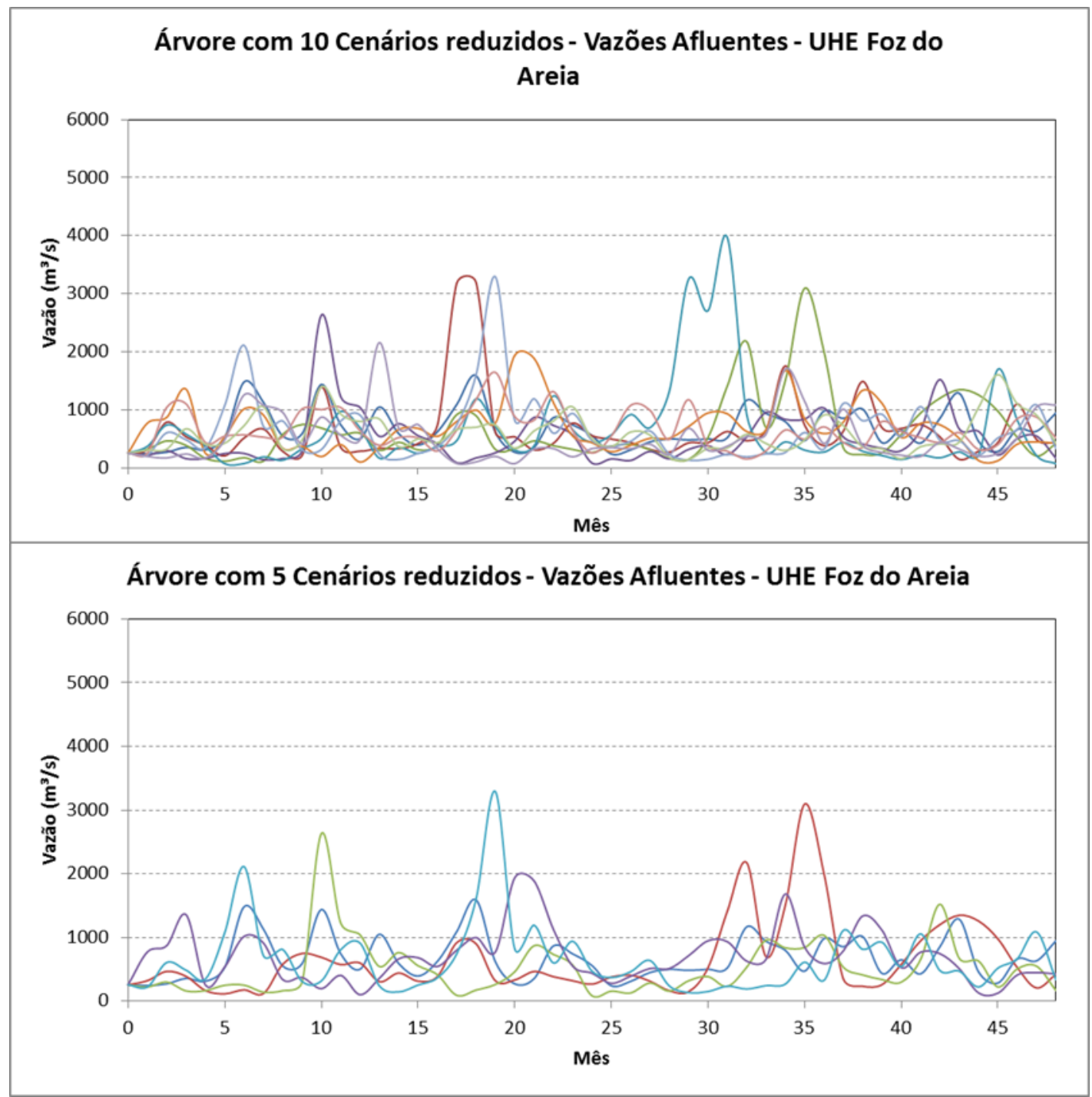

Figura 53. Árvores de Vazões Afluentes - UHE Foz do Areia (continuação)

Tabela 15. Comparação dos principais parâmetros estatísticos das séries de vazões - UHE Foz do Areia

\begin{tabular}{|c|c|c|c|c|c|c|c|}
\hline \multirow{2}{*}{ Parâmetros Estatísticos } & \multirow{2}{*}{\begin{tabular}{|c} 
Série Histórica \\
(1931 - 2012)
\end{tabular}} & \multirow{2}{*}{ 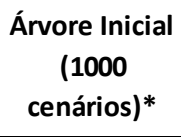 } & \multicolumn{5}{|c|}{ Árvore Reduzida - Número de cenários* } \\
\hline & & & 100 & 50 & 25 & 10 & 5 \\
\hline vazão média (m³/s) & 656 & 647 & 618 & 599 & 602 & 620 & 624 \\
\hline desvio Padrão $\left(\mathrm{m}^{3} / \mathrm{s}\right.$ & 495 & 474 & 451 & 446 & 460 & 461 & 472 \\
\hline Coeficiente de Variação & $76 \%$ & $72 \%$ & $73 \%$ & $75 \%$ & $76 \%$ & $74 \%$ & $76 \%$ \\
\hline Assimetria & 2,3 & 1,8 & 1,7 & 1,8 & 2,0 & 1,9 & 2,0 \\
\hline
\end{tabular}


Tabela 16. Parâmetros obtidos - UHE Foz do Areia

\begin{tabular}{|c|c|c|c|c|}
\hline $\begin{array}{c}\text { Número de } \\
\text { cenários da árvores } \\
\text { reduzida }\end{array}$ & $\begin{array}{c}\text { Porcentagem de } \\
\text { Redução }\end{array}$ & $\begin{array}{c}\text { Tempo de } \\
\text { Processamento } \\
\text { (HH:MM) }\end{array}$ & Método de Redução & Função Objetivo \\
\hline $\mathbf{5}$ & 0,937 & $00: 03$ & FAST BACKWARD + FORWARD & 13052580 \\
\hline $\mathbf{1 0}$ & 0,906 & $00: 03$ & FAST BACKWARD + FORWARD & 13304700 \\
\hline $\mathbf{1 5}$ & 0,882 & $00: 04$ & FAST BACKWARD + FORWARD & 13192010 \\
\hline $\mathbf{2 0}$ & 0,863 & $00: 04$ & FAST BACKWARD + FORWARD & 13046620 \\
\hline $\mathbf{2 5}$ & 0,847 & $00: 04$ & FAST BACKWARD + FORWARD & 13001330 \\
\hline $\mathbf{3 0}$ & 0,832 & $00: 04$ & FAST BACKWARD + FORWARD & 12930940 \\
\hline $\mathbf{4 0}$ & 0,805 & $00: 06$ & FAST BACKWARD + FORWARD & 12950210 \\
\hline $\mathbf{5 0}$ & 0,78 & $00: 07$ & FAST BACKWARD + FORWARD & 12802930 \\
\hline $\mathbf{6 0}$ & 0,761 & $00: 10$ & FAST BACKWARD + FORWARD & 12769150 \\
\hline $\mathbf{7 0}$ & 0,741 & $00: 14$ & FAST BACKWARD + FORWARD & 12722840 \\
\hline $\mathbf{8 0}$ & 0,722 & $00: 18$ & FAST BACKWARD + FORWARD & 12696300 \\
\hline $\mathbf{9 0}$ & 0,704 & $00: 23$ & FAST BACKWARD + FORWARD & 12910640 \\
\hline $\mathbf{1 0 0}$ & 0,687 & $00: 29$ & FAST BACKWARD + FORWARD & 12867530 \\
\hline $\mathbf{1 5 0}$ & 0,610 & $01: 18$ & FAST BACKWARD + FORWARD & 12739390 \\
\hline
\end{tabular}

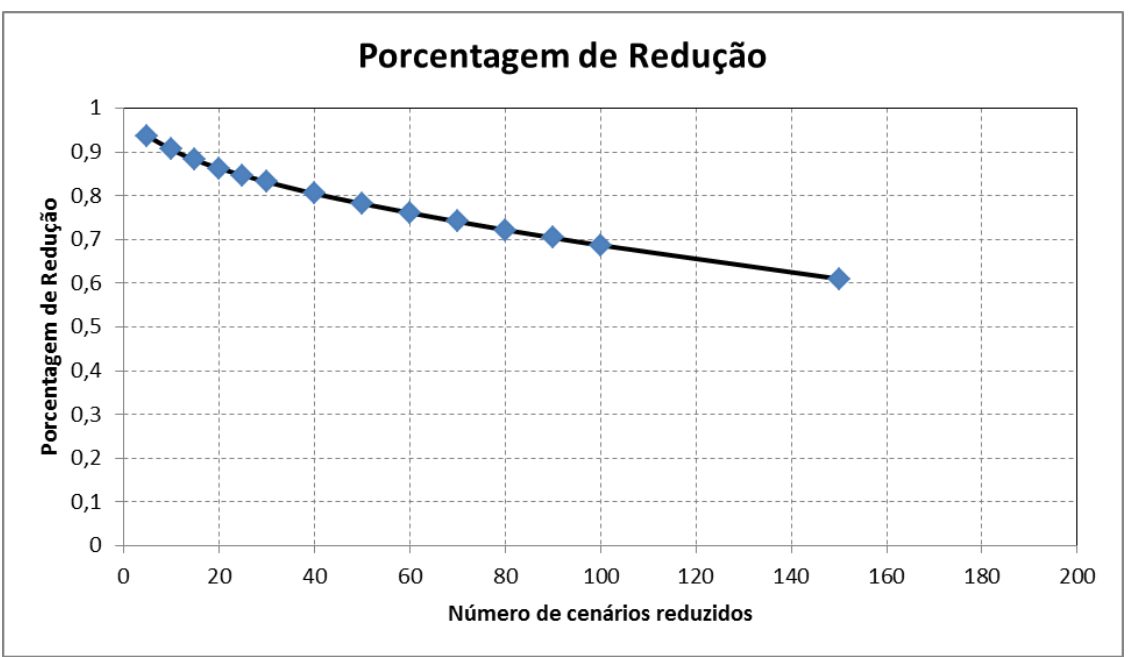

Figura 54. Porcentagem de Redução - UHE Foz do Areia

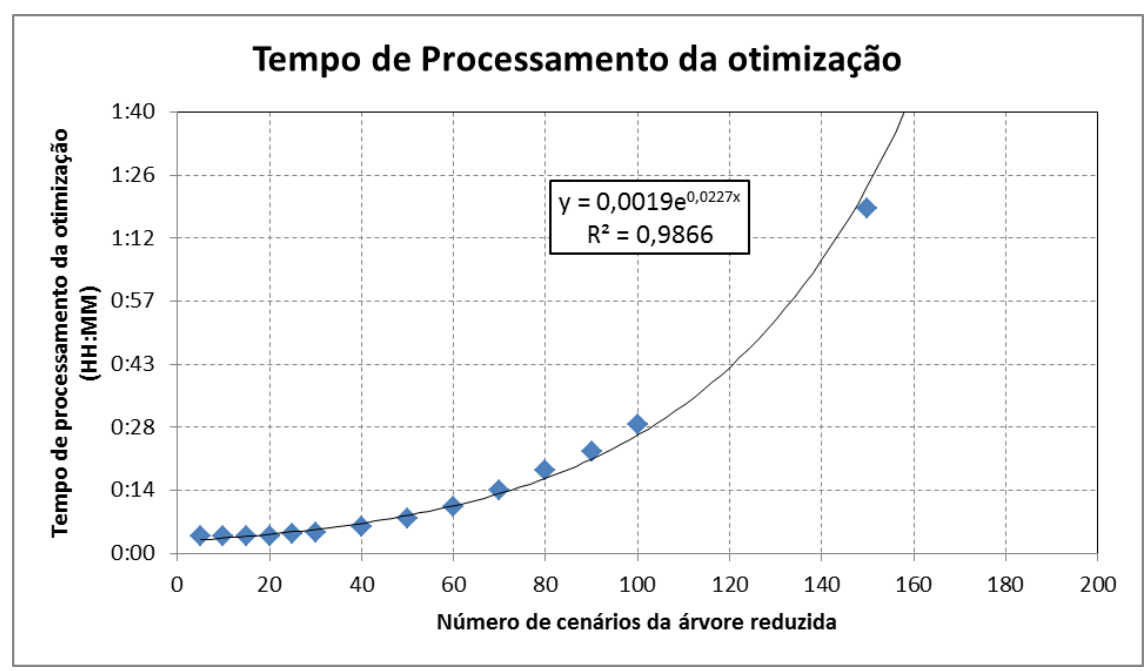

Figura 55. Tempo de Processamento - UHE Foz do Areia 


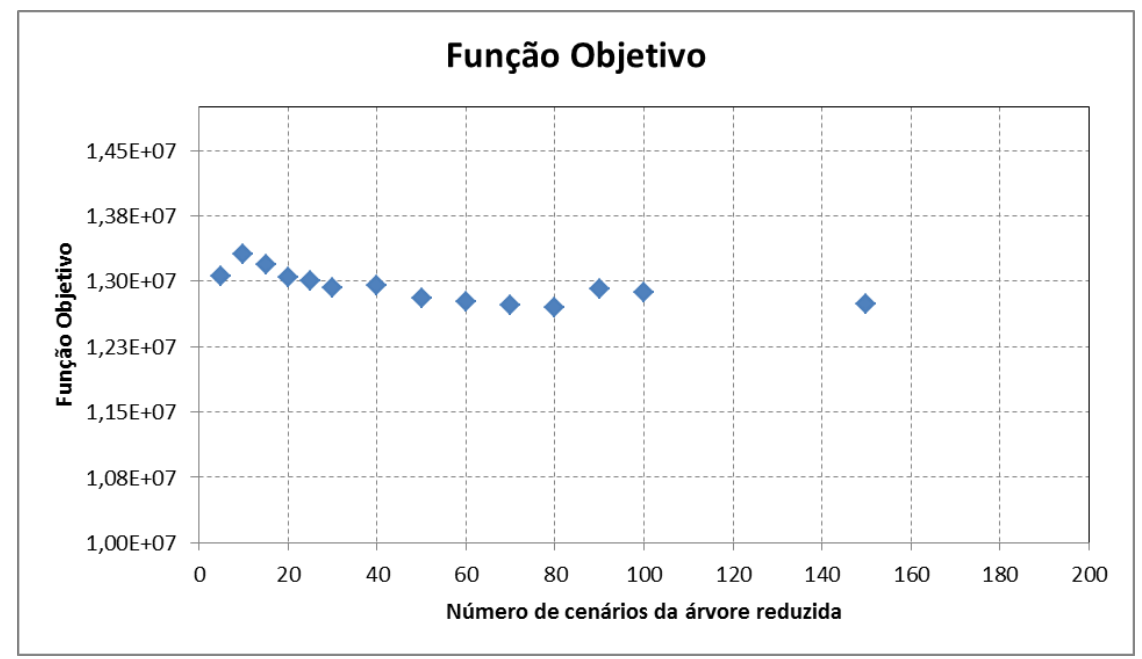

Figura 56. Função Objetivo - UHE Foz do Areia

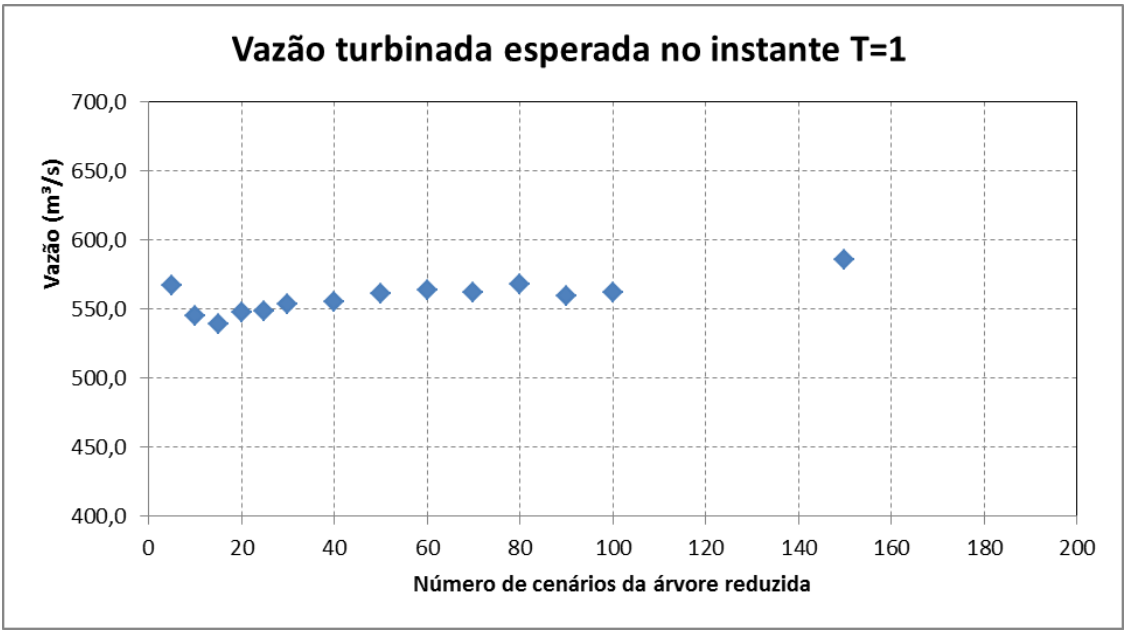

Figura 57. Vazão turbinada esperada no instante $T=1$ - UHE Foz do Areia

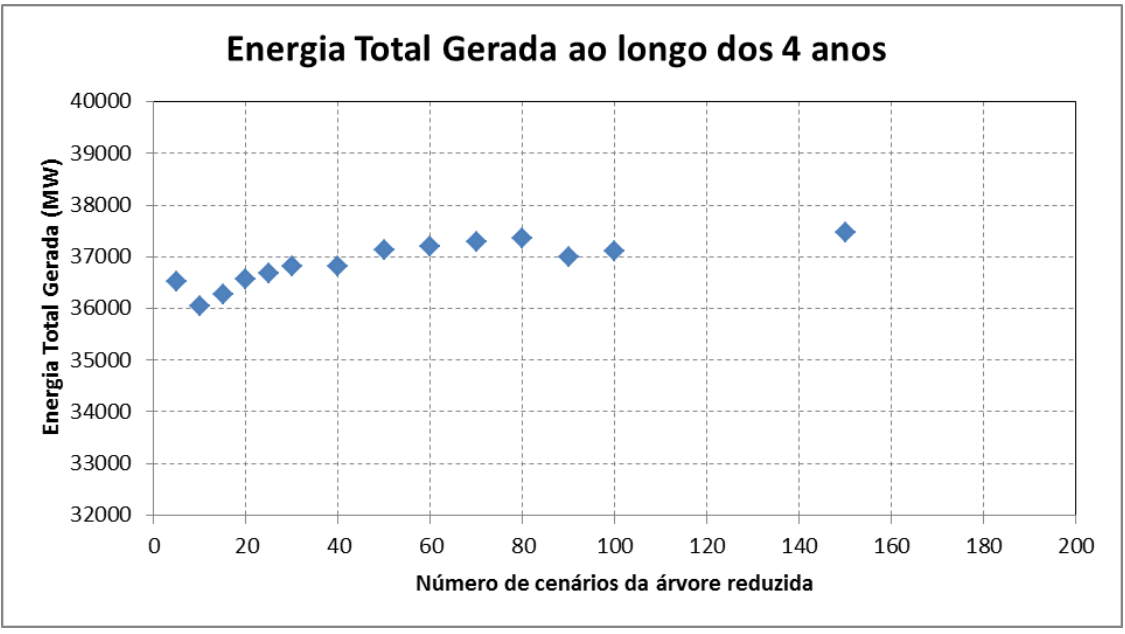

Figura 58. Energia gerada ao longo dos 4 anos - UHE Foz do Areia 


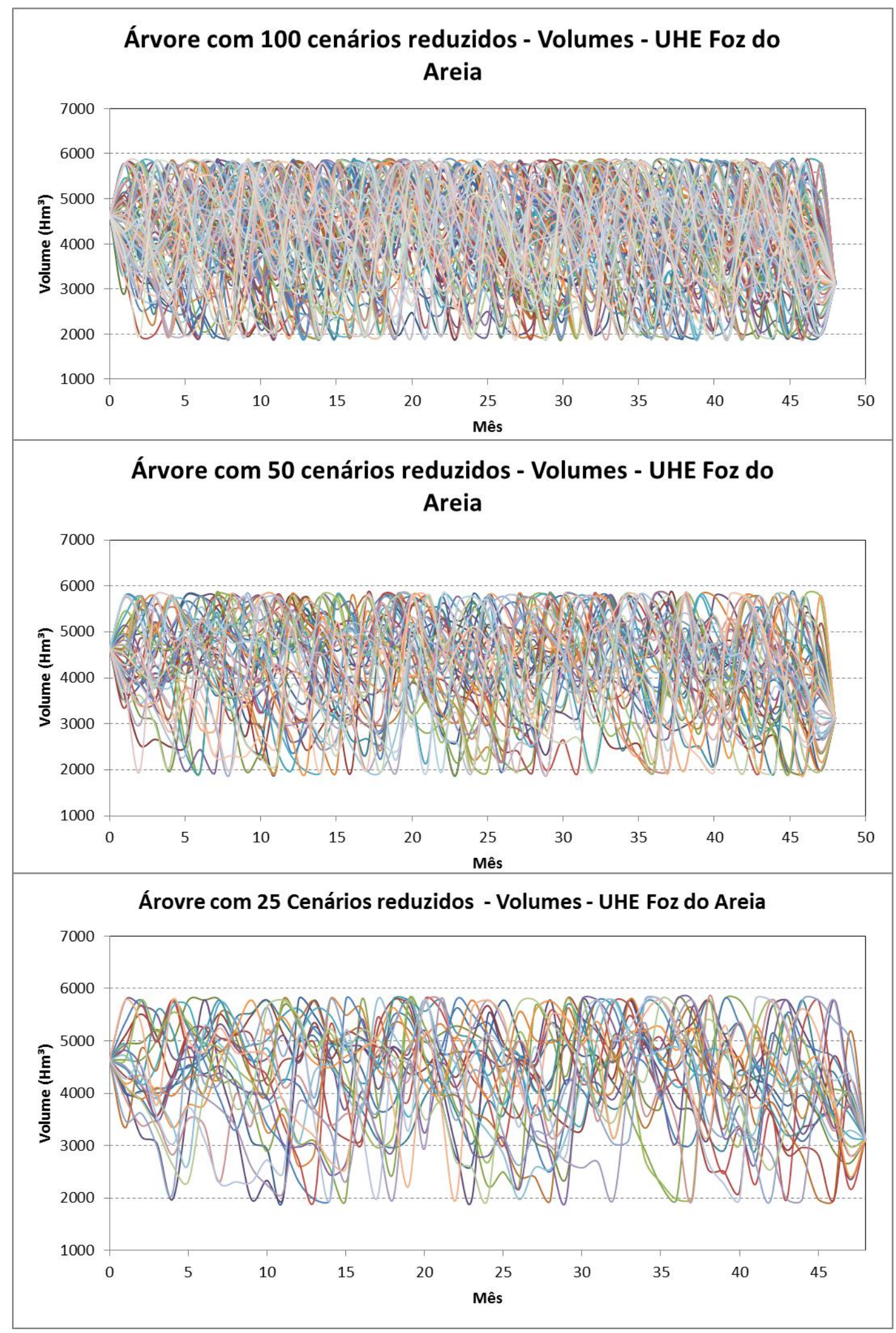

Figura 59. Árvores de cenários - Volumes - UHE Foz do Areia 


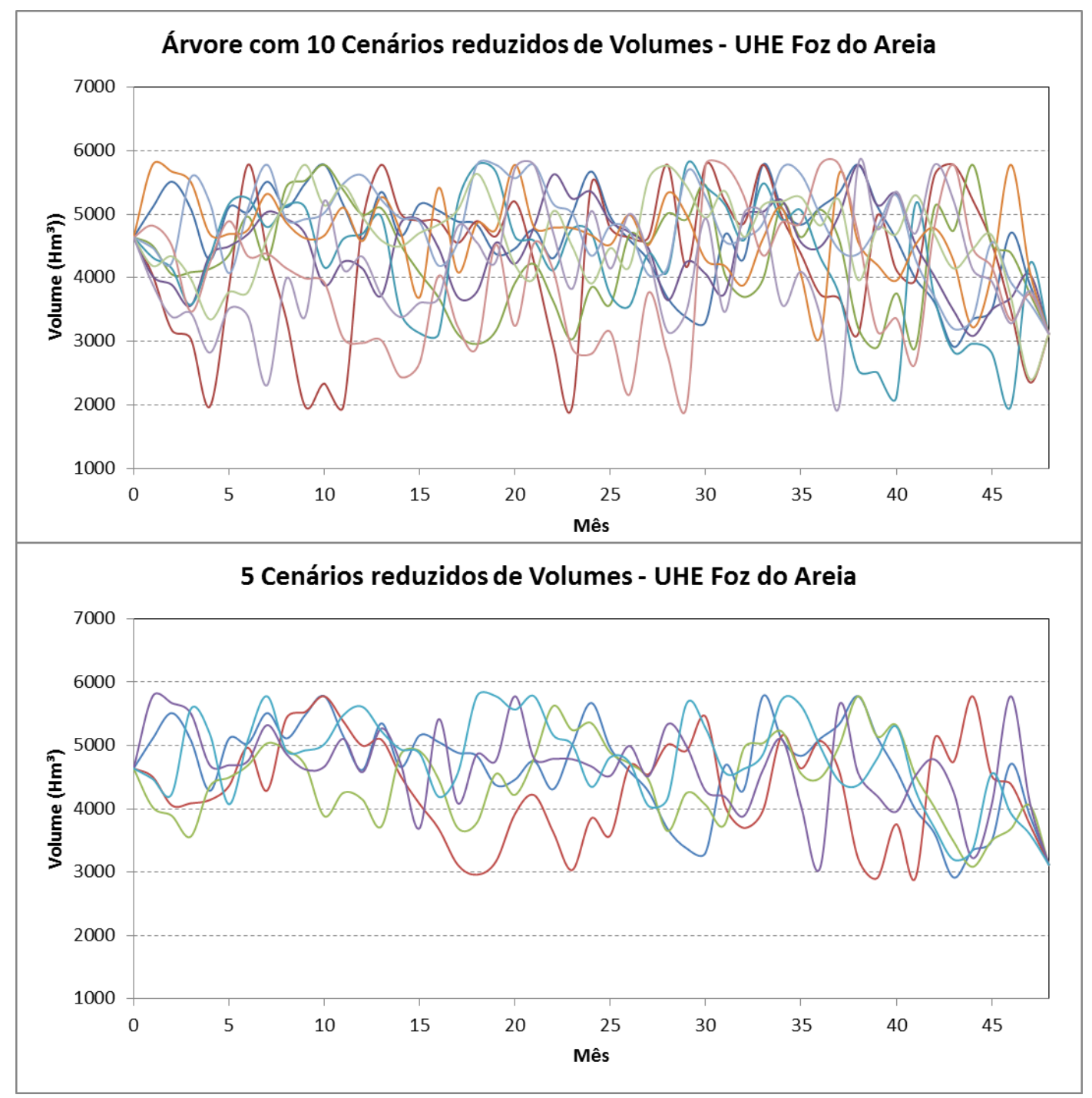

Figura 60. Árvores de cenários - Volumes - UHE Foz do Areia (continuação) 


\subsubsection{UHE Nova Ponte}

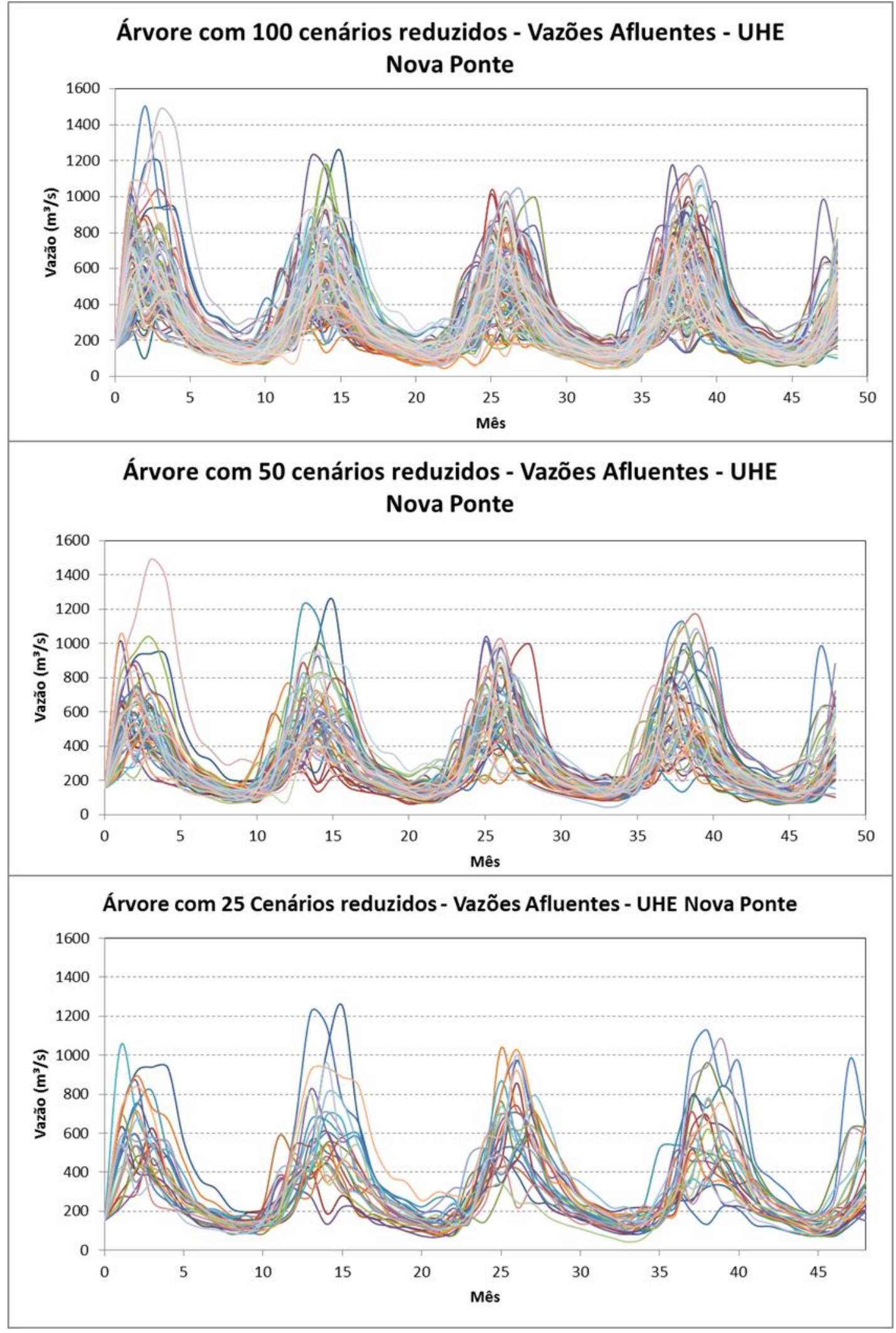

Figura 61. Árvores de Vazões Afluentes - UHE Nova Ponte 


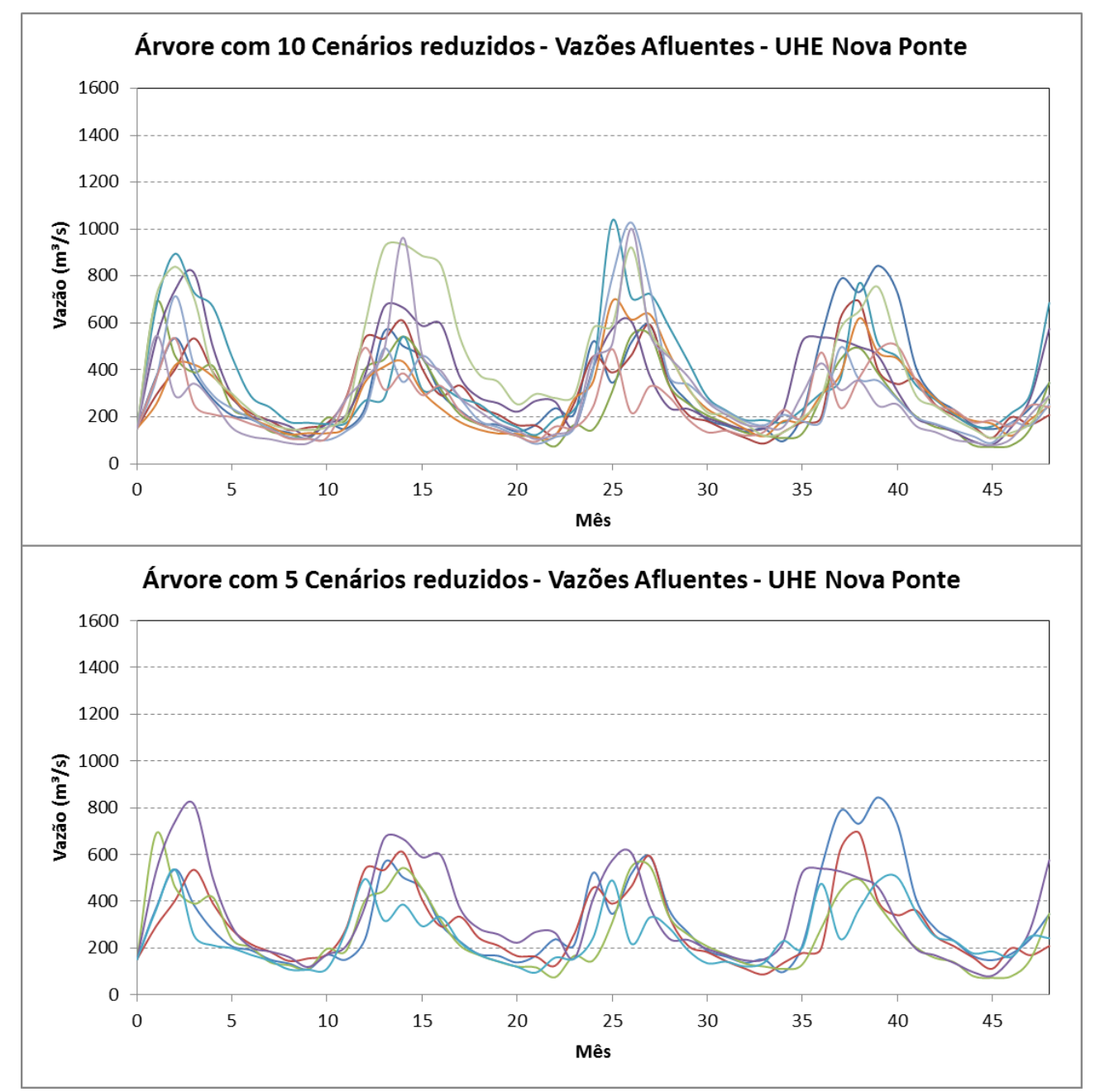

Figura 62. Árvores de Vazões Afluentes - UHE Nova Ponte (continuação)

Tabela 17. Comparação dos principais parâmetros estatísticos das séries de vazões - UHE Nova Ponte

\begin{tabular}{|c|c|c|c|c|c|c|c|}
\hline \multirow{2}{*}{ Parâmetros Estatísticos } & \multirow{2}{*}{\begin{tabular}{|c} 
Série Histórica \\
(1931 - 2012)
\end{tabular}} & \multirow{2}{*}{ 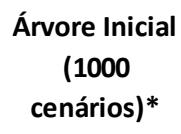 } & \multicolumn{5}{|c|}{ Árvore Reduzida - Número de cenários* } \\
\hline & & & 100 & 50 & 25 & 10 & 5 \\
\hline vazão média $\left(\mathrm{m}^{3} / \mathrm{s}\right)$ & 299 & 300 & 297 & 304 & 305 & 302 & 293 \\
\hline desvio Padrão $\left(\mathrm{m}^{3} / \mathrm{s}\right.$ & 199 & 195 & 185 & 189 & 188 & 179 & 165 \\
\hline Coeficiente de Variação & $61 \%$ & $65 \%$ & $62 \%$ & $62 \%$ & $62 \%$ & $59 \%$ & $56 \%$ \\
\hline Assimetria & 1,4 & 1,3 & 1,2 & 1,2 & 1,2 & 1,1 & 0,9 \\
\hline
\end{tabular}


Tabela 18. Parâmetros obtidos - UHE Nova Ponte

\begin{tabular}{|c|c|c|c|c|}
\hline $\begin{array}{c}\text { Número de } \\
\text { cenários da árvores } \\
\text { reduzida }\end{array}$ & $\begin{array}{c}\text { Porcentagem de } \\
\text { Redução }\end{array}$ & $\begin{array}{c}\text { Tempo de } \\
\text { Processamento } \\
\text { (HH:MM) }\end{array}$ & Método de Redução & Função Objetivo \\
\hline $\mathbf{5}$ & 0,678 & $00: 03$ & FAST BACKWARD + FORWARD & 4609048 \\
\hline $\mathbf{1 0}$ & 0,636 & $00: 03$ & FAST BACKWARD + FORWARD & 4530760 \\
\hline $\mathbf{1 5}$ & 0,615 & $00: 03$ & FAST BACKWARD + FORWARD & 4436424 \\
\hline $\mathbf{2 0}$ & 0,602 & $00: 03$ & FAST BACKWARD + FORWARD & 4450398 \\
\hline $\mathbf{2 5}$ & 0,591 & $00: 04$ & FAST BACKWARD + FORWARD & 4421383 \\
\hline $\mathbf{3 0}$ & 0,582 & $00: 04$ & FAST BACKWARD + FORWARD & 4385033 \\
\hline $\mathbf{4 0}$ & 0,566 & $00: 06$ & FAST BACKWARD + FORWARD & 4355258 \\
\hline $\mathbf{5 0}$ & 0,55 & $00: 09$ & FAST BACKWARD + FORWARD & 4308728 \\
\hline $\mathbf{6 0}$ & 0,541 & $00: 13$ & FAST BACKWARD + FORWARD & 4278199 \\
\hline $\mathbf{7 0}$ & 0,529 & $00: 18$ & FAST BACKWARD + FORWARD & 4272098 \\
\hline $\mathbf{8 0}$ & 0,519 & $00: 26$ & FAST BACKWARD + FORWARD & 4237714 \\
\hline $\mathbf{9 0}$ & 0,509 & $00: 35$ & FAST BACKWARD + FORWARD & 4236231 \\
\hline $\mathbf{1 0 0}$ & 0,499 & $00: 44$ & FAST BACKWARD + FORWARD & 4229363 \\
\hline $\mathbf{1 5 0}$ & 0,455 & $02: 34$ & FAST BACKWARD + FORWARD & 4214904 \\
\hline
\end{tabular}

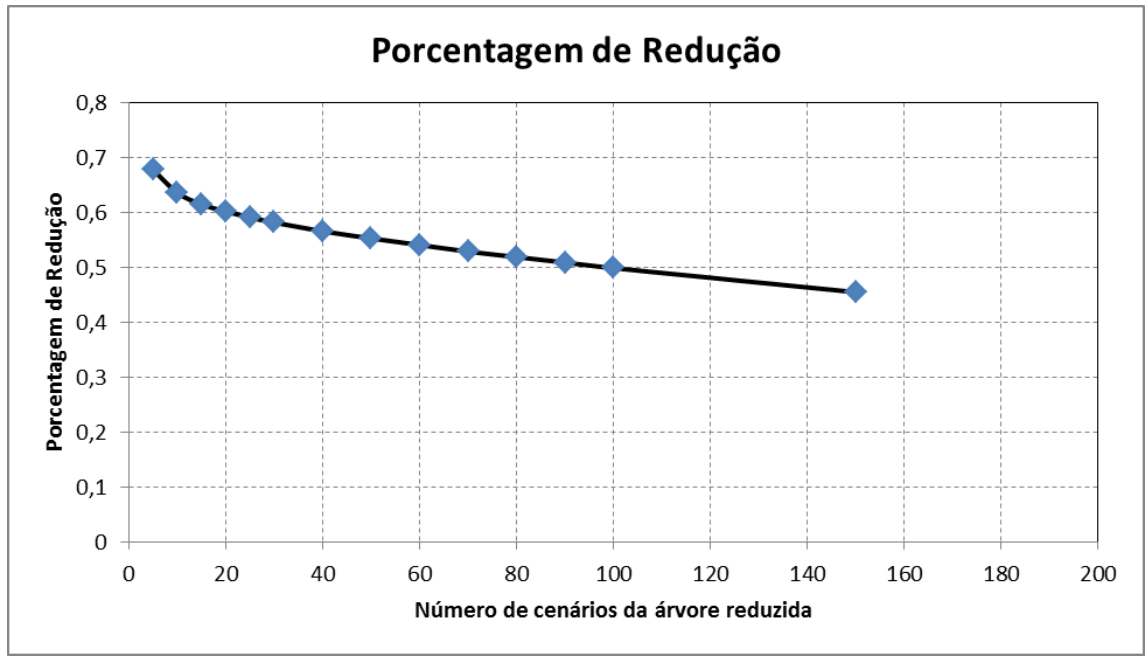

Figura 63. Porcentagem de Redução - UHE Nova Ponte

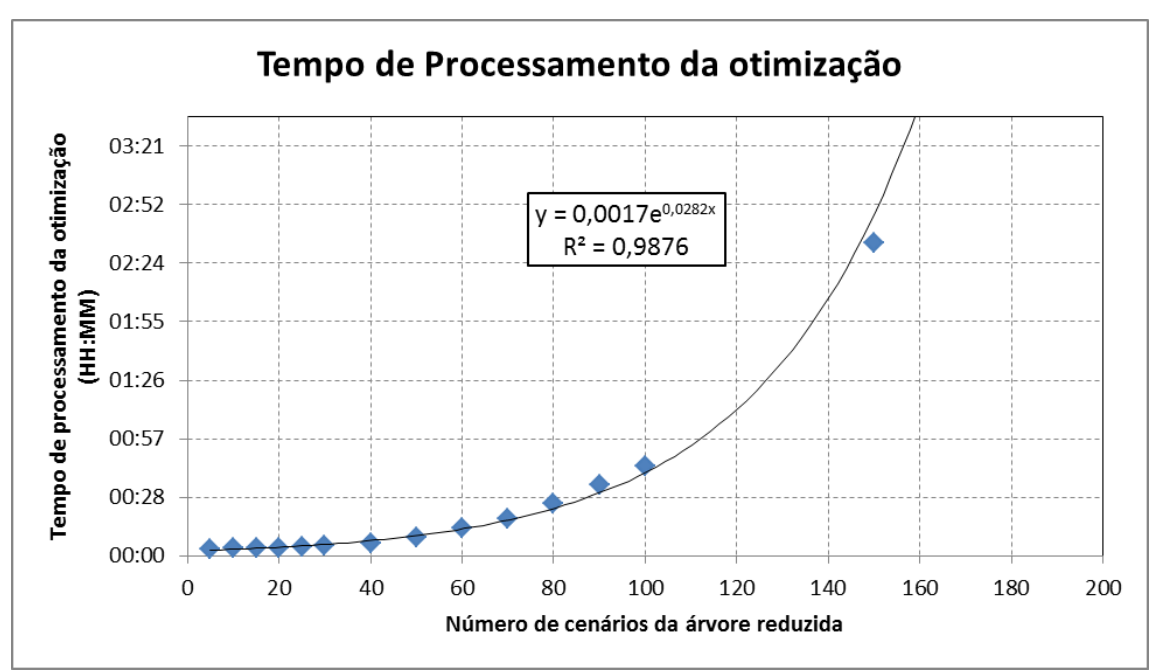

Figura 64. Tempo de Processamento - UHE Nova Ponte 


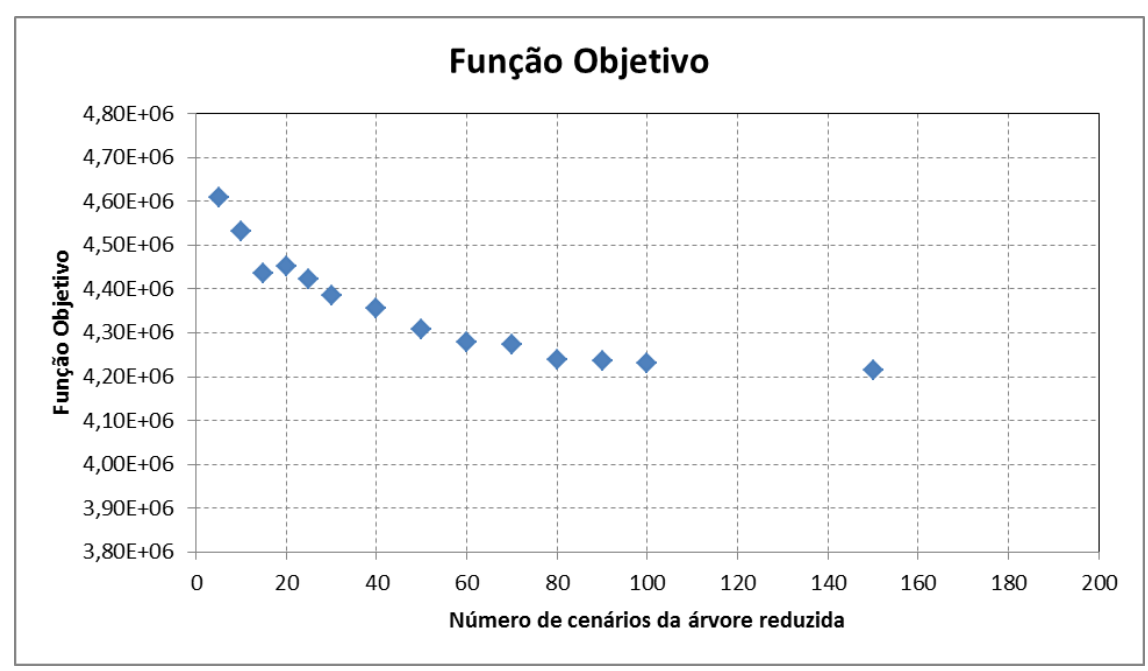

Figura 65. Função Objetivo - UHE Nova Ponte

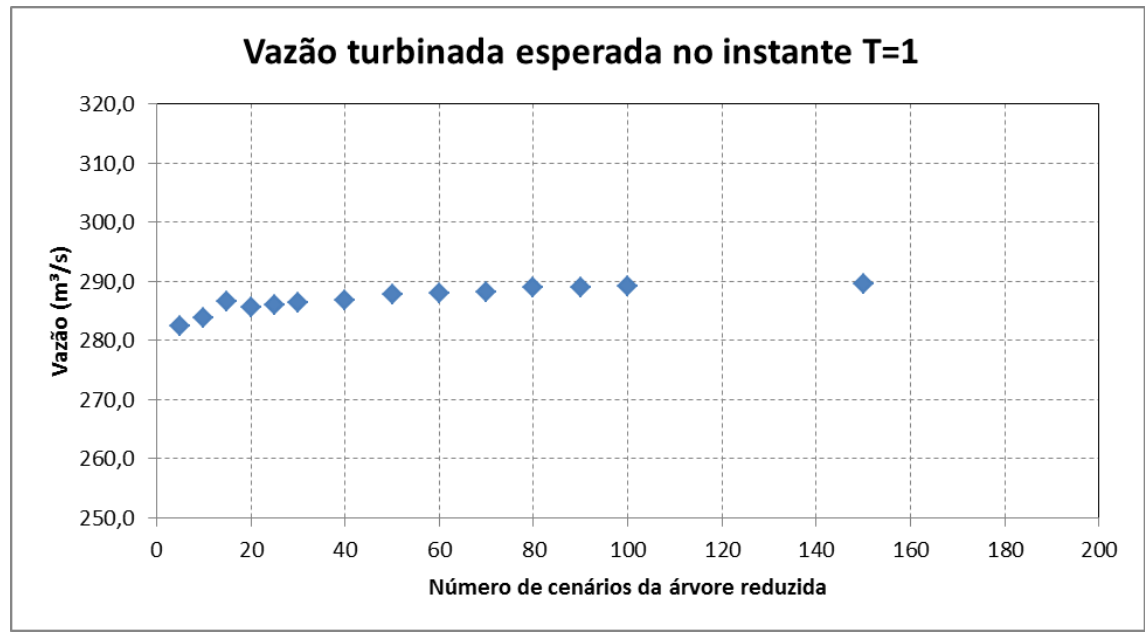

Figura 66. Vazão turbinada esperada no instante $T=1$ - UHE Nova Ponte

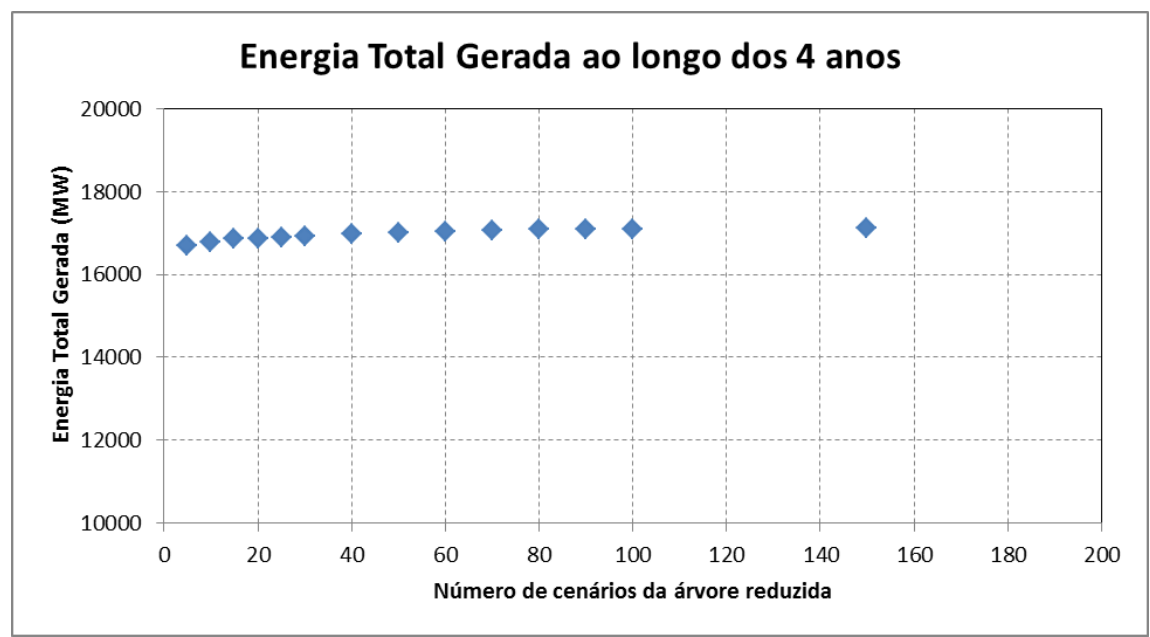

Figura 67. Energia gerada ao longo dos 4 anos - UHE Nova Ponte 


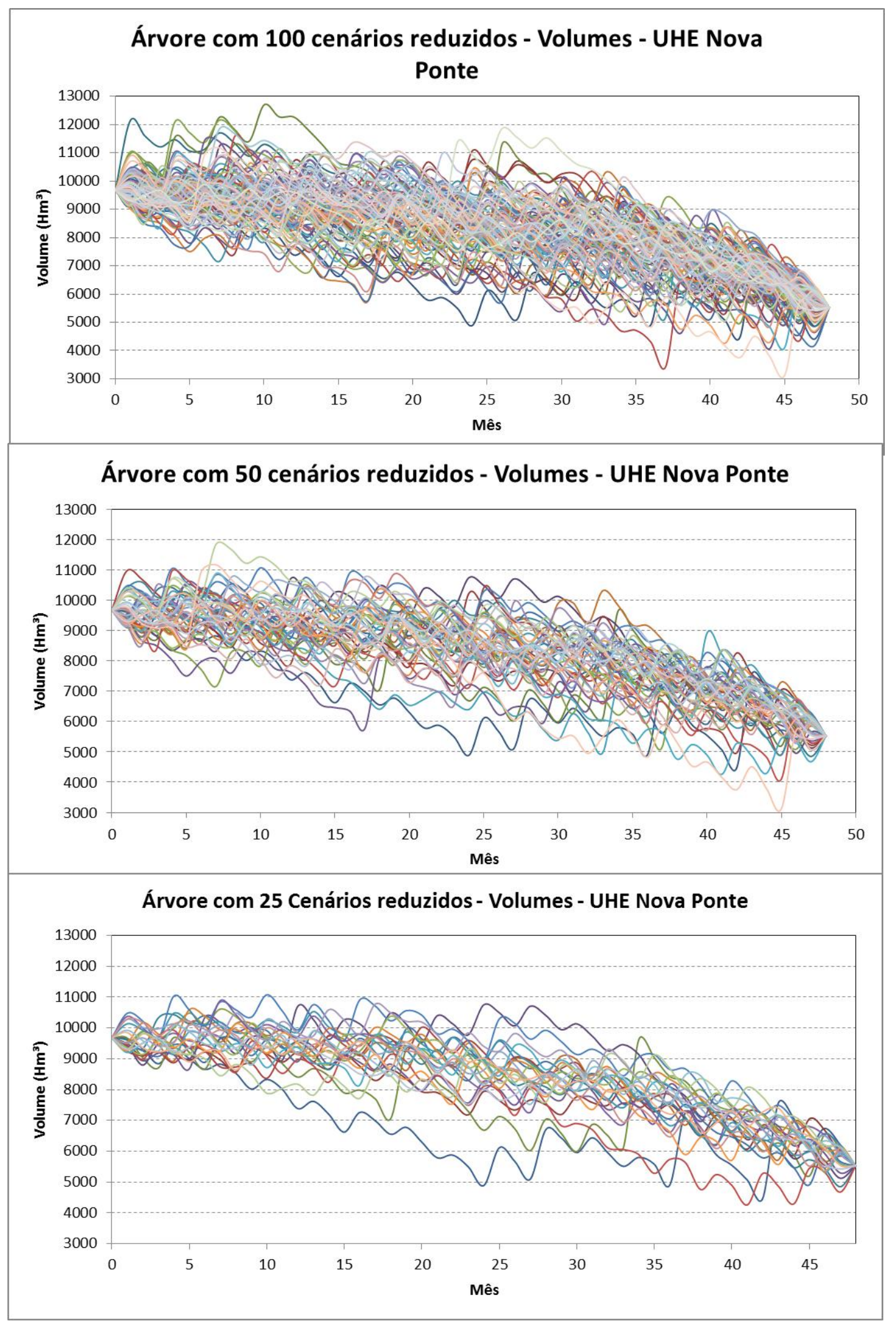

Figura 68. Árvores de cenários - Volumes - UHE Nova Ponte 


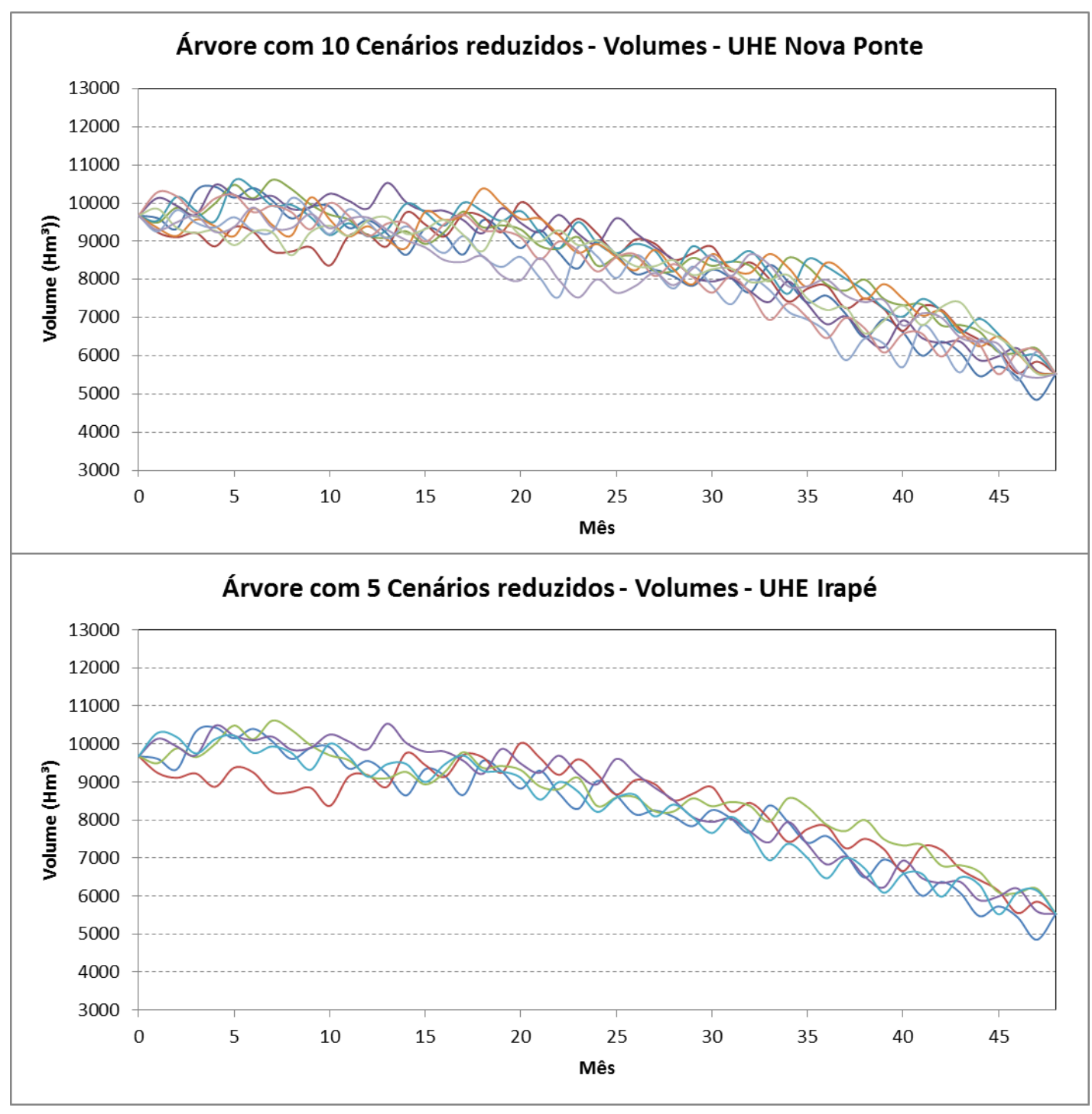

Figura 69. Árvores de cenários - Volumes - UHE Nova Ponte (continuação) 


\subsubsection{UHE Três Marias}
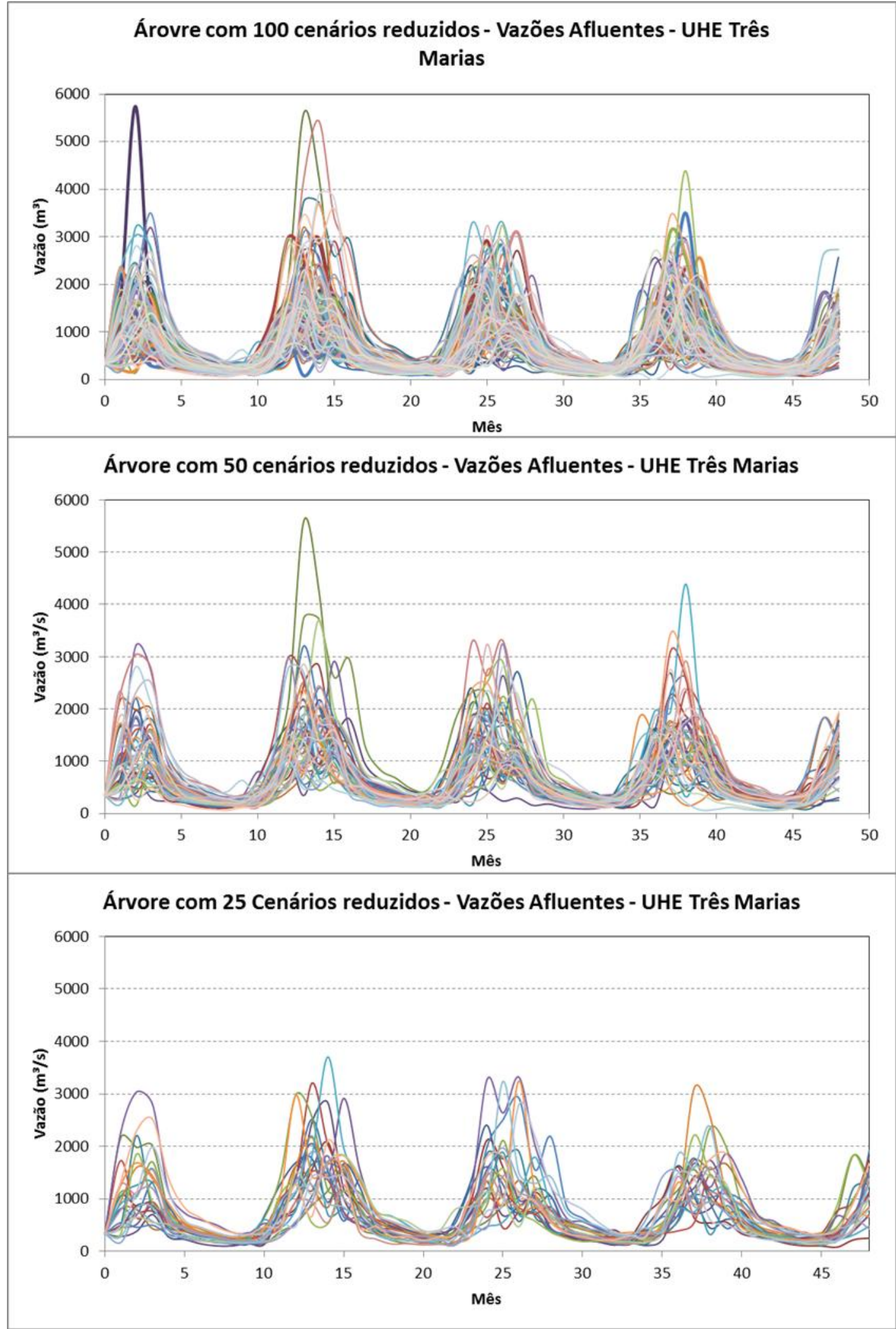

Figura 70. Árvores de Vazões Afluentes - UHE Três Marias 


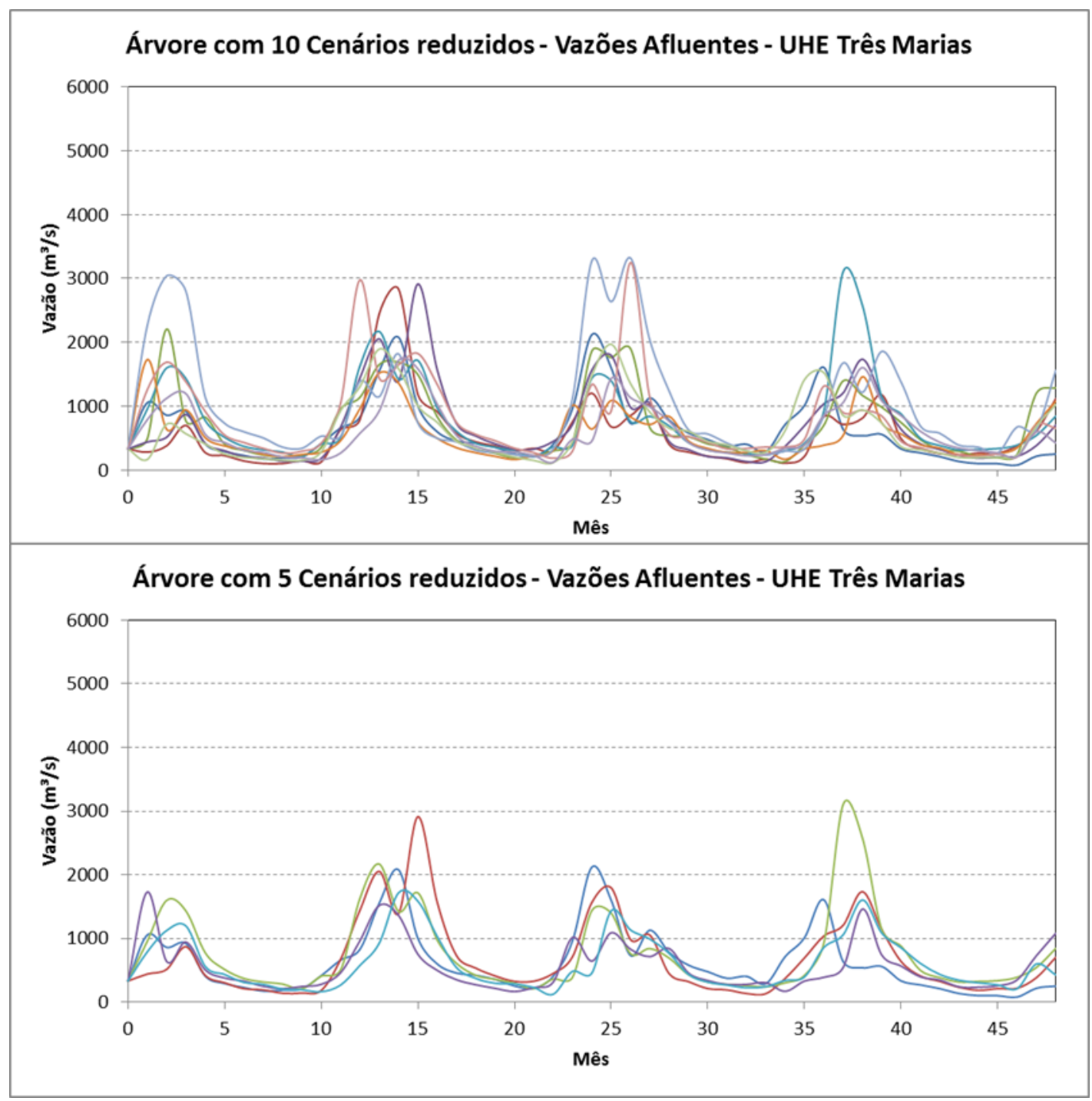

Figura 71. Árvores de Vazões Afluentes - UHE Três Marias (continuação)

Tabela 19. Comparação dos principais parâmetros estatísticos das séries de vazões - UHE Três Marias

\begin{tabular}{|c|c|c|c|c|c|c|c|}
\hline \multirow{2}{*}{ Parâmetros Estatísticos } & \multirow{2}{*}{\begin{tabular}{|c} 
Série Histórica \\
(1931 - 2012)
\end{tabular}} & \multirow{2}{*}{$\begin{array}{l}\text { Árvore Inicial } \\
\text { (1000 } \\
\text { cenários)* }\end{array}$} & \multicolumn{5}{|c|}{ Árvore Reduzida - Número de cenários* } \\
\hline & & & 100 & 50 & 25 & 10 & 5 \\
\hline vazão média ( $\left.\mathrm{m}^{3} / \mathrm{s}\right)$ & 691 & 672 & 664 & 665 & 683 & 674 & 643 \\
\hline desvio Padrão $\left(\mathrm{m}^{3} / \mathrm{s}\right.$ & 605 & 571 & 560 & 547 & 559 & 548 & 514 \\
\hline Coeficiente de Variação & $88 \%$ & $85 \%$ & $84 \%$ & $82 \%$ & $82 \%$ & $81 \%$ & $80 \%$ \\
\hline Assimetria & 1,8 & 1,6 & 1,7 & 1,6 & 1,6 & 1,6 & 1,5 \\
\hline
\end{tabular}


Tabela 20. Parâmetros obtidos - UHE Três Marias

\begin{tabular}{|c|c|c|c|c|}
\hline $\begin{array}{c}\text { Número de } \\
\text { cenários da árvores } \\
\text { reduzida }\end{array}$ & $\begin{array}{c}\text { Porcentagem de } \\
\text { Redução }\end{array}$ & $\begin{array}{r}\text { Tempo de } \\
\text { Processamento } \\
\text { (HH:MM) }\end{array}$ & Método de Redução & Função Objetivo \\
\hline $\mathbf{5}$ & 0,716 & $00: 03$ & FAST BACKWARD + FORWARD & 2146224 \\
\hline $\mathbf{1 0}$ & 0,673 & $00: 03$ & FAST BACKWARD + FORWARD & 2019879 \\
\hline $\mathbf{1 5}$ & 0,649 & $00: 03$ & FAST BACKWARD + FORWARD & 1998915 \\
\hline $\mathbf{2 0}$ & 0,634 & $00: 03$ & FAST BACKWARD + FORWARD & 1997121 \\
\hline $\mathbf{2 5}$ & 0,622 & $00: 03$ & FAST BACKWARD + FORWARD & 1982982 \\
\hline $\mathbf{3 0}$ & 0,611 & $00: 04$ & FAST BACKWARD + FORWARD & 1987578 \\
\hline $\mathbf{4 0}$ & 0,593 & $00: 04$ & FAST BACKWARD + FORWARD & 1982665 \\
\hline $\mathbf{5 0}$ & 0,58 & $00: 05$ & FAST BACKWARD + FORWARD & 1974165 \\
\hline $\mathbf{6 0}$ & 0,563 & $00: 06$ & FAST BACKWARD + FORWARD & 1977813 \\
\hline $\mathbf{7 0}$ & 0,55 & $00: 08$ & FAST BACKWARD + FORWARD & 1978061 \\
\hline $\mathbf{8 0}$ & 0,537 & $00: 09$ & FAST BACKWARD + FORWARD & 1977326 \\
\hline $\mathbf{9 0}$ & 0,525 & $00: 12$ & FAST BACKWARD + FORWARD & 1980626 \\
\hline $\mathbf{1 0 0}$ & 0,514 & $\mathbf{0 0 : 1 5}$ & FAST BACKWARD + FORWARD & 1979647 \\
\hline $\mathbf{1 5 0}$ & 0,464 & $00: 35$ & FAST BACKWARD + FORWARD & 1974010 \\
\hline
\end{tabular}

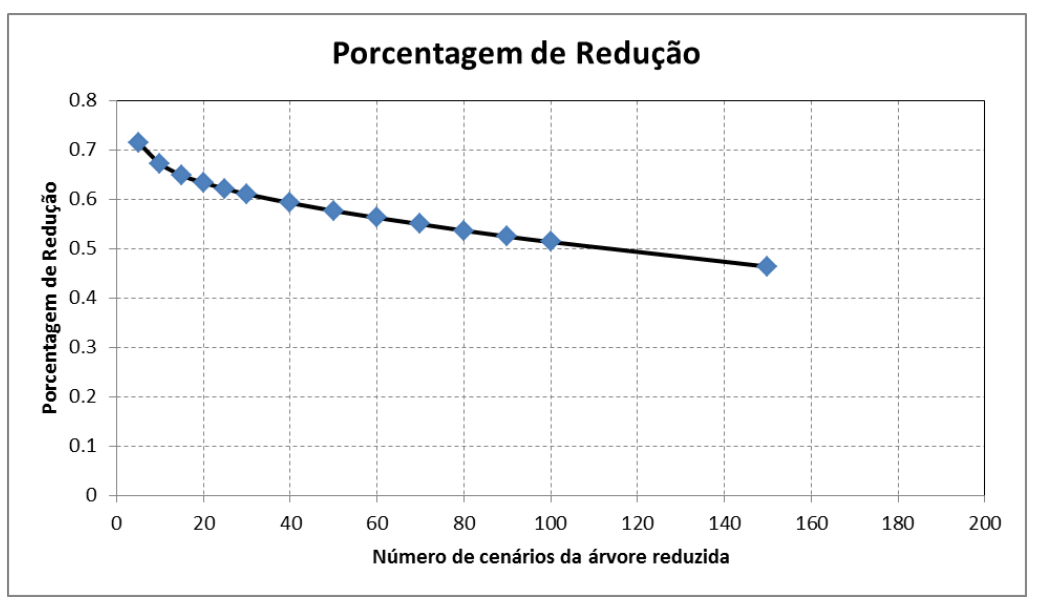

Figura 72. Porcentagem de Redução - UHE Três Marias

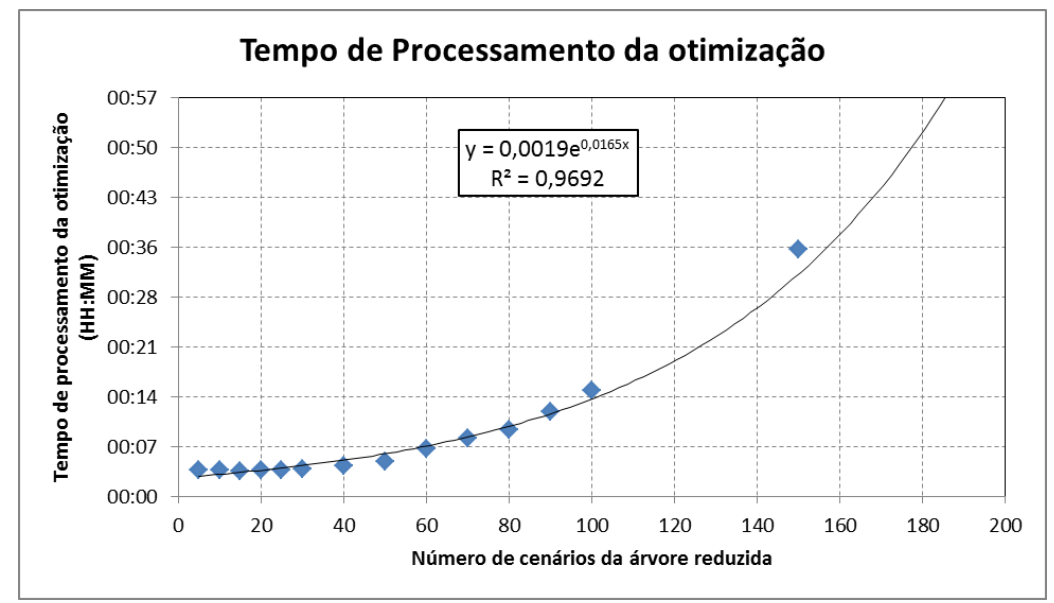

Figura 73. Porcentagem de Redução - UHE Três Marias 


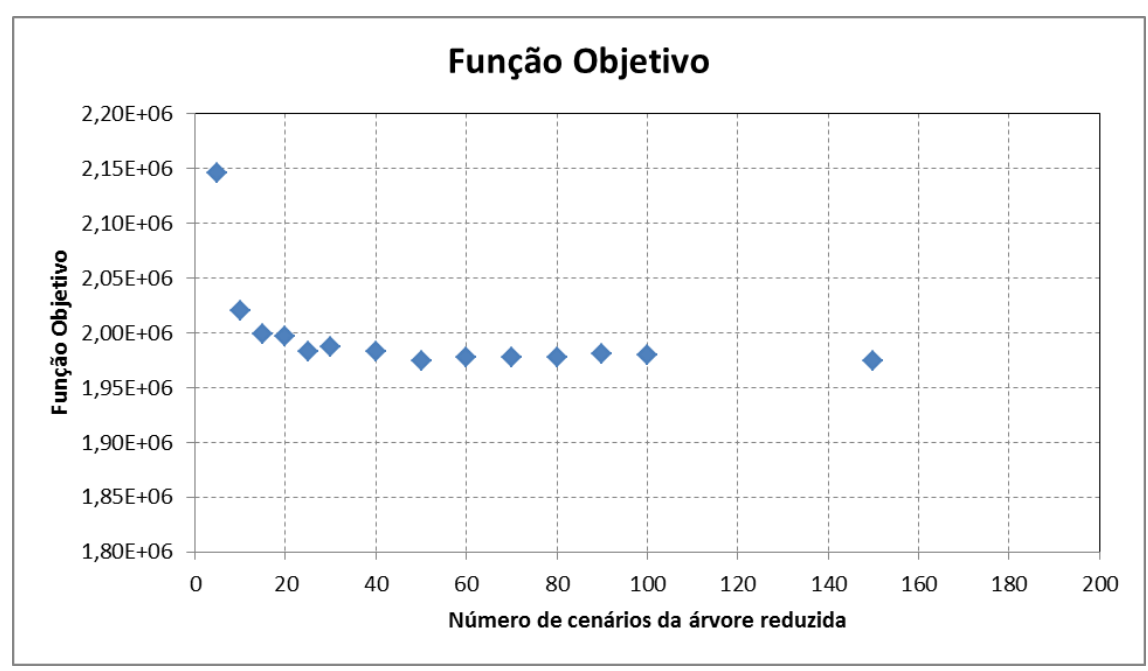

Figura 74. Função Objetivo - UHE Três Marias

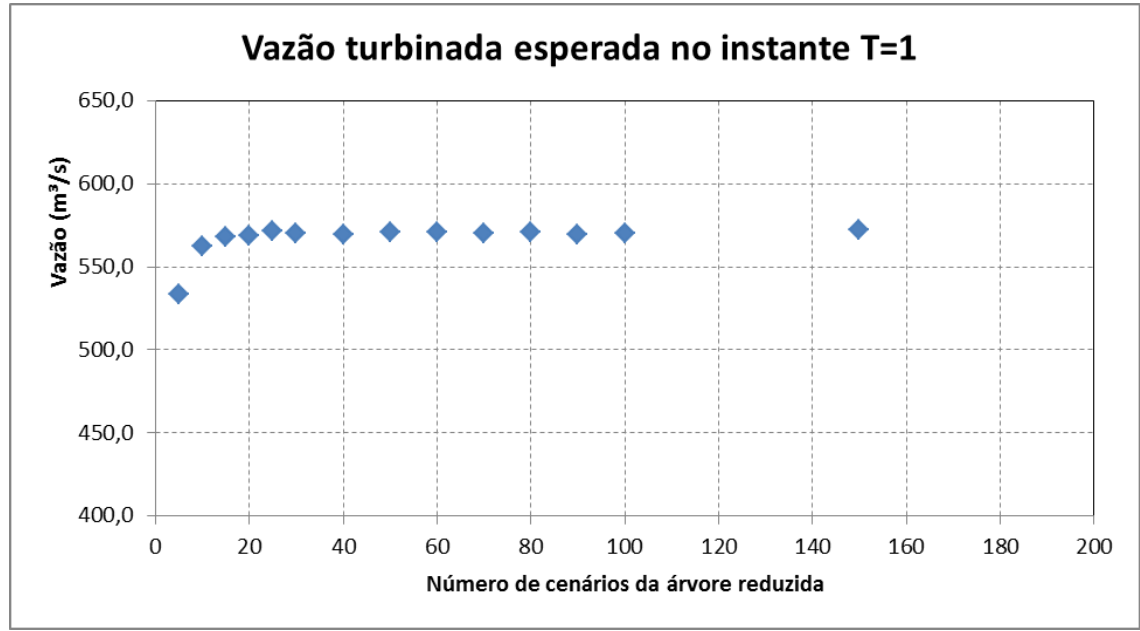

Figura 75. Vazão turbinada esperada no instante $T=1$ - UHE Três Marias

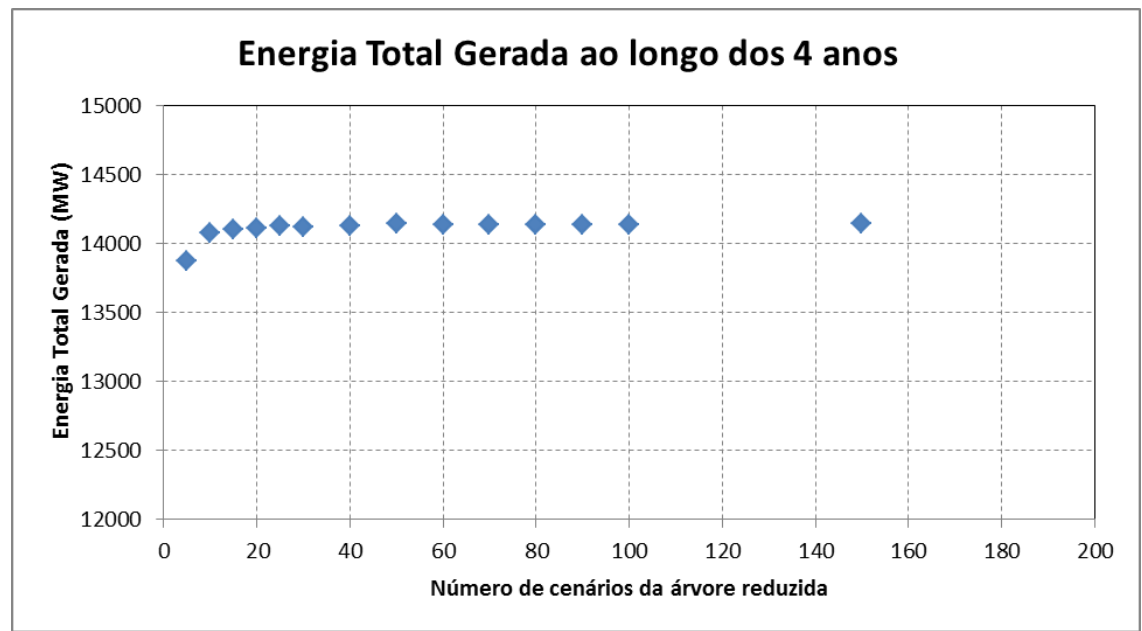

Figura 76. Energia gerada ao longo dos 4 anos - UHE Três Marias 


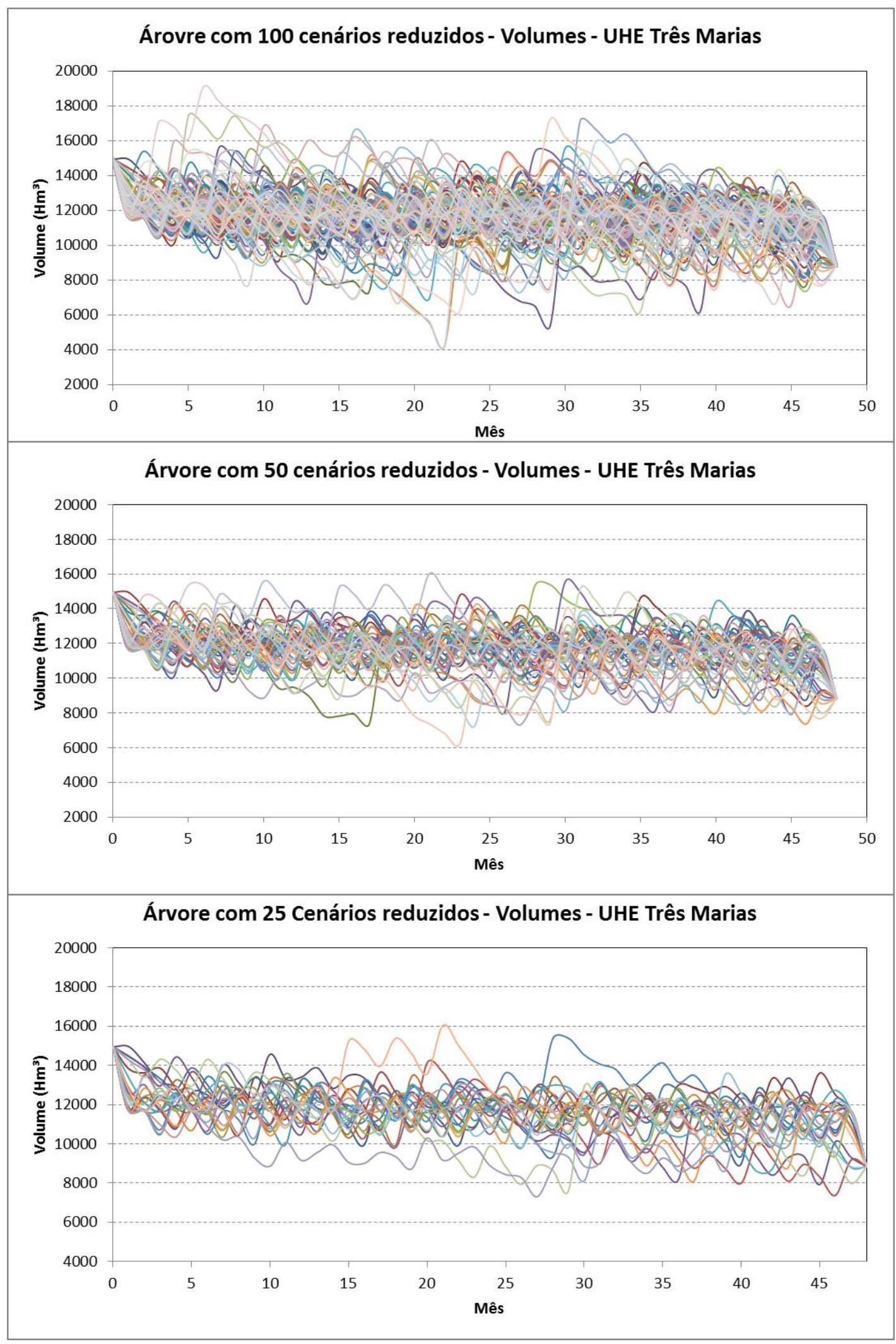

Figura 77. Árvores de cenários - Volumes - UHE Três Marias 


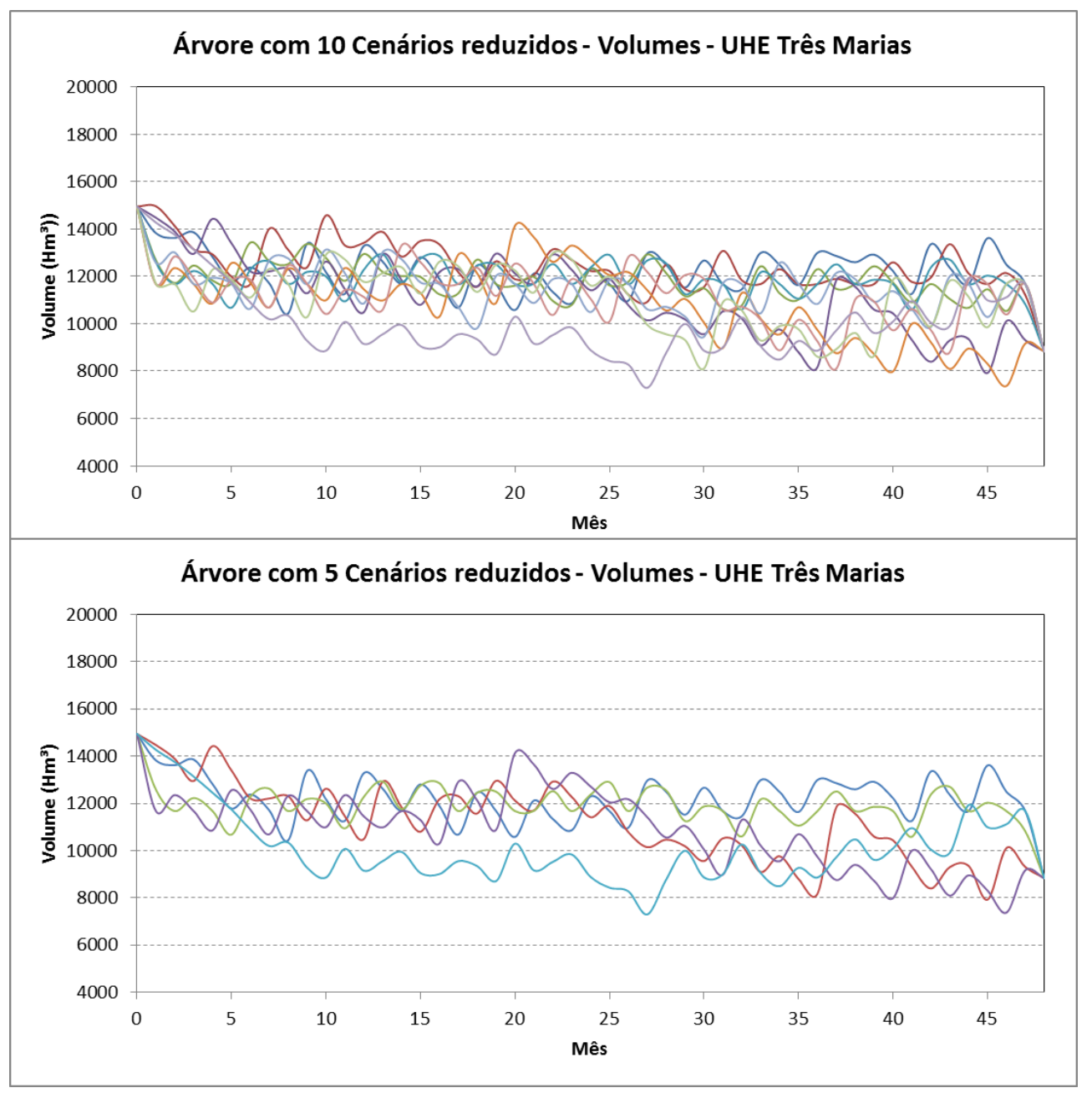

Figura 78. Árvores de cenários - Volumes - UHE Três Marias (continuação) 


\subsubsection{UHE Irapé}

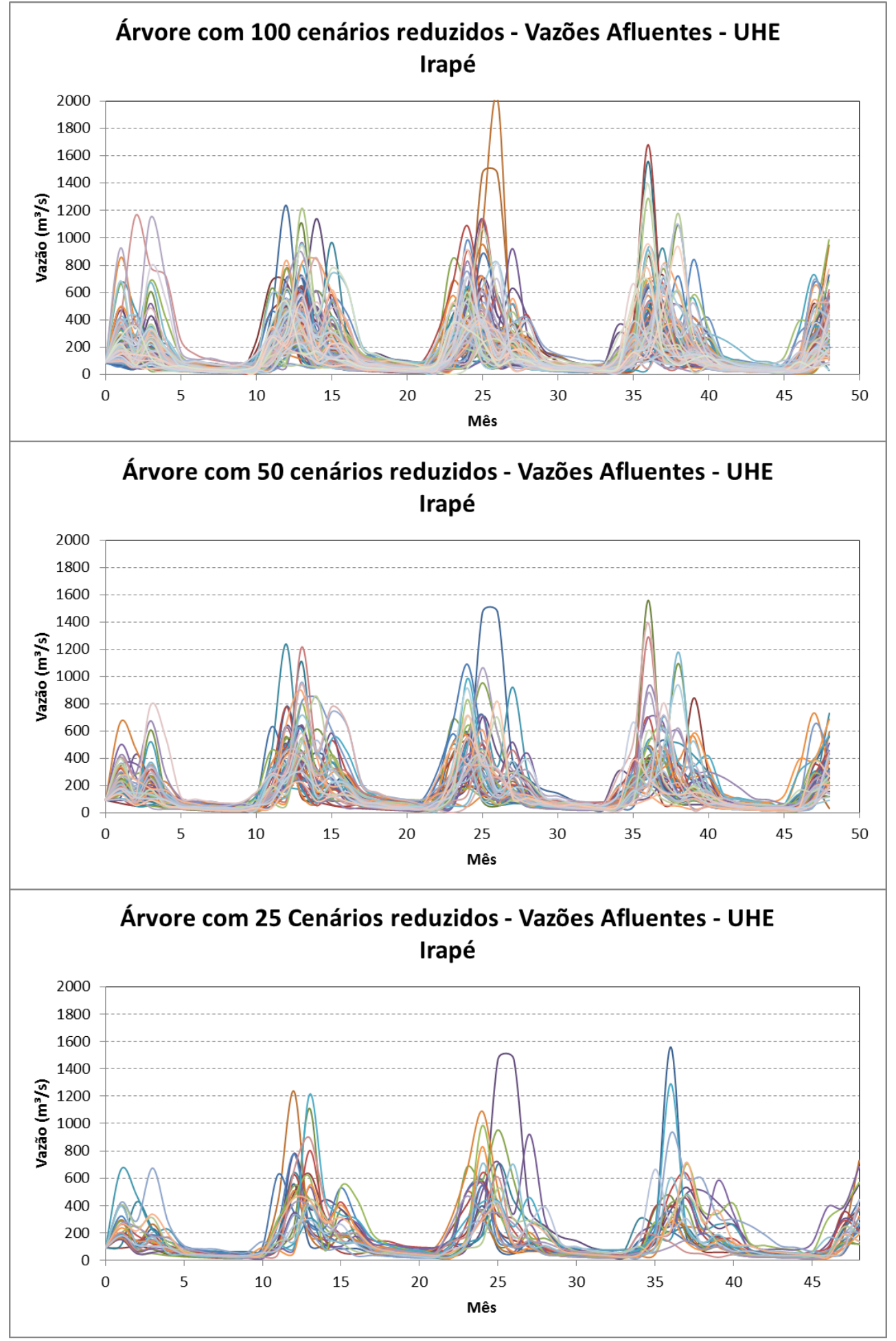

Figura 79. Árvores de Vazões Afluentes - UHE Irapé 


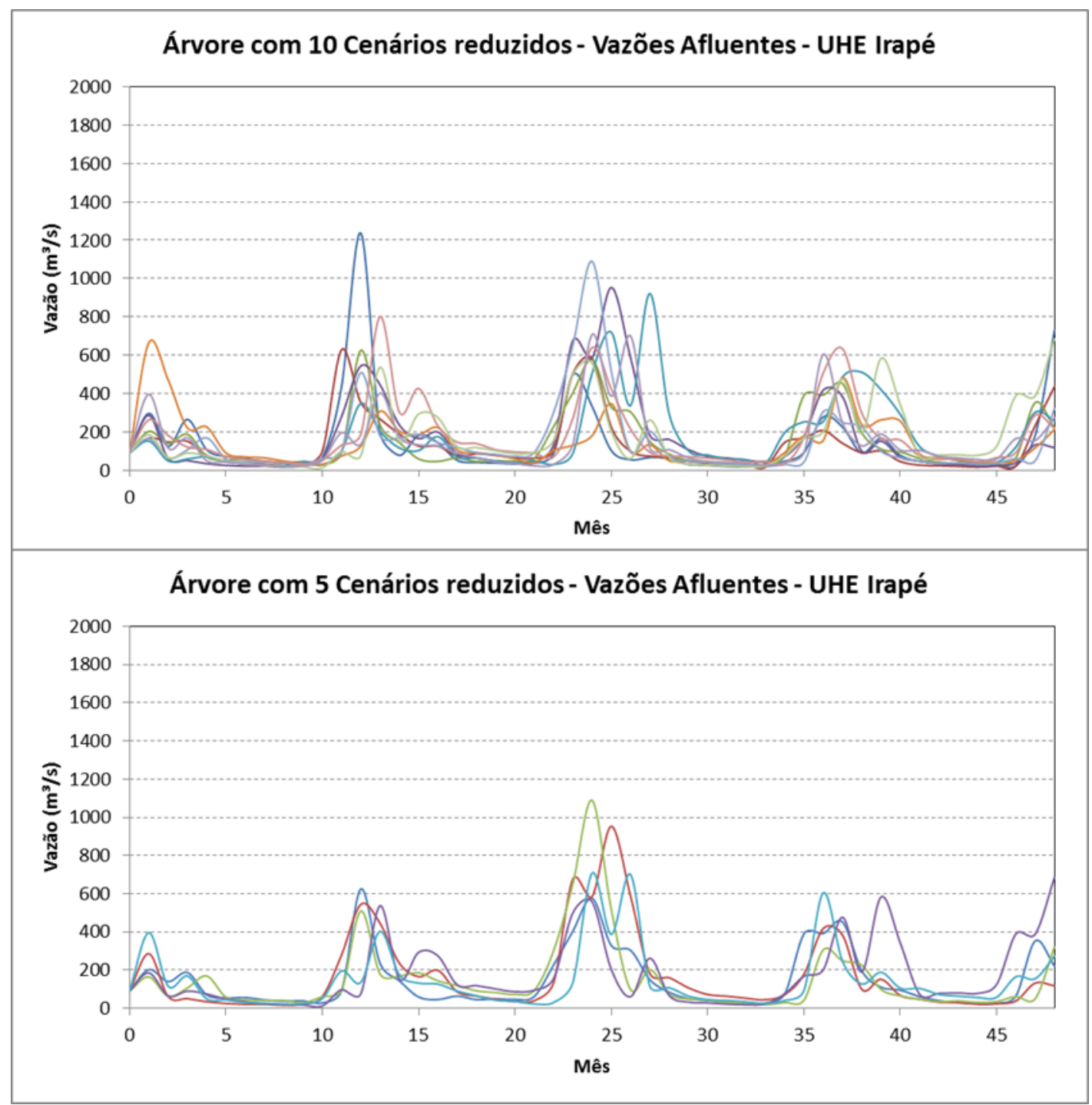

Figura 80. Árvores de Vazões Afluentes - UHE Irapé (continuação)

Tabela 21. Comparação dos principais parâmetros estatísticos das séries de vazões - UHE Irapé

\begin{tabular}{|c|c|c|c|c|c|c|c|}
\hline \multirow{2}{*}{ Parâmetros Estatísticos } & \multirow{2}{*}{\begin{tabular}{|c} 
Série Histórica \\
(1931 - 2012)
\end{tabular}} & \multirow{2}{*}{$\begin{array}{l}\text { Árvore Inicial } \\
\text { (1000 } \\
\text { cenários)* }^{*}\end{array}$} & \multicolumn{5}{|c|}{ Árvore Reduzida - Número de cenários* } \\
\hline & & & 100 & 50 & 25 & 10 & 5 \\
\hline vazão média (m³/s) & 150 & 150 & 150 & 150 & 155 & 158 & 157 \\
\hline desvio Padrão $\left(\mathrm{m}^{3} / \mathrm{s}\right.$ & 174 & 171 & 166 & 166 & 174 & 172 & 177 \\
\hline Coeficiente de Variação & $116 \%$ & $113 \%$ & $110 \%$ & $111 \%$ & $112 \%$ & $109 \%$ & $112 \%$ \\
\hline Assimetria & 2,6 & 2,2 & 2,2 & 2,2 & 2,3 & 2,1 & 2,1 \\
\hline
\end{tabular}


Tabela 22. Parâmetros obtidos - UHE Irapé

\begin{tabular}{|c|c|c|c|c|}
\hline $\begin{array}{c}\text { Número de } \\
\text { cenários da árvores } \\
\text { reduzida }\end{array}$ & $\begin{array}{c}\text { Porcentagem de } \\
\text { Redução }\end{array}$ & $\begin{array}{c}\text { Tempo de } \\
\text { Processamento } \\
\text { (HH:MM) }\end{array}$ & Método de Redução & Função Objetivo \\
\hline $\mathbf{5}$ & 0,797 & $00: 03$ & FAST BACKWARD + FORWARD & 3232209 \\
\hline $\mathbf{1 0}$ & 0,751 & $00: 03$ & FAST BACKWARD + FORWARD & 3266715 \\
\hline $\mathbf{1 5}$ & 0,723 & $00: 04$ & FAST BACKWARD + FORWARD & 2905623 \\
\hline $\mathbf{2 0}$ & 0,702 & $00: 04$ & FAST BACKWARD + FORWARD & 2899074 \\
\hline $\mathbf{2 5}$ & 0,684 & $00: 04$ & FAST BACKWARD + FORWARD & 2838795 \\
\hline $\mathbf{3 0}$ & 0,668 & $00: 05$ & FAST BACKWARD + FORWARD & 2821733 \\
\hline $\mathbf{4 0}$ & 0,641 & $00: 06$ & FAST BACKWARD + FORWARD & 2972828 \\
\hline $\mathbf{5 0}$ & 0,62 & $00: 08$ & FAST BACKWARD + FORWARD & 3121585 \\
\hline $\mathbf{6 0}$ & 0,597 & $00: 11$ & FAST BACKWARD + FORWARD & 3049247 \\
\hline $\mathbf{7 0}$ & 0,579 & $00: 15$ & FAST BACKWARD + FORWARD & 3054080 \\
\hline $\mathbf{8 0}$ & 0,563 & $00: 20$ & FAST BACKWARD + FORWARD & 3015159 \\
\hline $\mathbf{9 0}$ & 0,547 & $00: 24$ & FAST BACKWARD + FORWARD & 2986619 \\
\hline $\mathbf{1 0 0}$ & 0,533 & $00: 29$ & FAST BACKWARD + FORWARD & 2963289 \\
\hline $\mathbf{1 5 0}$ & 0,472 & $01: 15$ & FAST BACKWARD + FORWARD & 2885080 \\
\hline
\end{tabular}

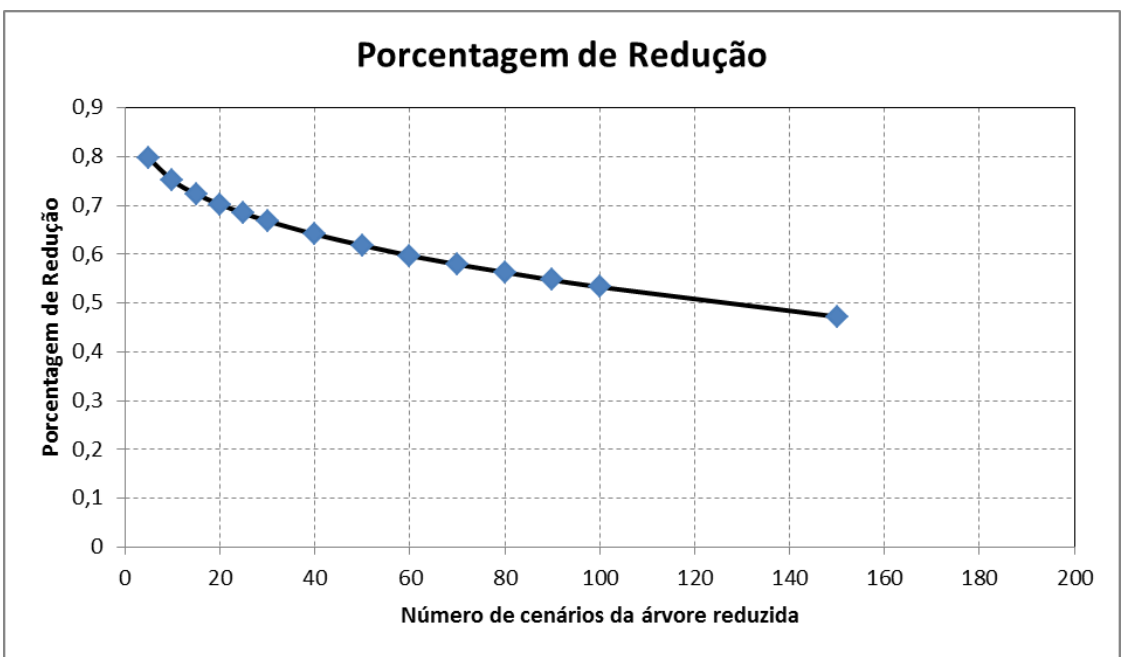

Figura 81. Porcentagem de Redução - UHE Irapé

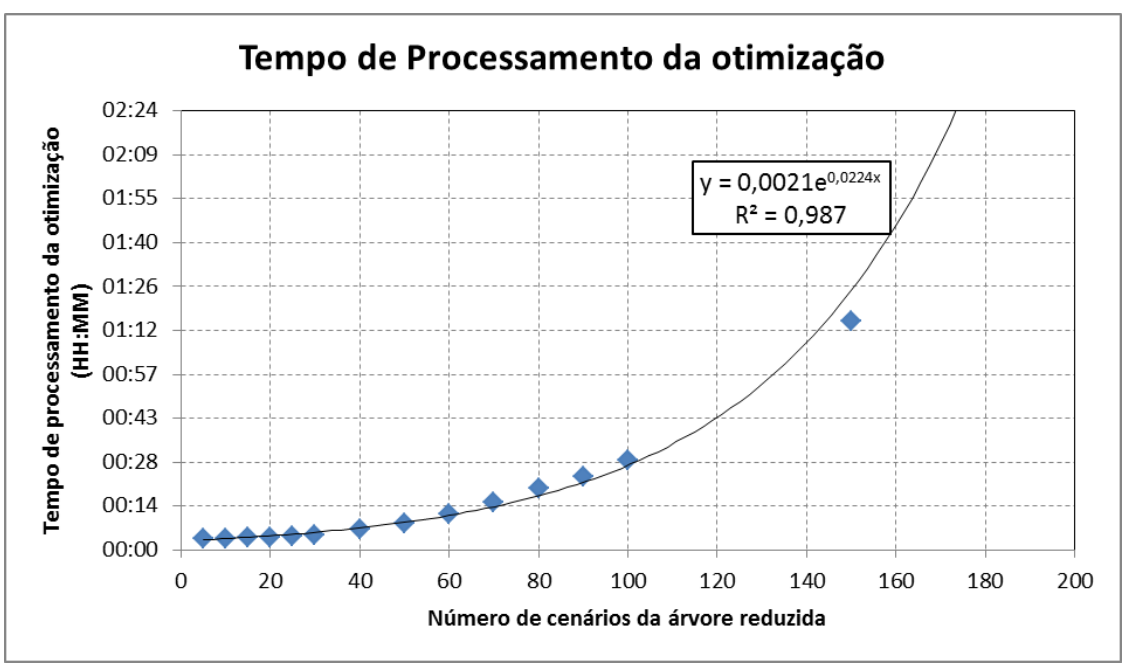

Figura 82. Tempo de Processamento - UHE Irapé 


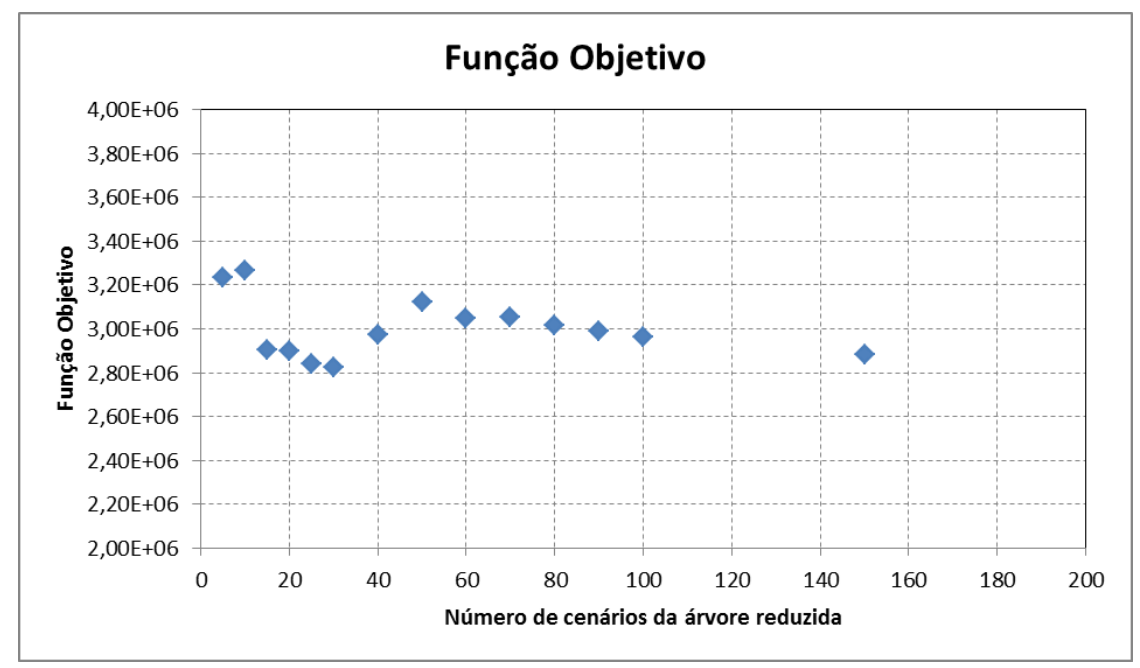

Figura 83. Função Objetivo - UHE Irapé

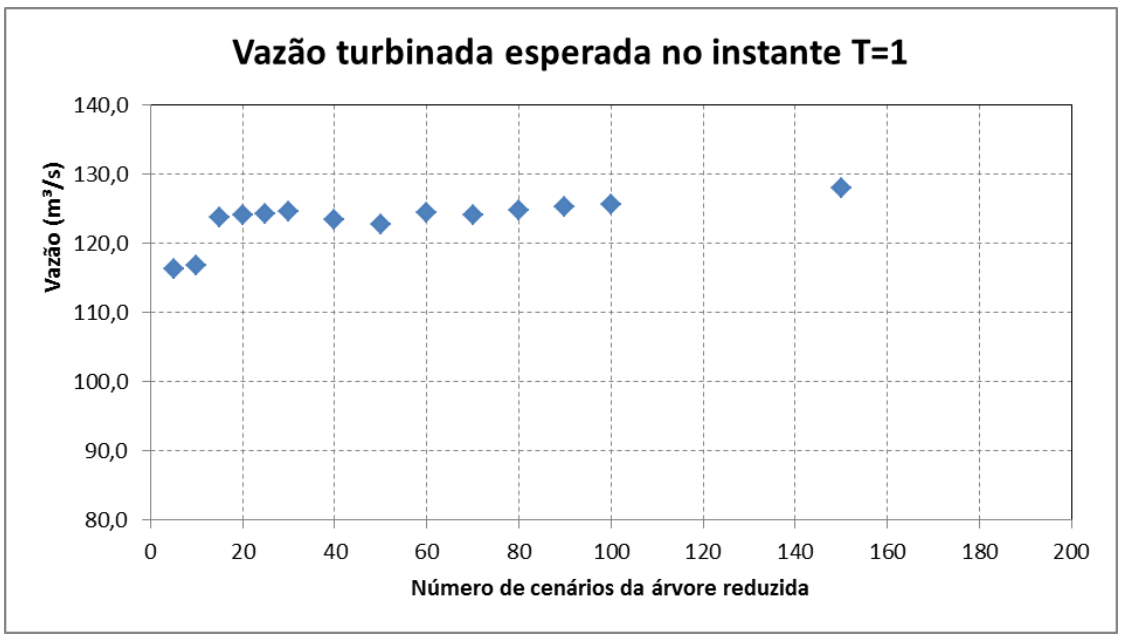

Figura 84. Vazão turbinada esperada no instante $T=1-$ UHE Irapé

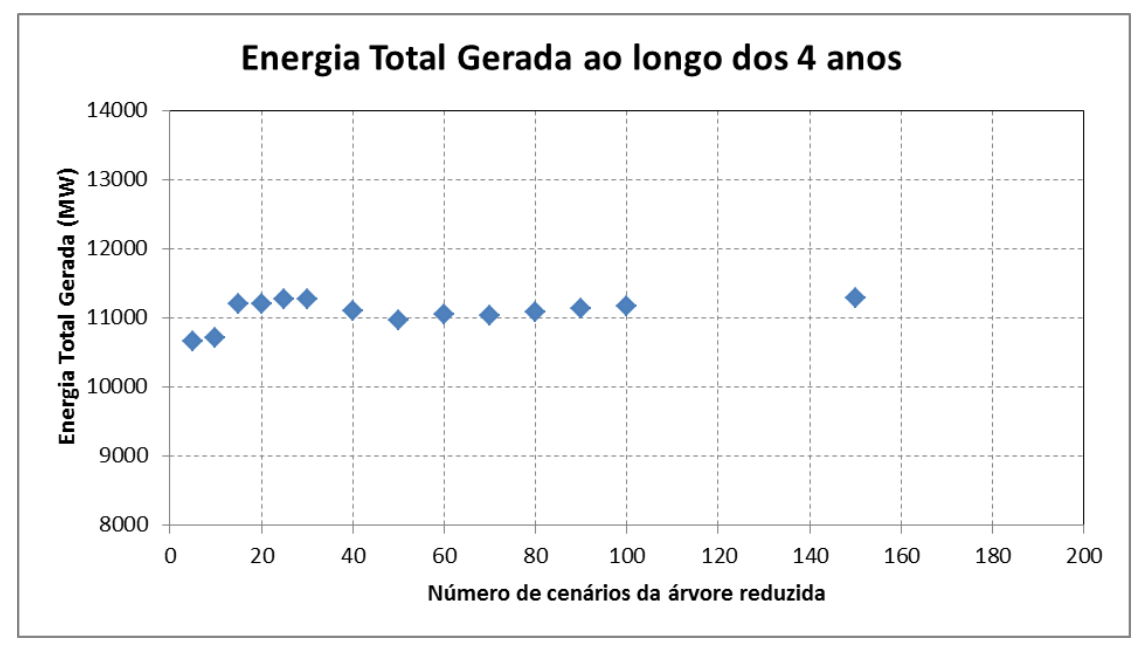

Figura 85. Energia gerada ao longo dos 4 anos - UHE Irapé 


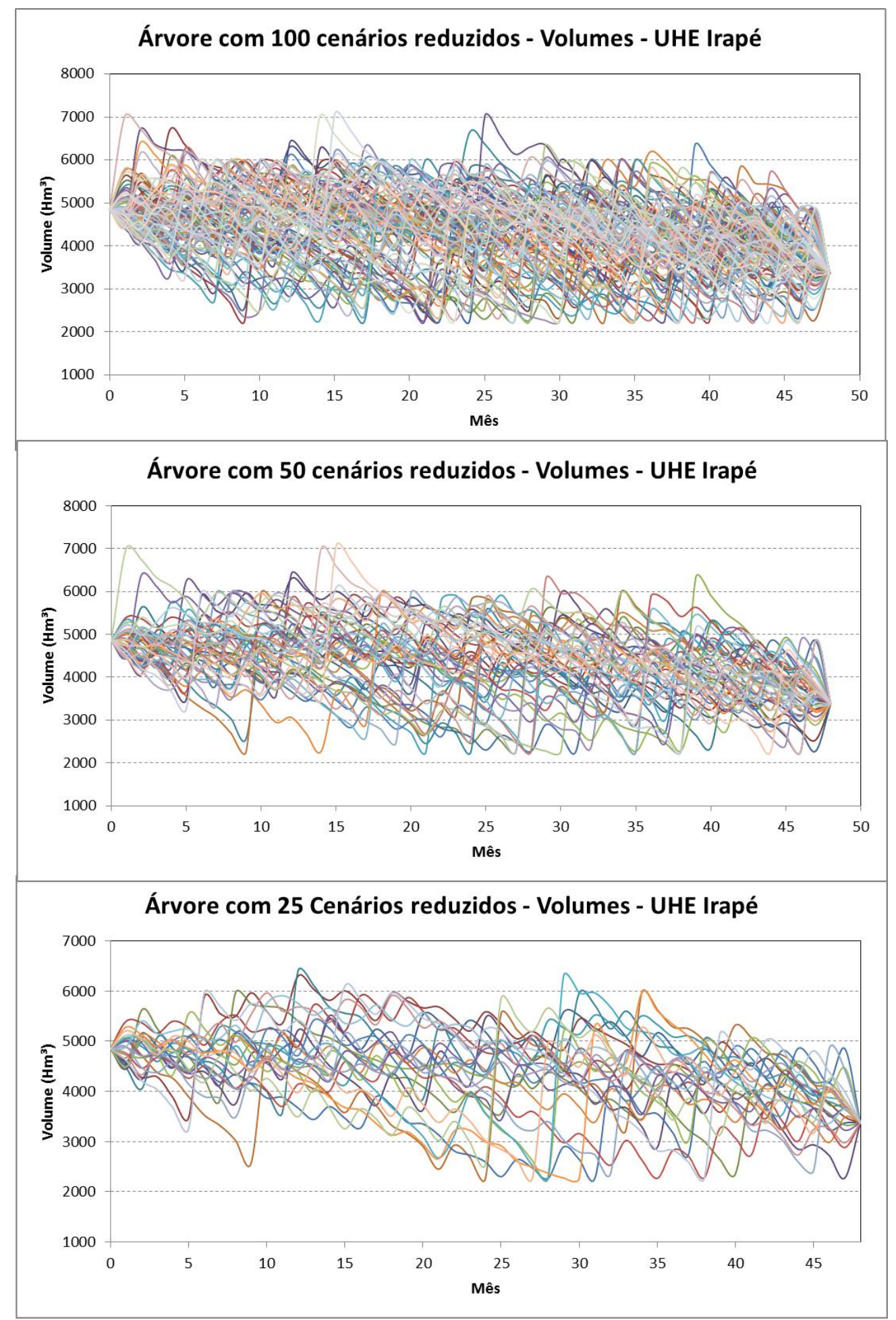

Figura 86. Árvores de cenários - Volumes - UHE Irapé 


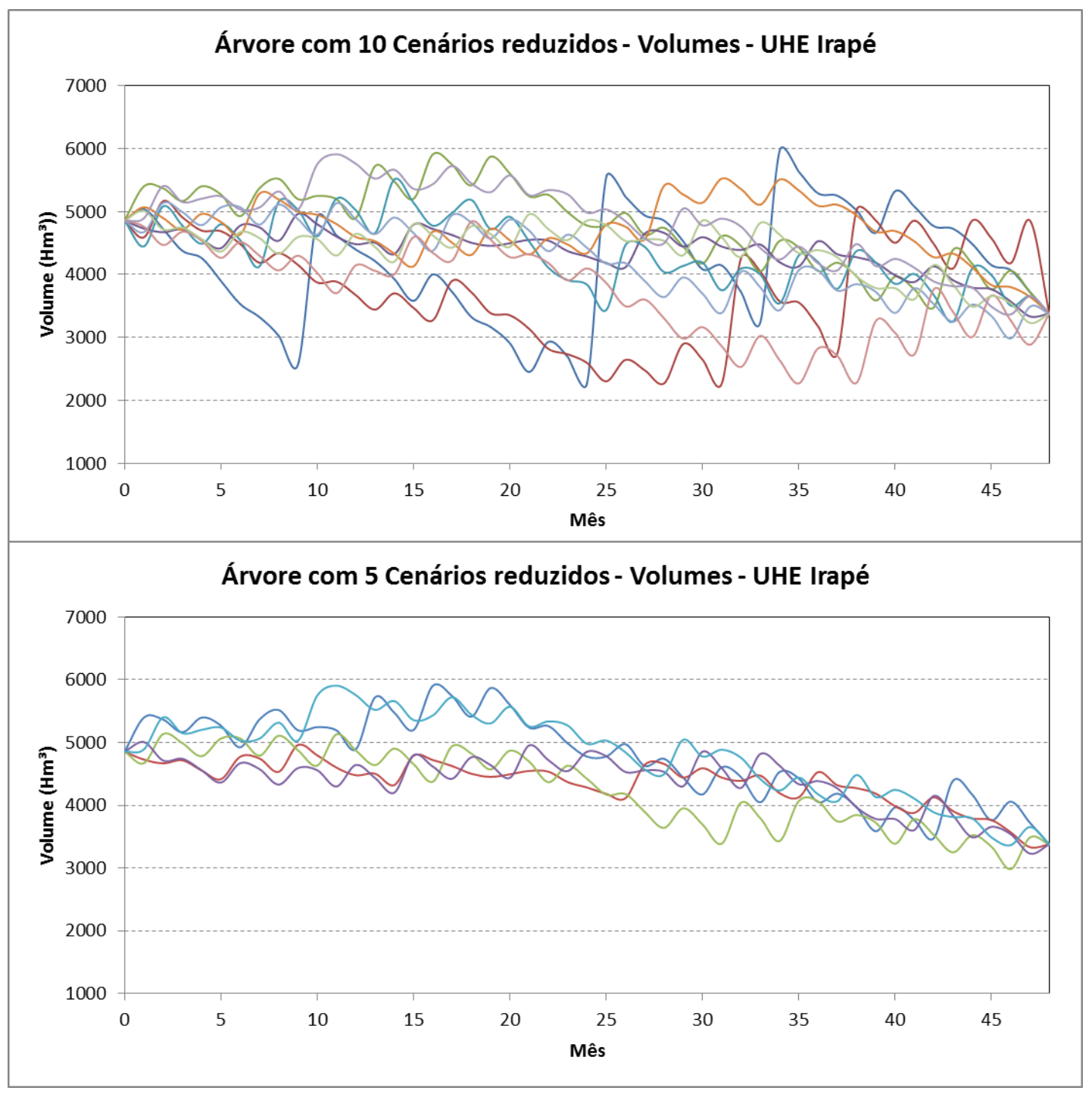

Figura 87. Árvores de cenários - Volumes - UHE Irapé (continuação) 


\subsubsection{UHE Serra da Mesa}

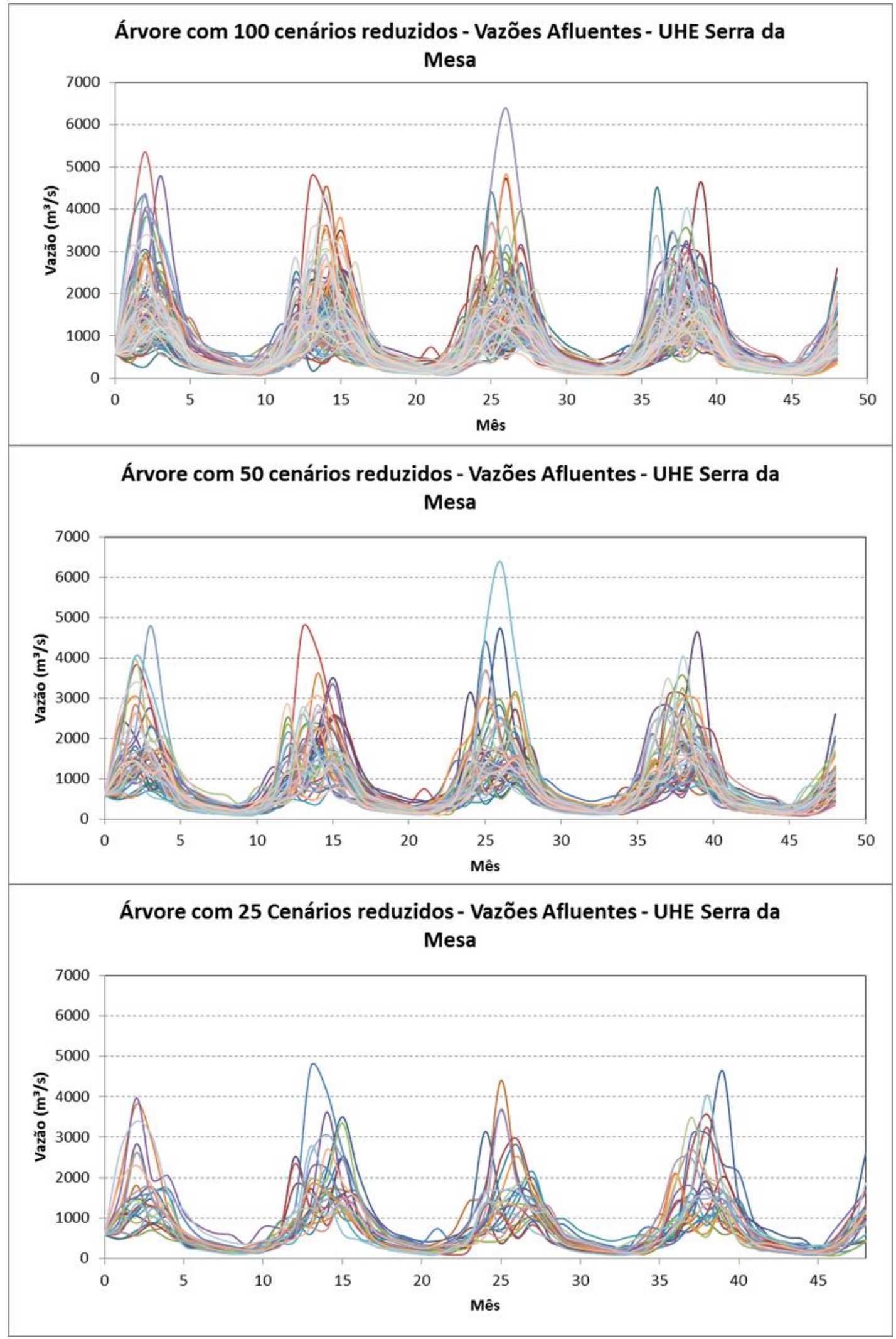

Figura 88. Árvores de Vazões Afluentes - UHE Serra da Mesa 


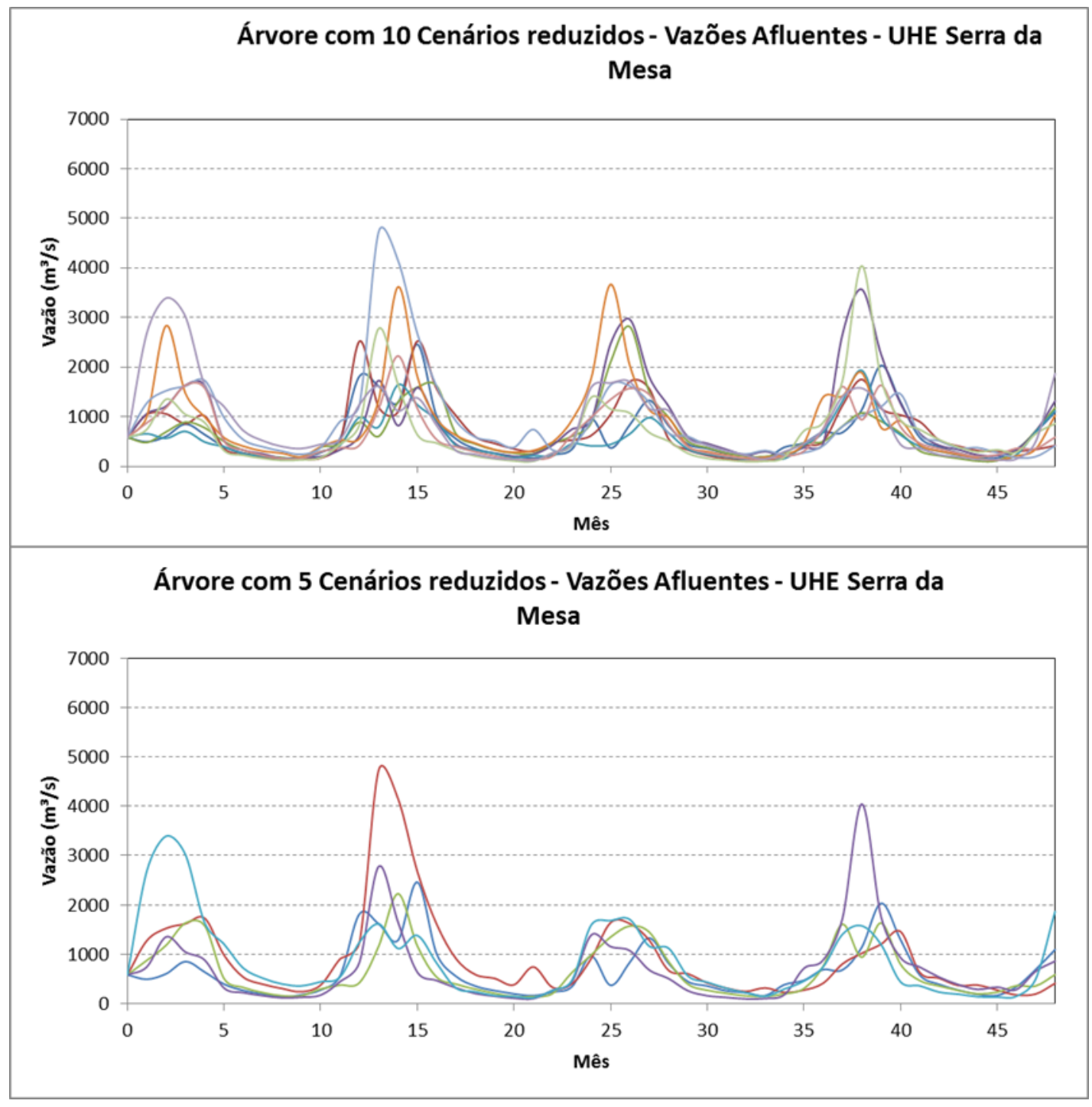

Figura 89. Árvores de Vazões Afluentes - UHE Serra da Mesa (continuação)

Tabela 23. Comparação dos principais parâmetros estatísticos das séries de vazões - UHE Serra da Mesa

\begin{tabular}{|c|c|c|c|c|c|c|c|}
\hline \multirow{2}{*}{ Parâmetros Estatísticos } & \multirow{2}{*}{\begin{tabular}{|c|} 
Série Histórica \\
(1931 - 2012)
\end{tabular}} & \multirow{2}{*}{ 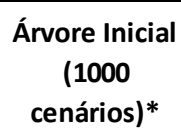 } & \multicolumn{5}{|c|}{ Árvore Reduzida - Número de cenários* } \\
\hline & & & 100 & 50 & 25 & 10 & 5 \\
\hline vazão média (m³/s) & 774 & 772 & 748 & 770 & 771 & 756 & 793 \\
\hline desvio Padrão $\left(\mathrm{m}^{3} / \mathrm{s}\right.$ & 690 & 657 & 649 & 672 & 681 & 682 & 744 \\
\hline Coeficiente de Variação & $89 \%$ & $84 \%$ & $87 \%$ & $87 \%$ & $88 \%$ & $90 \%$ & $94 \%$ \\
\hline Assimetria & 2,1 & 1,6 & 1,7 & 1,7 & 1,8 & 1,8 & 2,0 \\
\hline
\end{tabular}


Tabela 24. Parâmetros obtidos - UHE Serra da Mesa

\begin{tabular}{|c|c|c|c|c|}
\hline $\begin{array}{c}\text { Número de } \\
\text { cenários da árvores } \\
\text { reduzida }\end{array}$ & $\begin{array}{c}\text { Porcentagem de } \\
\text { Redução }\end{array}$ & $\begin{array}{c}\text { Tempo de } \\
\text { Processamento } \\
\text { (HH:MM) }\end{array}$ & Método de Redução & Função Objetivo \\
\hline $\mathbf{5}$ & 0,688 & $00: 03$ & FAST BACKWARD + FORWARD & 20837620 \\
\hline $\mathbf{1 0}$ & 0,649 & $00: 03$ & FAST BACKWARD + FORWARD & 20590480 \\
\hline $\mathbf{1 5}$ & 0,627 & $00: 03$ & FAST BACKWARD + FORWARD & 20294080 \\
\hline $\mathbf{2 0}$ & 0,609 & $00: 04$ & FAST BACKWARD + FORWARD & 20373510 \\
\hline $\mathbf{2 5}$ & 0,596 & $00: 04$ & FAST BACKWARD + FORWARD & 20352950 \\
\hline $\mathbf{3 0}$ & 0,585 & $00: 04$ & FAST BACKWARD + FORWARD & 19797730 \\
\hline $\mathbf{4 0}$ & 0,566 & $00: 06$ & FAST BACKWARD + FORWARD & 19595520 \\
\hline $\mathbf{5 0}$ & 0,55 & $00: 08$ & FAST BACKWARD + FORWARD & 19657970 \\
\hline $\mathbf{6 0}$ & 0,533 & $00: 11$ & FAST BACKWARD + FORWARD & 19559460 \\
\hline $\mathbf{7 0}$ & 0,519 & $00: 12$ & FAST BACKWARD + FORWARD & 19395300 \\
\hline $\mathbf{8 0}$ & 0,506 & $00: 20$ & FAST BACKWARD + FORWARD & 19273950 \\
\hline $\mathbf{9 0}$ & 0,493 & $00: 25$ & FAST BACKWARD + FORWARD & 19147060 \\
\hline $\mathbf{1 0 0}$ & 0,482 & $00: 31$ & FAST BACKWARD + FORWARD & 18807110 \\
\hline $\mathbf{1 5 0}$ & 0,43 & $01: 21$ & FAST BACKWARD + FORWARD & 18424930 \\
\hline
\end{tabular}

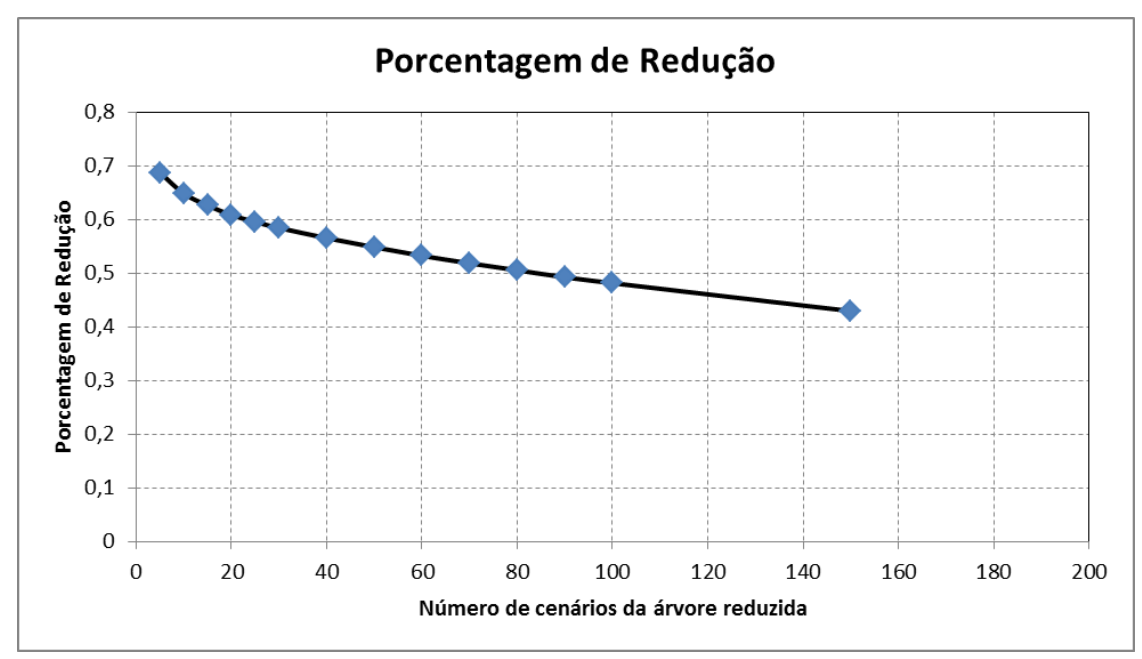

Figura 90. Porcentagem de Redução - UHE Serra da Mesa

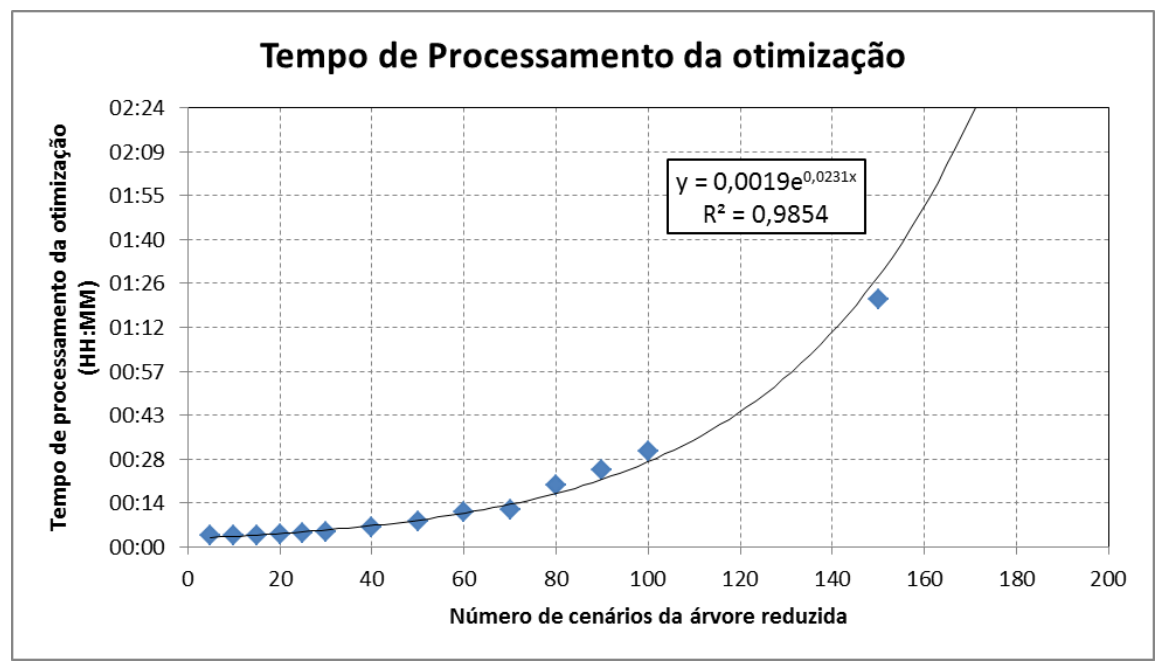

Figura 91. Tempo de Processamento - UHE Serra da Mesa 


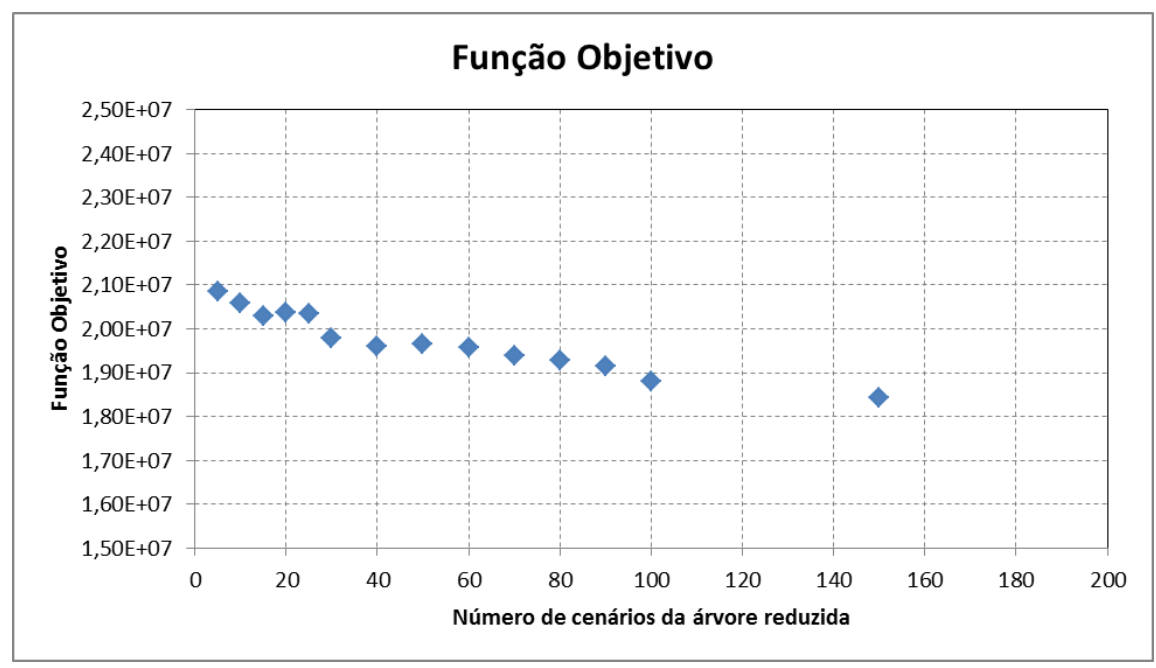

Figura 92. Função Objetivo - UHE Serra da Mesa

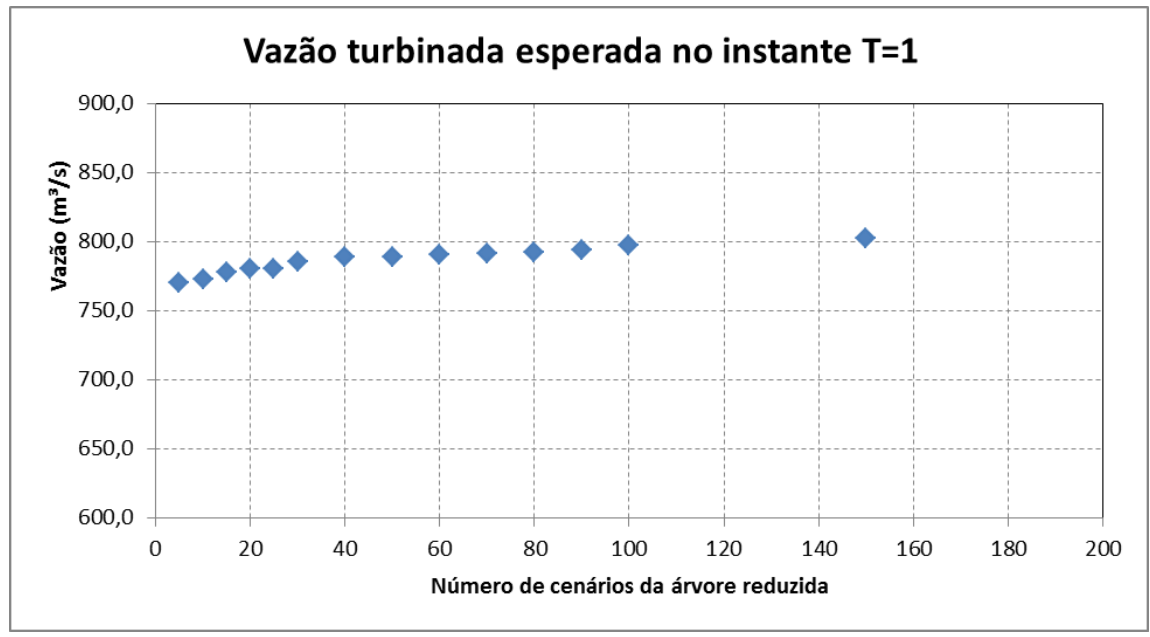

Figura 93. Vazão turbinada esperada no instante $T=1$ - UHE Serra da Mesa

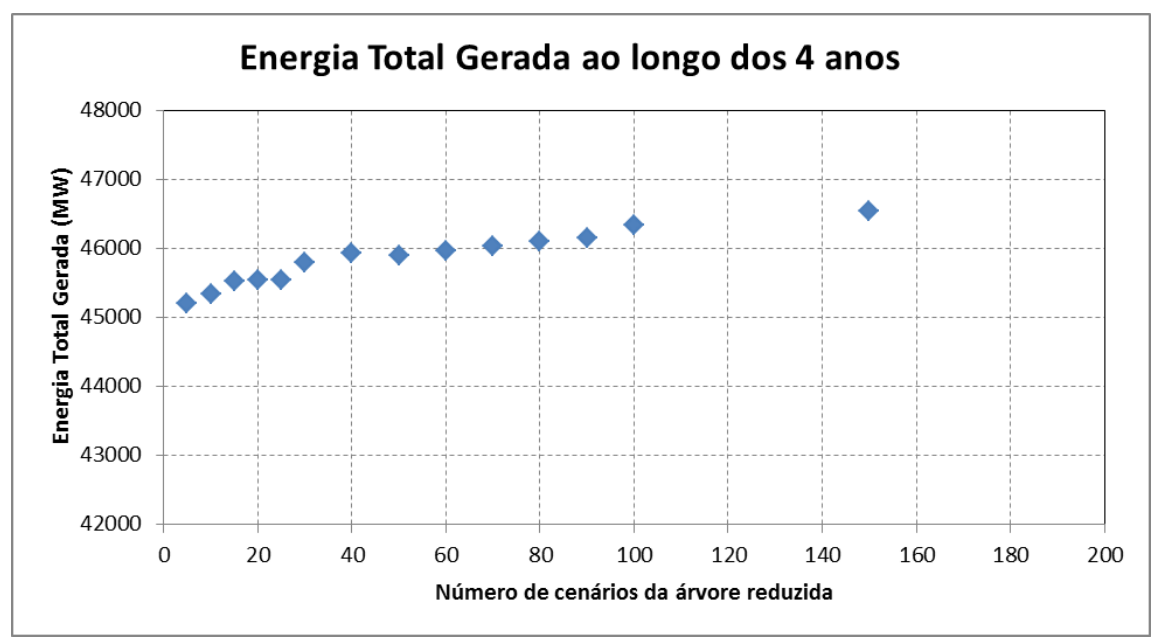

Figura 94. Energia gerada ao longo dos 4 anos - UHE Serra da Mesa 


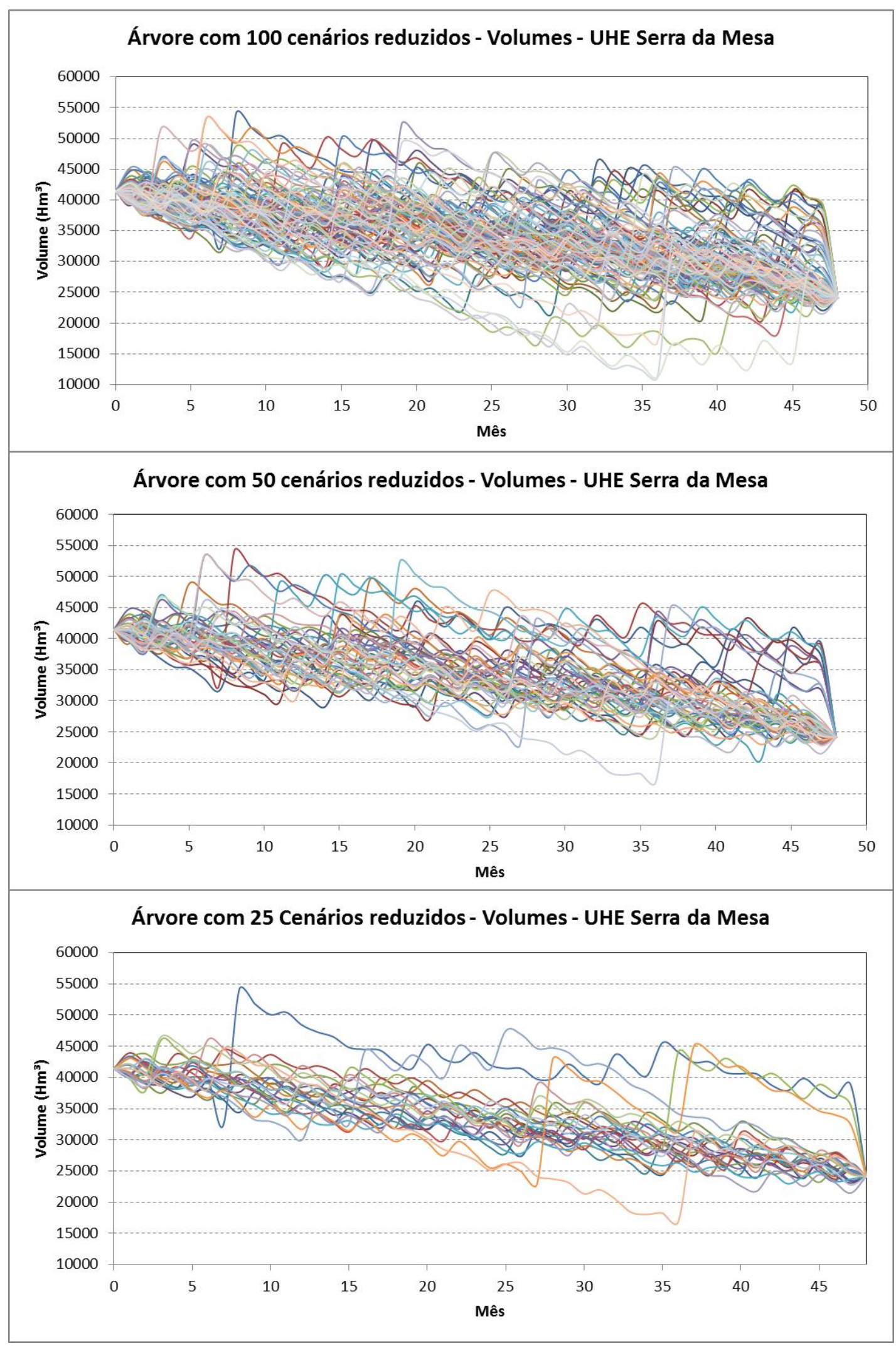

Figura 95. Árvores de cenários - Volumes - UHE Serra da Mesa 


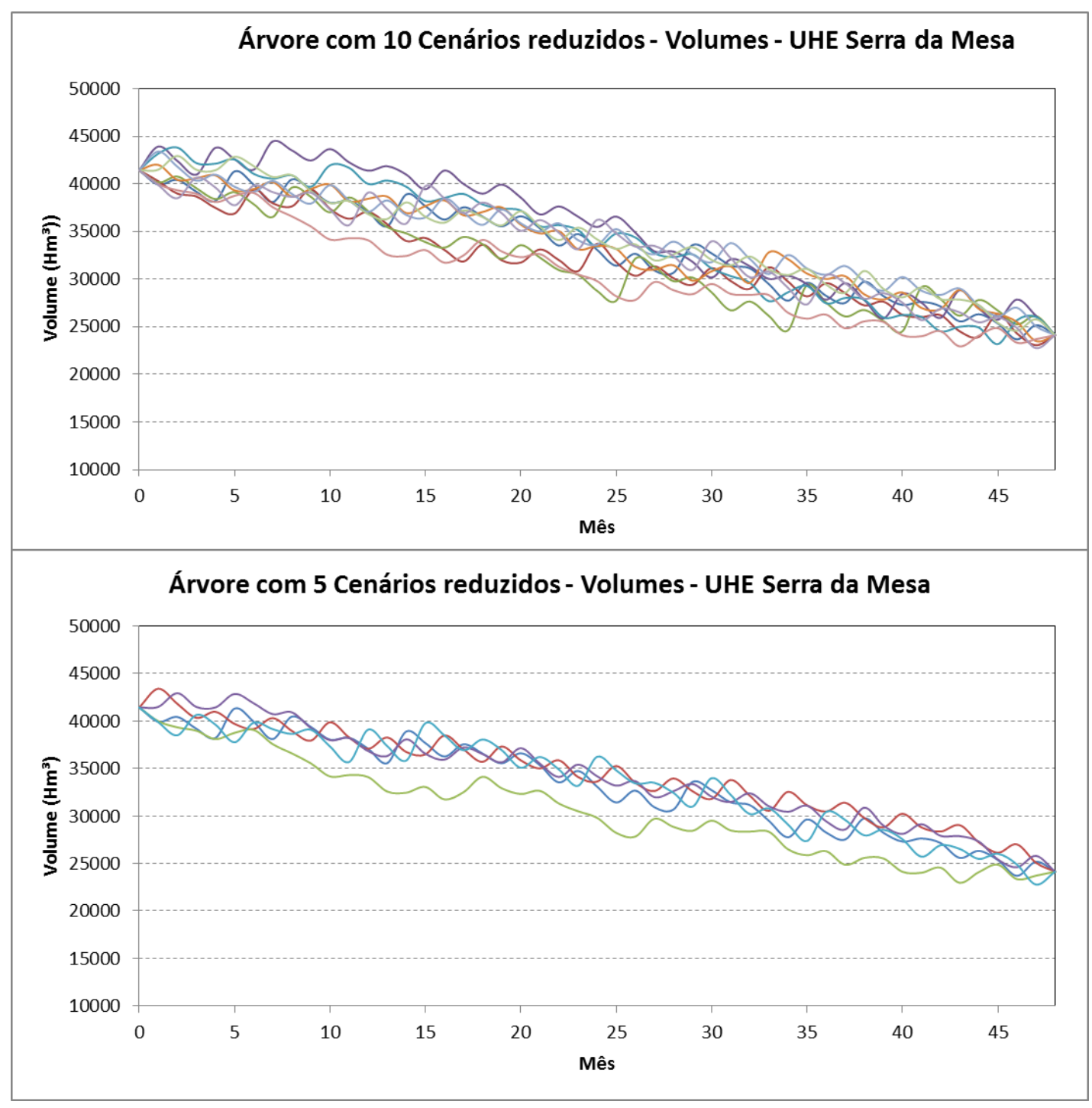

Figura 96. Árvores de cenários - Volumes - UHE Serra da Mesa (continuação) 


\subsubsection{UHE Balbina}

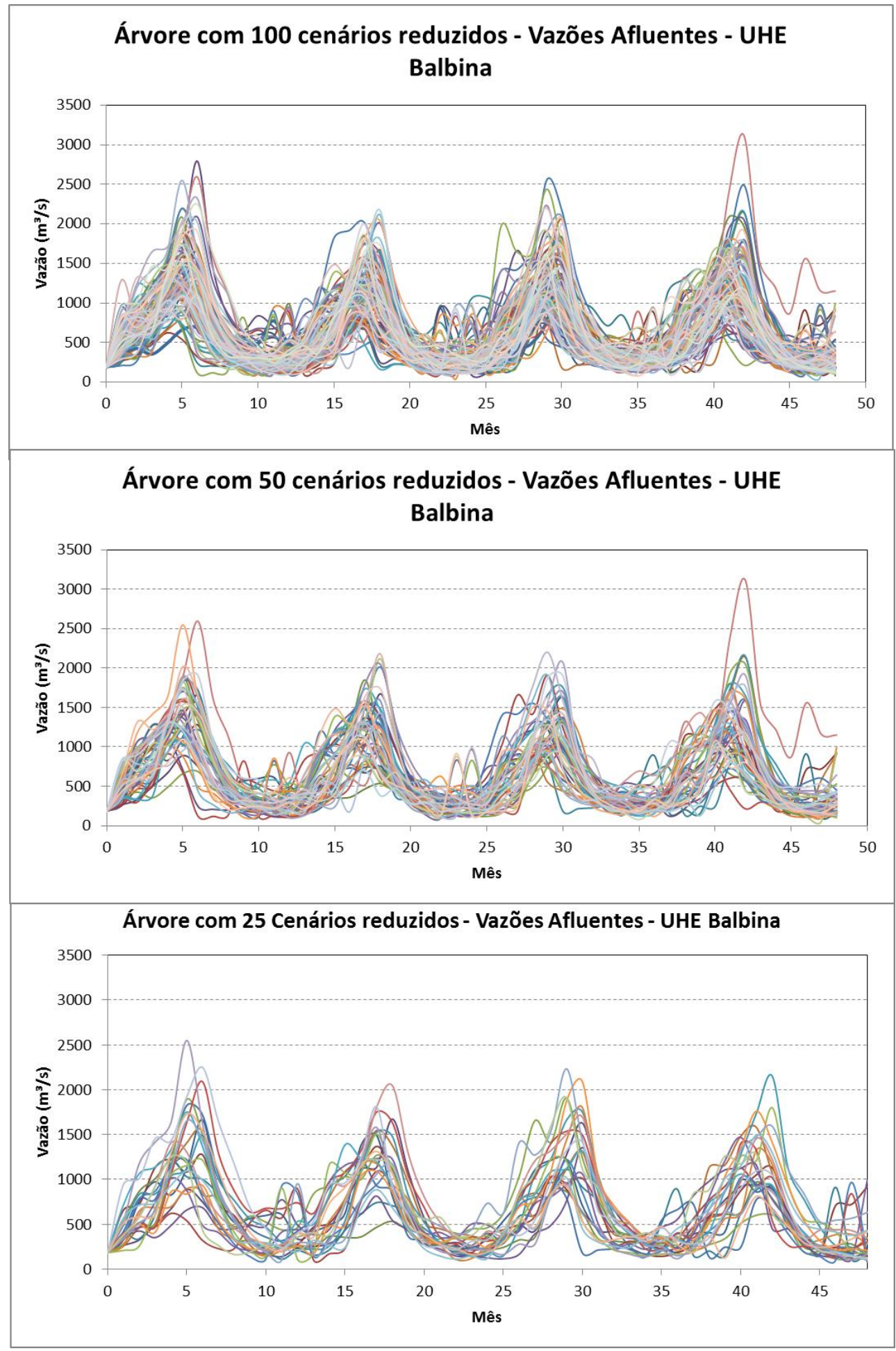

Figura 97. Árvores de Vazões Afluentes - UHE Balbina 


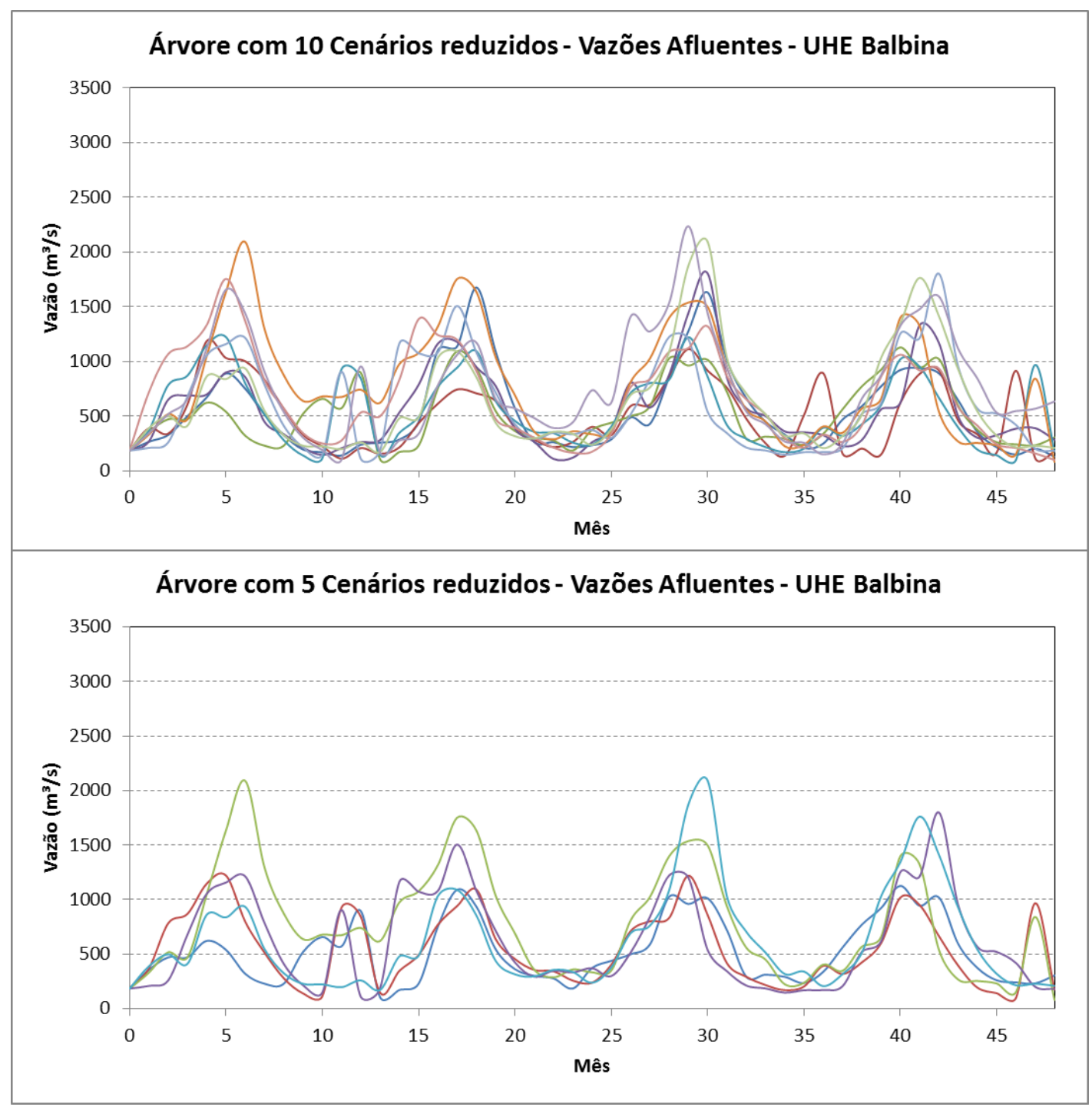

Figura 98. Árvores de Vazões Afluentes - UHE Balbina (continuação)

Tabela 25. Comparação dos principais parâmetros estatísticos das séries de vazões - UHE Balbina

\begin{tabular}{|c|c|c|c|c|c|c|c|}
\hline \multirow{2}{*}{ Parâmetros Estatísticos } & \multirow{2}{*}{\begin{tabular}{|c|} 
Série Histórica \\
(1931 - 2012)
\end{tabular}} & \multirow{2}{*}{ 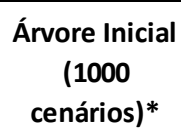 } & \multicolumn{5}{|c|}{ Árvore Reduzida - Número de cenários* } \\
\hline & & & 100 & 50 & 25 & 10 & 5 \\
\hline vazão média (m³/s) & 598 & 626 & 617 & 613 & 613 & 617 & 626 \\
\hline desvio Padrão $\left(\mathrm{m}^{3} / \mathrm{s}\right.$ & 410 & 407 & 408 & 410 & 403 & 392 & 399 \\
\hline Coeficiente de Variação & $69 \%$ & $65 \%$ & $66 \%$ & $67 \%$ & $66 \%$ & $64 \%$ & $64 \%$ \\
\hline Assimetria & 1,2 & 1,0 & 1,0 & 1,0 & 0,9 & 0,8 & 0,7 \\
\hline
\end{tabular}


Tabela 26. Parâmetros obtidos - UHE Balbina

\begin{tabular}{|c|c|c|c|c|}
\hline $\begin{array}{c}\text { Número de } \\
\text { cenários da árvores } \\
\text { reduzida }\end{array}$ & $\begin{array}{c}\text { Porcentagem de } \\
\text { Redução }\end{array}$ & $\begin{array}{c}\text { Tempo de } \\
\text { Processamento } \\
\text { (HH:MM) }\end{array}$ & Método de Redução & Função Objetivo \\
\hline $\mathbf{5}$ & 0,653 & $00: 03$ & FAST BACKWARD + FORWARD & 7591189 \\
\hline $\mathbf{1 0}$ & 0,613 & $00: 03$ & FAST BACKWARD + FORWARD & 7616837 \\
\hline $\mathbf{1 5}$ & 0,596 & $00: 03$ & FAST BACKWARD + FORWARD & 7611599 \\
\hline $\mathbf{2 0}$ & 0,585 & $00: 03$ & FAST BACKWARD + FORWARD & 7601478 \\
\hline $\mathbf{2 5}$ & 0,576 & $00: 03$ & FAST BACKWARD + FORWARD & 7599663 \\
\hline $\mathbf{3 0}$ & 0,568 & $00: 04$ & FAST BACKWARD + FORWARD & 7604052 \\
\hline $\mathbf{4 0}$ & 0,554 & $00: 05$ & FAST BACKWARD + FORWARD & 7599589 \\
\hline $\mathbf{5 0}$ & 0,541 & $00: 07$ & FAST BACKWARD + FORWARD & 7596265 \\
\hline $\mathbf{6 0}$ & 0,53 & $00: 08$ & FAST BACKWARD + FORWARD & 7598725 \\
\hline $\mathbf{7 0}$ & 0,519 & $00: 10$ & FAST BACKWARD + FORWARD & 7599941 \\
\hline $\mathbf{8 0}$ & 0,508 & $00: 13$ & FAST BACKWARD + FORWARD & 7599201 \\
\hline $\mathbf{9 0}$ & 0,498 & $00: 17$ & FAST BACKWARD + FORWARD & 7598072 \\
\hline $\mathbf{1 0 0}$ & 0,488 & $00: 32$ & FAST BACKWARD + FORWARD & 7601703 \\
\hline $\mathbf{1 5 0}$ & 0,442 & $01: 32$ & FAST BACKWARD + FORWARD & 7603722 \\
\hline
\end{tabular}

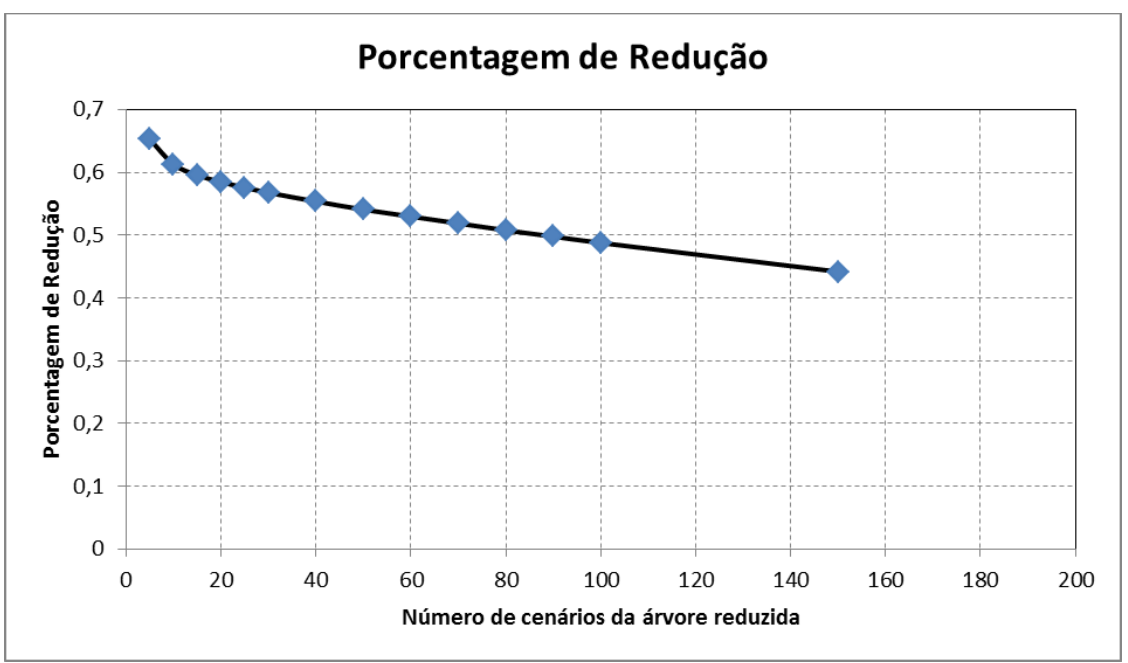

Figura 99. Porcentagem de Redução - UHE Balbina

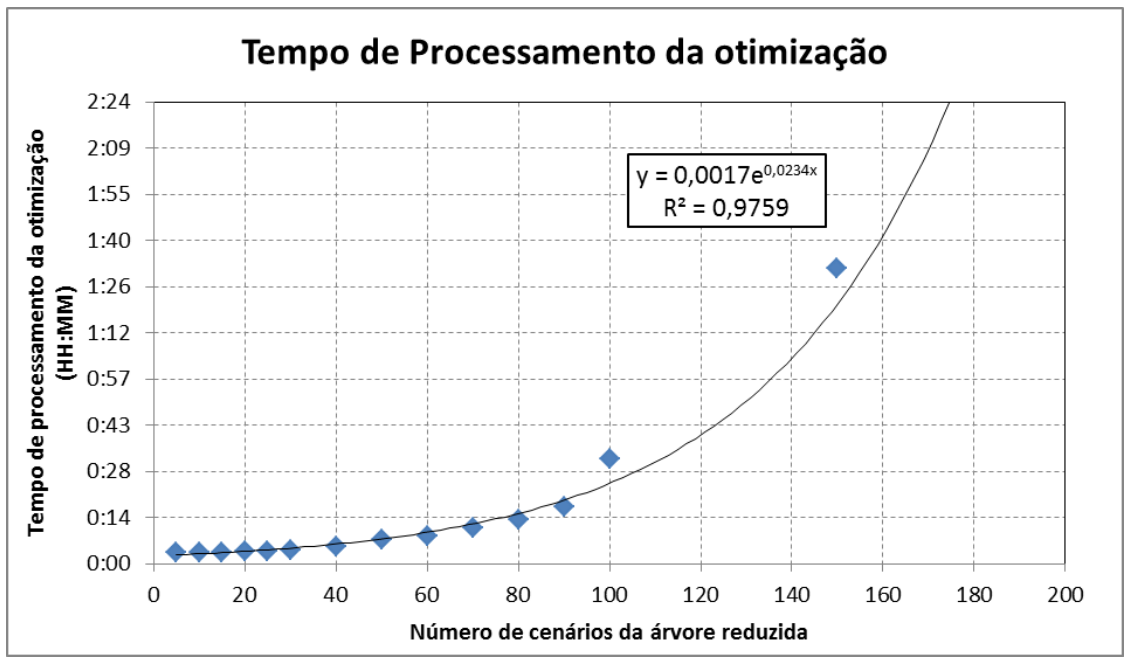

Figura 100. Tempo de Processamento - UHE Balbina 


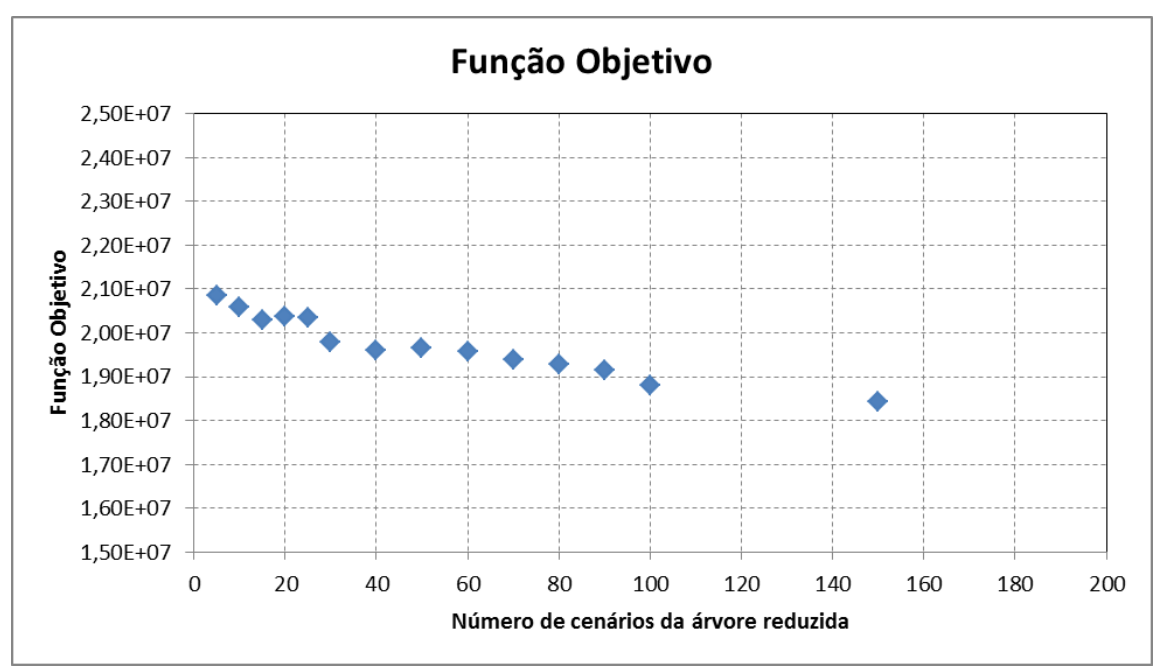

Figura 101. Função Objetivo - UHE Balbina

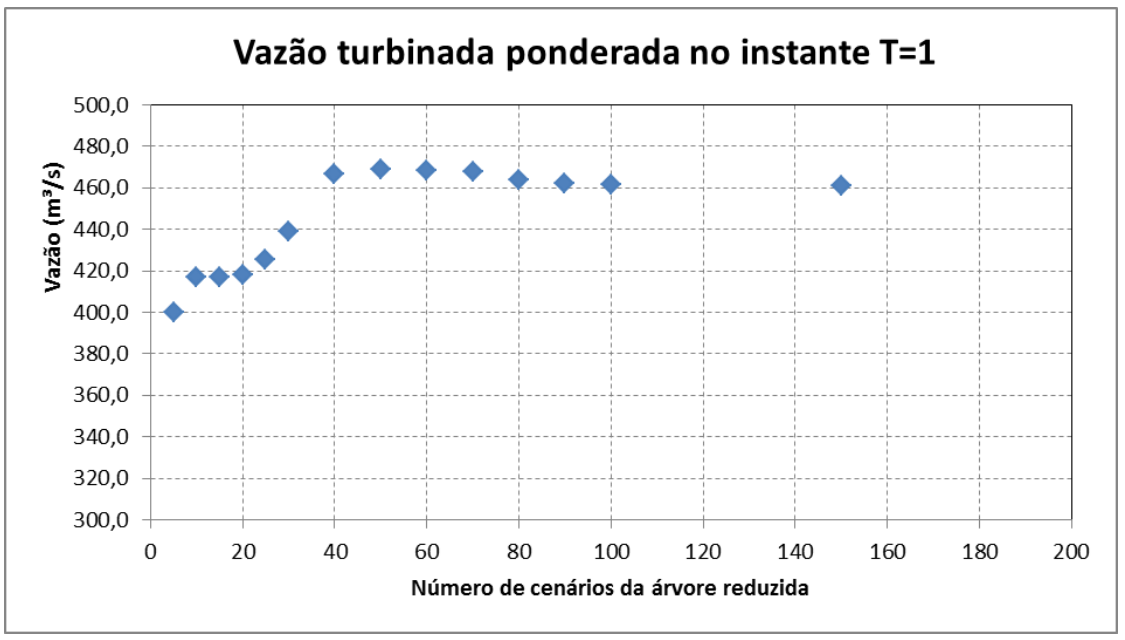

Figura 102. Vazão turbinada ponderada no instante $\mathrm{T}=1$ - UHE Balbina

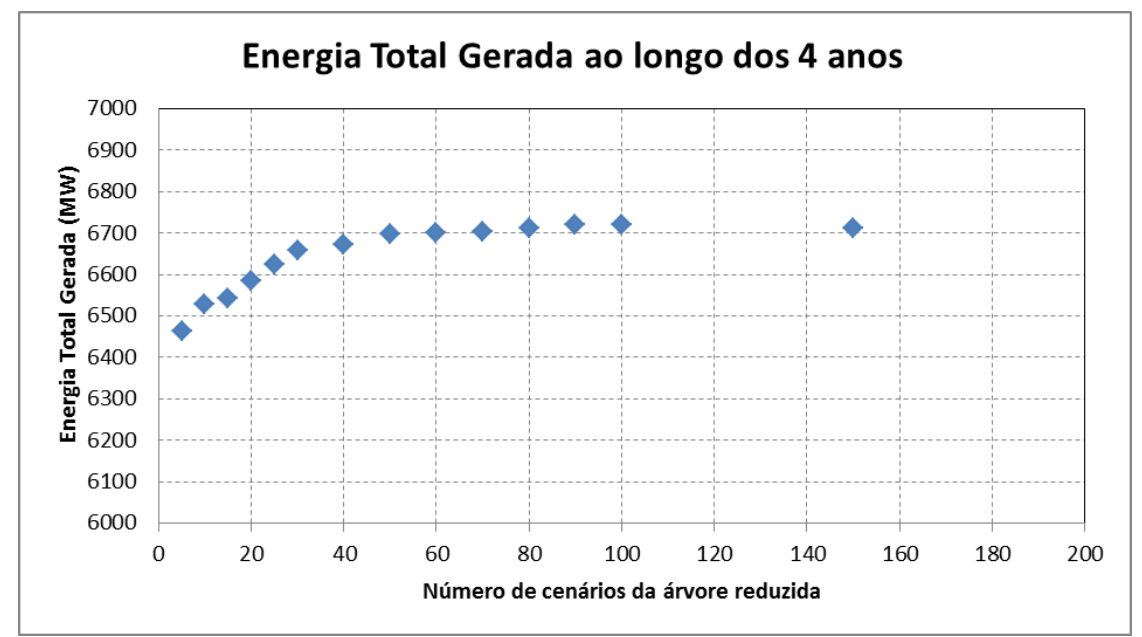

Figura 103. Energia gerada ao longo dos 4 anos - UHE Balbina 


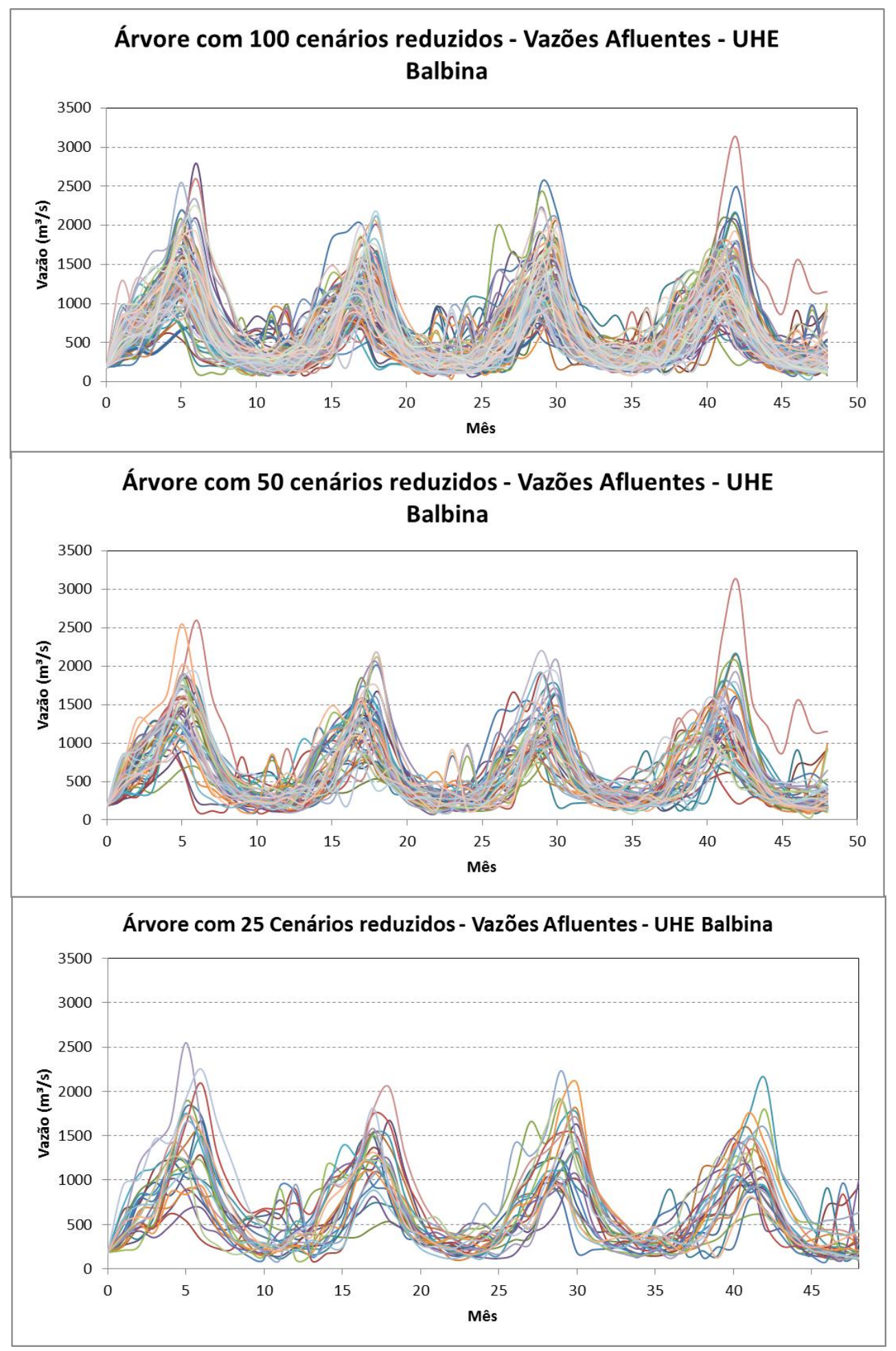

Figura 104. Árvores de cenários - Volumes - UHE Balbina 


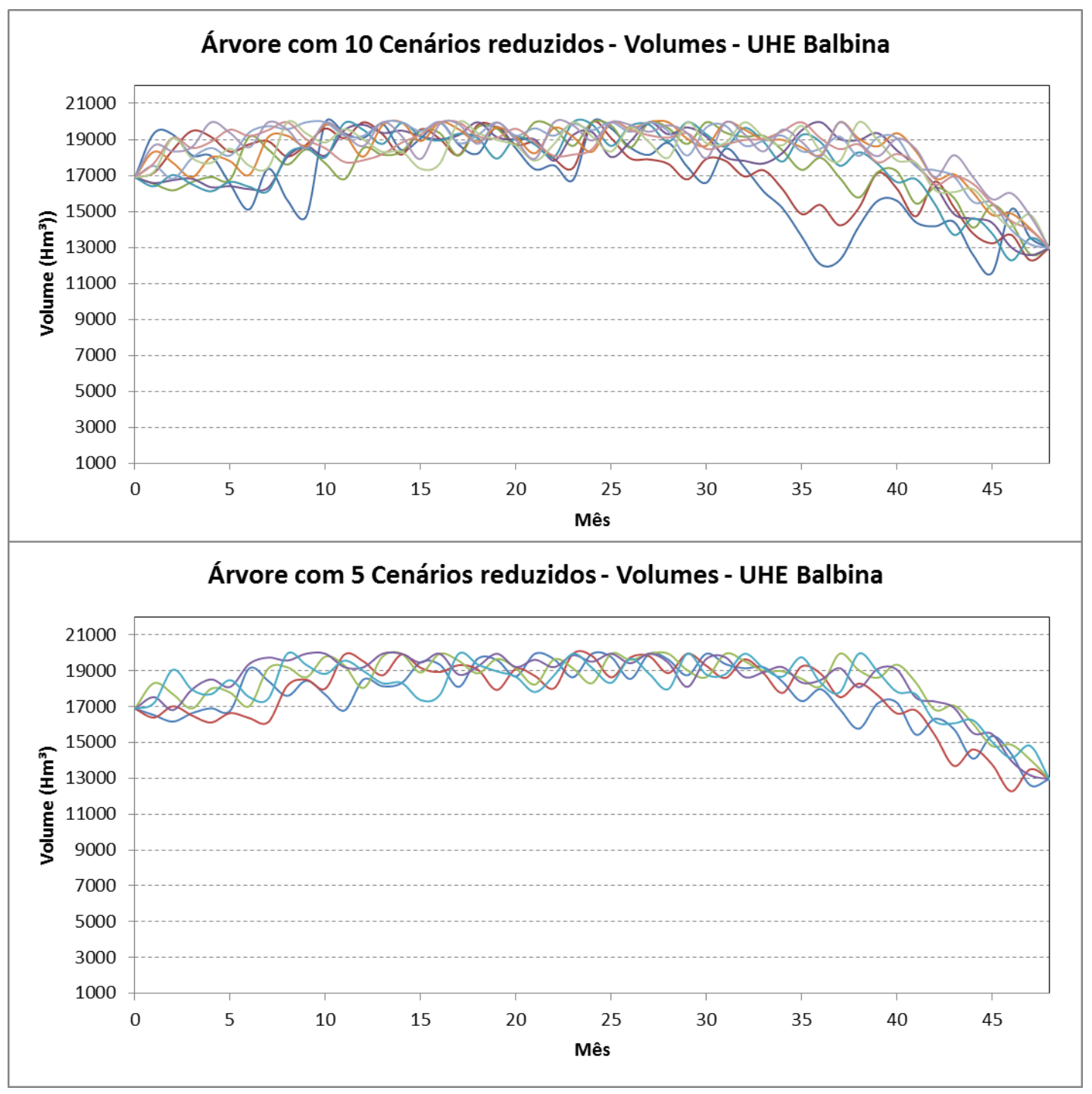

Figura 105. Árvores de cenários - Volumes - UHE Balbina (continuação) 


\subsubsection{Considerações a respeito dos resultados}

As análises realizadas nesse item levam às seguintes considerações:

- A ferramenta de redução SCENRED permite reduções significativas no número de cenários da árvore de cenários, sem, contudo, ocasionar em reduções significativas nas informações contidas na árvore inicial (1000 aberturas). Por exemplo:

Para o caso da UHE Três Marias, uma redução na árvore de 1000 para 50 cenários (ou seja, reduzindo a árvore para $5 \%$ do número de cenários iniciais) impacta em uma porcentagem de redução de apenas $52 \%$, ou seja, $52 \%$ do universo original de possibilidades. Este valor indica ainda que a proximidade entre os cenários na árvore reduzida sofreu uma redução de $52 \%$ em relação à proximidade entre os cenários na árvore inicial (1000 cenários).

Os parâmetros estatísticos básicos (tabelas 15, 17, 19, 21, 23 e 25) se mantiveram coerentes entre a série histórica, a árvore inicial e as árvores reduzidas.

Aliando esta informação ao fato de que o tempo computacional demandado para a aplicação da otimização considerando uma árvore com 50 cenários reduzidos foi de cerca de 5 minutos, e que o tempo demandando para uma otimização considerando 1000 cenários é de várias horas (com base na figura 48), pode-se verificar que a ferramenta de redução é de grande valia para a viabilização de técnicas de otimização estocástica considerando elevado número de cenários.

Estas considerações podem ser extrapoladas para as outras bacias em estudo.

- A redução no número de cenários de uma árvore realizado pelo SCENRED impacta na eliminação dos cenários que possuem pouca probabilidade de ocorrência. Este processo pode resultar na eliminação de cenários extremos de vazões (períodos de cheias ou secas).

- Quanto maior o número de cenários considerados na árvore reduzida, maior o número de variáveis envolvidas no processo de otimização e, consequentemente, maior a dimensão do problema, impactando em um 
maior tempo de processamento computacional para a solução da otimização estocástica. Este aumento incremental de tempo é exponencial, confirmando os estudos realizados por outros autores, de modo que a viabilidade do problema pode ser comprometida mediante a utilização de um número demasiado de cenários finais.

- O valor esperado da vazão turbinada no instante $T=1$ e da energia gerada ao longo do tempo de processamento é estável a partir de um determinado número de cenários reduzidos (em torno de 50 cenários finais).

- A utilização de poucos cenários na árvore reduzida (por exemplo: 5 cenários) não retrata comportamentos fora do padrão médio, ou seja, não é conservador e confiável para a tomada de decisão.

- A instabilidade dos resultados na utilização de árvores reduzidas com menos de 50 cenários pode ser atribuída às mesmas questões envolvendo a instabilidade nos resultados verificado no item 5.10.1.

- As árvores reduzidas das UHEs Foz do Areia e Três Marias apresentaram médias até cerca de $5 \%$ menores que a árvore inicial e a série histórica. Contudo, considerando que os parâmetros estatísticos da série histórica se referem a uma série com 82 anos de medições e os parâmetros da série gerada se referem a séries de 4 anos de extensão, considera-se que a ferramenta de redução é válida ao processo.

- Devido ao demasiado tempo computacional demandado para realizar otimizações com mais de 150 cenários, e ressaltando-se que a análise se limita a uma usina individualizada, o uso de árvores com muitos cenários se torna inviável para a dimensão do SIN. 
5.10.3 Analise de sensibilidade do modelo de redução de cenários e de otimização estocástica frente a diferentes regimes hidrológicos

De posse dos resultados obtidos no item 5.10.2 foi feita uma compilação dos resultados e uma análise integrada, pareando os resultados das otimizações das seis UHEs em estudo e visando correlacionar qualitativamente os comportamentos das otimizações aos regimes hidrológicos pertinentes a cada bacia em questão. Os principais resultados seguem nas figuras 106 a 110 a seguir.

\subsubsection{Resultados}

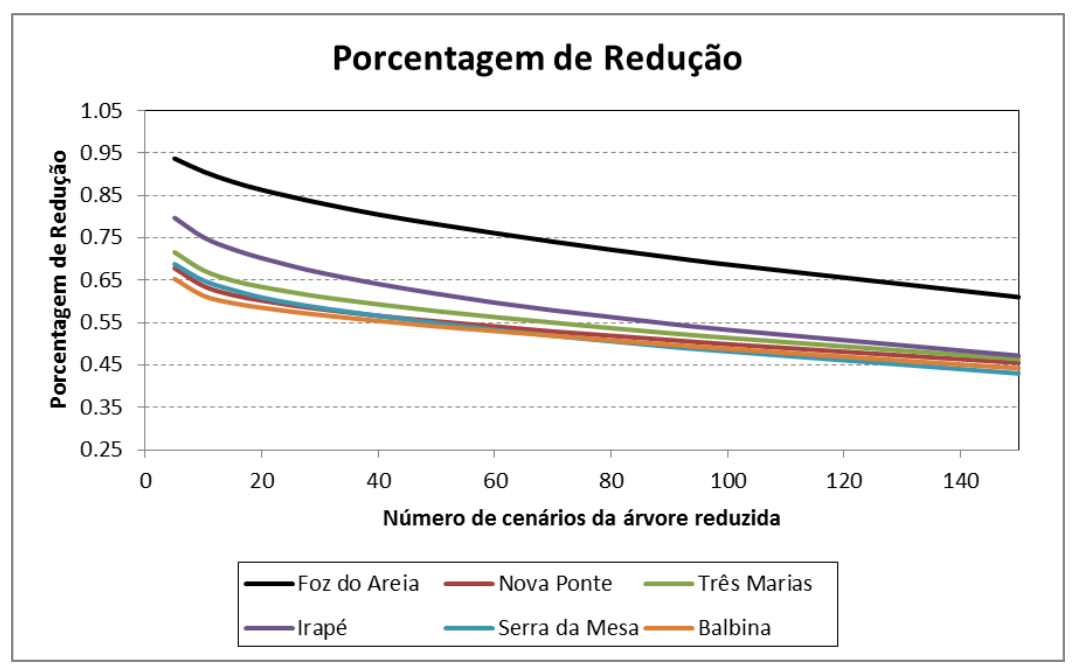

Figura 106. Comparação dos resultados: Porcentagem de redução

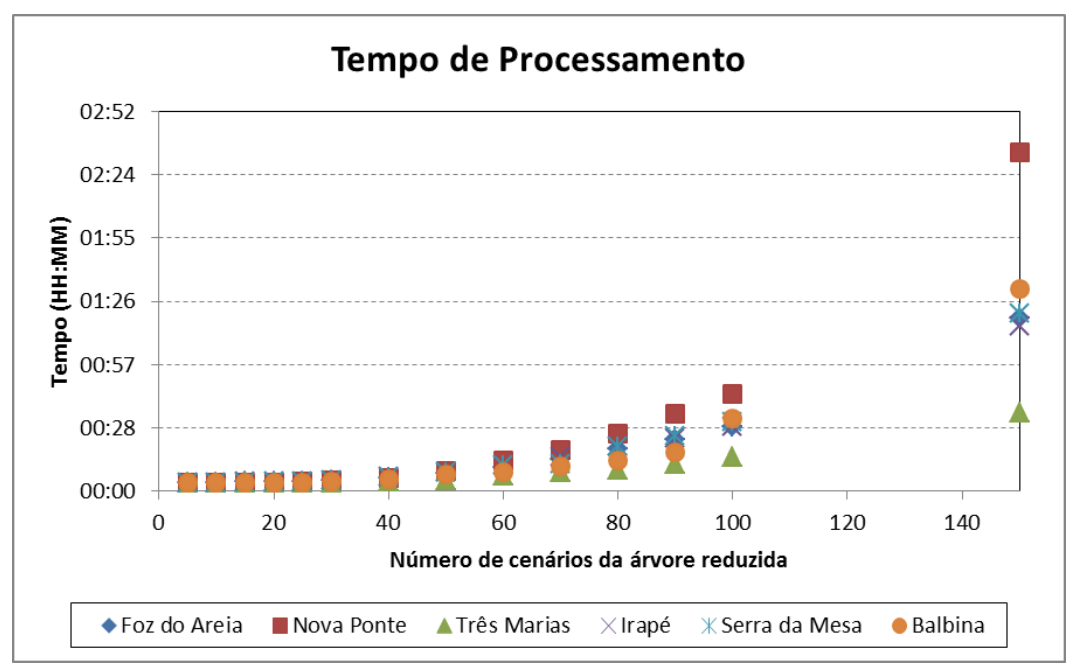

Figura 107. Comparação dos resultados: Tempo de Processamento 


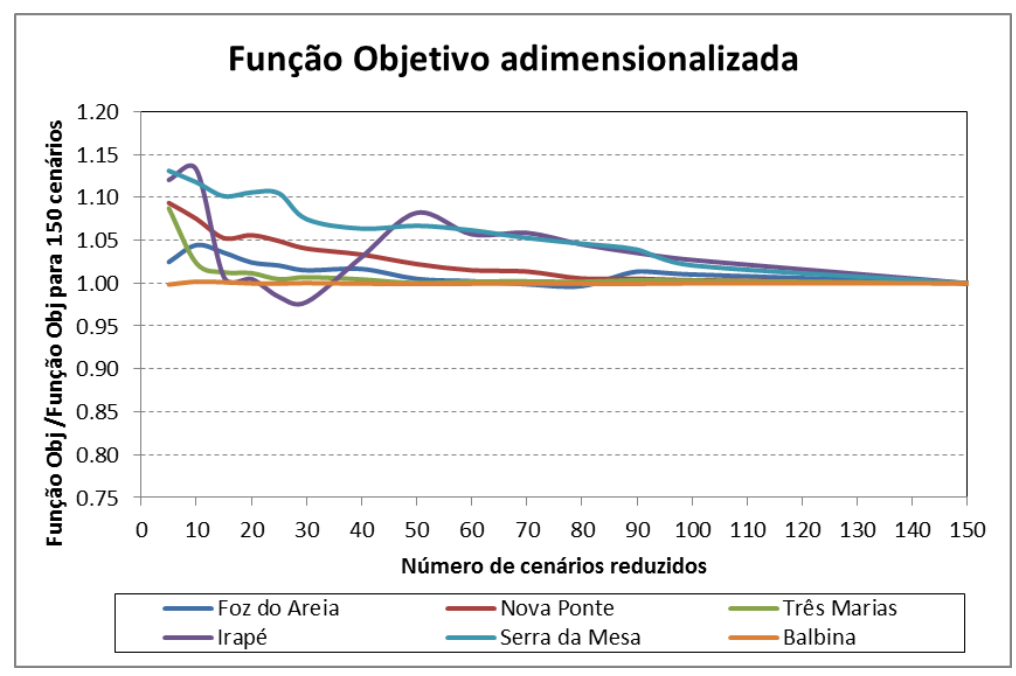

Figura 108. Comparação dos resultados: Função Objetivo

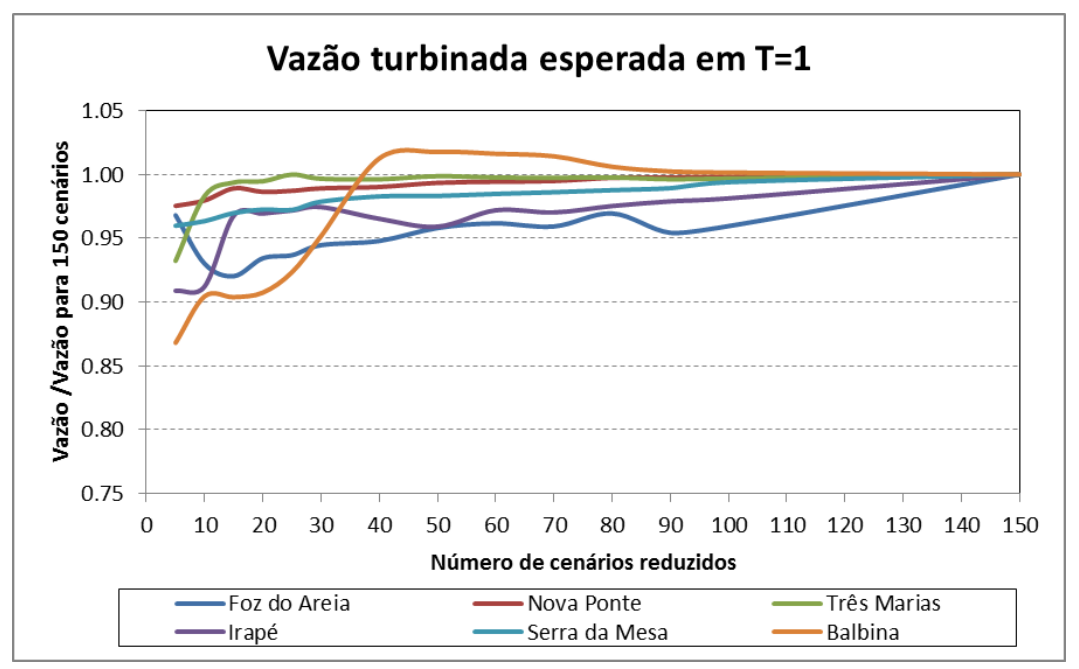

Figura 109. Comparação dos resultados: Vazão turbinada esperada

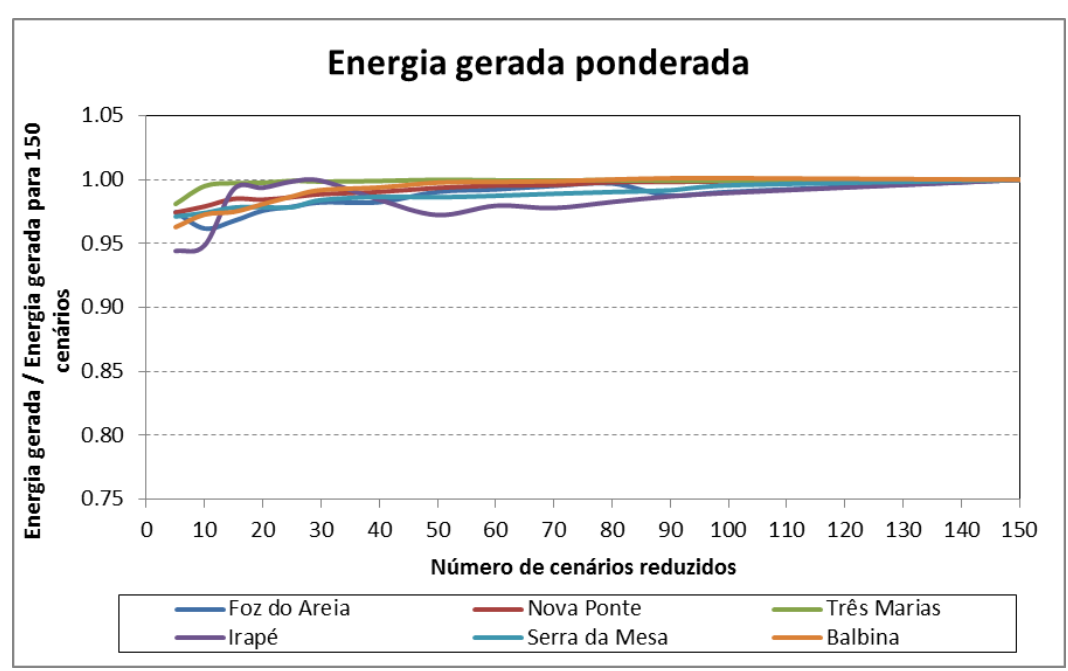

Figura 110. Comparação dos resultados: Energia gerada ponderada 


\subsubsection{Considerações Gerais}

Regimes hidrológicos menos definidos (ex: UHE Foz do Areia) resultam em séries sintéticas de vazões (cenários de vazões) mais divergentes.

De acordo com a equação 30, quanto menor o valor da porcentagem de redução da árvore reduzida mais próxima a árvore de cenários reduzida se encontra da árvore de cenários original. A partir disso pode-se concluir que a redução no número de cenários em árvores mais "comportados", ou seja, com regime hidrológico mais bem definido (como no caso das UHEs Nova Ponte, Três Marias, Irapé, Serra da Mesa e Balbina), não impacta na perda tão significativa de informação em relação à mesma operação em árvores com regime menos definido, como no caso da UHE Foz do Areia.

Todas as séries apresentam comportamentos similares quanto à relação entre o número de cenários e: o tempo de processamento, a função objetivo, a energia gerada e a vazão no tempo $T=1$, assim como descritos no item 5.10.2. Verifica-se, contudo, que as curvaturas das curvas geradas podem variar entre as diferentes UHEs. Estas diferenças podem ser atribuídas em função das configurações das árvores reduzidas.

A otimização da UHE Irapé consiste naquela que demonstrou maior divergência em relação às outras em relação ao comportamento da função objetivo, energia gerada e vazão no instante $T=1$. A série da UHE Irapé consiste, por sua vez, na série com o maior coeficiente de variação e assimetria.

Estas conclusões são importantes indicativos de que 0 processo de cenarização (configuração do número e aberturas de cenários) na otimização estocástica da geração hidrelétrica considerando muitas usinas, ou mesmo todo o SIN, pode ser otimizado. Pode-se gastar menores esforços computacionais e se utilizar árvores de menor, como é caso da maior parcela das usinas hidrelétricas do Brasil, principalmente aquelas que se situam nas regiões sudeste, centro oeste e nordeste. Por outro lado, deve utilizar árvores com maior número de cenários em usinas com regime hidrológico menos bem definidos, típicos das regiões sul do Brasil. 
Outro importante indicativo se refere à necessidade de ferramentas eficazes na determinação de uma solução inicial que se aproxime ao máximo da solução da otimização estocástica. Este consiste em um problema bastante recorrente em otimizadores que utilizam PNL, tal como o presente caso. As divergências dos valores dos tempos de processamento requeridos entre as diferentes usinas indica que o tempo de processamento requerido no processo de otimização estocástica pode ser significativamente reduzido através da utilização de ferramentas que visem soluções iniciais mais adequadas.

\subsubsection{Otimização estocástica frente a diferentes volumes iniciais do reservatório}

Todas as UHEs em estudo na presente dissertação possuem reservatórios de acumulação, com capacidade de regularização de vazões. Assim, para efeitos de planejamento da operação, a consideração do valor do Volume do reservatório no instante inicial da análise é importante, no sentido que pode impactar nos valores das vazões a serem turbinadas nos meses de planejamento. De modo geral, quanto mais elevado estiver o nível de um reservatório, e consequentemente maior o volume acumulado, em um determinado instante, maior a tendência de que a regra operativa seja menos conservadora e se turbina mais água.

Deste modo, a análise de sensibilidade proposta neste item tem como objetivo verificar a influência do valor do parâmetro de entrada Volume Inicial do reservatório nos resultados da otimização estocástica proposta.

Tendo como base os algoritmos de otimização estocástica desenvolvidos para as UHEs em análise, foram realizadas seis simulações para cada UHE em estudo, considerando diferentes valores de volumes iniciais dos reservatórios, mais especificamente variando o Volume Inicial entre $20 \%$ e $70 \%$ do Volume Útil do reservatório.

Foram consideradas, em todas as simulações, as mesmas árvores iniciais utilizadas no item 5.10 .2 ( 1.000 cenários iniciais), além de ter sido fixado, para todos os casos, uma redução dessas para uma árvore reduzida com 50 
cenários. A partir dessas árvores reduzidas foram, assim, realizadas as otimizações estocásticas pertinentes.

A tabela 27 a seguir apresenta os valores dos volumes iniciais considerados.

Tabela 27. Valores de Volume Inicial considerados

\begin{tabular}{|c|c|c|c|c|c|c|c|c|c|c|c|c|c|c|}
\hline & $\begin{array}{c}\text { Potência } \\
\text { Instalada } \\
\text { (MW) }\end{array}$ & $\begin{array}{l}\text { Volume Útil } \\
\qquad\left(\mathrm{Hm}^{3}\right)\end{array}$ & $\begin{array}{c}\text { Volume } \\
\text { Mínimo } \\
\left(\mathrm{Hm}^{3}\right)\end{array}$ & $\begin{array}{c}\text { Volume } \\
\text { Máximo } \\
\left(\mathrm{Hm}^{3}\right)\end{array}$ & \multicolumn{10}{|c|}{ Volume Inicial (em \% do Volume Útil), em $\mathrm{Hm}^{3}$} \\
\hline UHE Foz do Areia & 1676 & 3805 & 1974 & 5779 & 2355 & 2735 & 3116 & 3496 & 3877 & 4257 & 4638 & 5018 & 5399 & 5779 \\
\hline UHE Nova Ponte & 510 & 10380 & 2412 & 12792 & 3450 & 4488 & 5526 & 6564 & 7602 & 8640 & 9678 & 10716 & 11754 & 12792 \\
\hline UHE Irapé & 360 & 3696 & 2267 & 5963 & 2637 & 3006 & 3376 & 3745 & 4115 & 4485 & 4854 & 5224 & 5593 & 5963 \\
\hline UHE Serra da Mesa & 1275 & 43250 & 11150 & 54400 & 15475 & 19800 & 24125 & 28450 & 32775 & 37100 & 41425 & 45750 & 50075 & 54400 \\
\hline
\end{tabular}

Nos itens 5.10.4.1 a 5.10.4.6 a seguir são apresentados os principais resultados obtidos. O item 5.10.4.7 apresenta de modo conjunto os resultados, visando uma análise e comparação entre os resultados. As principais considerações por sua vez são apresentadas no item 5.10.4.8.

\subsubsection{UHE Foz do Areia}

Tabela 28. Resultados - UHE Foz do Areia

\begin{tabular}{|c|c|c|}
\hline $\begin{array}{l}\text { Volume Inicial (\% } \\
\text { do Volume Útil) }\end{array}$ & $\begin{array}{l}\text { Vazão turbinada } \\
\text { esperada }\left(\mathrm{m}^{3} / \mathrm{s}\right)\end{array}$ & $\begin{array}{c}\text { Energia gerada } \\
\text { ponderada } \\
(\mathrm{MW})\end{array}$ \\
\hline 20 & 410 & 36131 \\
\hline 30 & 439 & 36333 \\
\hline 40 & 468 & 36533 \\
\hline 50 & 497 & 36731 \\
\hline 60 & 526 & 36926 \\
\hline 70 & 561 & 37120 \\
\hline
\end{tabular}




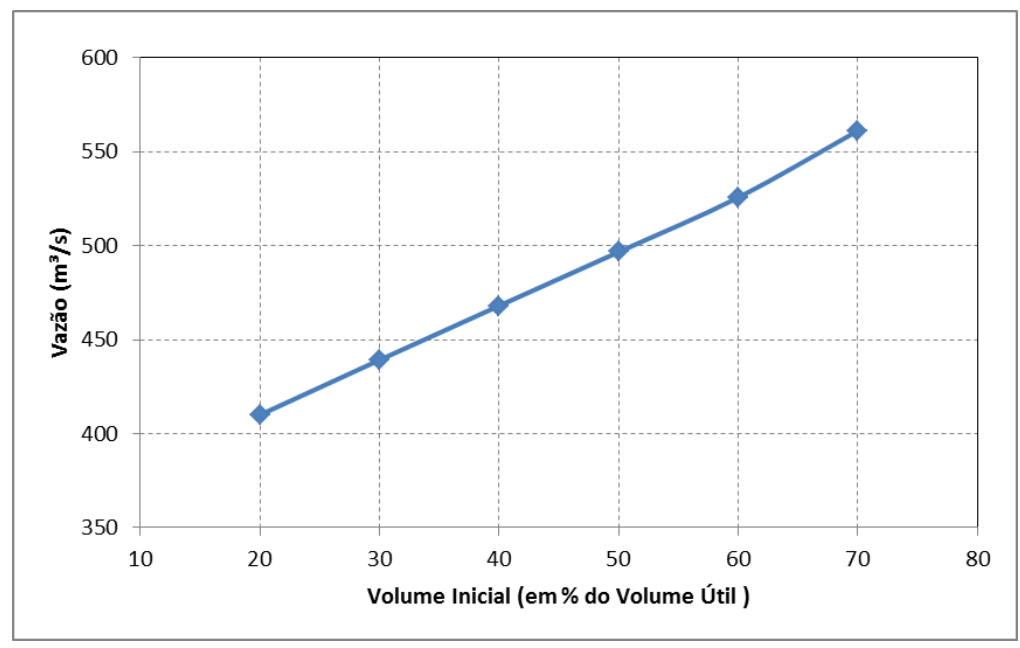

Figura 111. Volume Inicial x Vazão Turbinada Esperada - UHE Foz do Areia

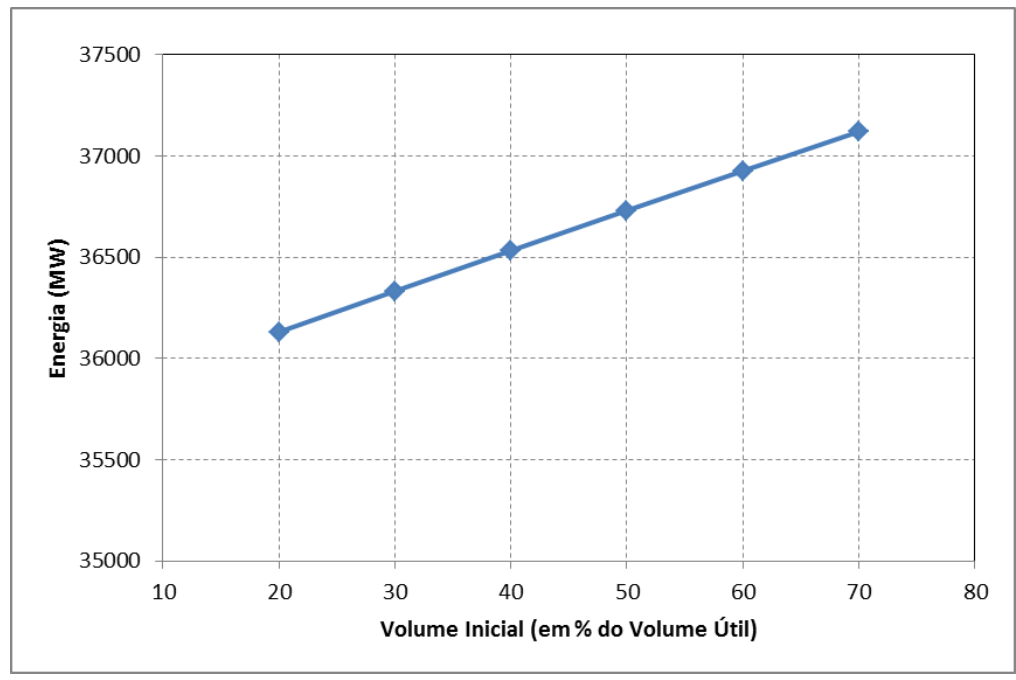

Figura 112. Volume Inicial x Energia Gerada Ponderada - UHE Foz do Areia

\subsubsection{UHE Nova Ponte}

Tabela 29. Resultados - UHE Nova Ponte

\begin{tabular}{|c|c|c|}
\hline $\begin{array}{c}\text { Volume Inicial (\% } \\
\text { do Volume Útil) }\end{array}$ & $\begin{array}{c}\text { Vazão turbinada } \\
\text { esperada }\left(\mathbf{m}^{\mathbf{3}} \mathbf{/ s}\right)\end{array}$ & $\begin{array}{c}\text { Energia gerada } \\
\text { ponderada } \\
\text { (MW) }\end{array}$ \\
\hline 20 & 216 & 14760 \\
\hline 30 & 231 & 15232 \\
\hline 40 & 246 & 15695 \\
\hline 50 & 260 & 16148 \\
\hline 60 & 274 & 16590 \\
\hline 70 & 288 & 17019 \\
\hline
\end{tabular}




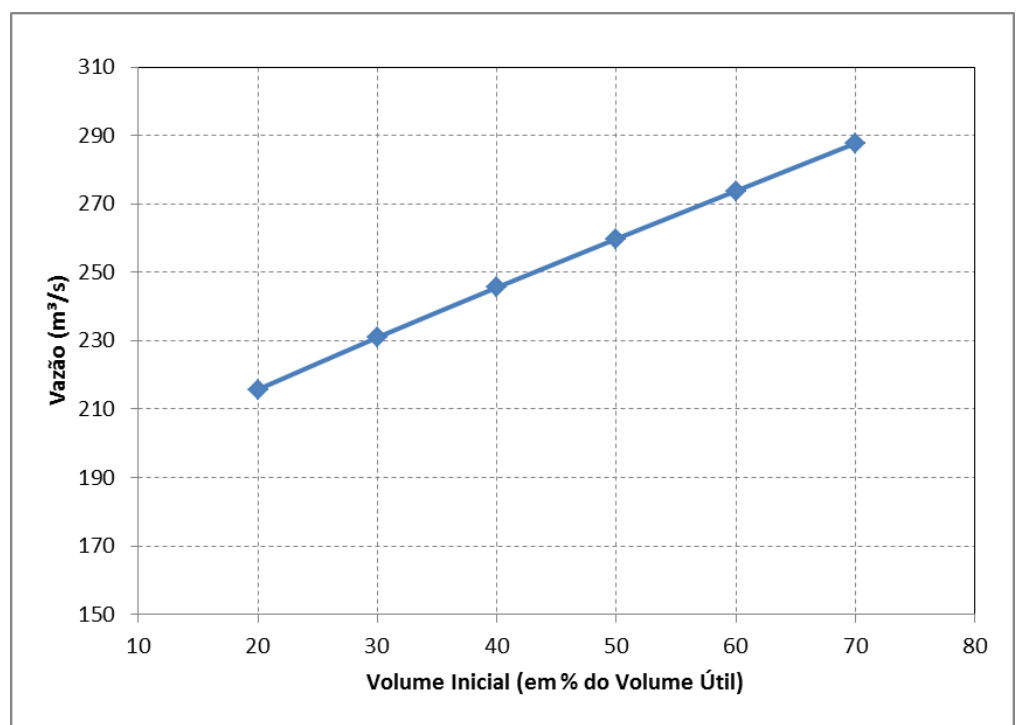

Figura 113. Volume Inicial x Vazão Turbinada Esperada - UHE Nova Ponte

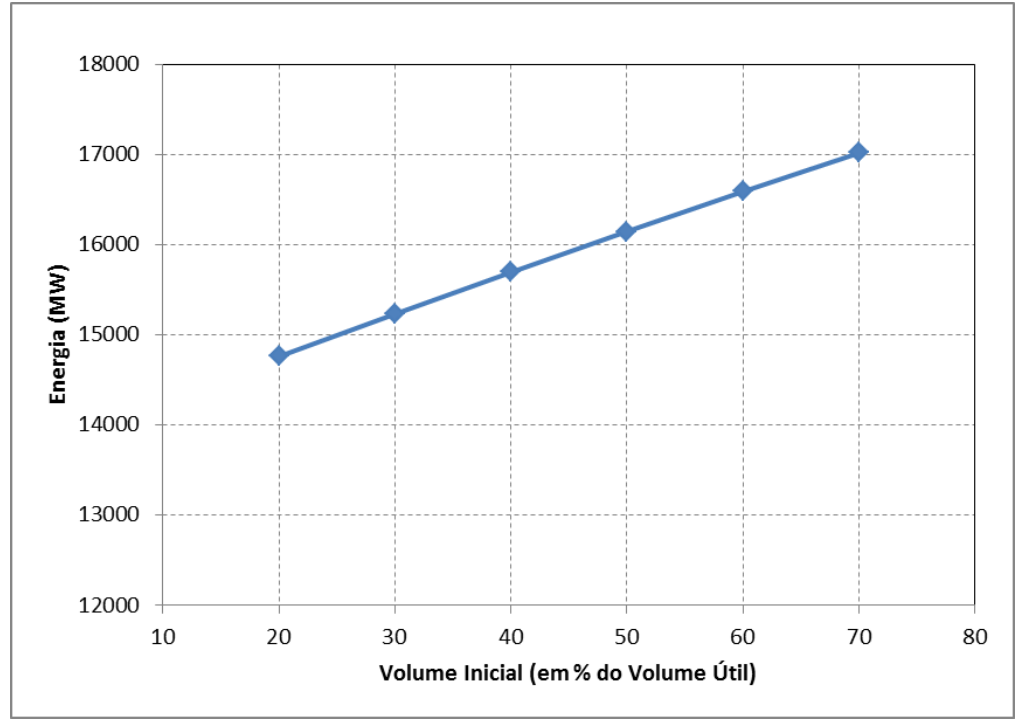

Figura 114. Volume Inicial x Energia Gerada Ponderada - UHE Nova Ponte

\subsubsection{UHE Três Marias}

Tabela 30. Resultados - UHE Três Marias

\begin{tabular}{|c|c|c|}
\hline $\begin{array}{c}\text { Volume Inicial (\% } \\
\text { do Volume Útil) }\end{array}$ & $\begin{array}{c}\text { Vazão turbinada } \\
\text { esperada }\left(\mathbf{m}^{\mathbf{3}} \mathbf{/ s}\right)\end{array}$ & $\begin{array}{c}\text { Energia gerada } \\
\text { ponderada } \\
\text { (MW) }\end{array}$ \\
\hline 20 & 509 & 13656 \\
\hline 30 & 528 & 13857 \\
\hline 40 & 550 & 14037 \\
\hline 50 & 572 & 14150 \\
\hline 60 & 578 & 14186 \\
\hline 70 & 586 & 14210 \\
\hline
\end{tabular}




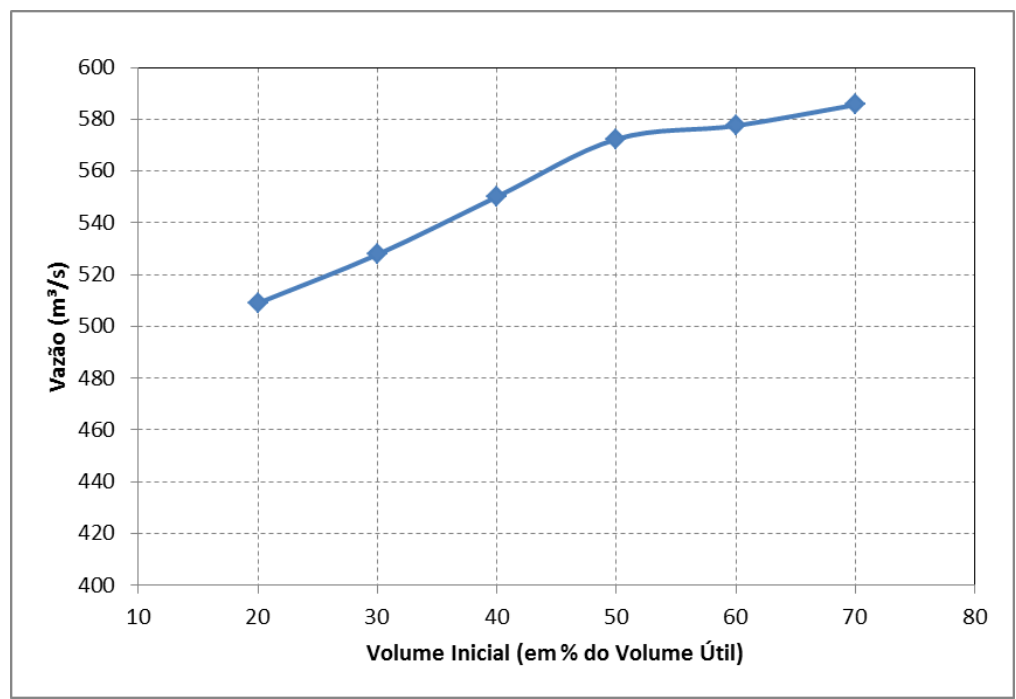

Figura 115. Volume Inicial x Vazão Turbinada Esperada - UHE Três Marias

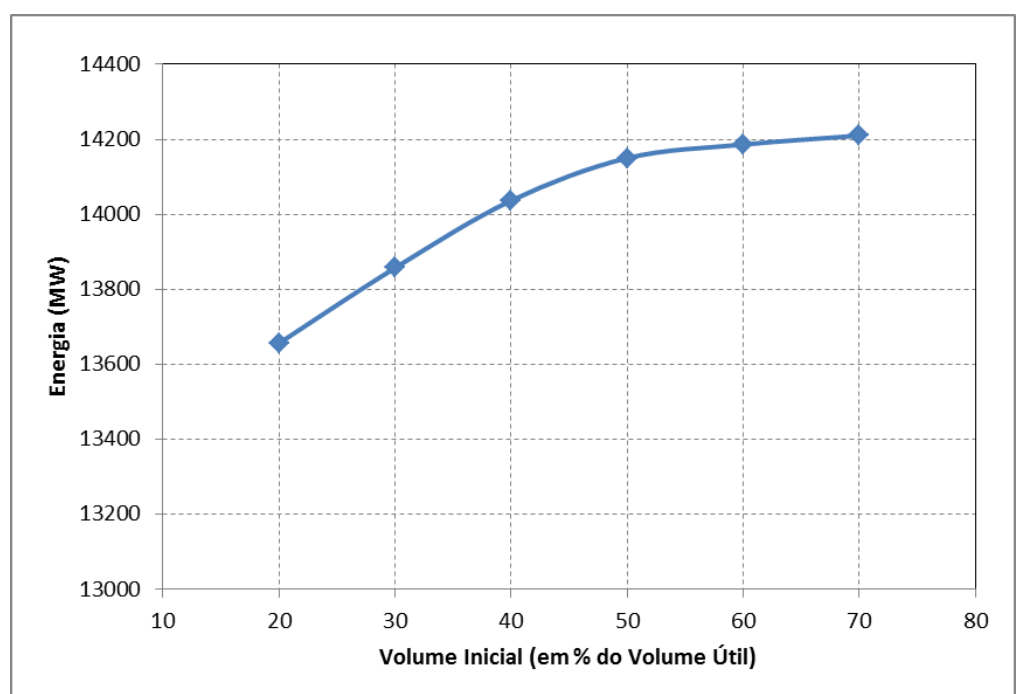

Figura 116. Volume Inicial x Energia Gerada Ponderada - UHE Três Marias

\subsubsection{UHE Irapé}

Tabela 31. Resultados - UHE Irapé

\begin{tabular}{|c|c|c|}
\hline $\begin{array}{c}\text { Volume Inicial (\% } \\
\text { do Volume Útil) }\end{array}$ & $\begin{array}{c}\text { Vazão turbinada } \\
\text { esperada }\left(\mathbf{m}^{\mathbf{3}} \mathbf{/ s}\right)\end{array}$ & $\begin{array}{c}\text { Energia gerada } \\
\text { ponderada } \\
\text { (MW) }\end{array}$ \\
\hline 20 & 97 & 9781 \\
\hline 30 & 102 & 10027 \\
\hline 40 & 107 & 10268 \\
\hline 50 & 112 & 10507 \\
\hline 60 & 117 & 10741 \\
\hline 70 & 123 & 10971 \\
\hline
\end{tabular}




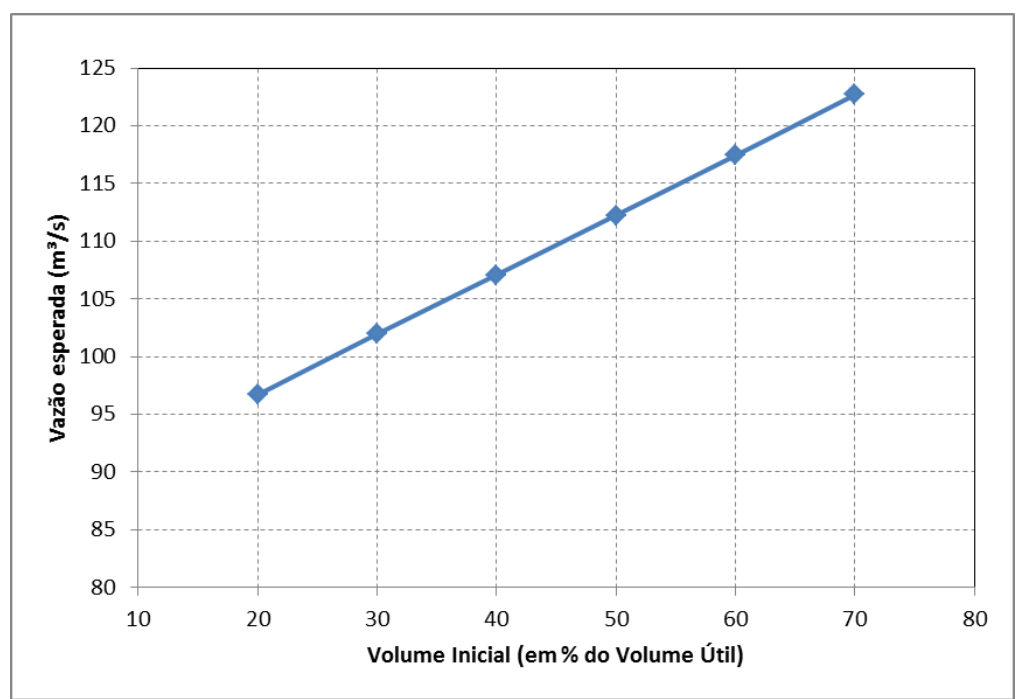

Figura 117. Volume Inicial x Vazão Turbinada Esperada - UHE Irapé

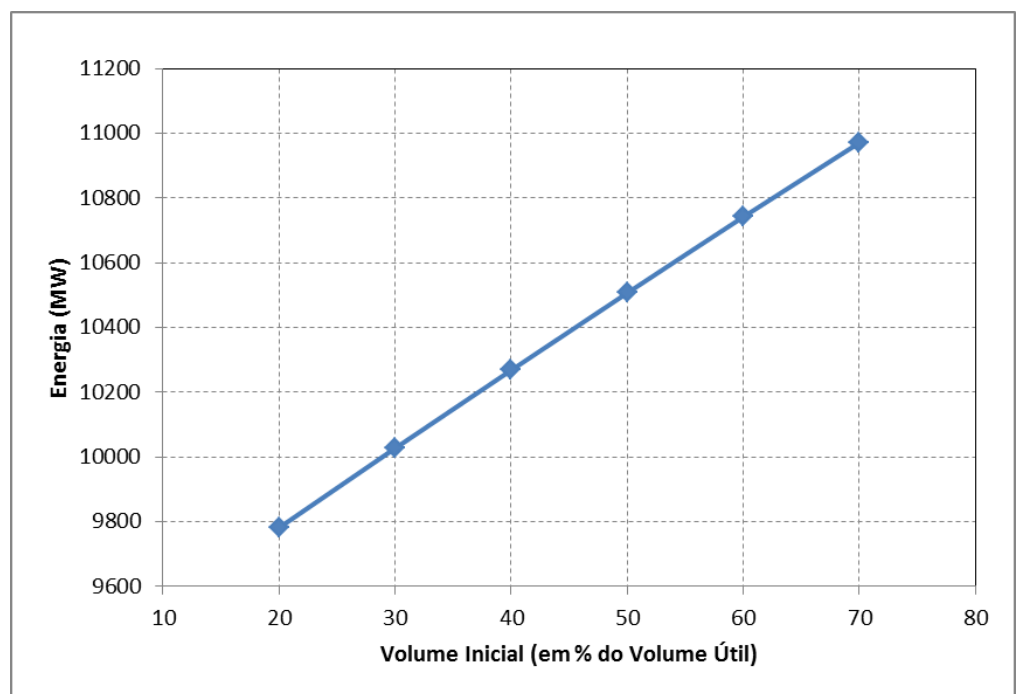

Figura 118. Volume Inicial x Energia Gerada Ponderada - UHE Irapé

\subsubsection{UHE Serra da Mesa}

Tabela 32. Resultados - UHE Serra da Mesa

\begin{tabular}{|c|c|c|}
\hline $\begin{array}{c}\text { Volume Inicial (\% } \\
\text { do Volume Útil) }\end{array}$ & $\begin{array}{c}\text { Vazão turbinada } \\
\text { esperada }\left(\mathbf{m}^{\mathbf{3}} \mathbf{/} \mathbf{s}\right)\end{array}$ & $\begin{array}{c}\text { Energia gerada } \\
\text { ponderada } \\
\text { (MW) }\end{array}$ \\
\hline 20 & 566 & 36825 \\
\hline 30 & 611 & 38747 \\
\hline 40 & 655 & 40626 \\
\hline 50 & 698 & 42454 \\
\hline 60 & 743 & 44218 \\
\hline 70 & 789 & 45907 \\
\hline
\end{tabular}




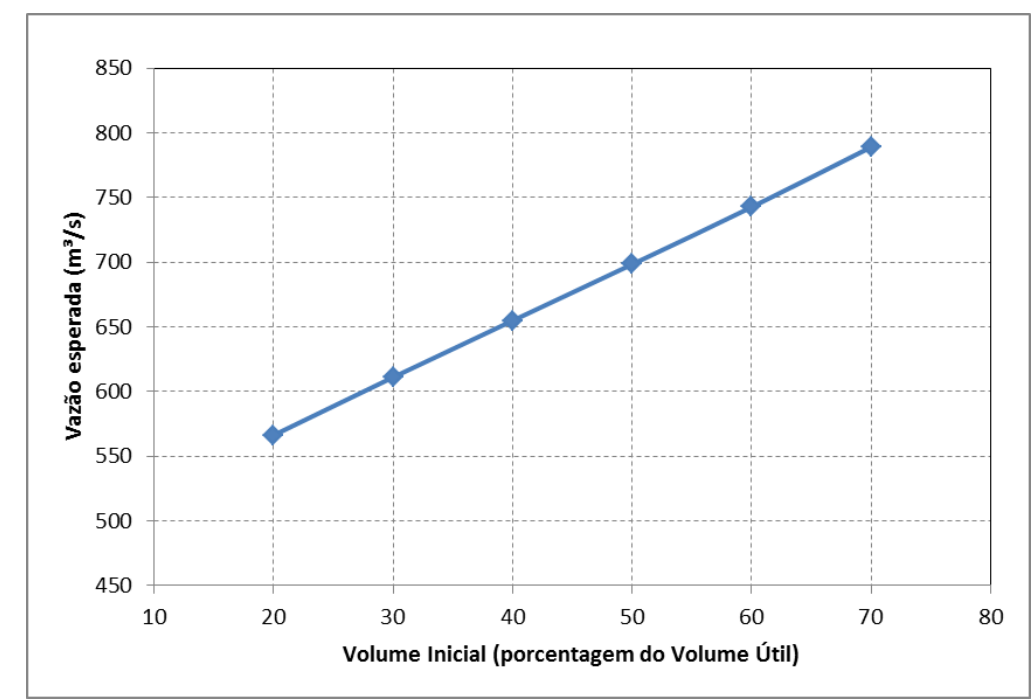

Figura 119. Volume Inicial x Vazão Turbinada Esperada - UHE Serra da Mesa

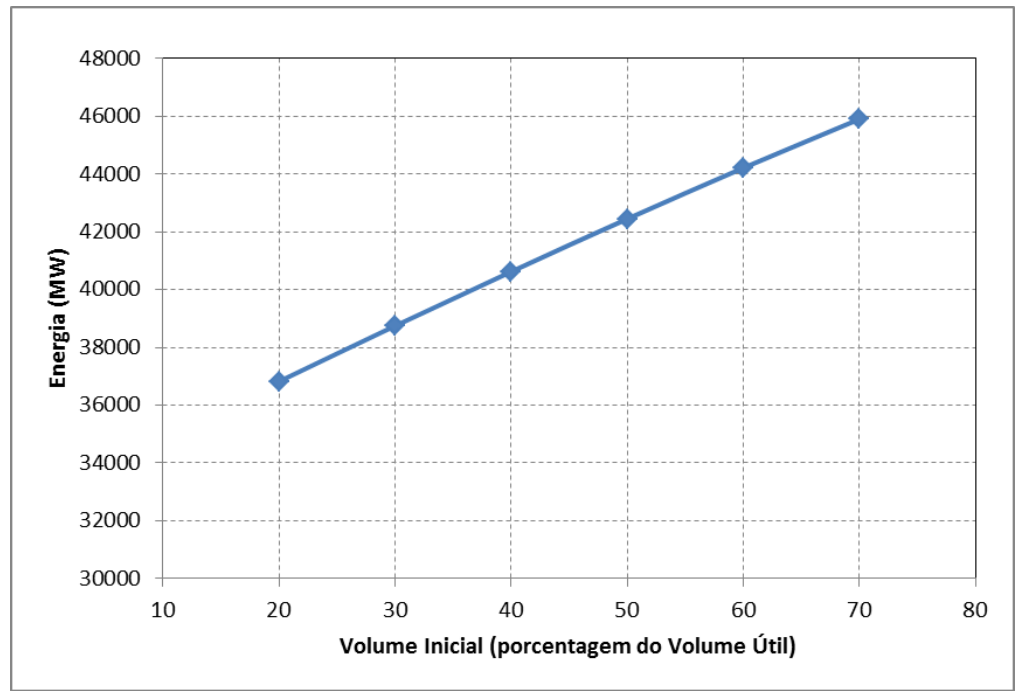

Figura 120. Volume Inicial x Energia Gerada Ponderada - UHE Serra da Mesa

\subsubsection{UHE Balbina}

Tabela 33. Resultados - UHE Balbina

\begin{tabular}{|c|c|c|}
\hline $\begin{array}{c}\text { Volume Inicial (\% } \\
\text { do Volume Útil) }\end{array}$ & $\begin{array}{c}\text { Vazão turbinada } \\
\text { esperada (m } \mathbf{3} \text { /s) }\end{array}$ & $\begin{array}{c}\text { Energia gerada } \\
\text { ponderada } \\
\text { (MW) }\end{array}$ \\
\hline 20 & 298 & 6223 \\
\hline 30 & 331 & 6320 \\
\hline 40 & 364 & 6415 \\
\hline 50 & 393 & 6510 \\
\hline 60 & 428 & 6604 \\
\hline 70 & 469 & 6697 \\
\hline
\end{tabular}




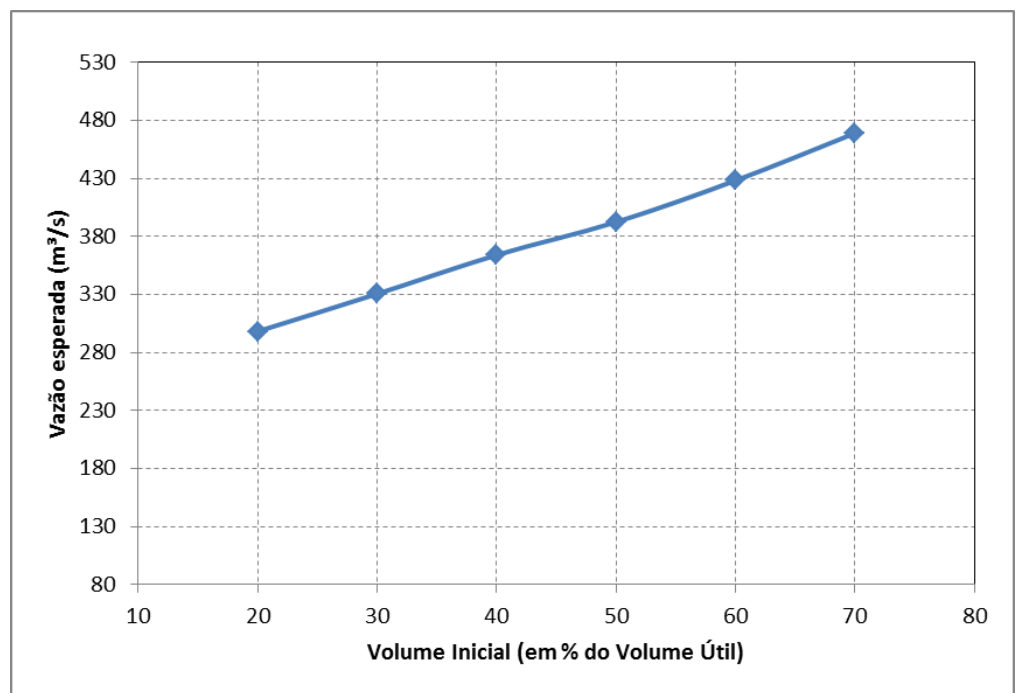

Figura 121. Volume Inicial x Vazão Turbinada Esperada - UHE Blbina

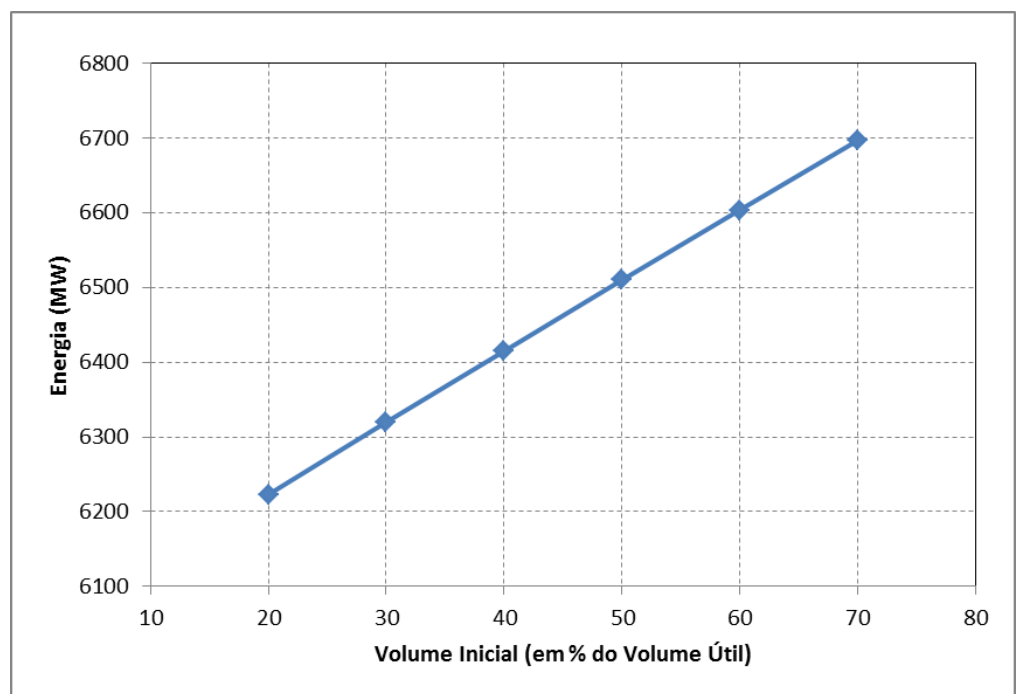

Figura 122. Volume Inicial x Energia Gerada Ponderada - UHE Balbina

\subsubsection{Resumo dos resultados}

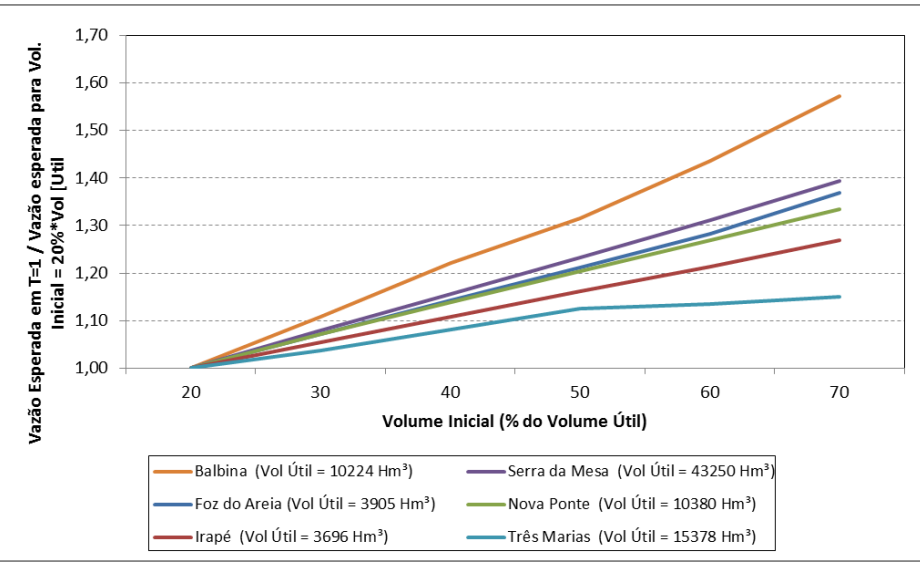

Figura 123. Resumo dos resultados - Vazão Turbinada Esperada x Volume Inicial 


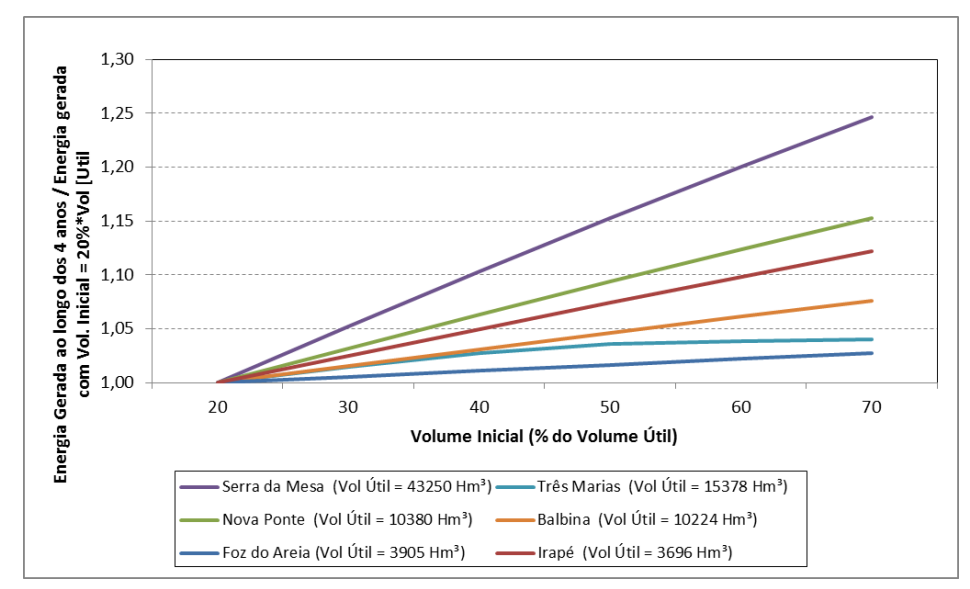

Figura 124. Resumo dos resultados - Energia Gerada x Volume Inicial

\subsubsection{Considerações Gerais}

A análise dos resultados permite concluir que:

O Volume Inicial do reservatório impacta significativamente nos resultados da otimização da geração hidrelétrica, sendo muito importante para a determinação das vazões turbinadas esperadas e na energia gerada ao longo do horizonte de planejamento.

Todas as UHEs apresentaram um comportamento similar quanto aos à consideração de diferentes volumes iniciais do reservatório. De modo geral, o aumento do valor da vazão turbinada esperada e da energia gerada ao se considerar volumes iniciais crescentes seguiu uma tendência linear, com exceção do caso da UHE Três Marias.

O aumento médio verificado nos seis casos, no que se refere ao valor da vazão a ser turbinada esperada em $T=1$, é de cerca de $7 \%$ para um aumento do volume do reservatório em $10 \%$ do volume útil.

Cada aumento em $10 \%$ no valor do volume útil, por sua vez, impacta no acréscimo linear da energia gerada, variando em 1\% na UHE Foz do Areia e $5 \%$ na UHE Serra da Mesa.

Estes resultados indicam, assim, que o volume inicial do reservatório possui uma maior influência nas decisões a serem tomadas no início do planejamento (representado nesse estudo pela vazão turbinada esperada) e menor nos 
parâmetros atrelados a todo o horizonte de planejamento, como a energia total gerada.

Além do mais, verifica-se, das figuras 123 e 124, que a condição do volume do reservatório no início do planejamento impacta mais significativamente nas usinas com maior capacidade de armazenamento.

\subsubsection{Otimização estocástica frente a diferentes horizontes de planejamento}

Um parâmetro de planejamento da operação hidroelétrica de grande influência tanto no processo de otimização quanto nos resultados finais consiste no horizonte de planejamento a ser considerado.

Uma vez que se trata de um parâmetro vinculado ao conceito de risco envolvido, a adoção de horizontes de planejamento muito curtos pode não abranger eventos hidrológicos plurianuais e apresentar em altos riscos à segurança energética. Por outro lado, a consideração de horizontes mais longos é mais conservador, porém, a consideração da estocasticidade e a previsão de vazões dentro desse horizonte podem ser de pouca precisão.

Dentro do contexto do planejamento da operação a médio prazo, o ONS utiliza, através do modelo NEWAVE, um horizonte de até 5 anos. Os estudos mais recentes com base no SSD HIDROTERM (Zambon, 2013), têm utilizado um horizonte de planejamento de 4 anos, considerando como base para a presente dissertação. Dentro desse contexto, a presente análise de sensibilidade tem como objetivo analisar o efeito da variação do horizonte de planejamento na decisão da vazão a ser turbinada no intervalo $T=1$, para as UHEs em análise.

O horizonte de planejamento foi variado entre 2 e 4 anos, sendo utilizada a mesma árvore de cenários iniciais dos itens anteriores ( 1.000 cenários iniciais e 50 cenários reduzidos). Os valores dos volumes inicial e final se mantiveram os mesmos da análise do item $5.10 .2(70 \%$ e $30 \%$ do volume útil, respectivamente).

Os itens 5.10.5.1 a 5.10.5.6 apresentam os resultados obtidos, e os comentários pertinentes estão descritos no item 5.10.7. 


\subsubsection{UHE Foz do Areia}

Tabela 34. Resultados - UHE Foz do Areia

\begin{tabular}{|c|c|c|c|c|}
\hline $\begin{array}{c}\text { Horizonte de } \\
\text { Planejamento }\end{array}$ & $\begin{array}{c}\text { Porcentagem de } \\
\text { Redução }\end{array}$ & $\begin{array}{c}\text { Tempo de } \\
\text { Processamento } \\
\text { (HH:MM) }\end{array}$ & $\begin{array}{c}\text { Vazão Esperada } \\
\text { em T=1 ( } \mathbf{3} / \mathbf{s})\end{array}$ & $\begin{array}{c}\text { Energia média } \\
\text { anual (MW) }\end{array}$ \\
\hline 2 anos & 0,688 & $00: 04$ & 604,89 & 12448 \\
\hline 3 anos & 0,748 & $00: 05$ & 561,18 & 9313 \\
\hline 4 anos & 0,782 & $00: 07$ & 561,17 & 9280 \\
\hline
\end{tabular}

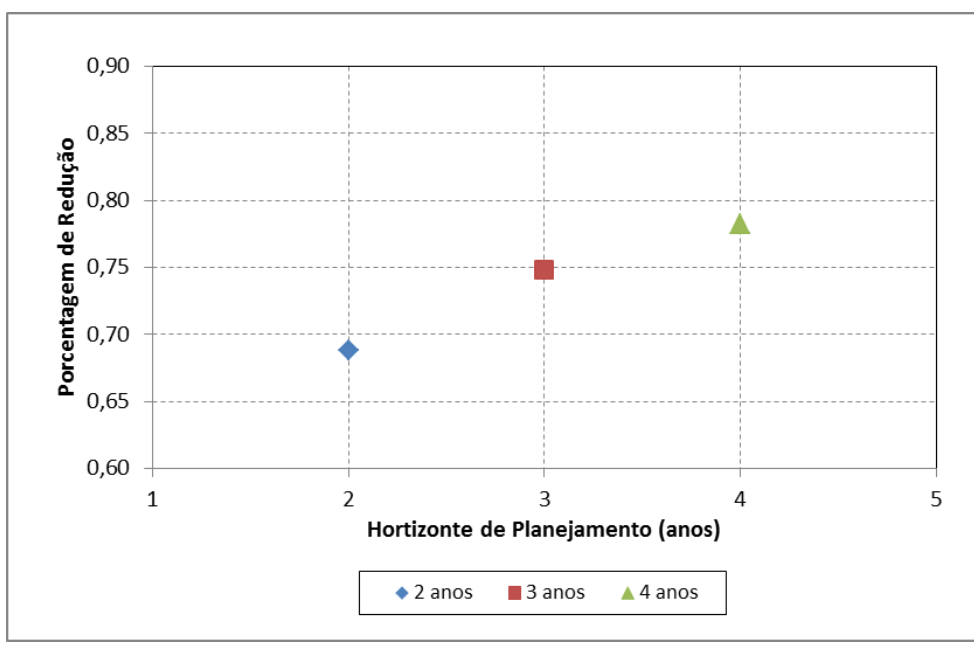

Figura 125. Horizonte de Planejamento x Porcentagem de Redução - UHE Foz do Areia

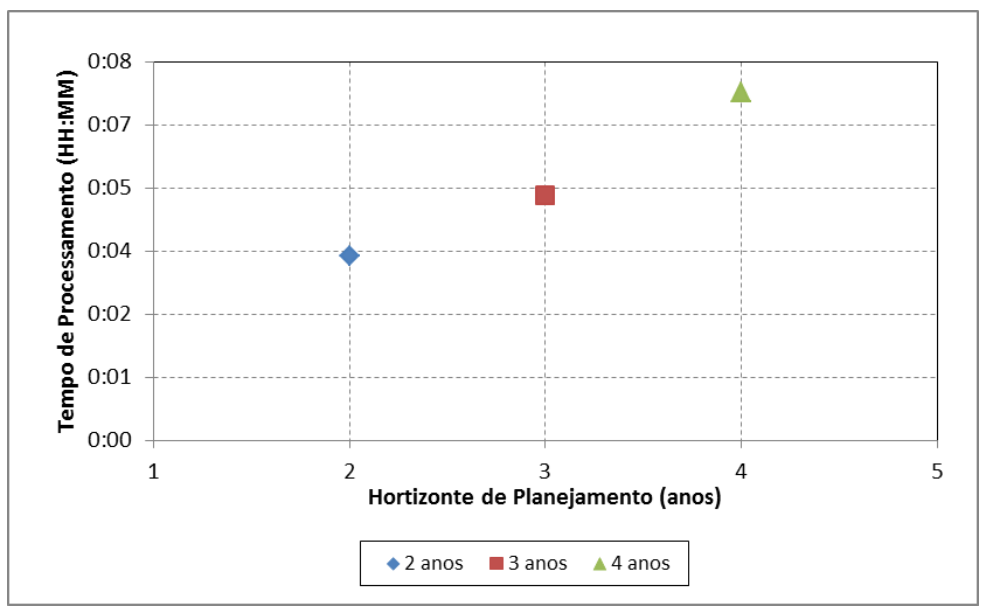

Figura 126. Horizonte de Planejamento x Tempo de Processamento - UHE Foz do Areia 


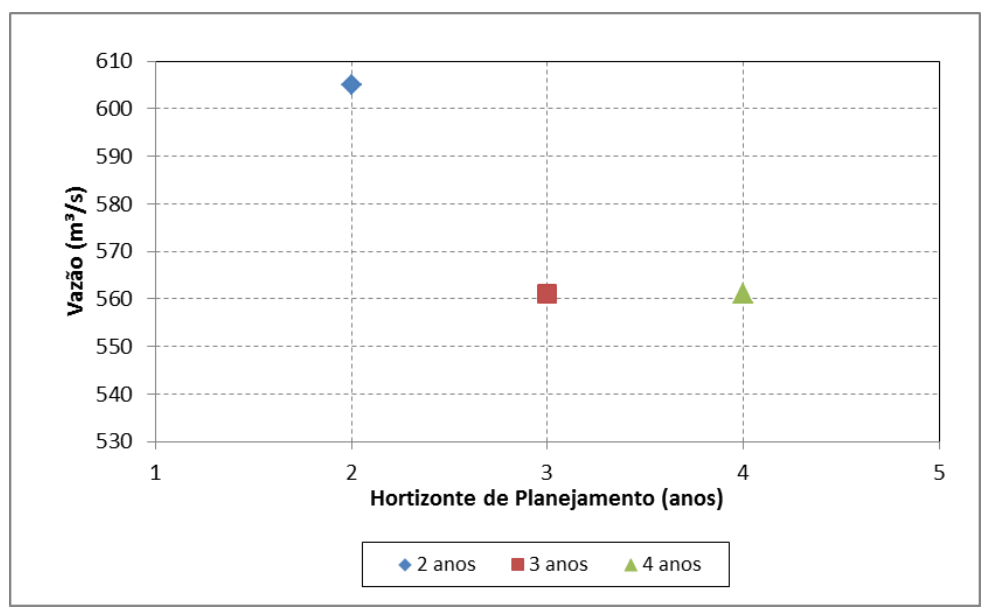

Figura 127. Horizonte de Planejamento x Vazão Turbinada Esperada - UHE Foz do Areia

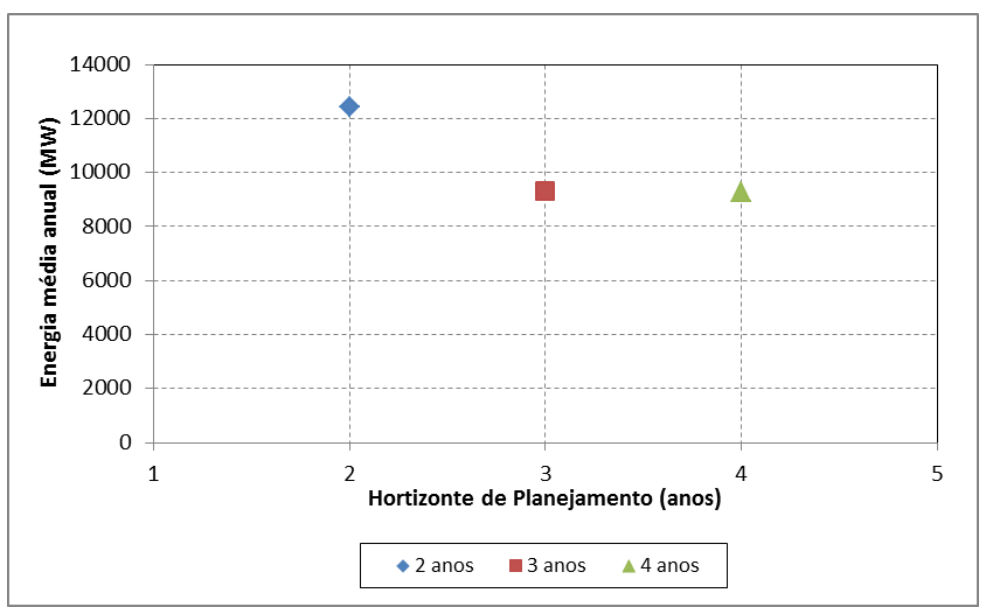

Figura 128. Horizonte de Planejamento x Energia Média Anual - UHE Foz do Areia

\subsubsection{UHE Nova Ponte}

Tabela 35. Resultados - UHE Nova Ponte

\begin{tabular}{|c|c|c|c|c|}
\hline $\begin{array}{c}\text { Horizonte de } \\
\text { Planejamento }\end{array}$ & $\begin{array}{c}\text { Porcentagem de } \\
\text { Redução }\end{array}$ & $\begin{array}{c}\text { Tempo de } \\
\text { Processamento } \\
\text { (HH:MM) }\end{array}$ & $\begin{array}{c}\text { Vazão Esperada } \\
\text { em T=1 ( } \mathbf{3} \text { /s) }\end{array}$ & $\begin{array}{c}\text { Energia média } \\
\text { anual (MW) }\end{array}$ \\
\hline 2 anos & 0,508 & $00: 04$ & 334,84 & 5673 \\
\hline 3 anos & 0,539 & $00: 05$ & 308,98 & 5475 \\
\hline 4 anos & 0,553 & $00: 09$ & 287,73 & 4255 \\
\hline
\end{tabular}




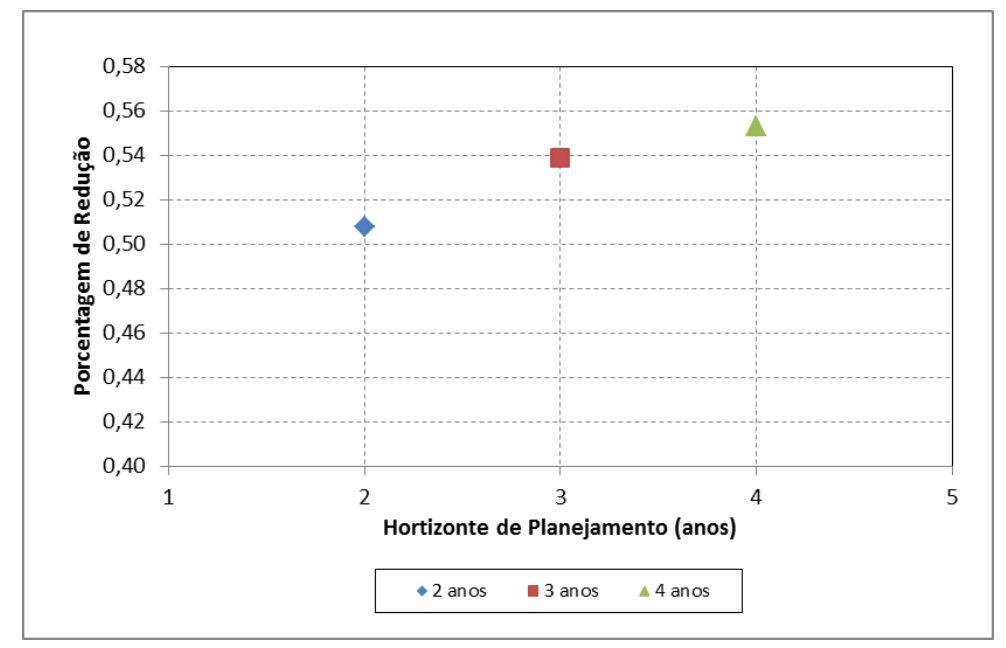

Figura 129. Horizonte de Planejamento x Porcentagem de Redução - UHE Nova Ponte

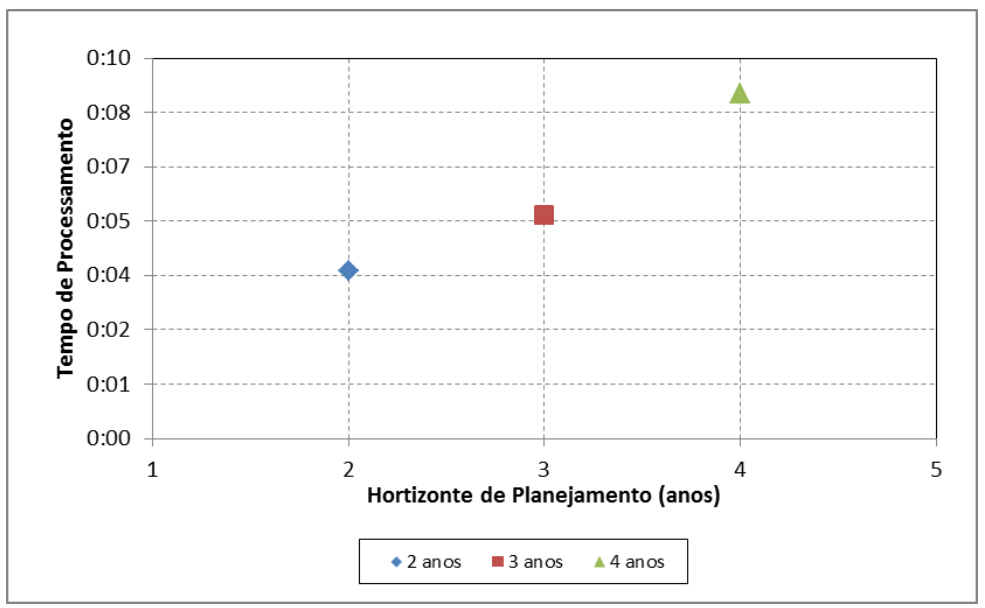

Figura 130. Horizonte de Planejamento x Tempo de Processamento - UHE Nova Ponte

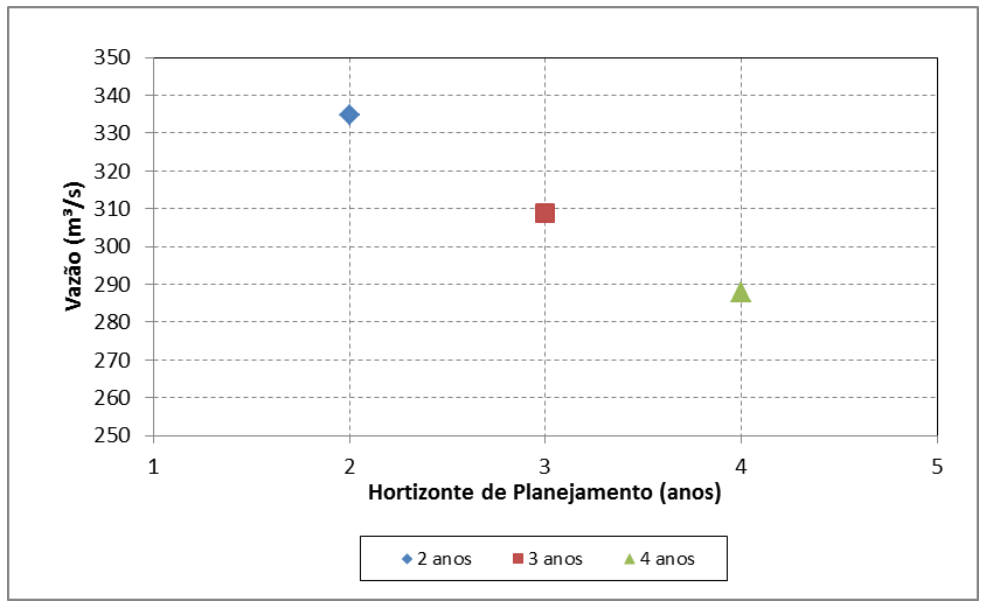

Figura 131. Horizonte de Planejamento x Vazão Turbinada Esperada - UHE Nova Ponte 


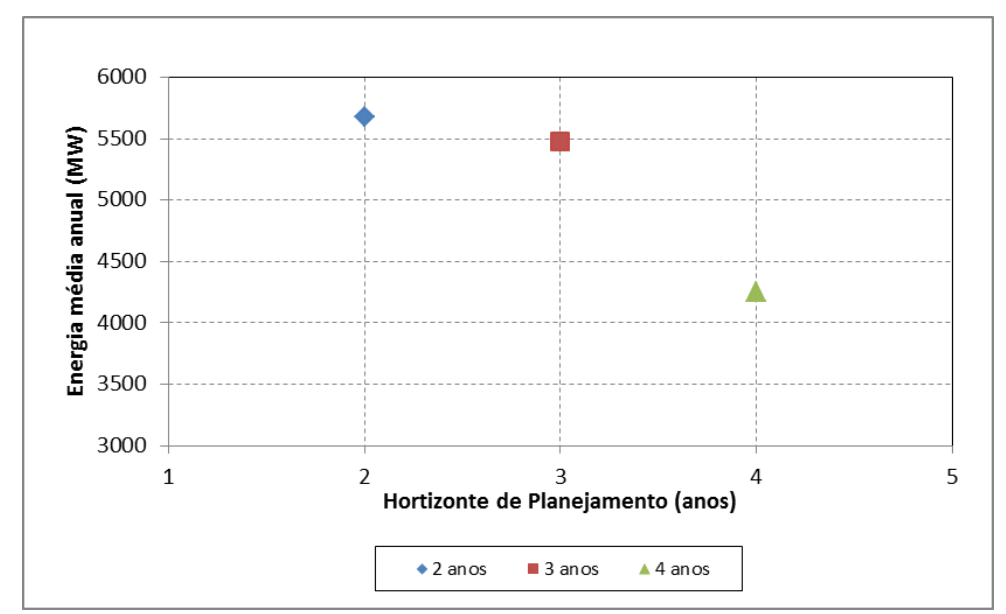

Figura 132. Horizonte de Planejamento x Energia Média Anual - UHE Nova Ponte

\subsubsection{UHE Três Marias}

Tabela 36. Resultados - UHE Três Marias

\begin{tabular}{|c|c|c|c|c|}
\hline $\begin{array}{c}\text { Horizonte de } \\
\text { Planejamento }\end{array}$ & $\begin{array}{c}\text { Porcentagem de } \\
\text { Redução }\end{array}$ & $\begin{array}{c}\text { Tempo de } \\
\text { Processamento } \\
\text { (HH:MM) }\end{array}$ & $\begin{array}{c}\text { Vazão Esperada } \\
\text { em T=1 }\left(\mathbf{m}^{\mathbf{3}} \mathbf{/ s}\right)\end{array}$ & $\begin{array}{c}\text { Energia média } \\
\text { anual (MW) }\end{array}$ \\
\hline 2 anos & 0,522 & $00: 03$ & 578,50 & 3540 \\
\hline 3 anos & 0,561 & $00: 04$ & 575,00 & 3500 \\
\hline 4 anos & 0,577 & $00: 05$ & 571,25 & 3465 \\
\hline
\end{tabular}

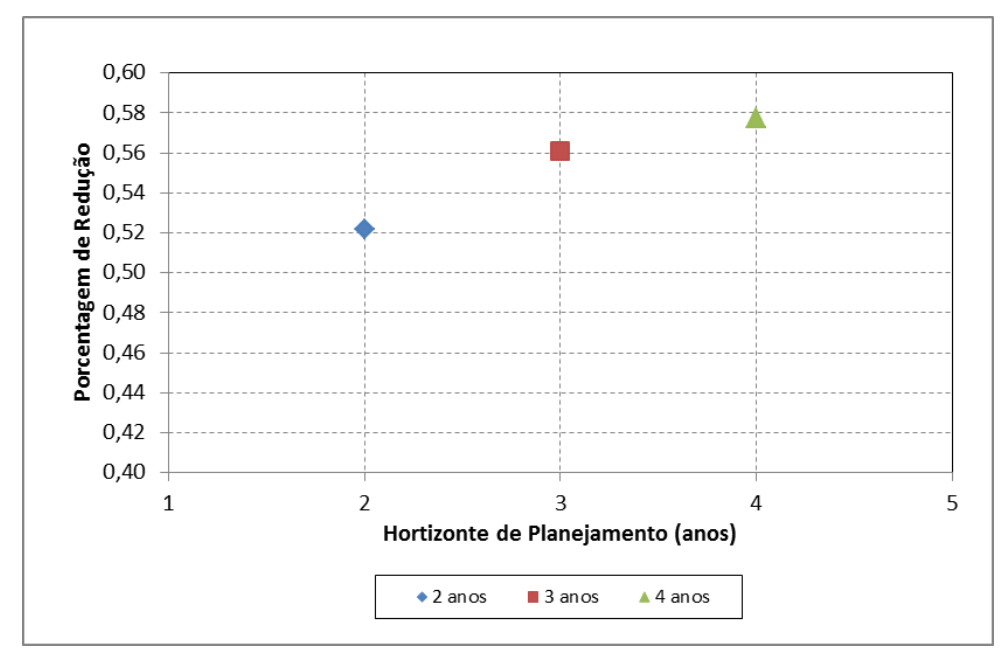

Figura 133. Horizonte de Planejamento x Porcentagem de Redução - UHE Três Marias 


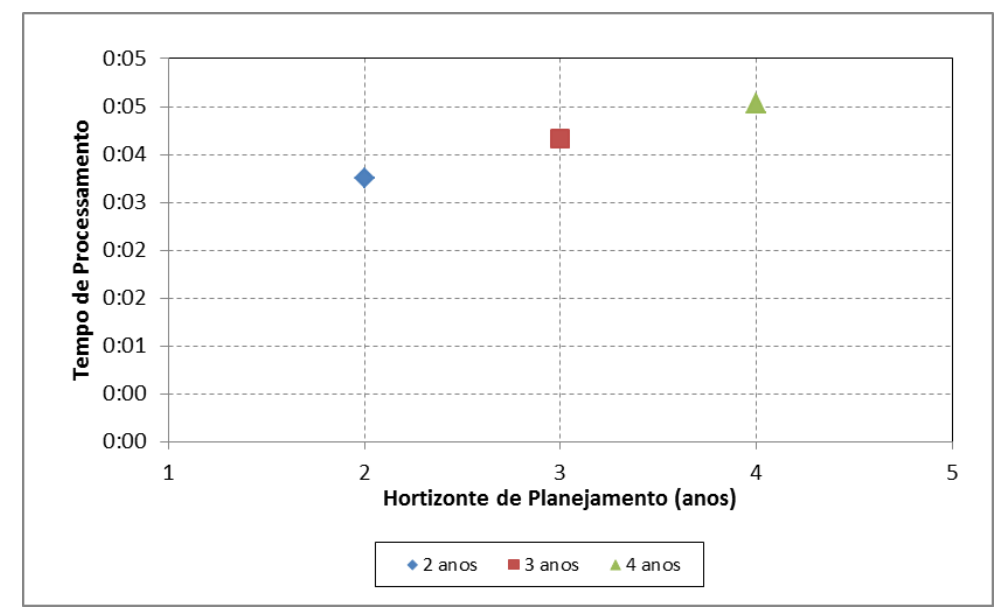

Figura 134. Horizonte de Planejamento x Tempo de Processamento - UHE Três Marias

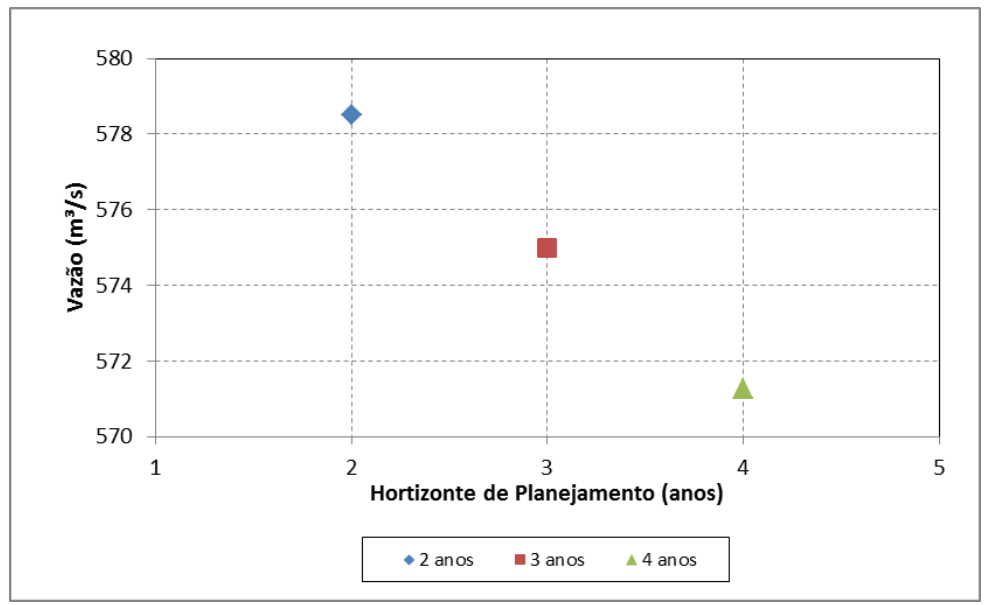

Figura 135. Horizonte de Planejamento x Vazão Turbinada Esperada - UHE Três Marias

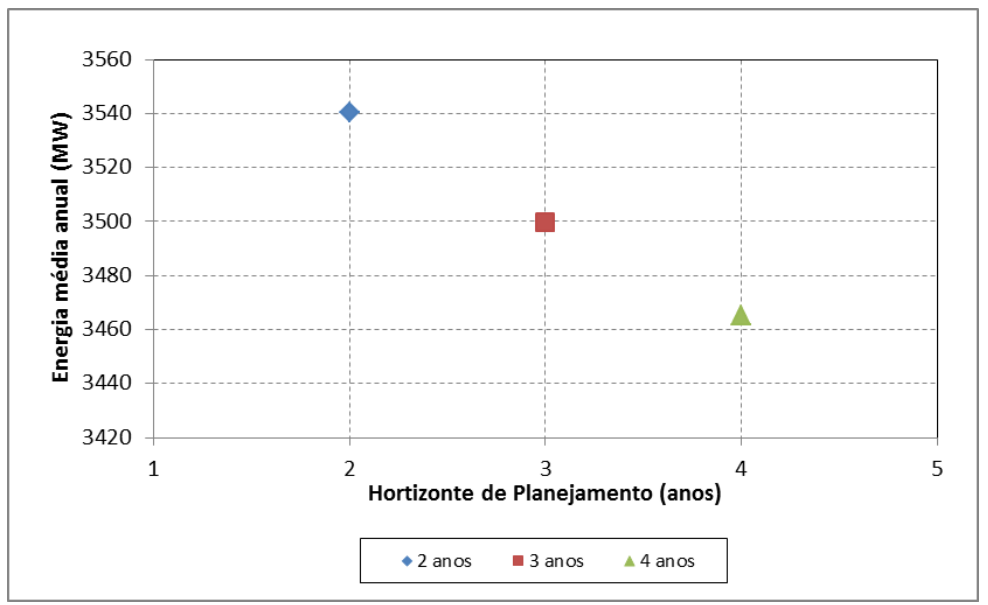

Figura 136. Horizonte de Planejamento x Energia Média Anual - UHE Três Marias 


\subsubsection{UHE Irapé}

Tabela 37. Resultados - UHE Irapé

\begin{tabular}{|c|c|c|c|c|}
\hline $\begin{array}{c}\text { Horizonte de } \\
\text { Planejamento }\end{array}$ & $\begin{array}{c}\text { Porcentagem } \\
\text { de Redução }\end{array}$ & $\begin{array}{c}\text { Tempo de } \\
\text { Processamento } \\
\text { (HH:MM) }\end{array}$ & $\begin{array}{c}\text { Vazão Esperada } \\
\text { em T=1 ( } \mathbf{3} \text { /s) }\end{array}$ & $\begin{array}{c}\text { Energia média } \\
\text { anual (MW) }\end{array}$ \\
\hline 2 anos & 0,54 & $00: 04$ & 145,67 & 3055 \\
\hline 3 anos & 0,598 & $00: 06$ & 140,03 & 2992 \\
\hline 4 anos & 0,618 & $00: 08$ & 122,68 & 2743 \\
\hline
\end{tabular}

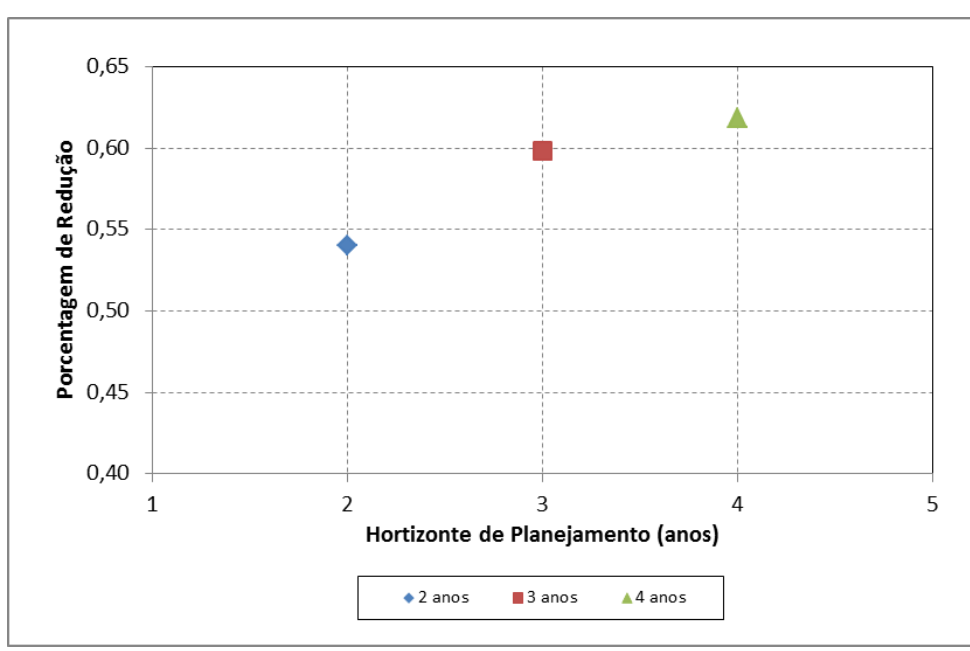

Figura 137. Horizonte de Planejamento x Porcentagem de Redução - UHE Irapé

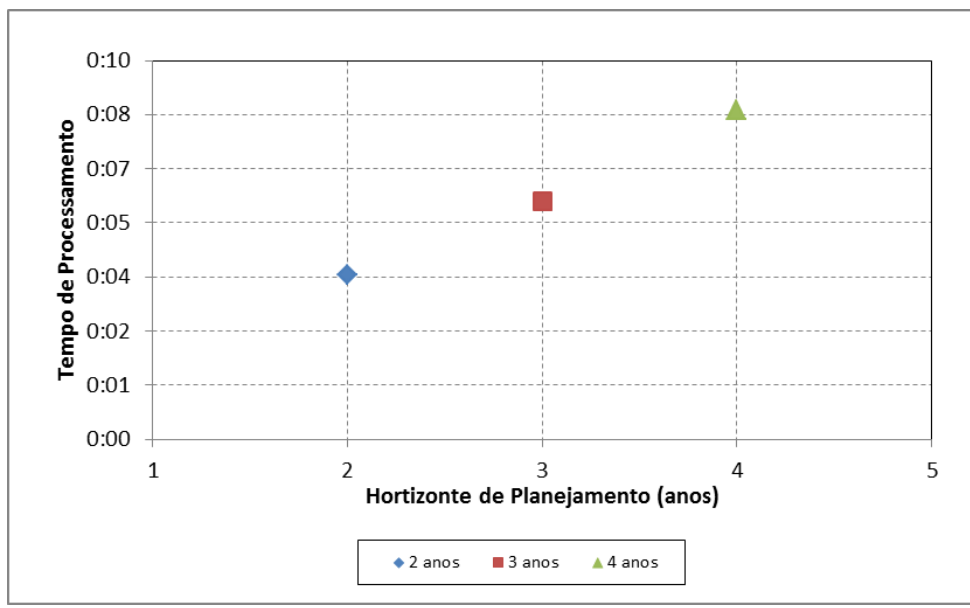

Figura 138. Horizonte de Planejamento x Tempo de Processamento - UHE Três Marias 


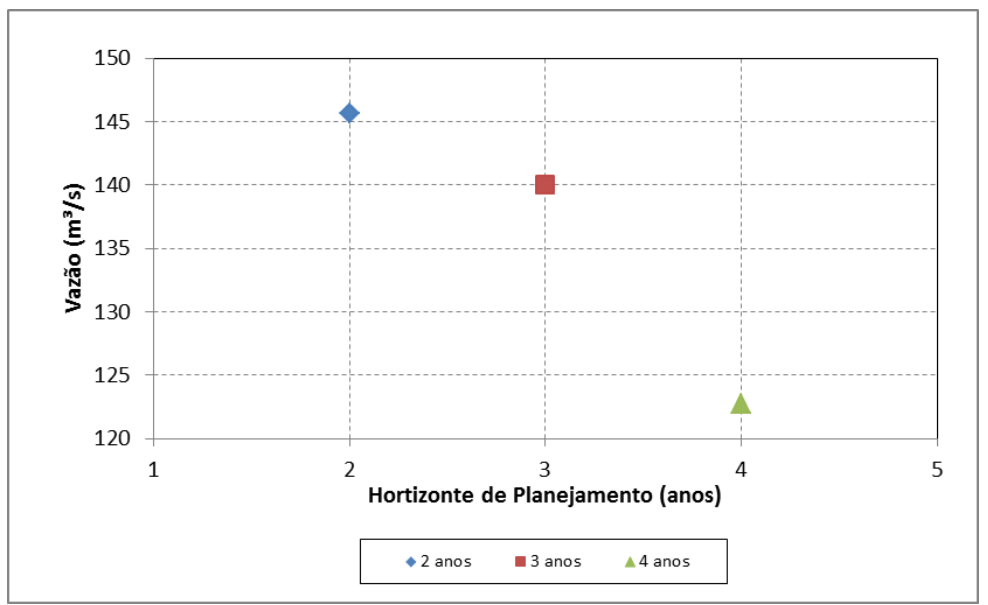

Figura 139. Horizonte de Planejamento x Vazão Turbinada Esperada - UHE Irapé

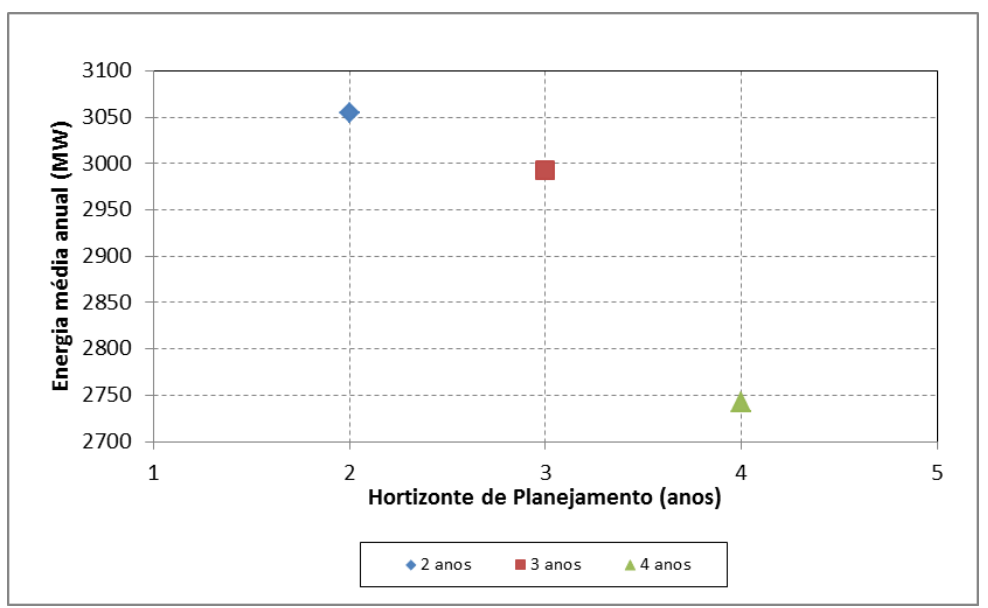

Figura 140. Horizonte de Planejamento x Energia Média Anual - UHE Irapé

\subsubsection{UHE Serra da Mesa}

Tabela 38. Resultados - UHE Serra da Mesa

\begin{tabular}{|c|c|c|c|c|}
\hline $\begin{array}{c}\text { Horizonte de } \\
\text { Planejamento }\end{array}$ & $\begin{array}{c}\text { Porcentagem de } \\
\text { Redução }\end{array}$ & $\begin{array}{c}\text { Tempo de } \\
\text { Processamento } \\
\text { (HH:MM) }\end{array}$ & $\begin{array}{c}\text { Vazão Esperada } \\
\text { em T=1 ( } \mathbf{3} / \mathbf{s} \text { ) }\end{array}$ & $\begin{array}{c}\text { Energia média } \\
\text { anual (MW) }\end{array}$ \\
\hline 2 anos & 0,488 & $00: 03$ & 881,18 & 12845 \\
\hline 3 anos & 0,529 & $00: 05$ & 881,18 & 12367 \\
\hline 4 anos & 0,549 & $00: 08$ & 789,00 & 11477 \\
\hline
\end{tabular}




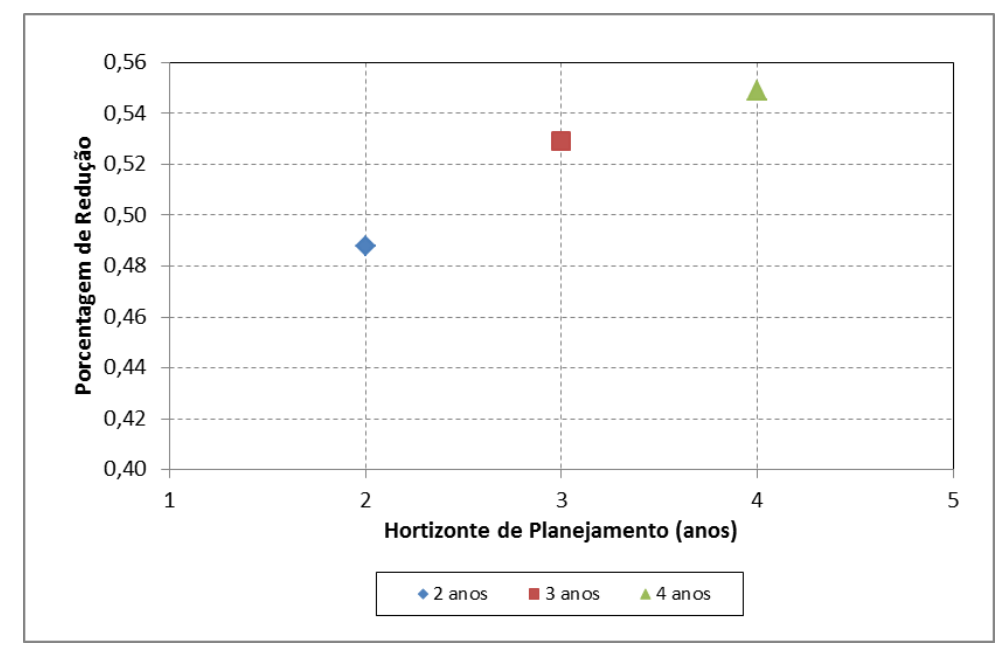

Figura 141. Horizonte de Planejamento x Porcentagem de Redução - UHE Serra da Mesa

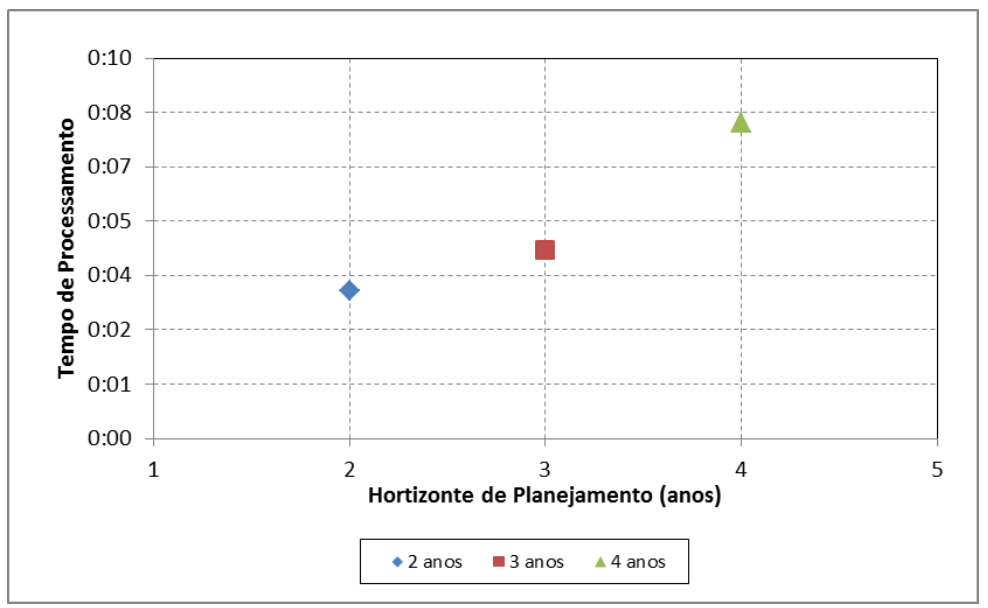

Figura 142. Horizonte de Planejamento x Tempo de Processamento - UHE Serra da Mesa

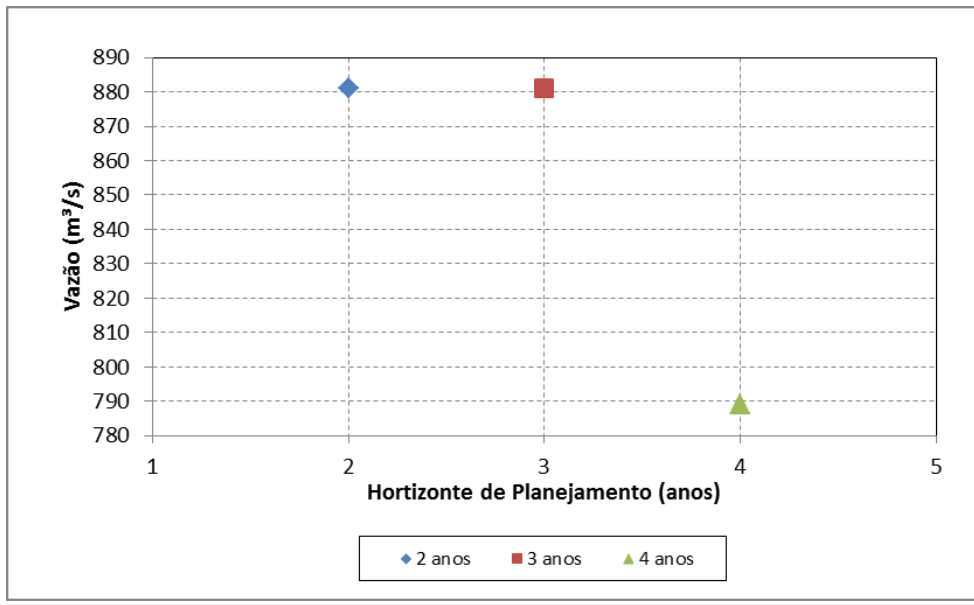

Figura 143. Horizonte de Planejamento x Vazão Turbinada Esperada - UHE Serra da Mesa 


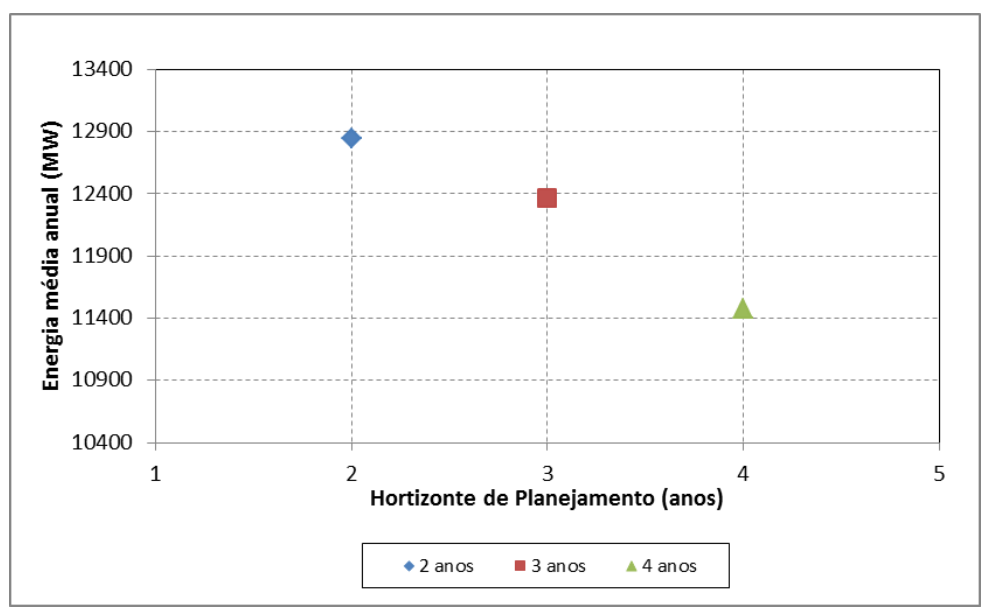

Figura 144. Horizonte de Planejamento x Energia Média Anual - UHE Serra da Mesa

\subsubsection{UHE Balbina}

Tabela 39. Resultados - UHE Balbina

\begin{tabular}{|c|c|c|c|c|}
\hline $\begin{array}{c}\text { Horizonte de } \\
\text { Planejamento }\end{array}$ & $\begin{array}{c}\text { Porcentagem de } \\
\text { Redução }\end{array}$ & $\begin{array}{c}\text { Tempo de } \\
\text { Processamento } \\
\text { (HH:MM) }\end{array}$ & $\begin{array}{c}\text { Vazão Esperada } \\
\text { em T=1 ( } \mathbf{3} / \mathbf{s})\end{array}$ & $\begin{array}{c}\text { Energia média } \\
\text { anual (MW) }\end{array}$ \\
\hline 2 anos & 0,506 & $00: 04$ & 336,80 & 755 \\
\hline 3 anos & 0,529 & $00: 05$ & 322,80 & 624 \\
\hline 4 anos & 0,541 & $00: 07$ & 295,67 & 562 \\
\hline
\end{tabular}

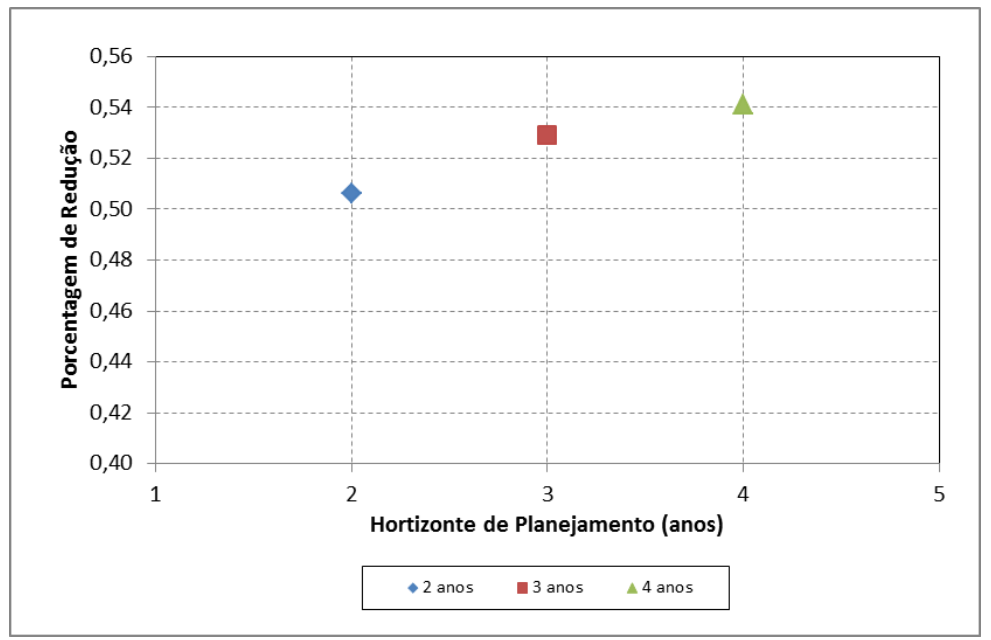

Figura 145. Horizonte de Planejamento x Porcentagem de redução - UHE Balbina 


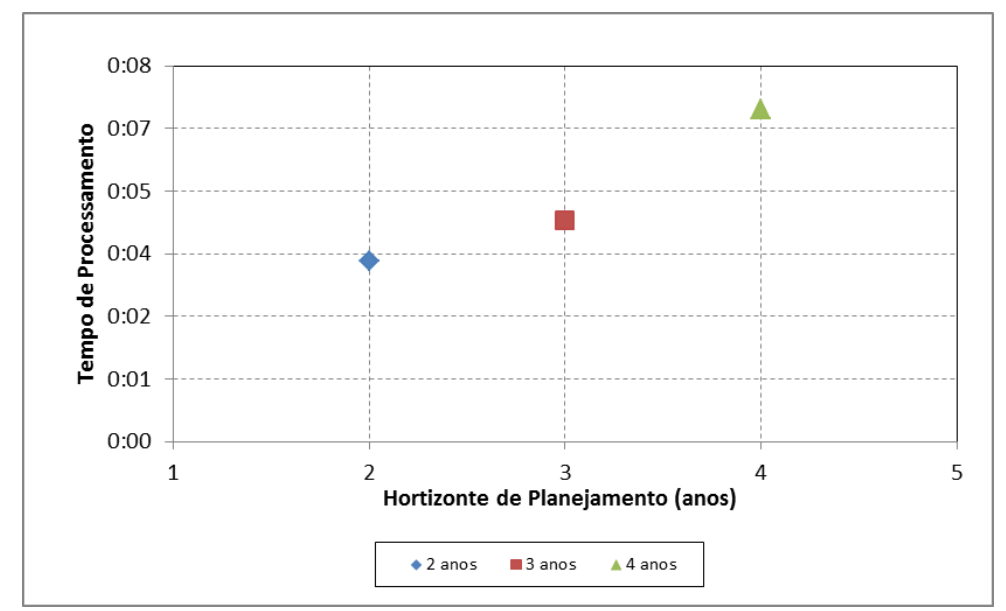

Figura 146. Horizonte de Planejamento x Tempo de Processamento - UHE Balbina

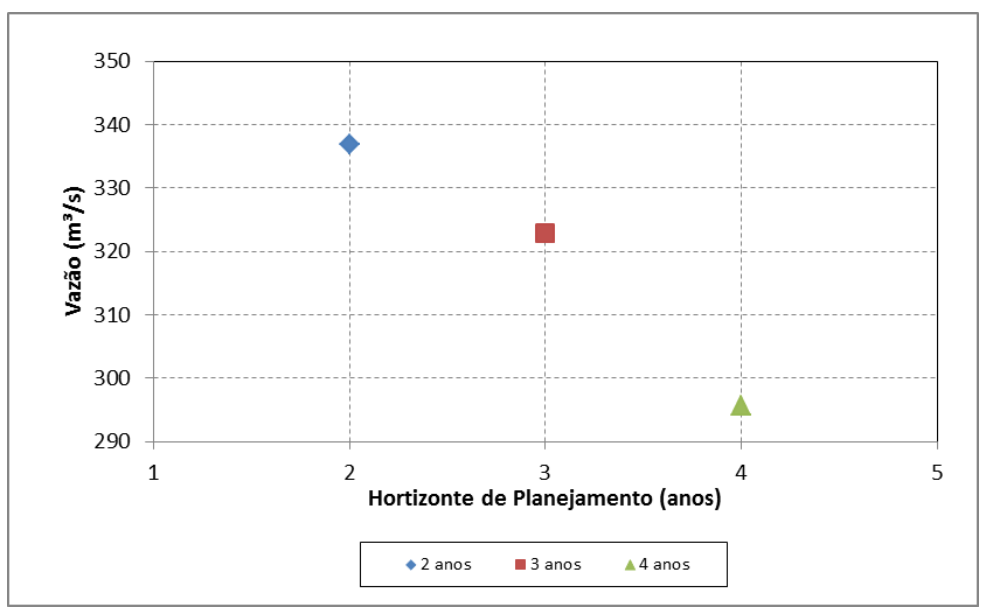

Figura 147. Horizonte de Planejamento x Vazão Turbinada Esperada - UHE Balbina

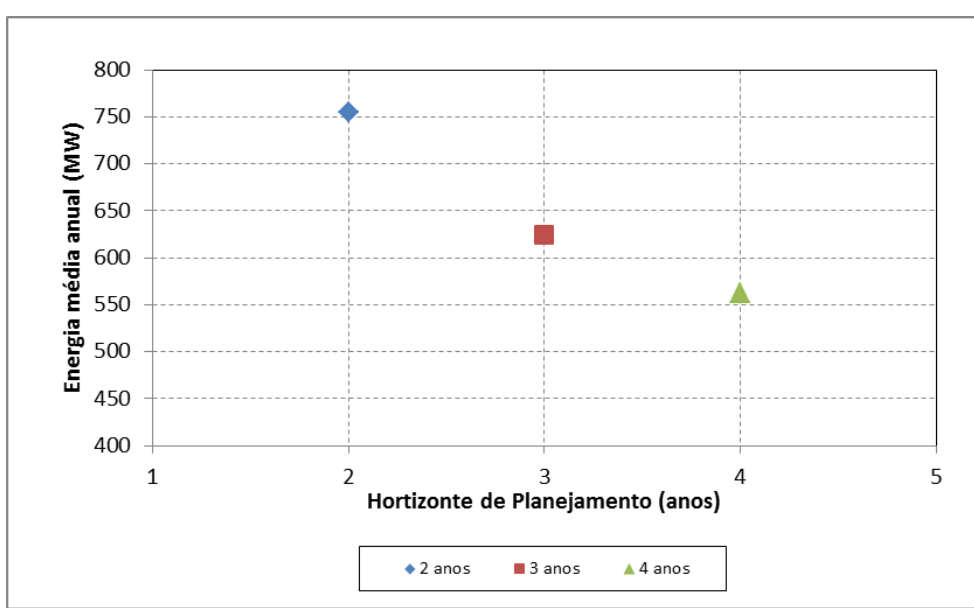

Figura 148. Horizonte de Planejamento x Energia Média Anual - UHE Balbina 


\subsubsection{Considerações Gerais}

Os resultados desta análise de sensibilidade indicam que:

O horizonte de planejamento impacta na configuração da árvore reduzida. Ou seja, partindo-se de uma mesma árvore de cenários iniciais, com 1000 cenários, a adoção de diferentes horizontes de planejamento impacta na decisão de quais os cenários que serão mantidos na árvore reduzida. Além do mais, a proximidade entre as árvores iniciais e reduzidas, expresso pela porcentagem de redução, é menor ao se considerar maiores horizontes de planejamento.

Assim como esperado, o tempo de processamento aumenta ao se considerar maiores horizontes de planejamento. Isso se deve ao aumento no número de variáveis envolvidas no processo de otimização estocástica. $O$ aumento no tempo de processamento em alguns casos (UHEs Foz do Areia e Três Marias) apresentou tendência linear, enquanto que no restante a tendência de aumento é exponencial.

Verifica-se que a vazão a ser turbinada no instante $T=1$ pode apresentar dois comportamentos gerais ao se aumentar o horizonte de planejamento: 1 manter-se constante ou redução em seu valor. Estes comportamentos distintos estão associados aos cenários preservados nas árvores reduzidas entre os diferentes horizontes. Caso, para dois diferentes horizontes, as árvores reduzidas correspondentes contenham os mesmos cenários preservados (e, consequentemente suas probabilidades associadas), a vazão a ser turbinada será a mesma, assim como verificado nas UHEs Foz da Areia e Balbina; e 2 para os demais casos verificou-se que a consideração de um horizonte de planejamento maior leva à maior tendência de conservação da água no reservatório e à vazões turbinadas menores. Ou seja, a consideração de um horizonte mais extenso leva a decisões mais conservadoras. Uma possível explicação se deve ao aumento da demanda ao longo do tempo, fazendo com que o modelo priorize gerar hidroeletricidade no longo prazo ao invés do curto é médio prazo. Outra possível causa se remete às árvores de cenários reduzidas em cada caso, pois, dado que a porcentagem de redução aumenta 
em horizontes mais extensos (ou seja, a árvore possui menos "caminhos" de possíveis realizações), o processo de otimização possui menor capacidade de otimizar a geração hidrelétrica. Por outro lado, menores horizontes de planejamento tendem a apresentar cenários mais favoráveis, o que impacta de modo favorável na otimização estocástica da geração hidrelétrica.

A energia anual gerada ao longo do horizonte de planejamento, seguindo a mesma lógica, diminuiu ao se considerar horizontes de planejamento mais extensos. Contudo, o incremento na energia total gerada entre diferentes horizontes apresentou variações entre cada caso.

\subsubsection{Análise da Otimização Estocástica considerando árvores de cenários históricos}

Esta análise de sensibilidade tem como objetivo verificar quais os principais resultados da otimização estocástica considerando a árvore de cenários históricos, e compará-los com os resultados obtidos nas outras análises.

A árvore de cenários históricos foi considerada, neste estudo, como a árvore formada por todas as possíveis séries de 4 anos consecutivas provenientes da série histórica de vazões médias mensais. Foi adotado o seguinte raciocínio: 0 cenário 1 é formado pelas vazões médias mensais entre jan/1931 e dez/1934; o cenário 2 - vazões entre jan/1932 e dez/35; cenário 3 - vazões entre jan/1933 e dez/36, e assim por diante. Assim, foram gerados no total 78 cenários de vazões históricas.

Os demais parâmetros de entrada da otimização estocástica são os mesmos considerados no item 5.10.2.

Os resultados das otimizações considerando as árvores de cenários históricos forma comparadas com os resultados das otimizações estocásticas considerando 1000 cenários iniciais e reduzindo para uma árvore com 150 cenários, apresentado no item 5.10.2.

As tabelas 40 a 45 apresentam as comparações dos resultados. Nos itens 5.10.6.1 a 5.10.6.6 são apresentados os resultados obtidos e no item 5.10.6.7 são resumidas as principais conclusões. 


\subsubsection{UHE Foz do Areia}

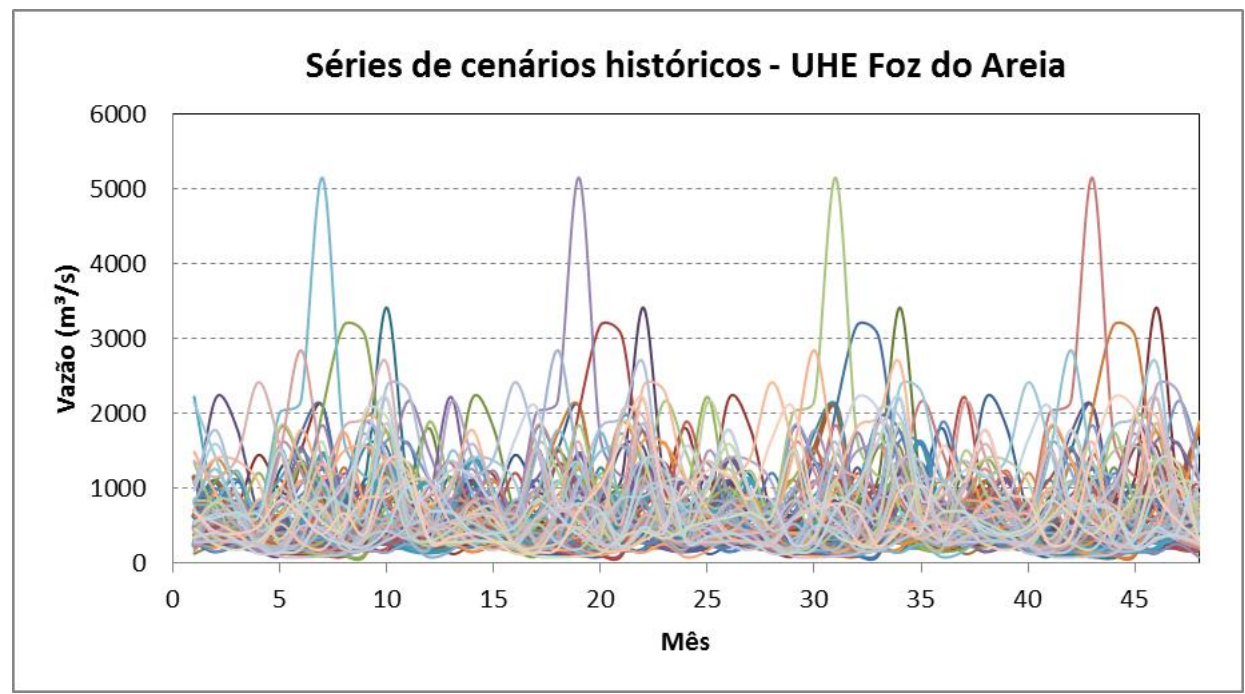

Figura 149. Séries de cenários históricos - UHE Foz do Areia

Tabela 40. Comparação dos resultados - UHE Foz do Areia

\begin{tabular}{|l|c|c|c|}
\hline \multicolumn{3}{|c|}{ UHE Foz do Areia } \\
\hline & $\begin{array}{c}\text { Árvore de Cenários } \\
\text { reduzidos }\end{array}$ & $\begin{array}{c}\text { Árvore de Cenários } \\
\text { Históricos }\end{array}$ & $\begin{array}{c}\text { variação dos } \\
\text { resultados }\end{array}$ \\
\hline $\begin{array}{l}\text { Vazão a ser turbinada em } \\
\mathrm{T}=1\left(\mathrm{~m}^{3} / \mathrm{s}\right)\end{array}$ & 586 & 596 & $2 \%$ \\
\hline $\begin{array}{l}\text { Energia gerada ao longo } \\
\text { dos 4 anos (MW) }\end{array}$ & 37475 & 39942 & $7 \%$ \\
\hline
\end{tabular}

\subsubsection{UHE Nova Ponte}

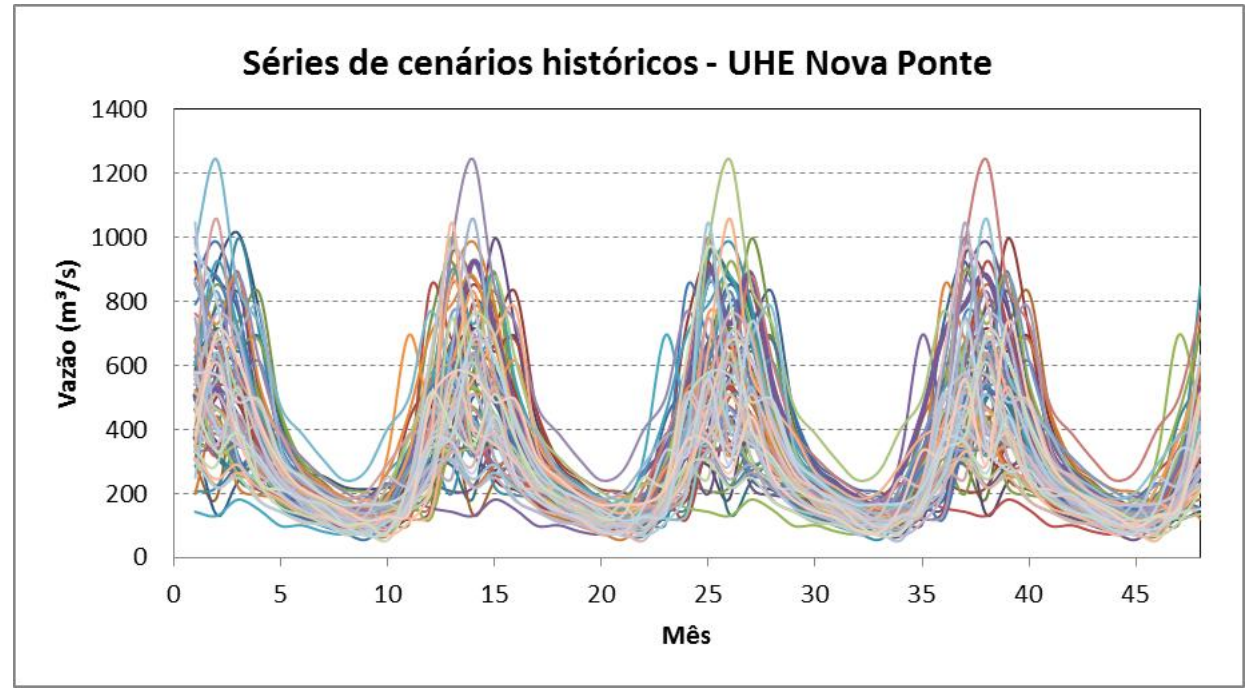

Figura 150. Séries de cenários históricos - UHE Nova Ponte 
Tabela 41. Comparação dos resultados - UHE Nova Ponte

\begin{tabular}{|l|c|c|c|}
\hline \multicolumn{4}{|c|}{ UHE Nova Ponte } \\
\hline & $\begin{array}{c}\text { Árvore de Cenários } \\
\text { reduzidos }\end{array}$ & $\begin{array}{c}\text { Árvore de Cenários } \\
\text { Históricos }\end{array}$ & $\begin{array}{c}\text { variação dos } \\
\text { resultados }\end{array}$ \\
\hline $\begin{array}{l}\text { Vazão a ser turbinada em } \\
\mathrm{T}=1\left(\mathrm{~m}^{3} / \mathrm{s}\right)\end{array}$ & 290 & 307 & $6 \%$ \\
\hline $\begin{array}{l}\text { Energia gerada ao longo } \\
\text { dos 4 anos }(\mathrm{MW})\end{array}$ & 17127 & 17142 & $0.1 \%$ \\
\hline
\end{tabular}

\subsubsection{UHE Três Marias}

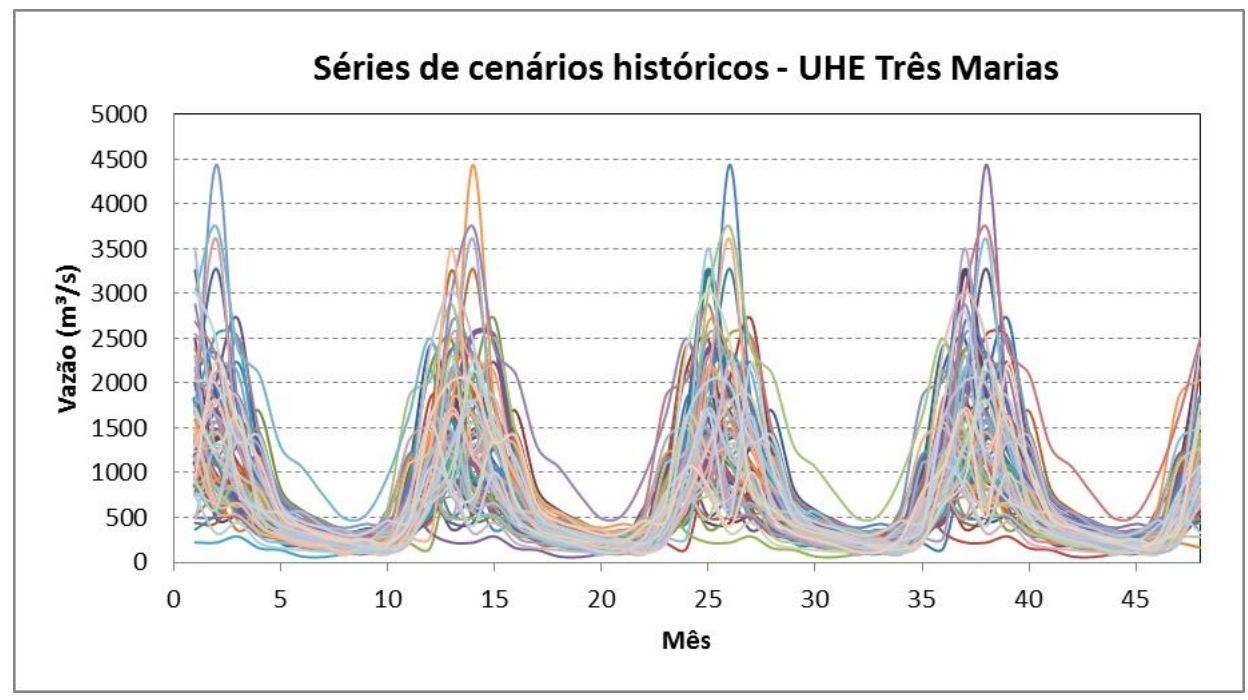

Figura 151. Séries de cenários históricos - UHE Três Marias

Tabela 42. Comparação dos resultados - UHE Três Marias

\begin{tabular}{|l|c|c|c|}
\hline \multicolumn{4}{|c|}{ UHE Três Marias } \\
\hline & $\begin{array}{c}\text { Árvore de Cenários } \\
\text { reduzidos }\end{array}$ & $\begin{array}{c}\text { Árvore de Cenários } \\
\text { Históricos }\end{array}$ & $\begin{array}{c}\text { variação dos } \\
\text { resultados }\end{array}$ \\
\hline $\begin{array}{l}\text { Vazão a ser turbinada em } \\
\mathrm{T}=1\left(\mathrm{~m}^{3} / \mathrm{s}\right)\end{array}$ & 572 & 579 & $1 \%$ \\
\hline $\begin{array}{l}\text { Energia gerada ao longo } \\
\text { dos 4 anos (MW) }\end{array}$ & 14143 & 13982 & $-1 \%$ \\
\hline
\end{tabular}


5.10.6.4UHE Irapé

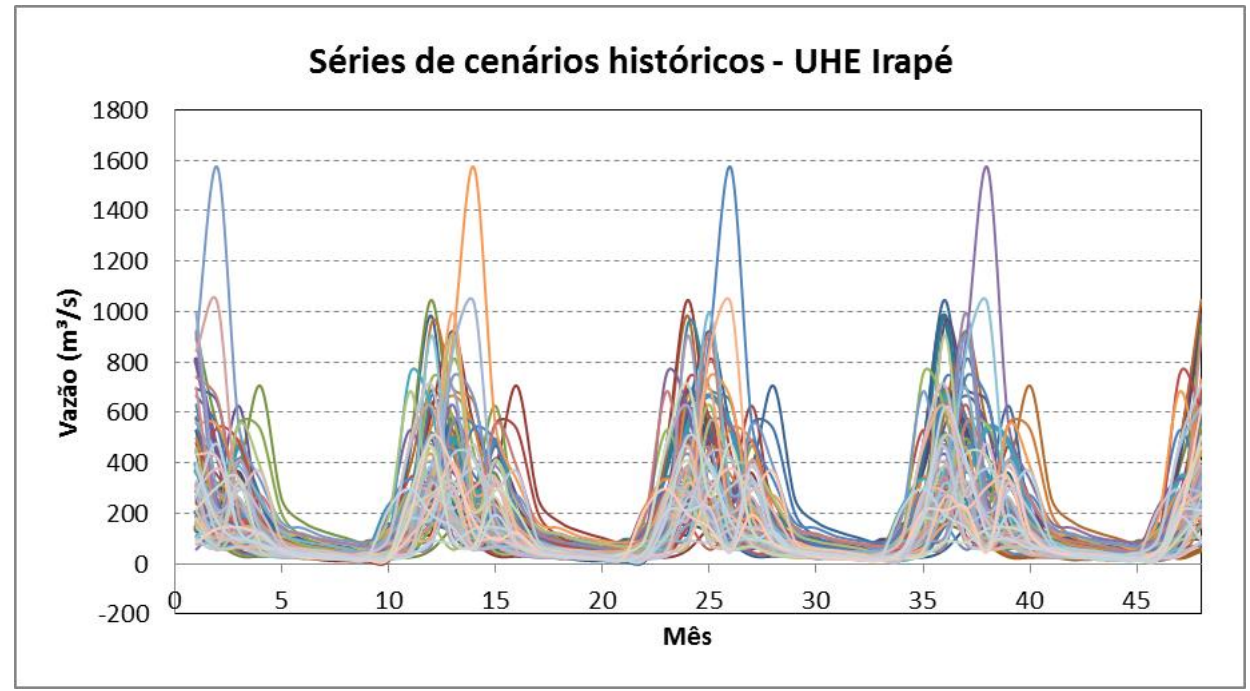

Figura 152. Séries de cenários históricos - UHE Irapé

Tabela 43. Comparação dos resultados - UHE Irapé

\begin{tabular}{|l|c|c|c|}
\hline \multicolumn{3}{|c|}{ UHE Irapé } \\
\hline & $\begin{array}{c}\text { Árvore de Cenários } \\
\text { reduzidos }\end{array}$ & $\begin{array}{c}\text { Árvore de Cenários } \\
\text { Históricos }\end{array}$ & $\begin{array}{c}\text { variação dos } \\
\text { resultados }\end{array}$ \\
\hline $\begin{array}{l}\text { Vazão a ser turbinada em } \\
\mathrm{T}=1\left(\mathrm{~m}^{3} / \mathrm{s}\right)\end{array}$ & 128 & 138 & $8 \%$ \\
\hline $\begin{array}{l}\text { Energia gerada ao longo } \\
\text { dos 4 anos }(\mathrm{MW})\end{array}$ & 11282 & 11632 & $3 \%$ \\
\hline
\end{tabular}

\subsubsection{UHE Serra da Mesa}

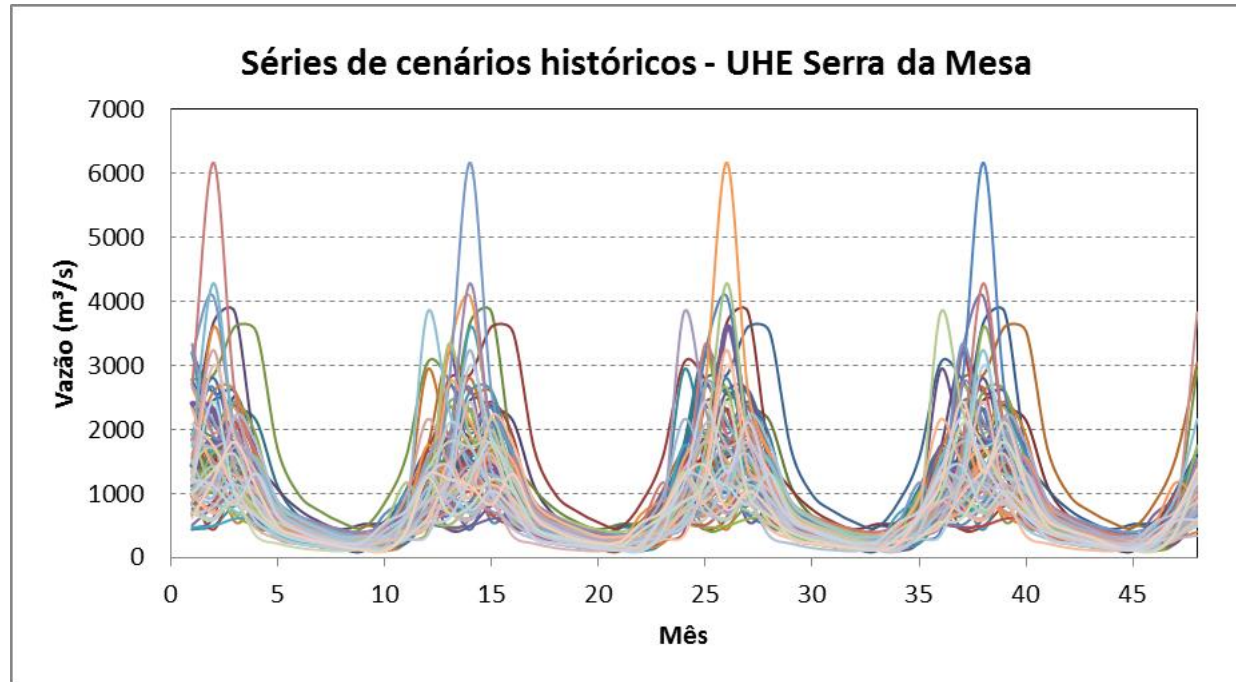

Figura 153. Séries de cenários históricos - UHE Serra da Mesa 
Tabela 44. Comparação dos resultados - UHE Serra da Mesa

\begin{tabular}{|l|c|c|c|}
\hline \multicolumn{4}{|c|}{ UHE Serra da Mesa } \\
\hline & $\begin{array}{c}\text { Árvore de Cenários } \\
\text { reduzidos }\end{array}$ & $\begin{array}{c}\text { Árvore de Cenários } \\
\text { Históricos }\end{array}$ & $\begin{array}{c}\text { variação dos } \\
\text { resultados }\end{array}$ \\
\hline $\begin{array}{l}\text { Vazão a ser turbinada em } \\
\mathrm{T}=1\left(\mathrm{~m}^{3} / \mathrm{s}\right)\end{array}$ & 802 & 809 & $1 \%$ \\
\hline $\begin{array}{l}\text { Energia gerada ao longo } \\
\text { dos 4 anos (MW) }\end{array}$ & 46545 & 45626 & $-2 \%$ \\
\hline
\end{tabular}

\subsubsection{UHE Balbina}

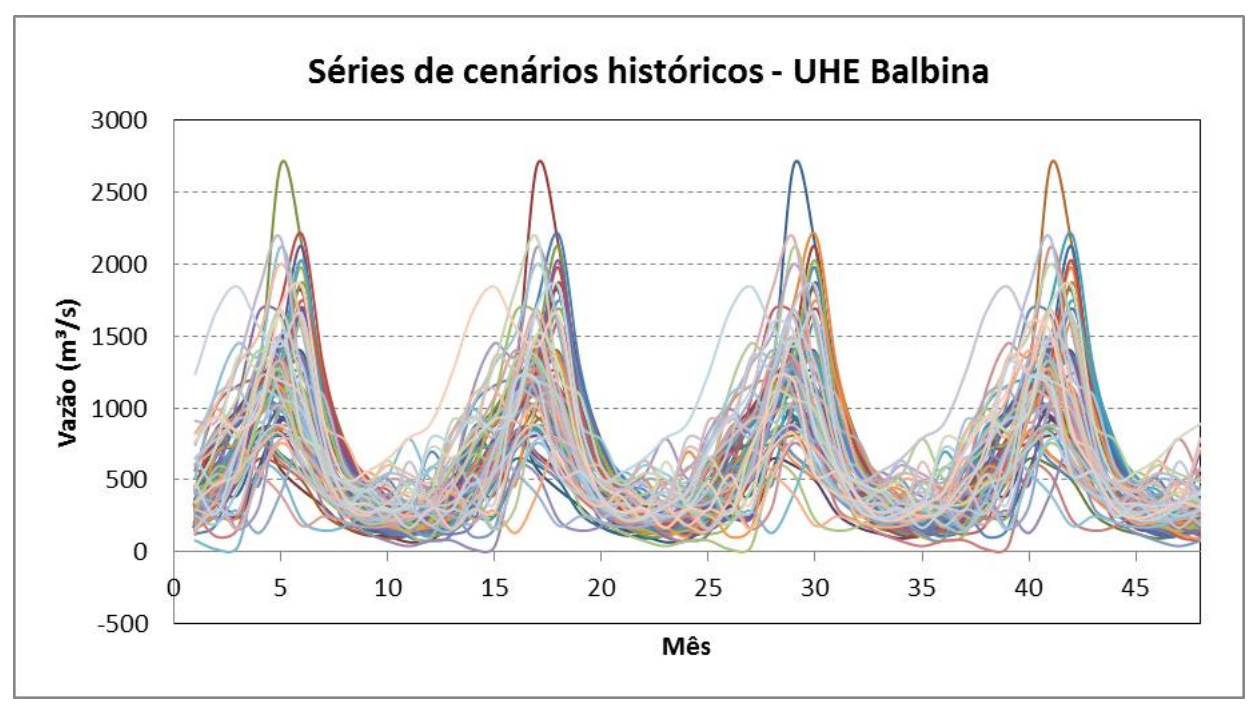

Figura 154. Séries de cenários históricos - UHE Balbina

Tabela 45. Comparação dos resultados - UHE Balbina

\begin{tabular}{|l|c|c|c|}
\hline \multicolumn{3}{|c|}{ UHE Balbina } \\
\hline & $\begin{array}{c}\text { Árvore de Cenários } \\
\text { reduzidos }\end{array}$ & $\begin{array}{c}\text { Árvore de Cenários } \\
\text { Históricos }\end{array}$ & $\begin{array}{c}\text { variação dos } \\
\text { resultados }\end{array}$ \\
\hline $\begin{array}{l}\text { Vazão a ser turbinada em } \\
\mathrm{T}=1\left(\mathrm{~m}^{3} / \mathrm{s}\right)\end{array}$ & 461 & 336 & $-27 \%$ \\
\hline $\begin{array}{l}\text { Energia gerada ao longo } \\
\text { dos 4 anos (MW) }\end{array}$ & 6712 & 6155 & $-8 \%$ \\
\hline
\end{tabular}




\subsubsection{Considerações Gerais}

Os resultados obtidos nesta análise levam a importantes considerações, destacando-se:

As árvores de cenários sintéticos, geradas pelos modelos estocásticos PAR (p), apresentam padrões estatísticos (média, desvio padrão) próximos das árvores formadas pelos cenários históricos.

De modo geral, os resultados obtidos pela otimização estocástica da geração hidrelétrica considerando árvores de cenários sintéticos (análises dos itens 5.10.1 a 5.10.5) são bastante próximos em relação aos resultados obtidos ao se utilizar as árvores de cenários históricos. A única exceção consistiu na UHE Balbina.

Uma vez que os modelos estocásticos PAR ( $p$ ) foram calibrados em função das estatísticas das séries históricas, o fato de os resultados ao se utilizar os dois tipos de árvores (sintéticos com base em modelos estocásticos e através de séries históricas) serem próximos, leva à conclusão de que os procedimentos estocásticos (construção e redução de cenários) considerados ao longo desse estudo são coerentes com os valores históricos esperados. No entanto, este fato leva à discussão sobre as reais vantagens em se utilizar modelos estocásticos que consideram séries sintéticas, uma vez que as séries históricas consistem em dados observados, suficientemente longos e disponíveis.

Este caso se enquadra em Kelman (1987), ao dizer que existem casos em que é preferível utilizar apenas a série histórica.

\subsubsection{Comparação entre Otimização Estocástica e Otimização Determinística do ponto de vista de eventos críticos}

Assim como descrito no item 5.8 a técnica de redução inerente ao SCENRED reduz a árvore de cenários inicial com base na manutenção dos cenários que possuem maior probabilidade de ocorrência.

Deste modo, uma árvore reduzida com poucos cenários preservados de vazões pode não conter cenários que apresentem eventos hidrológicos 
extremos, sendo o caso mais crítico eventos de secas prolongadas. Isso se deve à baixa probabilidade de ocorrência inerente a estes eventos.

Dentro de um Sistema de Suporte à Decisão, tal como o HIDROTERM, esta consideração é de extrema importância, por se tratar da consideração, ou não, de eventos extremos no planejamento da operação da geração hidrelétrica.

Mesmo se tratando de eventos extremos existem exemplos reais no contexto nacional de períodos hidrológicos críticos do ponto de vista de secas, tal como o período compreendido entre 1949 a 1954 (considerado pelo ONS como Período Crítico), o período do chamado "apagão", em 2011, e o período entre 2013 e 2014, que ocasionou em crises no abastecimento de água em diversas cidades do estado de São Paulo e na disponibilidade de energia hidrelétrica nas regiões sudeste, centro-oeste e nordeste principalmente. Todos estes eventos tiveram repercussão nacional nos anos seguintes e afetaram diversos setores da sociedade.

Neste contexto, a presente análise tem como objetivo comparar os resultados obtidos para a otimização estocástica da geração hidrelétrica com os resultados da otimização determinística (como base 0 algoritmo do HIDROTERM) considerando períodos hidrológicos de seca críticos de cada bacia em estudo. Esta análise possui um caráter qualitativo, e não visa fornecer conclusões sobre a validade do processo de otimização estocástica, mas sim o de destacar a ordem de grandeza da diferença entre os resultados dos dois processos.

Deste modo, foram selecionados os dois períodos hidrológicos de seca de 4 anos mais críticos ao longo do período histórico de cada usina, com base nos registros históricos de vazões médias mensais disponibilizados pelo ONS. Com base nestes períodos foi aplicado o algoritmo de otimização determinístico elaborado por Zambon (2008), ajustado para uma usina individualizada. As figuras 155 a 160 apresentam os períodos selecionados. Nos itens 5.10.6.01 5.10.6.06 a e os resultados foram comparados com os resultados provenientes das otimizações estocásticas apresentadas nos item 5.11.2. 


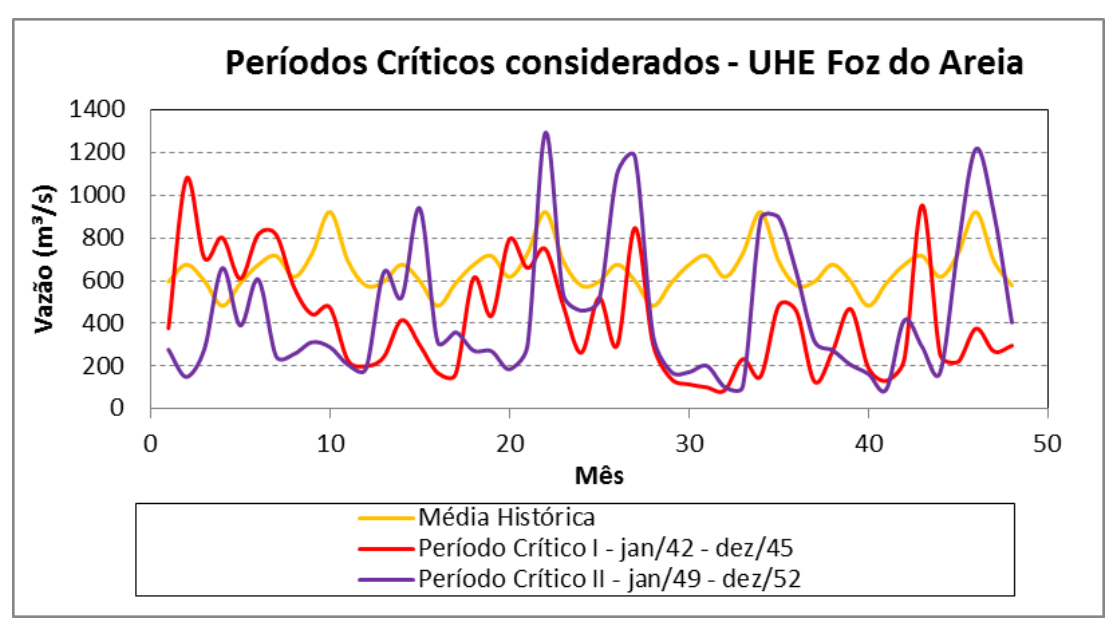

Figura 155. Períodos críticos - UHE Foz do Areia

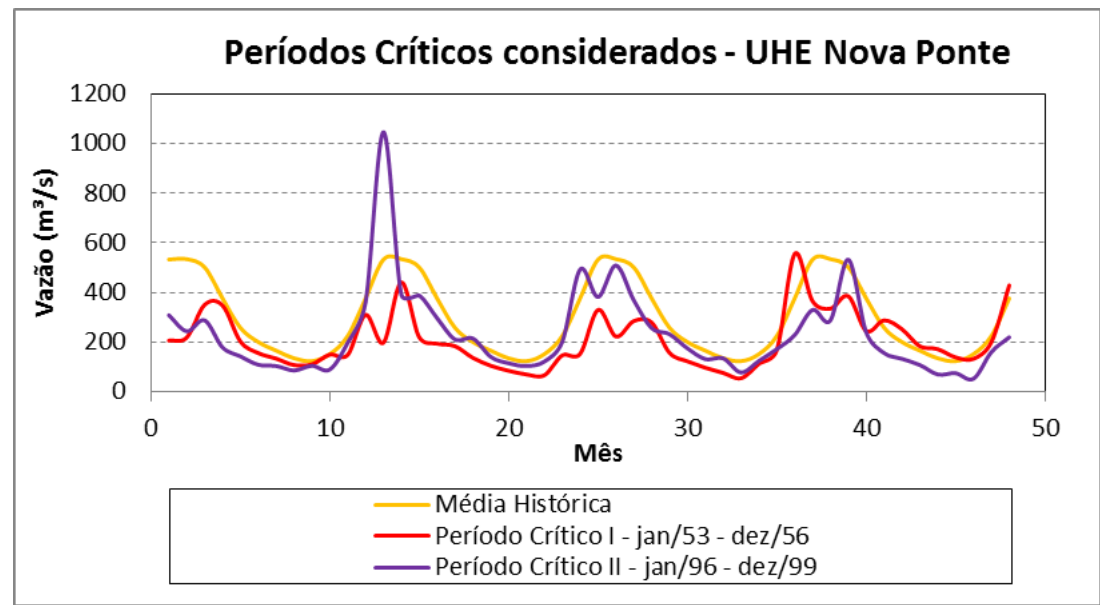

Figura 156. Períodos críticos - UHE Nova Ponte

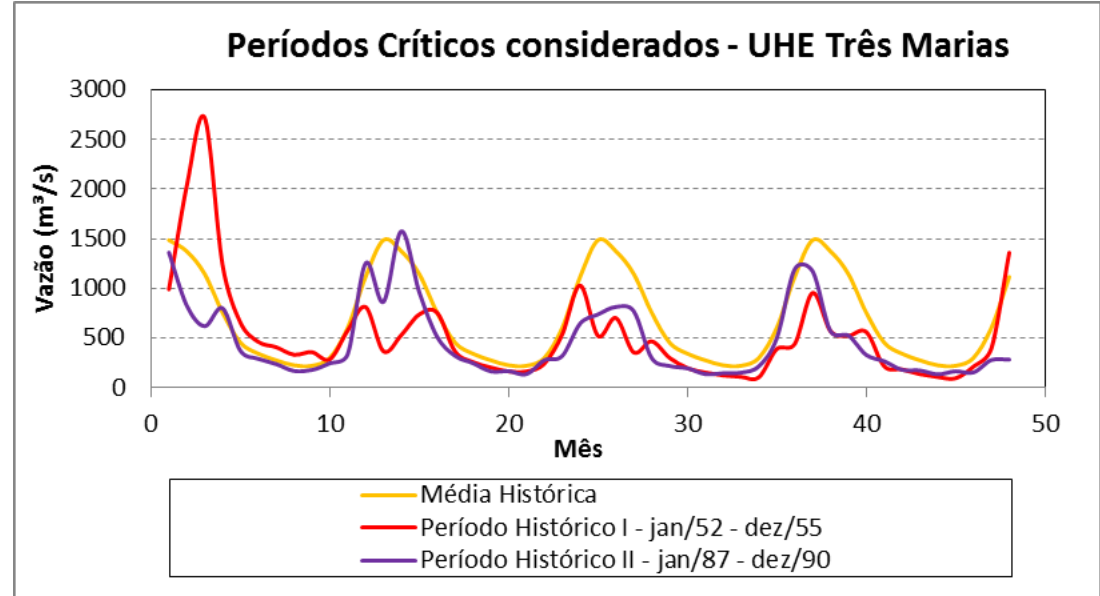

Figura 157. Períodos críticos - UHE Três Marias 


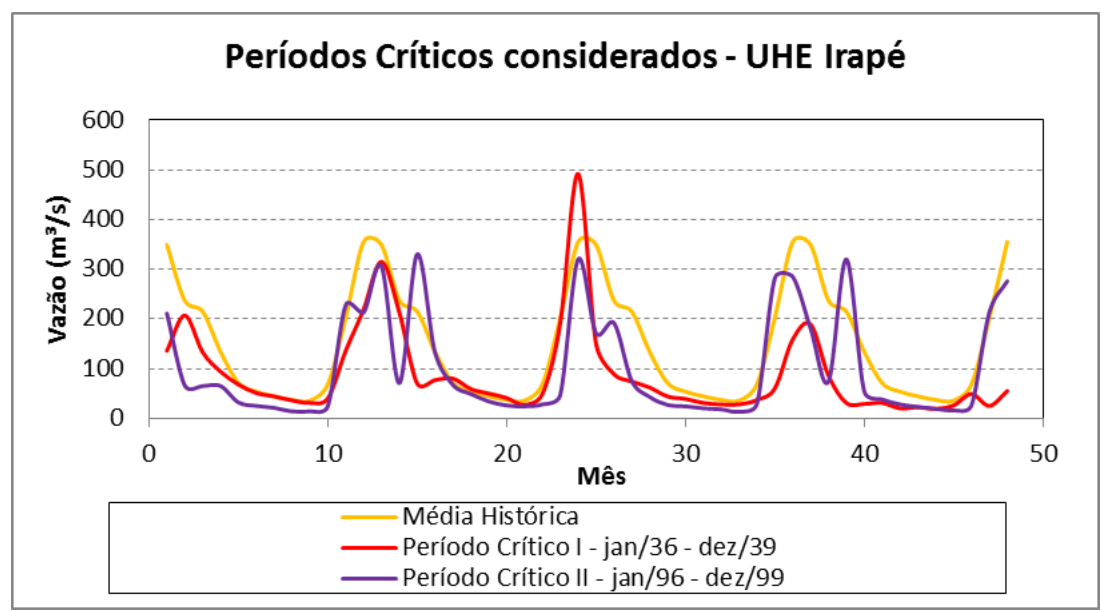

Figura 158. Períodos críticos - UHE Irapé

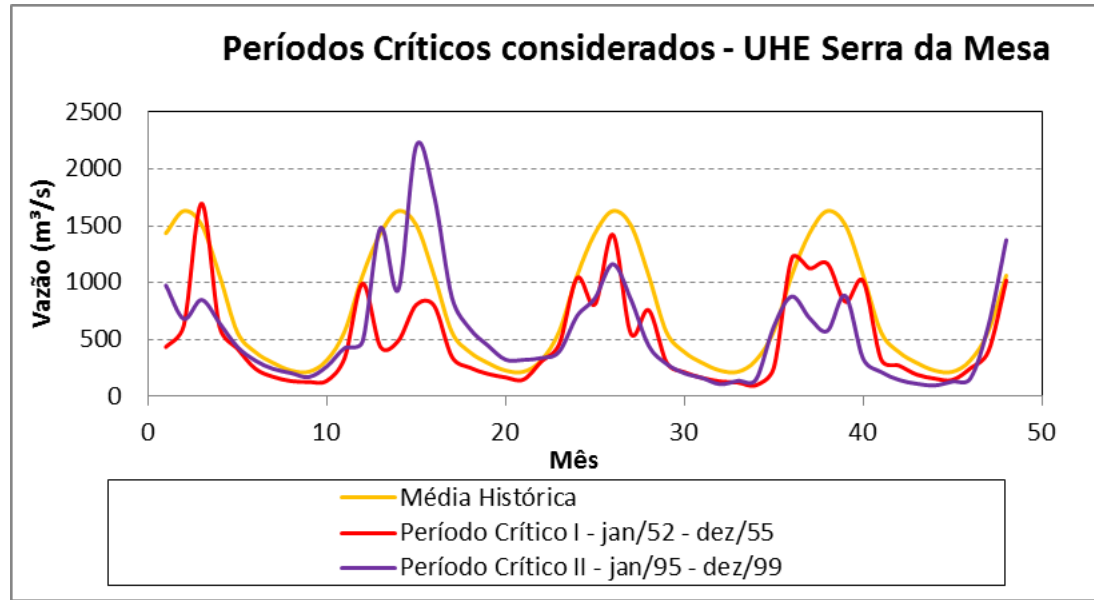

Figura 159. Períodos críticos - UHE Serra da Mesa

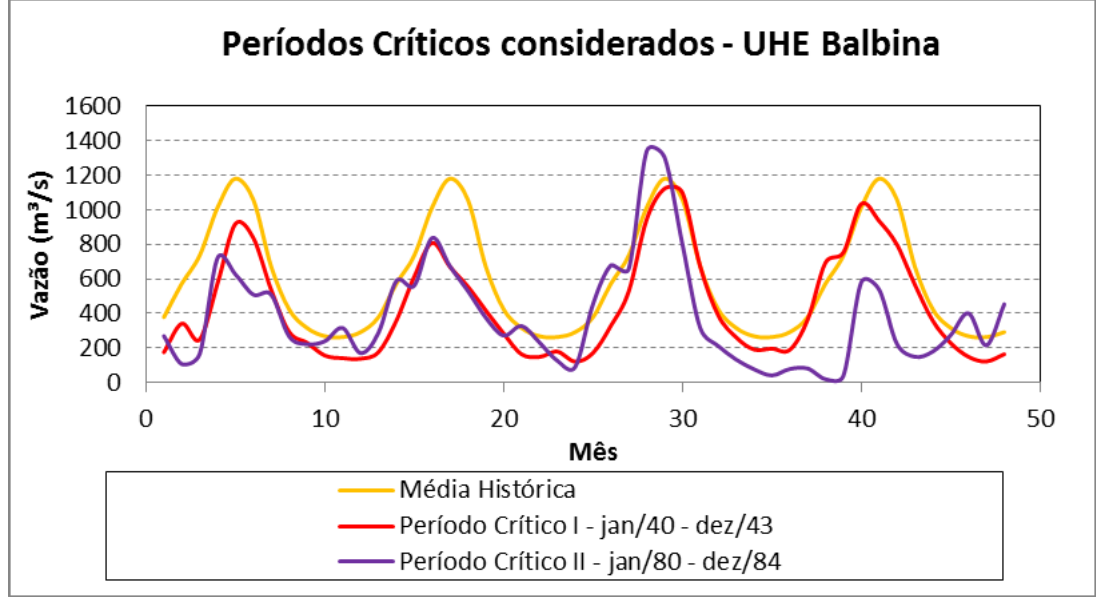

Figura 160. Períodos críticos - UHE Balbina 


\subsubsection{UHE Foz do Areia}

Tabela 46. Comparação dos resultados: Modelo Estocástico x Períodos Críticos - UHE Foz do Areia

\begin{tabular}{|l|c|c|c|}
\hline \multirow{2}{*}{} & \multirow{2}{*}{ Árvore de Cenários } & \multicolumn{2}{|c|}{ Períodos Críticos } \\
\cline { 3 - 4 } & & Jan/42 a dez/45 & jan/1948 a dez/52 \\
\hline Modelo Aplicado & Estocástico & Determinístico & Determinístico \\
\hline $\begin{array}{l}\text { Vazão a ser turbinada em } \\
\mathrm{T}=\mathbf{1}\left(\mathrm{m}^{3} / \mathrm{s}\right)\end{array}$ & 586 & 662 & 316 \\
\hline $\begin{array}{l}\text { Energia gerada ao longo } \\
\text { dos 4 anos (MW) }\end{array}$ & 37475 & 26937 & 28828 \\
\hline
\end{tabular}

\subsubsection{UHE Nova Ponte}

Tabela 47. Comparação dos resultados: Modelo Estocástico x Períodos Críticos - UHE Nova Ponte

\begin{tabular}{|l|c|c|c|}
\hline & \multirow{2}{*}{ Árvore de Cenários } & \multicolumn{2}{|c|}{ Períodos Críticos } \\
\cline { 3 - 4 } & & Jan/53 a dez/55 & jan/1995 a dez/99 \\
\hline Modelo Aplicado & Estocástico & Determinístico & Determinístico \\
\hline $\begin{array}{l}\text { Vazão a ser turbinada em } \\
\mathrm{T}=1\left(\mathrm{~m}^{3} / \mathrm{s}\right)\end{array}$ & 290 & 204 & 232 \\
\hline $\begin{array}{l}\text { Energia gerada ao longo } \\
\text { dos 4 anos (MW) }\end{array}$ & 17127 & 12583 & 13783 \\
\hline
\end{tabular}

\subsubsection{UHE Três Marias}

Tabela 48. Comparação dos resultados: Modelo Estocástico x Períodos Críticos - UHE Três Marias

\begin{tabular}{|l|c|c|c|}
\hline \multirow{2}{*}{} & \multirow{2}{*}{ Árvore de Cenários } & \multicolumn{2}{|c|}{ Períodos Críticos } \\
\cline { 3 - 4 } & & Jan/51 a dez/55 & jan/1986 a dez/90 \\
\hline Modelo Aplicado & Estocástico & Determinístico & Determinístico \\
\hline $\begin{array}{l}\text { Vazão a ser turbinada em } \\
\mathrm{T}=1\left(\mathrm{~m}^{3} / \mathrm{s}\right)\end{array}$ & 572 & 579 & 527 \\
\hline $\begin{array}{l}\text { Energia gerada ao longo } \\
\text { dos 4 anos (MW) }\end{array}$ & 14143 & 12204 & 12308 \\
\hline
\end{tabular}




\subsubsection{UHE Irapé}

Tabela 49. Comparação dos resultados: Modelo Estocástico x Períodos Críticos - UHE Irapé

\begin{tabular}{|l|c|c|c|}
\hline & \multirow{2}{*}{ Árvore de Cenários } & \multicolumn{2}{|c|}{ Períodos Críticos } \\
\cline { 3 - 4 } & & Jan/35 a dez/39 & jan/1995 a dez/99 \\
\hline Modelo Aplicado & Estocástico & Determinístico & Determinístico \\
\hline $\begin{array}{l}\text { Vazão a ser turbinada em } \\
\text { T=1 (m³ } / \mathrm{s})\end{array}$ & 128 & 83 & 88 \\
\hline $\begin{array}{l}\text { Energia gerada ao longo } \\
\text { dos 4 anos (MW) }\end{array}$ & 11282 & 7450 & 8495 \\
\hline
\end{tabular}

\subsubsection{UHE Serra da Mesa}

Tabela 50. Comparação dos resultados: Modelo Estocástico x Períodos Críticos - UHE Serra da Mesa

\begin{tabular}{|l|c|c|c|}
\hline \multirow{2}{*}{} & \multirow{2}{*}{ Árvore de Cenários } & \multicolumn{2}{|c|}{ Períodos Críticos } \\
\cline { 3 - 4 } & & Jan/51 a dez/55 & jan/1995 a dez/99 \\
\hline Modelo Aplicado & Estocástico & Determinístico & Determinístico \\
\hline $\begin{array}{l}\text { Vazão a ser turbinada em } \\
\text { T=1 (m³ } / \mathrm{s} \text { ) }\end{array}$ & 802 & 571 & 641 \\
\hline $\begin{array}{l}\text { Energia gerada ao longo } \\
\text { dos 4 anos (MW) }\end{array}$ & 46545 & 33679 & 36795 \\
\hline
\end{tabular}

\subsubsection{UHE Balbina}

Tabela 51. Comparação dos resultados: Modelo Estocástico x Períodos Críticos - UHE Balbina

\begin{tabular}{|l|c|c|c|}
\hline & \multirow{2}{*}{ Árvore de Cenários } & \multicolumn{2}{|c|}{ Períodos Críticos } \\
\cline { 3 - 4 } & & Jan/42 a dez/45 & jan/1948 a dez/52 \\
\hline Modelo Aplicado & Estocástico & Determinístico & Determinístico \\
\hline $\begin{array}{l}\text { Vazão a ser turbinada em } \\
\text { T=1 (m } 3 \text { } / \mathrm{s})\end{array}$ & 461 & 294 & 229 \\
\hline $\begin{array}{l}\text { Energia gerada ao longo } \\
\text { dos 4 anos (MW) }\end{array}$ & 6712 & 5080 & 4373 \\
\hline
\end{tabular}




\subsubsection{Considerações a respeito dos resultados}

Os períodos críticos considerados possuem significativa diferença entre as UHEs utilizadas, verificando-se, no entanto, que as décadas de 40 e 50 consistiram em um período crítico de seca do ponto de vista hidrológico.

O processo de otimização estocástica proposto, aliado à técnica de redução de cenários do SCENRED, e adotando árvores reduzidas com 50 cenários, se mostram pouco conservadores em relação ao planejamento da operação ao se considerar períodos hidrológicos críticos de seca. Esta diferença se deve à:

- A ferramenta SCENRED reduz a árvore inicial de cenários com base na probabilidade de ocorrência dos cenários iniciais de vazões afluentes. Os cenários hidrológicos críticos possuem baixas probabilidades de ocorrência e, consequentemente, maior probabilidade de serem eliminados.

- Quanto maior a porcentagem de redução de cenários em uma árvore, menor a probabilidade que figurem cenários hidrológicos críticos. Assim, árvores com poucos cenários tendem à valores médios. Consequentemente, os resultados da otimização estocástica podem girar em torno de valores médios esperados. Este efeito é reduzido ao se aumentar o número de cenários da árvore reduzida.

Assim, hipoteticamente, caso se tivesse sido previstas as vazões a serem turbinadas em determinado instante, com base em árvores de cenários muito reduzidas, e que a série de vazões afluentes seguisse 0 comportamento verificado em um período histórico crítico, a segurança do abastecimento elétrico poderia estar comprometida. 


\section{Conclusões}

Foi implantada um algoritmo de otimização estocástica a partir do algoritmo de otimização do SSD HIDROTERM, desenvolvido por Zambon (2008), e com base na técnica de redução de cenários desenvolvida por Heitsch et Romisch (2001) - SCENRED, ambos tendo como base a plataforma GAMS.

A técnica utilizada de redução de cenários por agrupamento consiste em uma ferramenta prática e ágil para viabilizar o processo de otimização estocástica, reduzindo a dimensionalidade do problema. Contudo, esta técnica prioriza os cenários mais representativos, ou seja, os cenários que mais se aproximam na árvore inicial. Esta técnica tende a excluir cenários extremos (como eventos de seca prolongada), que possuem pouca probabilidade de ocorrência, mas, que caso se transformem na realidade, podem impactar significativamente na segurança da garantia do atendimento elétrica à população. Assim, a solução da otimização estocástica deve ser sempre ser realizada conjuntamente com uma ferramenta de Suporte a Decisão, uma vez que as decisões podem recair sobre análises mais subjetivas.

O número de cenários de vazões afluentes ao reservatório impacta diretamente nos resultados da otimização estocástica da geração hidrelétrica. Ao se utilizar árvores com poucos cenários os resultados podem variar significativamente. Por outro lado, árvores com muitos cenários levam a resultados próximos na otimização estocástica, além de apresentar um universo de possibilidades melhor representado. Os resultados indicam que árvores com cinquenta ou mais cenários levam a resultados suficientemente estáveis e confiáveis.

O acréscimo no tempo de processamento segue as indicações bibliográficas, de modo que o tempo necessário cresce exponencialmente com o acréscimo no número de cenários.

A aplicação de técnicas de redução de cenários se mostra necessária para a viabilidade do processo de otimização estocástica. Os resultados mostraram um tempo médio de 20 minutos para a solução de um problema envolvendo uma árvore com 100/150 cenários. Este tempo pode ser otimizado ao se utilizar um computador com melhor capacidade de processamento, contudo, ao se 
extrapolar o problema para a solução de um problema envolvendo a complexidade do SIN, e, contando que o tempo de processamento cresce exponencialmente com o aumento do número de variáveis, a viabilidade da solução pode demorar demasiadas horas e ser considerada inviável do ponto de vista computacional.

As UHEs foram selecionadas de modo a representar diferentes bacias hidrográficas brasileiras frente ao processo de otimização estocástica. Dessa análise se verificou que alguns parâmetros hidrológicos, principalmente a sazonalidade anual, podem influenciar na qualidade do processo de otimização estocástica. De modo geral, regimes hidrológicos menos definidos resultam em séries sintéticas de vazões (ou cenários de vazões) mais divergentes. De maneira análoga, regimes hidrológicos mais bem definidos geram árvores com menor variabilidade. Assim, poder-se-ia considerar que, para regimes hidrológicos mais definidos não haveria a necessidade de árvores com um número demasiadamente elevado de cenários de vazões, em relação ao caso de árvores de cenários em regimes menos definidos. Este indicativo pode ser importante para eventuais aprimoramentos do algoritmo de otimização estocástica do planejamento da geração.

Foi verificado, durante as otimizações estocásticas, que quanto mais próximos os valores atribuídos inicialmente às variáveis (vazões turbinadas e vazões vertidas), menor o tempo de processamento requerido. Assim, recomenda-se a complementação do algoritmo de otimização estocástica considerando ferramentas de busca por valores iniciais mais adequados às variáveis de cada cenário em questão.

As análises buscaram identificar a sensibilidade do modelo frente à variação de algumas dos principais parâmetros de entrada. Verifica-se, no entanto, que o problema é multidimensional, sendo difícil fornecer afirmações estatísticas consolidadas, mas sim tendências e considerações de ordem geral. Os estudos realizados buscaram percorrer algumas destas "dimensões", de modo a subsidiar futuros estudos.

Os resultados são sensivelmente influenciados pela condição do reservatório no instante inicial (volume inicial). De modo geral, quanto mais cheio o 
reservatório, maior a tendência de maiores vazões turbinadas. Esta variação, no entanto, também é verificada para o caso da otimização determinística. Há a indicação de que o volume do reservatório no instante inicial impacta de modo mais significativo nas usinas com maior volume útil.

A redução do horizonte de planejamento de 4 até 2 anos implica em soluções menos conservadoras, resultando em maiores vazões turbinadas. Os resultados se mostram mais conservadores quando os cenários preservados, entre as duas árvores (originais e reduzidas), são próximos ou iguais.

A utilização de árvores de cenários históricos pode representar em uma alternativa mais adequada no contexto da análise estocástica do planejamento da geração por envolver menores esforços matemáticos e computacionais. Isso se deve ao fato de tratarem de séries já disponíveis e com extensão suficientemente para os estudos, e pela proximidade dos resultados daqueles obtidos pela otimização estocástica a partir de modelos estocásticos utilizando séries sintéticas. Contudo, esta análise deve ser complementada a partir de outras análises de sensibilidade.

A solução da otimização estocástica da geração hidrelétrica deve ser realizada conjuntamente com uma ferramenta de Suporte a Decisão, uma vez que a utilização de árvores de cenários de vazões pode apresentar decisões de ordem subjetiva, tal como a inclusão/exclusão de cenários extremos, que possuem baixa probabilidade de ocorrência, mas que caso venham a retratar a realidade possuem um impacto significativo na operação e segurança elétrica nacional.

Estes resultados poderiam sofrer alterações significativas caso a ferramenta de redução de cenários seguisse uma metodologia diferente, com diferentes critérios de redução de cenários. 


\section{Pesquisas Futuras}

As análises realizadas forneceram algumas informações relevantes em relação ao comportamento do processo de otimização estocástica da geração hidrelétrica, contudo, abre portas para outros questionamentos não abordados na presente dissertação. São indicados as seguintes pesquisas e estudos futuros, entre outros:

- Analisar em maior profundidade as reais vantagens do processo de otimização estocástica em relação à otimização determinística;

- Incorporar o modelo estocástico de geração de séries sintéticas ao modelo de redução e otimização estocástica da geração hidrelétrica; Deste modo será possível a construção de um modelo integrado de geração e de redução de cenários sintéticos de vazões, além de permitir a modelagem de algoritmos de reduções sucessivas de cenários;

- Complementar a análise das vantagens ao se utilizar árvores de cenários sintéticos gerados a partir de modelos estocásticos em relação à árvores de cenários históricos.

- Analisar a aplicação de outras técnicas de redução de cenários ao algoritmo de otimização estocástica da geração hidrelétrica;

- Adicionar testes estatísticos, tais como distância euclidiana ou hamming à etapa de redução de cenários;

- Complementar as análises de sensibilidade de modo a se verificar o efeito de outras variáveis envolvidas no processo;

- Incorporar a incerteza da dependência espacial entre as usinas (Matriz de Carga) aos modelos de otimização estocástica;

- Incorporar as etapas de compilação de dados de vazões ao modelo de redução de cenários e ao ambiente GAMS, evitando gastos de tempo com a importação e exportação de dados entre os softwares GAMS e EXCEL;

- Estender as análises para outras usinas do SIN e posteriormente para todo o SIN. 


\section{Referências Bibliográficas}

ALMEIDA, S.B; Carvalho, N.O; Efeitos do assoreamento de reservatórios na geração de energia elétrica: Análise da UHE Mascarenhas, ES. IN: X Simpósio Brasileiro de Recursos Hídricos, RS, 1993.

ANEEL - Banco de Informações de geração - BIG, disponível em:

<http://www.aneel.gov.br/aplicacoes/capacidadebrasil/capacidadebrasil.asp>, Acessado em 21 de janeiro de 2014.

ANEEL - Energia Assegurada, disponível em:

$<$ http://www.aneel.gov.br/aplicacoes/capacidadebrasil/energiaassegurada.asp>, Acessado em 23 de janeiro de 2014.

BALLINI, R. Análise e Previsão de Vazões Utilizando Modelos de Séries Temporais, Redes Neurais e Redes Neurais Nebulosas. Universidade Estadual de Campinas: Tese de Doutorado em Engenharia Elétrica, Faculdade de Engenharia Elétrica e de Computação, 2000.

BOX, G. E. P., JENKINS, G. M., REINSEL, G. C. Time Series Analysis: Forecasting and Control, 3 ed. Prentice Hall, New Jersey, 1994.

BOX, G. E. P., MULLER M. E., 1958. A Note on the Generation of Random Normal Deviates, The Annals of Mathematical Statistics, Vol. 29, No. 2, 610-611, 1958.

BARROS, M. T. L., ROS, D. A. et LOPES, J. E. G., Objective Functions for Hydropower System Operation, World Water and Environmental Resources Congress, Maio de 2005.

BRAGA, D.; Processos Autorregressivos Periódicos Gama: Uma Aplicação para Série de Energia Natural Afluente, Rio de Janeiro, Maio de 2011.

BUARQUE, Sérgio C., Metodologia e Técnicas de construção de cenários globais e regionais, IPEA, texto para discussão 939, Brasília, Fevereiro de 2003. 
CBIE (Centro Brasileiro de Infraestrutura), Sistema Elétrico Brasileiro Expansão Hidrotérmica - Leilões de Energia Elétrica - Regionais e por Fonte, Agosto de 2011.

CCEE (Câmara de Comercialização de Energia Elétrica), Mecanismo de Realocação de Energia, disponível em: <http://www.ccee.org.br>, Acessado em 08 de junho de 2013.

CEMIG (Companhia Energética de Minas Gerais), Energia - Geração. Disponível em: <http://www.cemig.com.br/>, Acessado em 15 de dezembro de 2013.

Centrais Elétricas do Brasil (ELETROBRÁS). Sistema de Informações do Potencial Elétrico Brasileiro. Disponível em < http://www.eletrobras.gov.br/ EM_Atuacao_SIPOT/sipot.asp>, Acessado em 27 de novembro de 2012.

CBAraguari - Comitê da Bacia Hidrográfica do Rio Aragurai, disponível em: <http://www.cbharaguari.org.br>, Acessado em 03 de fevereiro de 2014.

MACEIRA, M.E.P., Manual de Referência - Modelo NEWAVE, Relatório Técnico, CEPEL, Rio de Janeiro, 2001.

CICOGNA, Marcelo Augusto, Sistema de Suporte à Decisão para o Planejamento e a Programação da Operação de Sistemas de Energia Elétrica, Tese de Doutorado, Dezembro de 2013.

COPEL (Companhia Paranaense de Energia) - Hidrelétricas, disponível em: <http://www.copel.com/hpcopel/root/nivel2.jsp?endereco=\%2Fhpcopel\%2Froot \%2Fpagcopel2.nsf\%2F044b34faa7cc1143032570bd0059aa29\%2Fe307f2c9b2 edc56303257412004fdb91>, Acessado em 09 de novembro de 2013.

DEUS, Flávia Lanzetti Daher de, Geração de Cenários de Energia Natural afluente através da metodologia do Hipercubo Latino, Dissertação de Mestrado, Rio de Janeiro, Junho de 2010. 
DEUS, Marcella Lanzetti Daher de, Séries Temporais Aplicadas ao Planejamento da Operação do Sistema Interligado Nacional - SIN, Dissertação de Mestrado, Rio de Janeiro, Junho de 2008.

DETZEL, Daniel H. Marco; BESSA, Marcelo R.; Vallejos, CLAUDIO A. V.; SANTOS, Adriano B.; THOMSEN, Luiza S.; MINE, Miriam R. M; BLOOT, Márcio L.; ESTRÓCIO, João P., Estacionariedade das Afluências às Usinas Hidrelétricas Brasileiras, Revista Brasileira de Recursos Hídricos Volume 16 n.3 - Jul/Set de 2011.

DOMENICA, Nico Di; LUCAS, Cormac; MITRA, Gautam; VALENTE, Patrick; Scenario generation for stochastic programming and simulation: a modelling perspective, IMA Journal of Management Mathematics, UK, 2007.

DUPACOVÁ, Jitka; Scenario generation for multistage models, Material for GAMS course on Stochastic Programming, 2003.

D24AM Notícias - "Amazonas Energia conclui interligação do linhão para inserir Manaus no sistema nacional", disponível em: <http://www.d24am.com/noticias/economia/amazonas-energia-concluiinterligacao-do-linhao-para-inserir-manaus-no-sistema-nacional/90750>, Acessado em 01 de dezembro de 2013.

EFRON, B. Bayes and likelihood calculations from confidence intervals. Biometrika, 80 3-26, 1993.

EPE - Ministério de Minas e Energia, Balanço Energético Nacional (BEN), disponível em: <https://ben.epe.gov.br/>, Acessado em: 5 de outubro de 2012.

EPE - Ministério de Minas e Energia, Plano Decenal de Energia 2020, disponível em: <http://www.epe.gov.br/pdee/forms/epeestudo.aspx>, Acessado em 17 de agosto de 2011.

EPE - Ministério de Minas e Energia, Plano Decenal de Energia 2022, disponível em: <http://www.epe.gov.br/pdee/forms/epeestudo.aspx>, Acessado em 09 de janeiro de 2013. 
FALCETTA, F.A.M, ZAMBON, R.C., Evolução da Capacidade de Regularização do Sistema Hidrelétrico Brasileiro, XX Simpósio Brasileiro de Recursos Hídricos, RS, Novembro de 2013.

FLeTEN, S. E., HAUGSTVEDT, D., SteinSB $\varnothing$, J. A., BELSNES, M. M. et FLEISCHMANN, F., Bidding hydropower generation: Integrating short-term and long-term, 17th PSCC Proceedings, Stockholm, Sweden, August, 2011.

FOLHA DE SÃO PAULO, "Balbina, usina construída nos anos 80 , é vista como o maior pesadelo amazônico", disponível em:

<http://www1.folha.uol.com.br/fsp/dinheiro/fi0912200710.htm>, Acessado em 01 de novembro de 2013.

FOLLEStAD, T, WOLFGANG, O, BELSNES, M. M. An Approach for assessing the effect of scenario tree approximations in stochastic hydropower scheduling models, 17th Power Systems Computation Conference Stockholm Sweden, Agosto de 2011.

FURNAS, Parque Gerador, disponível em:

<http://www.furnas.com.br/hotsites/sistemafurnas/usina_hidr_serramesa.asp>, acessado em 03 de março de 2014.

GAMS - General Algebraic Modeling System., disponível em: <www.gams.com>, Acessado em: 21 de abril de 2011.

GAMS - A User's Guide Tutorial by Richard E. Rosenthal, Development Corporation, Washington, DC, USA, 2006.

HEITSCH, H., ROMISCH W., Generation of Multivariate Scenario Trees to Model Stochasticity in Power Management, IEEE St. Petersburg Power Tech, 2005.

HEITSCH, H., ROMISCH, W., Scenario reduction algorithms in stochastic programming. Preprint 01-8, Institut f"ur Mathematik, Humboldt-Universit"at zu Berlin, 2001. 
$\mathrm{HEITSCH}, \mathrm{H}$. et ROMISCH, W., Scenario tree reduction for multistage stochastic programs, Computational Management Science, vol. 6, pp 117133, 2009.

HIDROTERM - Projeto Hidroterm, disponível em: <https://sites.google.com/site/fechidroterm/arquivos>, Acessado em 21 de outubro de 2013.

DUPACOVA, J., GROWE-KUSKA, N., ROMISCH, W., Scenario reduction in stochastic programming: An approach using probability metrics. Revised version to appear in Mathematical Programming, 2003.

HIPEL, K.W. et MCLEOD, A.I., Time Series Modelling of Water Resources and Environmental Systems, Elsevier Science BV, Amsterdam, 1994.

KALL, Peter; WALLACE, S.W., Stochastic programming - Second Edition 2003, disponível em:

http://www.csee.wvu.edu/ xinl/library/books/stochastic_programming.pdf, Acessado em 18 de julho de 2012.

KAUT, M., S. WALLACE W., Evaluation of scenario generation methods for stochastic programming, Pacific Journal of Optimization, vol. 3, pp 257-271, Norway, Março de 2007.

KELMAN, J., Uso de Séries Sintéticas no Planejamento e Operação de Sistemas Hidrotérmicos, In: I Seminário Latinoamericano sobre Aproveitamento de Recursos Hidráulicos, Colombia, Medellín, 1987.

LABADIE, J. W.: FONTANE, D.G.;LEE, J; KO, I.H. Adaptive Decision Support System for Real-Time Operation of the Geum River Basin, Korea. In: World Water and Enviromental Resources Congress, Anchorage, Alaska, USA, 2005.

LATORRE, J.M., CERISOLA, S., RAMOS, A., 2007, Clustering Algorithms for Scenario Tree Generation: Application to Natural Hydro Inflow, European Journal of Operational Research 181 pp. 1339-1353. 
LOPES, João E. Gonçalves, Modelo de Planejamento da Operação de Sistemas Hidrotérmicos de Produção de Energia Elétrica, Tese de Doutorado, São Paulo, 2007.

MARTINEZ, L. Políticas de Controle Malha Fechada e Malha Aberta no Planejamento da Operação Energética de Sistemas Hidrotérmicos, Tese de Doutorado, Campinas, 2001.

MENDES, Ludmilson Abritta, O impacto dos usos consuntivos na operação de sistemas de reservatórios para produção de energia elétrica, Tese de Doutorado, São Paulo, 2012.

MOMOH, J. A., EL-HAWARY, M.E., ADAPA, R. A review of selection optimal power flow literature to 1993, Parts I, II: Newton, linear programming and interior point methods. IEEE Trans. System, 14(1), 105-111, 1999.

NAZARENO, J.S. Um Algoritmo de Otimização Determinístico para o Estudo e Planejamento da Operação de Sistemas Hidrotérmicos de Potência. Dissertação de Mestrado - EESC, São Carlos, 2005.

OLIVEIRA, Fernando Luiz Cyrino, Nova abordagem para geração de cenários de afluências no planejamento da operação energética de médio prazo, Dissertação de Mestrado, Rio de Janeiro, Março de 2010.

OLIVEIRA, Fernando Luiz Cyrino, Modelo de Séries Temporais para Construção de Árvores de Cenários Aplicados à Otimização Estocástica, Tese de Doutorado, Rio de Janeiro, Julho de 2013.

OLIVEIRA, Welington Luis de, Redução ótima de cenários em programação estocástica. Aplicação às vazões afluentes aos aproveitamentos hidroelétricos, Dissertação de Mestrado, Rio de Janeiro, Agosto de 2007.

ONS, Carga de Energia - Evolução Mensal, disponível em: <http://www.ons.org.br/sala_imprensa/energia/carga_propria.aspx>, Acessado em 14 de janeiro de 2014. 
ONS , PSR, Conceitos e Metodologias usados para Geração de Árvores de Cenários de Vazões Multivariadas, Outubro de 2004.

ONS, Geração De Cenários De Afluências A Partir Dos Ruídos das Séries Históricas, NT 085/2008, Rio de Janeiro, 2008.

ONS, Séries Históricas de Vazões, disponível em: <http://www.ons.org.br/operacao/vazoes_naturais.aspx>, Acessado em 21 de janeiro de 2014.

PENNA, Débora Dias Jardim, Definição da Árvore de Cenários de Afluências para o Planejamento da Operação Energética de Médio Prazo, Tese de Doutorado, Rio de Janeiro, Julho de 2009.

PIRES, João Rodolfo Cortês, Otimização e Geração de Cenários Aplicadas à contratação de Energia Elétrica, Tese de Doutorado, São José dos Campos, 2008.

RAMOS, Andrés, Stochastic Optimization, Universidad Pontificia Comillas, 2010-2011.

REIS, Ricardo Luis dos; ANDRADE, Marinho G.; EHLERS, Ricardo Sandes; SÁFADI, Thelma, Modelos autoregressivos periódicos aplicados ao estudo de vazões médias mensais.

SAMS - Stochastic Analisys Modeling and Simulation, disponível em: <http://www.sams.colostate.edu/>, Acessado em 31 de fevereiro de 2013.

SIGURBJÖRNSSON, S., RAFNAR. Scenario Tree Generation by Optimal, Discretization, Informatics and Mathematical Modelling, Kongens Lyngby, 2008.

SILVA, Túlio de Souza, Aplicação do Método Amostragem Seletiva Global na Construção da àrvore de cenérios de afluências utilizada no Planejamento da operação Energética de Médio Prazo, Projeto de Conclusão de Curso, Rio de Janeiro, Junho de 2010. 
SIMONOVIC, S.P. Reservoir System Analysis: Closing gap between theory and practise, Journal of Water Planning and Management, Maio de 1992.

SOUZA, Reinaldo Castro; MARCATOB, André Luís Marques, DIAS, Bruno Henriques; OLIVEIRA, Fernando Luiz Cyrino, Operação Ótima de Sistemas Hidrotérmicos com Geração de Cenários Hidrológicos Através de Modelos Auto-Regressivos Periódicos identificados via Bootstrap, 15은 CONGRESSO DA APDIO, Livro de Actas. Coimbra: INESC-COIMBRA,.P. 2132242011, Coimbra, 2011.

TOSCANO, André Emilio, Comparação entre os modelos NEWAVE e ODIN no planejamento energético do Sistema Interligado Nacional, Dissertação de Mestrado, Campinas, Fevereiro de 2009.

WURBS, R. Reservoir-system simulation and optimization models, Journal of Water Resources Planning and Management, Julho de 1993.

YEH, W.W-G. Reservoir Management and operations models: A state of Art Review. Water Resource Research, p; 1797-1929, 1985.

ZAMBELLI, Mônica de Souza, Planejamento da Operação Energética do Sistema Interligado Nacional Baseado em Modelo de Controle Preditivo, Tese de Doutorado, Campinas, Dezembro de 2009.

ZAMBON, Renato Carlos, Planejamento da operação de sistemas hidrotérmicos de grande porte, Tese de Doutorado, São Paulo, 2008.

ZAMBON, Renato Carlos., BARROS, Mario T. L, BARBOSA, Paulo S. F. FRANCATO, Alberto L., LOPES, João E. G., NOGUEIRA, Luis F. A. M, YEH, William W. G; A Stochastic Hydrothermal Decision Support System for Planning Operation: New Developments for the HIDROTERM model, World Environmental and Water Resources Congress, Cincinnati, Ohio, Maio de 2013. 